\title{
NOVAS OBSERVAÇÕES SOBRE A DISTRIBUIÇÃO DOS GRUPOS CERAMISTAS PRÉ-HISTÓRICOS NO OESTE E SUL DO ESTADO DE SÃO
}

\author{
PAULO, BRASIL
}

\author{
Glauco Constantino Perez \\ Astolfo Gomes de Mello Araujoii \\ Mercedes Okumura iii
}

iPós-doutorando no Instituto de Biociências, Universidade de São Paulo, Laboratório de Estudos Evolutivos Humanos (LEEH/IB) Email: glauco1113@usp.br

iiCoordenador do Laboratório de Interdisciplinar de Pesquisas em Evolução, Cultura e Meio Ambiente (LEVOC) do Museu de Arqueologia e Etnologia da Universidade de São Paulo (MAE/USP) E-mail: astwolfo@usp.br

iiiCoordenadora do Laboratório de Estudos Evolutivos Humanos, Instituto de Biociências, Universidade de São Paulo. E-mail: okumura@ib.usp.br
Resumo: Este artigo pretende realizar atualização dos estudos realizados até o momento sobre as pesquisas e simulações em um Sistema de Informação Geográfico (SIG) da distribuição dos grupos produtores de cerâmica nos territórios do oeste e sul paulista, entre as bacias dos rios Tietê e Paranapanema. Para tanto, realizamos análises da distribuição espacial (Método IDW e Kriging) de sítios dos grupos ceramistas correspondentes às Tradições Tupiguarani e Itararé-Taquara. Estudos previamente publicados incluíam 421 sítios com coordenadas geográficas conhecidas. Aqui, apresentamos esses sítios e incluímos 340 sítios com coordenada aproximada, estimada como sendo localizada no perímetro urbano do município aferido ao sítio arqueológico. Desse modo, foi possível ampliar a quantidade de sítios utilizados nas simulações, alcançando um total de 761 sítios. Tal ampliação da amostra analisada gerou resultados distintos em relação aos padrões anteriormente observados. Palavras-Chave: Arqueologia Paulista, Sistema de Informação Geográfica (SIG), Análises Espaciais.

Abstract: This article intends to update the studies carried out to date on research and simulations using a Geographic Information System (GIS) about the distribution of pré-historic ceramic groups producers in the territories of the west and south of São Paulo, between the basins of the Tietê and Paranapanema rivers. For this purpose, we performed analyzes of the spatial distribution (IDW and Kriging Method) of sites belonging to the ceramist groups corresponding to the Tupiguarani and Itararé-Taquara Tradition. Previously published studies included 421 sites with approximate coordinates. In this article, we present these sites and include 340 sites with an unknown coordinate, estimated to be located in the urban perimeter of the municipality measured against the archaeological site. Thus, it was possible to increase the number of sites used in the simulations, reaching a total of 761 sites. Such expansion of the analyzed sample generated different results in relation to the patterns previously observed. Key Words: São Paulo State's Archaeology, Geographic Information System (GIS), Spatial Analyses. 


\section{Introdução}

Neste artigo são apresentadas novas análises através do uso de Sistema de Informação Geográfica (SIG) para a compreensão da distribuição de sítios arqueológicos no Estado de São Paulo. Ressaltamos que, até o momento, foram publicados resultados nos quais apenas 421 sítios georeferenciados haviam sido analisados (Perez, 2018a). Neste trabalho são avaliados 761 sítios arqueológicos de grupos produtores de cerâmica nas regiões oeste e sul paulista, área compreendida entre as bacias hidrográficas dos rios Paranapanema e Tietê.

O que nos guia para a elaboração destes processamentos e simulações virtuais é a intenção de identificar possíveis fronteiras culturais entre os grupos produtores de cerâmica na região. De acordo com Schmitz (2007), as populações indígenas entendem o conceito de fronteira coincidindo com um determinado ambiente natural; a fronteira para grupos indígenas tem suas bases em identidades como a língua, cultura ou numa longa convivência, mas sem uma estrutura política que mantenha a unidade da fronteira - ao contrário do que ocorre atualmente, no qual países têm seus territórios marcados por limites definidos e fortemente controlados.

O controle sobre o movimento em fronteiras indígenas é dado por diferentes partes, afirma Schmitz (2007), defendendo os limites e organizando as relações com outras unidades indígenas. Apesar disso, nas regiões de fronteira se criam relações informais de toda ordem, não abolindo a estrutura, nem o limite, mas tendo certa flexibilidade. Esta definição de Schmitz (2007) pode abstrair uma agência política indígena, como demonstram Noelli \& Sallum (2020).

Ainda na tentativa de encontrar um conceito para as questões de fronteiras, temos o termo descrito na Enciclopédia elaborada por Zientara (1989), postulando que a origem do conceito de fronteira reside em movimentos próprios do ser vivo, sendo a fronteira algo com um caráter movediço. A partir dessa definição é possível compreender que a constituição de fronteira parte da mobilidade e, portanto, esse é um aspecto intrínseco a ela, mesmo que se algumas sociedades humanas tentem fixar definitivamente as suas próprias divisas.

A ideia que Zientara (1989) apresenta permite inferir que o conceito universalmente difundido de fronteira, a partir de uma linha fixa e que separa duas regiões diferentes não seja completamente correto, pois tal conceito abarca mais do que apenas divisões políticas de 
países atuais. A fronteira, ou melhor, seu conceito torna-se uma abstração fora de um mapa geográfico. Dessa maneira:

As fronteiras separam comunidades humanas, mas podem também determinar um gênero particular. Isto é, sobretudo válido para os confins de Estado que corram através de uma região densamente povoada: onde as populações que vivem numa zona de fronteira dão origem a uma comunidade fundada em interesses particulares, mantém entre elas, do lado de cá e do lado de lá da fronteira, uma intensa comunicação (...) Tratam-se, porém, de um fenômeno que só acontece à margem das grandes comunidades. (Zientara, 1989, p. 309-310)

Assim, pode-se perceber que para grupos humanos, a fronteira tem pressupostos sociais e não só geográficos. Ela depende da consciência do grupo que tende a isolar-se e é tanto mais sólida, quanto mais profundas são as diferenças entre esse grupo e os seus vizinhos. 0 fenômeno social de fronteira que é elaborado pelo grupo híbrido e tem como função barrar, bloquear, restringir o movimento de pessoas e bens, sendo mutável, ou melhor, adaptável sobretudo a partir das intensificações ou afrouxamento das relações intergrupais. Tal discussão nos leva a um conceito mais abstrato e flexível de fronteira.

A partir dessa conceituação para fronteira aplicada as sociedades atuais, Barth (1997) revisita tal conceito e o aplica aos grupos étnicos, criando assim o termo conhecido como Fronteiras Étnicas, em que se manifestam questões como a persistência das fronteiras, apesar dos fluxos de pessoas que as atravessam e a permanência de relações sociais aparentemente estáveis nelas, o que sugere ser uma concepção mais palpável e próxima de realidades humanas, independente da etnicidade.

Outra definição para o conceito de fronteira é a elaborada por Bradshaw (1999), que e defende como espaços dicotômicos que abordam a coexistência/separação, de inclusão/exclusão dependendo do grau e dos níveis de interação presentes nesses limites espaciais e sociais. Para compreender e melhorar a visualização do conceito, o autor caracteriza fronteiras como paredes porosas por onde convergem comunidades diferenciadas que podem interagir, mas nelas ainda permanecem a insegurança social, o contrabando de mercadorias, as migrações "ilegais", o desemprego e a deterioração ambiental.

Observar o Estado de São Paulo como um local, no qual um mosaico de populações pretéritas ocuparam o espaço de forma dinâmica, nos faz pensar em constantes contatos e trocas de informações que devem ser exploradas devido à riqueza de dados que essas fronteiras podem nos oferecer. O Estado de São Paulo pode ser considerado como bom candidato a ser área de 
fronteira para grupos indígenas ceramistas que se desenvolveram tanto na porção sul do Brasil, como nas regiões sudeste e centro-oeste. (Robrahn-González, 2000, 2003; Afonso, 2005; Faccio, 2011; Correa, 2014; Noelli \& Correa, 2018; Noelli \& Sallum, 2020). RobrahnGonzález (2000), destaca que:

Cada grande unidade classificatória analisada (as tradições ceramistas) não foi estabelecida no Estado, mas sim em outras regiões brasileiras, que teriam constituído suas áreas centrais de ocupação. São Paulo aparece como limite para duas delas (tradição Itararé e Aratu/Sapucaí) e como limite de divisões internas na outra (tradição Tupiguarani). (Robrahn-González, 2000)

Desse modo, Faccio (2011) também coloca o estado de São Paulo como região de "atrito e interação entre grupos do Planalto Atlântico (Tupinambás) e Planalto Central (Jês)" (Sic Faccio (2011). A autora entende que proporcionaria situações distintas de entendimento da ocupação do estado de São Paulo e relata que o termo "atrito" usado por ele denotaria disputas pelo território, e quando apresenta o termo "interação" nos faz pensar em relações entre grupos indígenas diferentes.

Assim, este artigo pretende apresentar os resultados obtidos com a inclusão de sítios cerâmicos sem coordenadas geográficas exatas, a partir da adoção das coordenadas dos respectivos municípios em que estão registrados. Pretende-se ampliar o mapeamento das ocupações humanas ceramistas na região estudada, bem como seus limites e possíveis áreas de trocas, contatos e fronteiras no espaço.

\section{Método adotado: o Banco de Dados utilizado e as interpolações}

Para contextualizar este artigo, os dados foram reunidos em pesquisa apresentada por Perez (2018a), que elaborou um Banco de Dados (BD), o qual reuniu informações de dois grandes repositórios de dados referentes à arqueologia paulista: Instituto do Patrimônio Histórico e Artístico Nacional Superintendência de São Paulo (Iphan/SP) e a Biblioteca do Museu de Arqueologia e Etnologia da Universidade de São Paulo.

Nesse levantamento, foram consultados: 57 relatórios de diversas empresas de arqueologia preventiva; 42 artigos de revistas; 12 teses; 10 dissertações; 5 obras literárias específicas ao tema; 2 obras de publicação de acervo; 1 inventário organizado por José Luiz de Morais em 2001; 1 citação classificada como 'outro' que se refere a uma citação a um trabalho feito no projeto Saint Hilaire de 1984, somando-se um total de 130 obras. 
Além disso, tivemos acesso online às fichas cadastrais, bem como de outras 12 caixas-arquivos, contendo mais fichas impressas para o estado todo. Esses dados correspondem às publicações produzidas desde o ano 1895 (com o primeiro número da Revista do Museu Paulista), até o ano de 2015, quando se encerrou o levantamento bibliográfico.

O BD conta com 783 sítios arqueológicos de grupos ceramistas e neste artigo, são utilizados 761 sítios $(97,1 \%)$ para as simulações. A diferença entre o total de sítios do BD e os utilizados deve-se à existência de 22 sítios arqueológicos no qual inexiste qualquer informação de localização, município ou coordenada geográfica, o que impossibilitou qualquer estimativa de localização ou inferência espacial.

Nas Tabelas 1 e 2 são apresentadas as quantificações dos sítios avaliados para este artigo. $\mathrm{Na}$ Tabela 1, nota-se a quantidade de sítios "sem localização" espacial de cada tradição arqueológica identificada para a região sul e oeste do estado de São Paulo (Tradição Tupiguarani e Tradição Itararé-Taquara). Tais dados serão introduzidos nas novas simulações. Já na Tabela 2, o conteúdo se refere à presença ou ausência de informações sobre datações dos sítios. Verifica-se que 90,9\% desses sítios não apresentam datações, impossibilitando qualquer inferência diacrônica para a região.

Nesse sentido, os dados apresentados consideram os sítios arqueológicos em sua totalidade como um conjunto, planificados sem distinções temporais. Essa maneira de organizar a informação nos permite, por um lado, identificar áreas de ocupação intensa dos espaços, mas por outro, dificulta uma interpretação cronológica relacionada à dinâmica temporal de ocupação da paisagem sul-paulista.

Tabela 1: Quantidade de sítios utilizados na simulação e suas referências sobre localização geográfica.

\begin{tabular}{|c|c|c|c|c|c|c|c|c|c|c|}
\hline \multicolumn{11}{|c|}{ Tradição } \\
\hline \multirow[t]{2}{*}{ Localização } & \multicolumn{2}{|c|}{$\begin{array}{l}\text { Itararé- } \\
\text { Taquara }\end{array}$} & \multicolumn{2}{|c|}{ Sem referência } & \multicolumn{2}{|c|}{$\begin{array}{l}\text { Tupiguarani e } \\
\text { Itararé-Taquara }\end{array}$} & \multicolumn{2}{|c|}{ Tupiguarani } & \multirow[t]{2}{*}{$\begin{array}{l}\text { Total } \\
\text { № }\end{array}$} & \multirow[t]{2}{*}{$\begin{array}{c}\text { Total } \\
\%\end{array}$} \\
\hline & № & $\%$ & № & $\%$ & № & $\%$ & № & $\%$ & & \\
\hline $\begin{array}{ll}\text { Sem localização } \\
\text { exata }\end{array}$ & 110 & $14.45 \%$ & 42 & $5.52 \%$ & 4 & $0.53 \%$ & 184 & $24.18 \%$ & 340 & $\begin{array}{c}44.68 \\
\%\end{array}$ \\
\hline
\end{tabular}


Tabela 2: Quantidades de sítios que apresentam datação utilizados na simulação em relação as datações conhecidas.

\begin{tabular}{|c|c|c|c|c|c|c|c|c|c|c|}
\hline \multirow{3}{*}{ Datação } & \multicolumn{8}{|c|}{ Tradição } & \multirow{3}{*}{ Total № } & \multirow{3}{*}{ Total \% } \\
\hline & \multicolumn{2}{|c|}{$\begin{array}{l}\text { Itararé- } \\
\text { Taquara }\end{array}$} & \multicolumn{2}{|c|}{ Sem referência } & \multicolumn{2}{|c|}{$\begin{array}{l}\text { Tupiguarani e } \\
\text { Itararé-Taquara }\end{array}$} & \multicolumn{2}{|c|}{ Tupiguarani } & & \\
\hline & № & $\%$ & № & $\%$ & № & $\%$ & № & $\%$ & & \\
\hline Ausente & 178 & $23.39 \%$ & 88 & $11.56 \%$ & 6 & $0.79 \%$ & 420 & $55.19 \%$ & 692 & $90.93 \%$ \\
\hline Presente & 6 & $0.79 \%$ & 1 & $0.13 \%$ & 2 & $0.26 \%$ & 60 & $7.88 \%$ & 69 & $9.07 \%$ \\
\hline Total & 184 & $24.18 \%$ & 89 & $11.70 \%$ & 8 & $1.05 \%$ & 480 & $63.07 \%$ & 761 & $100.00 \%$ \\
\hline
\end{tabular}

Consideramos que, até o presente momento, os trabalhos de divulgação das simulações da distribuição dos sítios pelo Estado de São Paulo eram dados que contavam apenas com sítios com coordenadas geográficas (UTM) precisas, sendo que $53,7 \%$ dos sítios eram considerados (Perez, 2018a, 2018b). A partir desses dados foi realizada a inclusão dos sítios que não apresentavam informações a respeito das coordenadas geográficas, mas apresentam, em suas descrições levantadas no BD, apenas a localização do município respectivo.

A inclusão desses sítios com informação da procedência do município foi categórica, atribuindo ao sítio arqueológico da coordenada de um ponto específico, dentro do limite urbano de cada município e não áreas rurais com a preocupação que futuramente pudesse gerar qualquer confusão ou ruído para sítios que pudessem ser localizados futuramente. Neste caso, plotamos os sítios sem coordenadas geográficas conhecidas sempre sobre estruturas construídas e conhecidas do município, como: uma praça central, uma igreja, o centro de um estádio de futebol, ou mesmo prédio de destaque local.

Para que essas escolhas fossem precisas realizamos a plotagem sítio a sítio, através do Google Earth, que permite observar a aproximação das imagens de satélite e assim atribuir uma coordenada para um sítio específico, plotando sobre o edifício escolhido no município. Os métodos de elaboração dos mapas e simulações foram amplamente descritos em Perez (2018b).

Neste artigo optamos por utilizar dois tipos de interpolações espaciais possíveis pelo ArcGis 10.2., com a ferramenta Análise Espacial (Spatial analyses). Tais interpoladores (IDW e Kriging) utilizam do espaço reconhecido para estipular como devem ser as distribuições espaciais dos 
PEREZ, G. C.; ARAUJO, A. G. de M.; OKUMURA, M.

conjuntos de pontos distribuídos pelo território. Os cálculos matemáticos desses interpoladores consideram a proximidade entre os pontos dos sítios arqueológicos (coordenadas geográficas), as semelhanças entre esses pontos (características atribuídas na tabela de atributos correspondentes ao sítio) e o local no espaço que ocupam. Cada interpolador apresenta um algoritmo distinto (fórmula matemática que o explica) e, assim, oferecem resultados diferentes (para mais informações consultar Perez, 2018b).

IDW - Inverse Distance Weighting (Ponderação do Inverso das Distâncias)

O primeiro método adotado foi o IDW, que utiliza o modelo estatístico denominado "Inverso das Distâncias" (Alves et al. 2008), isso quer dizer que o modelo baseia-se em uma dependência espacial, ou seja, supõe-se que: quanto mais próximo os pontos estiverem um ao outro, maior deverá ser a correlação entre seus valores e mais parecidos serão. Nesse tipo de interpolação de dados, Jakob (2006) relata que se atribui maior peso para as amostras mais próximas do que para as amostras mais distantes do ponto a ser interpolado.

\section{Kriging}

Este método descrito amplamente por Jakob (2002, 2003, 2006), e também chamado de Krigagem, é conhecido por apresentar modelos matemáticos e estatísticos que permitem assumir que as observações são independentes, sem correlação. Assim, a informação dos locais permite o cálculo de distâncias entre as observações e modela uma autocorrelação como uma função de distância específica.

Nesse artigo não serão detalhadas as funções matemáticas e o funcionamento desses métodos dentro o ArcGis, pois fogem ao objetivo desse trabalho. Para maiores informações a respeito da utilização dos dados matemáticos consultar Perez (2018a e 2018b).

\section{Algumas observações técnicas sobre os interpoladores}

Dentro do software ArcGis 10.2 existe a ferramenta Análise Espacial (Spatial analyses), cujo funcionamento já foi explicado. O resultado apresentado pelos interpoladores utilizados (IDW e Kriging) podem ser expressos a partir de duas expressões de visualização: stretched (esticada) e classified (classificada). 
A forma stretched permite a inclusão de até três valores conhecidos para a visualização do resultado da interpolação (um máximo, um mínimo e um valor intermediário). Acima desse número de valores, a forma indicada é a classified. Neste trabalho apresentamos as duas formas de distribuição para a interpolação IDW:

- Apresentação com três valores (excluindo os sítios sem referência a uma tradição arqueológica) - com visualização stretched;

- Apresentação com quatro valores (incluindo os sítios sem referência a uma tradição arqueológica) - com visualização classified.

Para o interpolador Kriging é apresentado o resultado com a visualização da distribuição no formato stretched, nas quais foram excluídos os dados dos sítios sem atribuição a uma tradição arqueológica.

\section{Resultados obtidos e discussão}

Serão apresentados os mapas obtidos a partir das novas interpolações mencionadas. Para efeito de comparação, foram expostos os mapas anteriormente elaborados que contavam com 421 sítios (Mapas 1 e 4) e os novos mapas gerados, a parti da análise de 761 sítios (Mapas 2, 3 e 5).

No Mapa 1 são apresentados os dados de 421 sítios arqueológicos de ambas as tradições arqueológicas, analisadas a partir do interpolador IDW com o formato de visualização classified, apresentado em Perez (2018a). Nesse mapa é possível observar a distribuição dos sítios ao longo do território pesquisado, na qual os sítios da Tradição Itararé-Taquara (áreas azuis) ocupam áreas do sul, do oeste e a área central do estado de São Paulo, enquanto os sítios da Tradição Tupiguarani (áreas rosas) estão no entorno desses nódulos gerados pelo interpolador. As áreas em verde são aquelas que o sistema indica como áreas de ocupação, tanto de sítios da Tradição Tupiguarani, quanto da Tradição Itararé-Taquara e os sítios Sem Referência a uma tradição (áreas amarelas) estariam em zonas que poderiam delimitar fronteira entre os grupos.

Através desse tipo de visualização, as áreas de ocupação parecem ser bastante delimitadas, o que causa estranhamento quando se considera fronteira como uma área de contatos entre as populações, como apresentado no início deste artigo. Ainda, chamamos a atenção para as 
áreas da região sul do estado e do oeste: essas áreas apresentam uma distribuição de cores bastante homogênea.

No Mapa 2, em que há o mesmo tipo de interpolação e visualização classified apresentada no Mapa 1, porém foram incluídos um total de 761 sítios arqueológicos. A inclusão de mais sítios na análise resultou em uma distribuição dos sítios pela paisagem do oeste paulista, que parece ser mais complexa do que aquela anteriormente proposta. Na região sul, emerge um núcleo de uma possível ocupação Tupiguarani ou área de influência dessa Tradição, em meio ao que até então estávamos considerando uma área estritamente dominada pela Tradição ItararéTaquara.

No Mapa 3 é apresentada a interpolação IDW com uma visualização streched. Nesse mapa os sítios que foram identificados como 'Sem referência a uma tradição arqueológica' foram retirados da interpolação - como foi explicado anteriormente, esse tipo de visualização esticada só permite três valores. Nota-se no Mapa 3 a simplificação das áreas que apareciam no Mapa 2, e as áreas de influência da Tradição Tupiguarani ganham espaço em quase toda região oeste do estado de São Paulo, embora ainda existam grandes núcleos de áreas de influência da Tradição Itararé-Taquara (inclusive na região entre o médio rio Paranapanema e Alto-médio rio Tietê). Destaca-se novamente a região sul do estado, pois surge uma área associada à Tradição Tupiguarani, bem ao centro dessa região, considerada tradicionalmente como de influência estrita da Tradição Itararé-Taquara. Nesse Mapa 3, fica mais evidente essa influência Tupiguarani na região do que no Mapa 2.

A partir do Mapa 3, é possível observar áreas de ocupação, interação e confluência dos dois grupos analisados. Na porção sul do Estado surge uma aglomeração de sítios Tupiguarani, envolta por uma área de contato entre Tupiguarani e Itararé-Taquara. Essa incrustação está sobre o município paulista de Iporanga, região do Vale do Ribeira do Iguape. É possível que, se ampliássemos as simulações para além das fronteiras geográficas do estado de São Paulo, encontraríamos sítios arqueológicos de grupos Tupiguarani na região Sengés, Doutor Ulysses, Cerro Azul, Adrianópolis e Bocaiúva do Sul, no Nordeste do Estado do Paraná. 


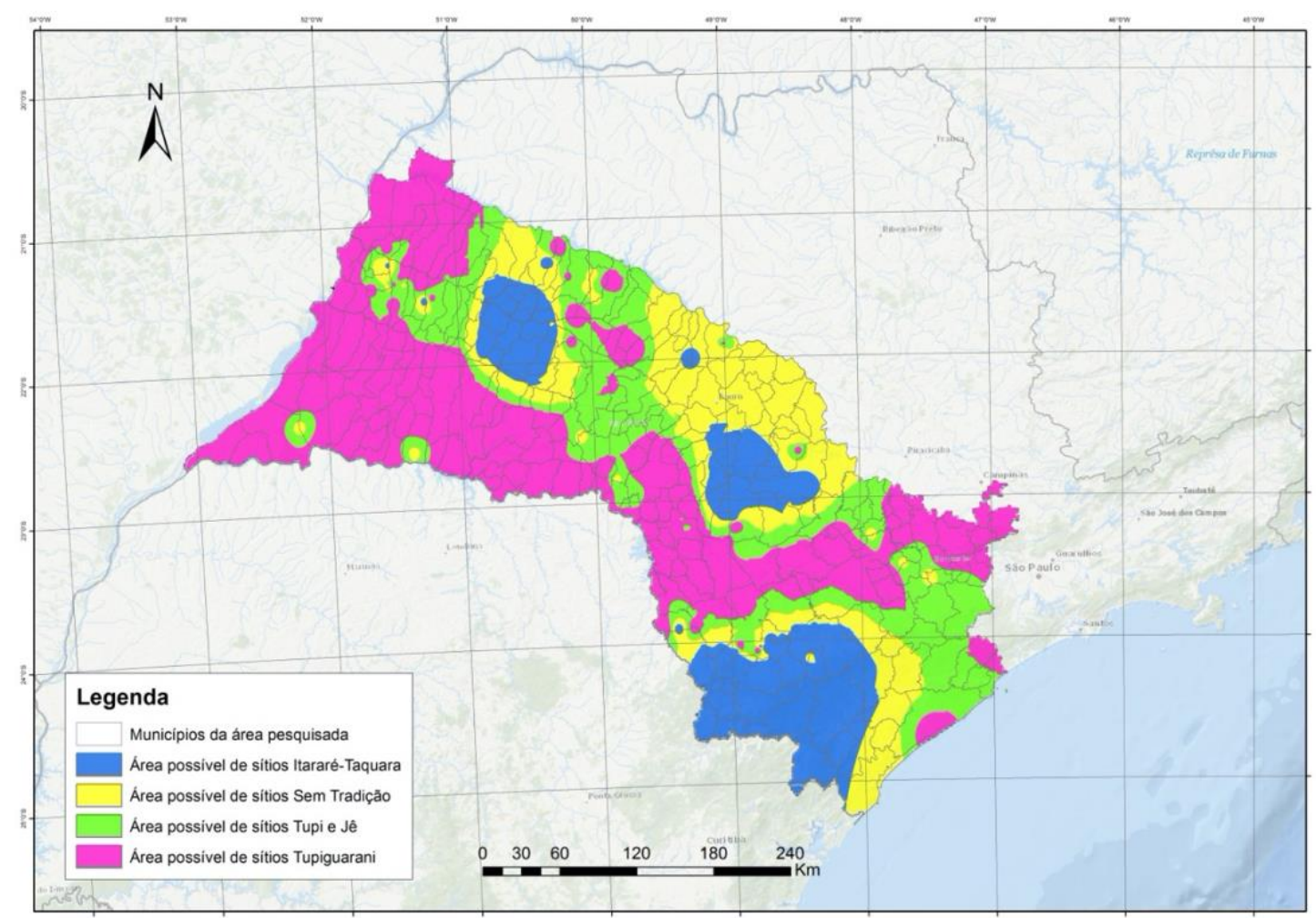

Mapa 1: Mapa produzido a partir do método de interpolação IDW com 421 sítios arqueológicos plotados e técnica classified. Adaptado de Perez (2018a).

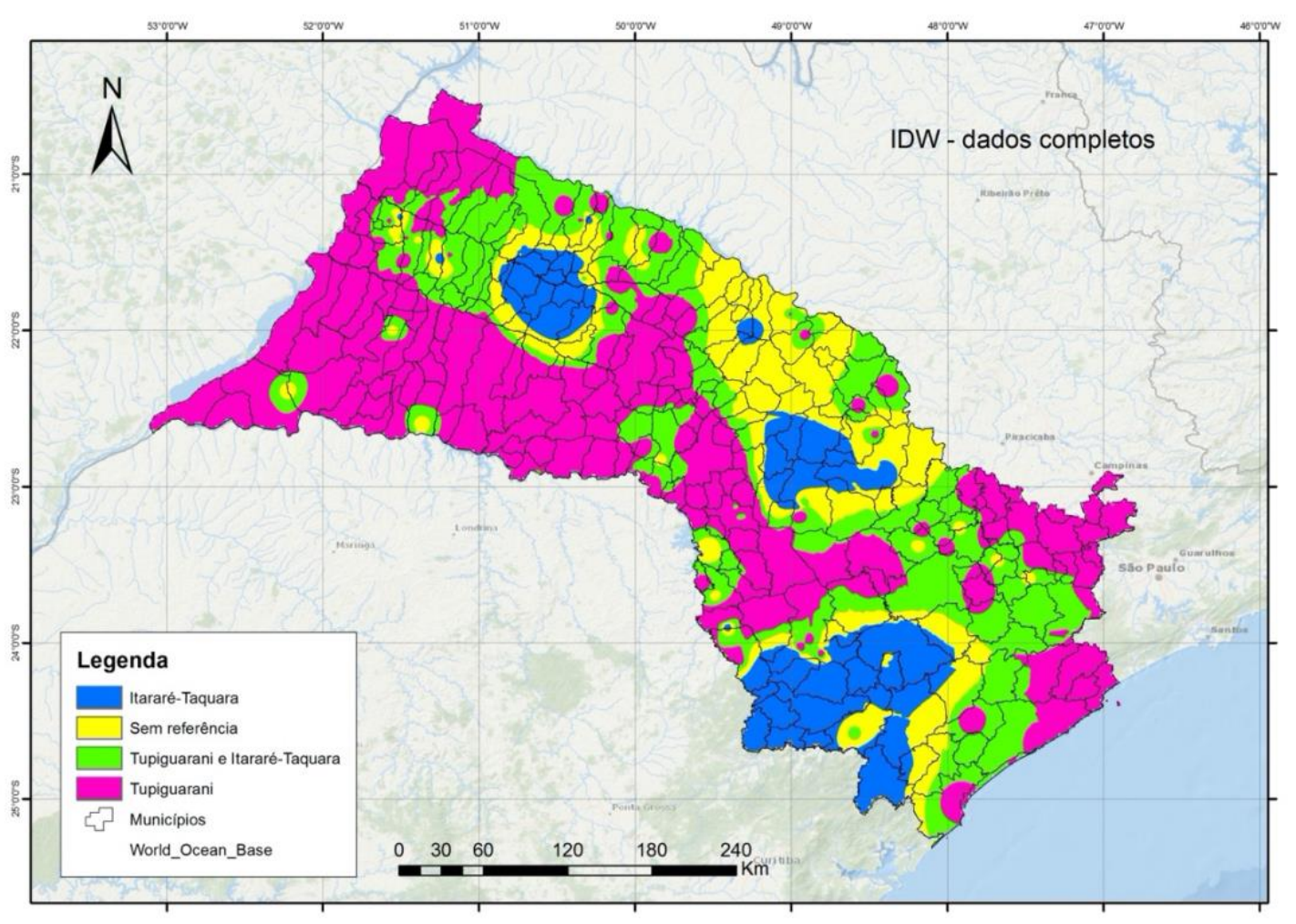

Mapa 2: Mapa produzido a partir do método de interpolação IDW com 761 sítios arqueológicos plotados e técnica classified. 


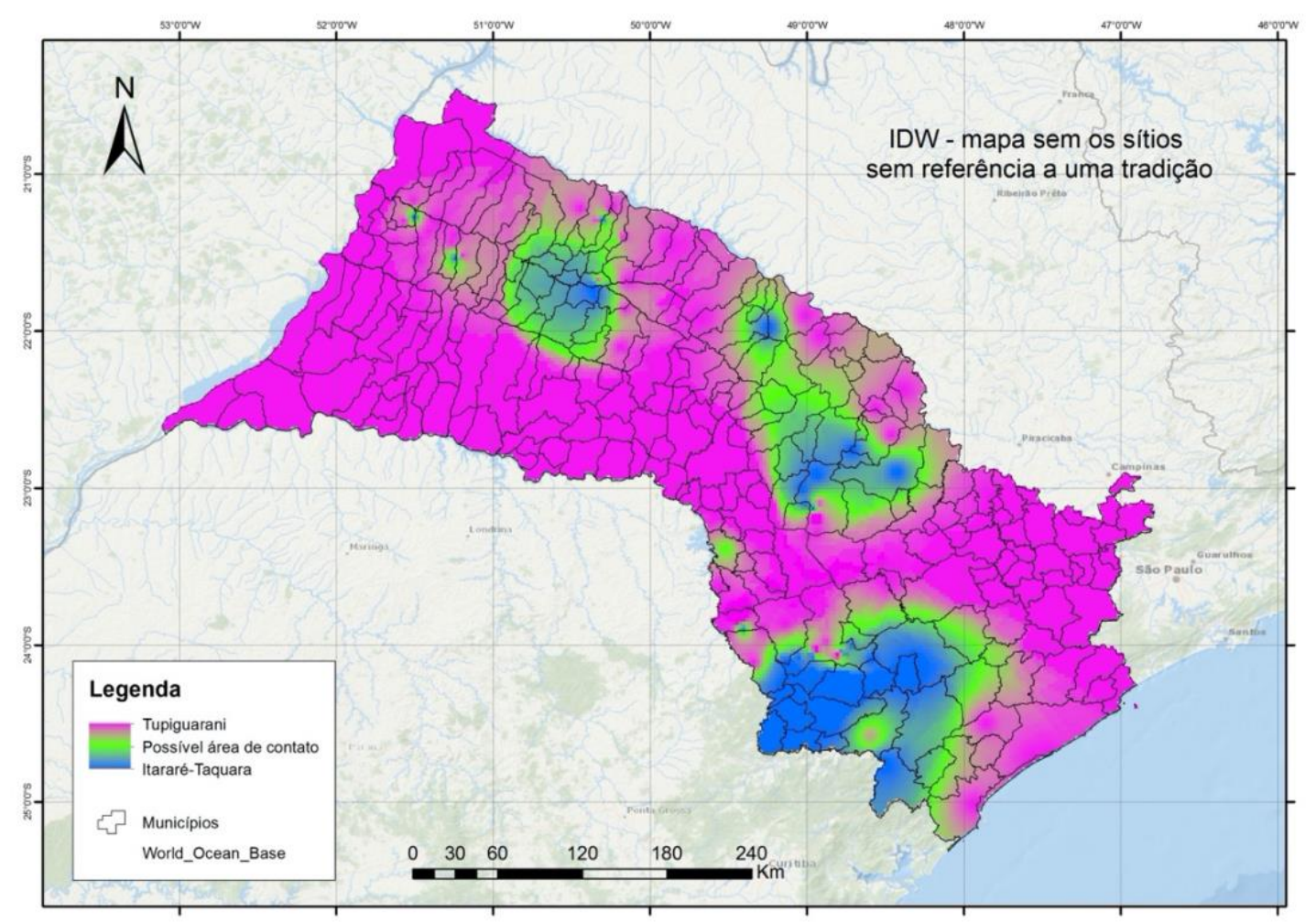

Mapa 3: Mapa produzido com a interpolação de 761 sítios através do método IDW com a técnica de visualização stretched.

Devido ao sucesso da utilização da visualização em formato streched, na qual se consideram apenas três categorias de sítios (Tradição Itararé-Taquara, Tradição Tupiguarani e possível área de contato), realizamos a interpolação Kriging, como são demonstrados os Mapa 4 e 5 com os 421 sítios e 761 sítios respectivamente.

O Mapa 4 foi reproduzido e adaptado de Perez (2018a, 2018b) e, embora seja possível a identificação de áreas de influência de ambas Tradições e seus contatos, é possível observar áreas esverdeadas distribuídas por todo o território rosa. Isso quer dizer que, tais áreas esverdeadas poderiam ser regiões de contato entre os grupos da Tradição Tupiguarani com a Tradição Itararé-Taquara indicadas pelo interpolador.

No Mapa 5 com resultado desta modelagem percebemos que muitas das informações que ficaram tão definidas anteriormente - especialmente no extremo Oeste e Sul do estado, desapareceram, tornando-se um mapa com maior diluição dos limites entre ambas as Tradições, mesmo com a inserção dos 761 sítios ao modelo gerado. Tais áreas anteriormente "definidas" possivelmente podem ser consideradas falsas, dada a ampliação da amostra analisada. 
A justificativa para insistimos nesse interpolador Kriging é que, anteriormente, (PEREZ, 2018a, 2018b) este interpolador demonstrou parecer ser eficaz do que o IDW comparando aos resultados apresentados e a observação das áreas de influência dos grupos ceramistas. Com essa experiência aqui apresentada, ressaltamos que a maneira de apresentação e inclusão de mais dados no sistema, pode naturalmente, resultar em diferentes mapas e cabe ao pesquisador julgar a melhor maneira de apresentar a sua pesquisa. Aqui, a distribuição espacial dos sítios parece ser melhor observada ao usarmos IDW com a visualização streched, do que ao usarmos a Krigagem com a mesma maneira de visualização, pois essa função apresenta áreas difusas e não linhas bem definidas, como entendemos a conceituação de fronteira.

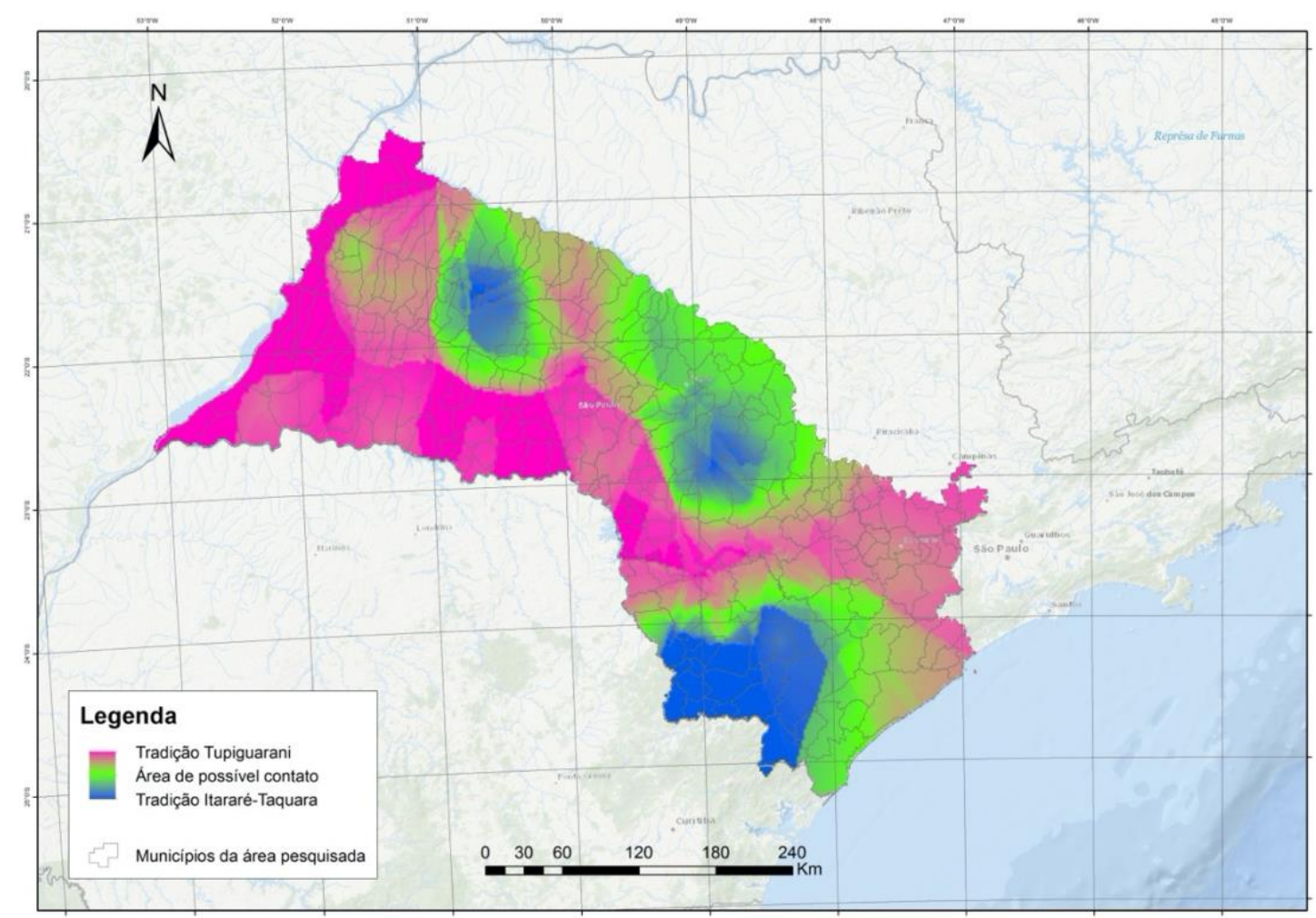

Mapa 4: Mapa apresentando a área pesquisada com Interpolador Kriging e 421 sítios plotados e visualizados a partir da técnica de visualização stretched. Adaptado de Perez (2018a). 


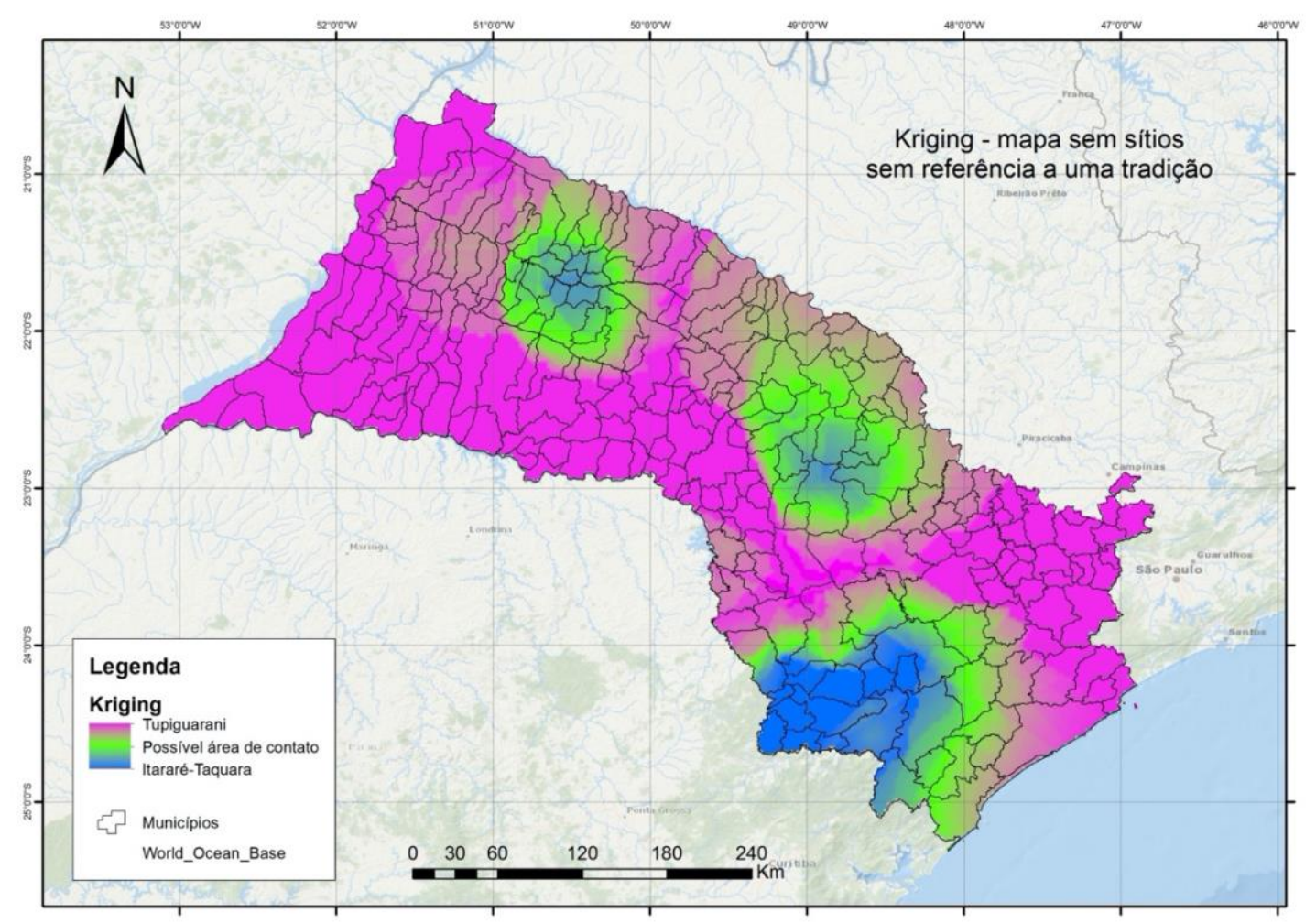

Mapa 5: Mapa apresentando a área pesquisada com Interpolador Kriging e 761 sítios plotados e visualizados a partir da técnica stretched.

Nesse sentido, esse artigo ampliou a quantidade de sítios abordados durante a utilização de interpoladores dentro do SIG e suas Análises Espaciais, destacando a adequação das visualizações das simulações virtuais do interesse do pesquisador.

\section{Considerações finais}

Os mapas aqui apresentados são modelos de distribuições espaciais que podem ser interpretados à luz de hipóteses acerca dos locais ocupados pelos grupos ceramistas pretéritos no território paulista e sua inteiração mútua. Infelizmente, para a elaboração destes mapas, não foi possível considerar a variante temporal, pois de acordo com o levantamento de Perez (2018a) existem poucas datações realizadas para os sítios daquela região. Deve-se levar em consideração que essas amplas áreas esverdeadas podem representar, não apenas áreas de contato (o que implica em uma visão sincrônica), mas também áreas de sobreposição, em que territórios ocupados por grupos Tupiguarani tenham sido posteriormente ocupados por grupos Itararé-Taquara ou vice-versa (vide Araujo 2007). 
Apesar dessas limitações, os resultados apresentados sugerem uma intensa ocupação e o inegável contato entre as populações produtoras de cerâmica das Tradições Tupiguarani e Itararé-Taquara. Nossos resultados podem ser testados e refinados com o aumento de observações empíricas, permitindo verificar se os padrões obtidos nas simulações correspondem aos padrões observados, o que certamente será útil para elaborar novas hipóteses explicativas regionais.

Além disso, a inclusão dos sítios sem coordenadas geográficas exatas possibilitou a identificação de áreas com influência da Tradição Tupiguarani, em áreas que até então nos era desconhecida, como o sul do Estado de São Paulo, divisa com o estado do Paraná, no município de Iporanga - região do Vale do Rio Ribeira do Iguape, o que exige ainda maiores estudos e definições, principalmente na área próxima, no Nordeste do estado do Paraná. Já em relação à distribuição dos sítios Itararé-Taquara, aparentemente existem três grandes áreas de ocupação consolidadas ao Sul do estado, área entre o médio Paranapanema e Tietê e a região do baixo Tietê.

\section{Referências}

AFONSO, M. C. 2005. Um olhar para a arqueologia pré-histórica do Estado de São Paulo. 2005. Tese (Livre Docência em Arqueologia). Museu de Arqueologia e Etnologia, Universidade de São Paulo, São Paulo.

ALVES, C. A.; SENA JUNIOR, D. G. 2008. Estudo do interpolador IDW para utilização em agricultura de precisão. Universidade Federal Rural do Rio de Janeiro, Seropédica, p.26. 2008.

ARAUJO, A. G. de M. 2007. A tradição cerâmica Itararé-Taquara: características, área de ocorrência e algumas hipóteses sobre a expansão dos grupos Jê no sudeste do Brasil. Revista de Arqueologia, 20(1):9-38.

BARTH, F. 1997. Grupos étnicos e suas fronteiras. IN: POUTIGNAIT, Philippe; STREIFF-FENART, Jocelyne. Teorias da etnicidade. UNESP, São Paulo: 187-227.

BRADSHAW, R.; GOMEZ, R. L. 1999. Fronteras: uma visión teórica em el período contemporâneo. In: Aldea Mund. , ano 4, n. 7, may-oct.

CORREA, Â. A. 2014. Pindorama de Mboîa e l̂akaré: continuidade e mudança na trajetória das populações Tupi. Tese (Doutorado em Arqueologia). Museu de Arqueologia e Etnologia, Universidade de São Paulo, São Paulo. 
FACCIO, N B. 2011. Arqueologia Guarani na área do Projeto Paranapanema: estudos dos sítios de lepê, SP. Tese (Livre Docência em Arqueologia). São Paulo. Museu de Arqueologia e Etnologia da Universidade de São Paulo.

JAKOB, A. A. E. 2002. A krigagem como método de análise de dados demográficos. XIII Encontro da Associação Brasileira de Estudos Populacionais, Ouro Preto, p. 1-15. Nov.

JAKOB, A. A. E. 2003. Análise Sócio-Demográfica da Constituição do Espaço Urbano da Região Metropolitana da Baixada Santista no período 1960-2000. Tese de Doutorado. Programa de Doutorado em Demografia do Instituto de Filosofia e Ciências Humanas da Universidade Estadual de Campinas. Campinas, SP: 2003.

JAKOB, A. A. E. 2006. O uso de métodos de interpolação espacial de dados nas análises sociodemográficas. XV Encontro Nacional de Estudos Populacionais, ABEP. Caxambu - MG, p. 2-22, set. 2006.

MORAIS, J. L. 2002. Resgate arqueológico na área de influência da duplicação das rodovias SP 342 e SP346: preservação de patrimônio dos sítios Ipê e Mota Pais. Relatório técnico científico final. São Paulo.

PEREZ, G. C. 2018a. Arqueologia Paulista e o marcador cerâmico como delimitador de fronteira étnica: um estudo das regiões sul e oeste do Estado de São Paulo. (Doutorado em Arqueologia). Museu de Arqueologia e Etnologia, Universidade de São Paulo, São Paulo, Disponível em: [http://www.teses.usp.br/teses/disponiveis/71/71131/tde-05042018092642/pt-br.php]

PEREZ, G. C.; AFONSO, M. C.; MOTA, L. T. 2018b. Métodos de análise espacial para sítios arqueológicos: um modelo preditivo para o Estado de São Paulo. Cadernos do LepaArq. v.15, p.98. [HTTP://DX.DOI.ORG/10.15210/LEPAARQ.V15130.13746]

ROBRAHN-GONZÁLEZ, E. M. 2000. São Paulo, terra de fronteiras: a ocupação de grupos ceramistas pré-coloniais. IN: Anais do IX Congresso da Sociedade de Arqueologia Brasileira, Rio de Janeiro. CD-ROM.

ROBRAHN-GONZÁLEZ, E. M. 2003. Repensando as fronteiras culturais de grupos ceramistas no Estado de São Paulo. IN: Resumos. XIII Congresso da Sociedade de Arqueologia Brasileira, São Paulo, p. 175.

SCHMITZ, P. I. 2007. Índios guaranis, Kaingang e Xokleng: territórios indígenas e fronteiras. IN: MOREIRA, L. F. V. (Org.). Instituições, fronteiras e políticas na História Sul-americana. Curitiba: Editora Juruá. p. 129-148.

ZIENTARA, B. 1989. Fronteira. Enciclopédia Einaudi - Estado e Guerra. Lisboa: Imprensa Nacional - Casa da Moeda, v. 14. 


\begin{tabular}{|c|c|c|c|c|c|c|c|c|c|c|c|c|c|c|c|c|}
\hline \multirow[b]{2}{*}{$\begin{array}{c}\text { Município } \\
\text { Atual }\end{array}$} & \multirow[b]{2}{*}{ Nome do Sitio } & \multirow[b]{2}{*}{\begin{tabular}{|l} 
Dataçōes \\
existentes \\
(SiM/NÃO)
\end{tabular}} & \multirow[b]{2}{*}{$\begin{array}{l}\text { Informaçöes } \\
\text { Dataçãom } \\
\text { ostram }\end{array}$} & \multicolumn{5}{|c|}{ Coordenadas Exatas } & \multicolumn{3}{|c|}{ Coordenadas Aproximandas } & \multirow[b]{2}{*}{\begin{tabular}{|c} 
Ref. \\
No \\
CNSA
\end{tabular}} & \multirow[b]{2}{*}{$\begin{array}{l}\text { Local dos } \\
\text { dados }\end{array}$} & \multirow[b]{2}{*}{ Referência Bibliografica associada } & \multirow[b]{2}{*}{ Segunda referência } & \multirow[b]{2}{*}{ Informaçōes extras/observaçōes } \\
\hline & & & & Datum & ZONA & $\begin{array}{c}\text { Longitud } \\
\mathrm{e}(\mathrm{E})\end{array}$ & \begin{tabular}{|c|} 
Latitu \\
de \\
(N)
\end{tabular} & $\begin{array}{l}\text { Coordenadas } \\
\text { em Graus, } \\
\text { minuts, } \\
\text { segundos }\end{array}$ & $\underset{\mathrm{A}}{\mathrm{zoN}}$ & \begin{tabular}{|c} 
Longitu \\
de (E)
\end{tabular} & \begin{tabular}{|c|c|}
$\begin{array}{c}\text { Latitude } \\
\text { (N) }\end{array}$ \\
\end{tabular} & & & & & \\
\hline chavantes & $\begin{array}{l}10 \mathrm{CHV} \\
22.218 .469\end{array}$ & Século XVII & & & & & & & $22 \mathrm{~K}$ & 632431 & 7451357 & & $\begin{array}{l}\text { Biblioteca } \\
\text { MAE }\end{array}$ & 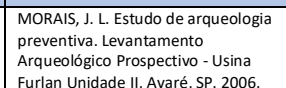 & 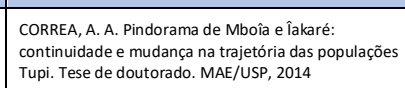 & \\
\hline Araçatuba & $\begin{array}{l}\text { Porto } \\
\text { Menezes }\end{array}$ & não & & & & & & & $22 \mathrm{~K}$ & 557667 & 7653655 & & $\begin{array}{l}\text { Biblioteca } \\
\text { MAE }\end{array}$ & 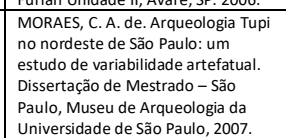 & 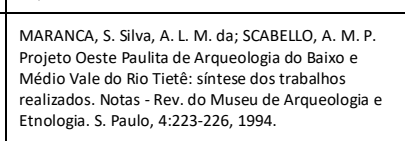 & 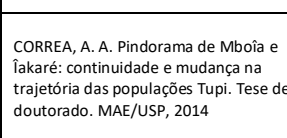 \\
\hline Araçatuba & Porto Sargeb & não & & & & & & & $22 \mathrm{~K}$ & 557667 & 7653655 & & \begin{tabular}{|l|} 
Biblioteca \\
MAE
\end{tabular} & 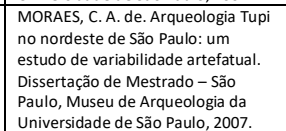 & 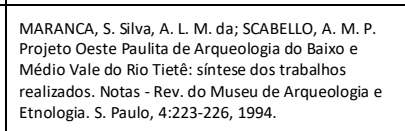 & 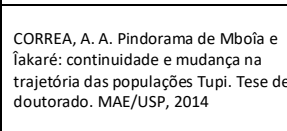 \\
\hline Itapeva & $\begin{array}{l}\text { Abrigo de } \\
\text { Itapeva }\end{array}$ & não & & $\begin{array}{l}\text { South } \\
\text { American } \\
69\end{array}$ & 22 & 706005 & \begin{tabular}{|l|l|}
7337 \\
175
\end{tabular} & $\begin{array}{l}2400351 \text { "S } 48 \\
5826^{\prime} \mathrm{W}\end{array}$ & & & & $\begin{array}{l}\text { Spoog } \\
37\end{array}$ & \begin{tabular}{|l|} 
CNSA e \\
Biblioteca \\
MAE
\end{tabular} & $\begin{array}{l}\text { Projeto Paranapanema - } \\
\text { Levantamento Arqueoológico do Alto } \\
\text { Taquari }\end{array}$ & 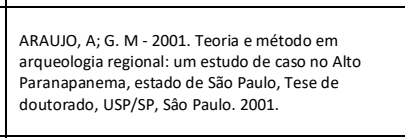 & 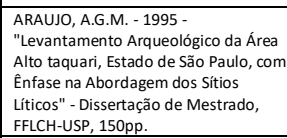 \\
\hline Arealva & Cardoso & não & & & & & & & $22 \mathrm{~K}$ & 715627 & 7562461 & & \begin{tabular}{|l|} 
Biblioteca \\
MAE
\end{tabular} & 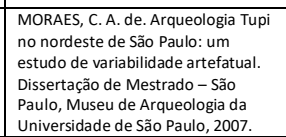 & 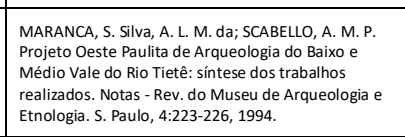 & 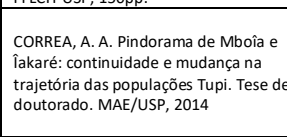 \\
\hline Arealva & $\begin{array}{l}\text { Chacara Boa } \\
\text { Vista }\end{array}$ & não & & & & & & & $22 \mathrm{~K}$ & 715627 & 7562461 & & $\begin{array}{l}\text { Biblioteca } \\
\text { MAE }\end{array}$ & 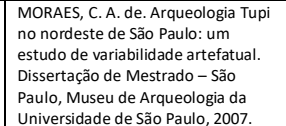 & 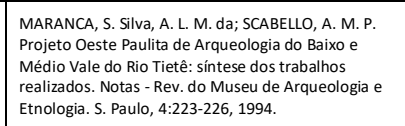 & 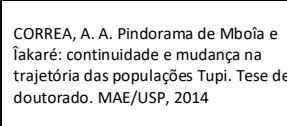 \\
\hline Avaré & $\begin{array}{l}\text { Córrego } \\
\text { Caiprinha }\end{array}$ & não & & & & & & & $22 \mathrm{~K}$ & 712742 & 7443906 & & $\begin{array}{l}\text { Arquivo } \\
\text { IPANA- } \\
\text { Relarorio } \\
\text { s } \\
\end{array}$ & 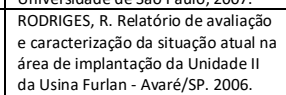 & & $\begin{array}{l}\text { esse sitio aparece citado em uma } \\
\text { planilha apresentada pelo uator. Não } \\
\text { existe qualquer outra referencia ao } \\
\text { sitio. }\end{array}$ \\
\hline Arealva & $\begin{array}{l}\text { Fazenda } \\
\text { Matăo }\end{array}$ & não & & & & & & & $22 \mathrm{~K}$ & 715627 & 7562461 & & \begin{tabular}{|l|} 
Biblioteca \\
MAE
\end{tabular} & 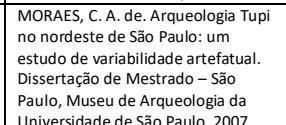 & 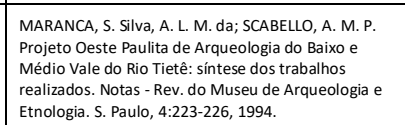 & 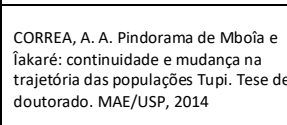 \\
\hline $\begin{array}{l}\text { Barra do } \\
\text { Turvo }\end{array}$ & \begin{tabular}{|l|} 
Águas \\
Quentes।
\end{tabular} & não & & & & & & & $22 J$ & 752465 & 7259584 & & CNSA & $\begin{array}{l}\text { DEBLASISI, P. Re Relatórí. Projeto } \\
\text { Arqueolólico do Médio Ribeira. } \\
\text { 1982-1997. }\end{array}$ & & proximidade ao rio Águas Quentes \\
\hline $\begin{array}{l}\text { Barra do } \\
\text { Turvo }\end{array}$ & \begin{tabular}{|l|} 
Águas \\
Quentes II
\end{tabular} & não & & & & & & & $22 J$ & 752465 & 7259584 & & CNSA & $\begin{array}{l}\text { DEBLASIS, P. Relatário. Projeto } \\
\text { Arqueológico do Médio Ribeira. } \\
\text { 1982-19977. }\end{array}$ & & proximidade ao rio Águas Quentes \\
\hline Arealva & São Bento & não & & & & & & & $22 \mathrm{~K}$ & 715627 & 7562461 & & $\begin{array}{l}\text { Biblioteca } \\
\text { MAE }\end{array}$ & 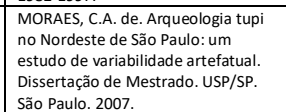 & 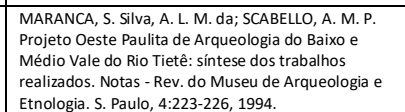 & 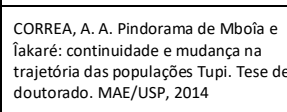 \\
\hline Avaré & $\begin{array}{l}\text { AVR } \\
\text { 22.202.502 }\end{array}$ & não & & & & & & & $22 \mathrm{~K}$ & 712742 & 7443908 & & $\begin{array}{l}\text { Biblioteca } \\
\text { MAE }\end{array}$ & 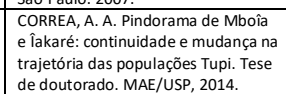 & & \\
\hline $\begin{array}{l}\text { Barăo de } \\
\text { Antonina }\end{array}$ & $\begin{array}{l}\text { Acampamento } \\
\text { Trếs } 1\end{array}$ & não & & & & & & & $22 \mathrm{~K}$ & 646729 & 7386065 & 25446 & \begin{tabular}{|l|} 
CNSA e \\
Biblioteca \\
MAE
\end{tabular} & 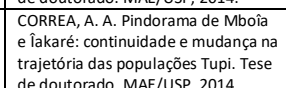 & & \\
\hline
\end{tabular}




\begin{tabular}{|c|c|c|c|c|c|c|c|c|c|c|c|c|c|}
\hline $\begin{array}{l}\text { Barão de } \\
\text { Antonina }\end{array}$ & $\begin{array}{l}\text { Acampamento } \\
\text { Três } 3\end{array}$ & não & & & & & $22 \mathrm{~K}$ & 646729 & 7386065 & 25448 & \begin{tabular}{|l|} 
CNSA e \\
Biblioteca \\
MAE
\end{tabular} & 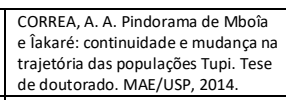 & \\
\hline $\begin{array}{l}\text { Barão de } \\
\text { Antonina }\end{array}$ & $\begin{array}{l}\text { Riacho Sem } \\
\text { Nome } 1\end{array}$ & não & & & & & $22 \mathrm{~K}$ & 646729 & 7386065 & 25451 & \begin{tabular}{|l|} 
CNSA e \\
Biblioteca \\
MAE \\
\end{tabular} & 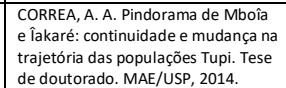 & \\
\hline $\begin{array}{l}\text { Barão de } \\
\text { Antonina }\end{array}$ & $\begin{array}{l}\text { Riacho Sem } \\
\text { Nome 2 }\end{array}$ & não & & & & & $22 \mathrm{~K}$ & 646729 & 7386065 & $\begin{array}{l}25468 ; \\
25452\end{array}$ & \begin{tabular}{|l|l|} 
CNSA e \\
Biblioteca \\
MAE \\
\end{tabular} & 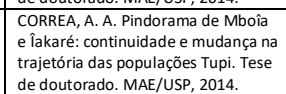 & \\
\hline $\begin{array}{l}\text { Barão de } \\
\text { Antonina }\end{array}$ & $\begin{array}{l}\text { Ribeirão } \\
\text { Marimbondo } \\
1\end{array}$ & não & & & & & $22 \mathrm{~K}$ & 646729 & 7386065 & 25469 & \begin{tabular}{|l|} 
CNSA e \\
Biblioteca \\
MAE \\
\end{tabular} & 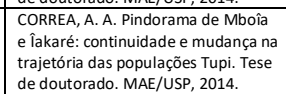 & \\
\hline $\begin{array}{l}\text { Barão de } \\
\text { Antonina }\end{array}$ & $\begin{array}{l}\text { Salto do } \\
\text { Itararé } 10\end{array}$ & não & & & & & $22 \mathrm{~K}$ & 646729 & 7386065 & 25476 & \begin{tabular}{|l|} 
CNSA e \\
Biblioteca \\
MAE
\end{tabular} & 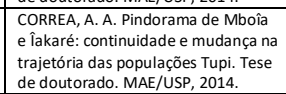 & \\
\hline $\begin{array}{l}\text { São Pedro do } \\
\text { Turvo }\end{array}$ & \begin{tabular}{|l} 
Água do \\
Saltinho 1
\end{tabular} & não & & $22 \mathrm{~K}$ & 0635586 & \begin{tabular}{|l}
7484 \\
317
\end{tabular} & & & & $\begin{array}{l}\text { Spoo6 } \\
47\end{array}$ & CNSA & 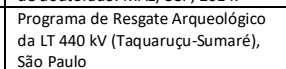 & Documento Arqueologia SC Ltda \\
\hline lacanga & $\begin{array}{l}\text { Asua } \\
\text { Espalhada I }\end{array}$ & não & SAD 69 & 22 & 700043 & \begin{tabular}{|l}
7589 \\
539
\end{tabular} & & & & & CNSA & 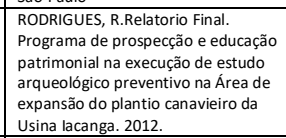 & \\
\hline $\begin{array}{l}\text { Barra do } \\
\text { Turvo }\end{array}$ & Cedro I & não & & & & & $22 J$ & 752465 & 7259584 & & \begin{tabular}{|l|} 
CNSA e \\
Biblioteca \\
MAE \\
\end{tabular} & 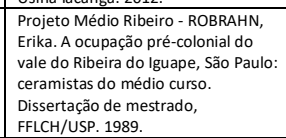 & $\begin{array}{l}\text { proximidade ao rio Bugre - Bacia do rio } \\
\text { Turvo }\end{array}$ \\
\hline $\begin{array}{l}\text { Barra do } \\
\text { Turvo }\end{array}$ & $\begin{array}{l}\text { Primeiro } \\
\text { Ribeiräoll }\end{array}$ & não & & & & & $22 J$ & 752465 & 7259584 & & \begin{tabular}{|l|} 
CNSA e \\
Biblioteca \\
MAE
\end{tabular} & 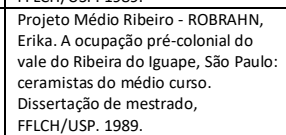 & \\
\hline $\begin{array}{l}\text { Barãode } \\
\text { Antonina }\end{array}$ & $\begin{array}{l}\text { Salto do } \\
\text { Itararé } 11\end{array}$ & não & & & & & $22 \mathrm{~K}$ & 646729 & 7386065 & 25477 & \begin{tabular}{|l|} 
CNSA e \\
Biblioteca \\
MAE
\end{tabular} & 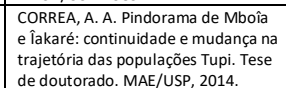 & \\
\hline $\begin{array}{l}\text { Barra do } \\
\text { Turvo }\end{array}$ & \begin{tabular}{|l} 
Ribeirão do \\
Bugre I
\end{tabular} & não & & & & & $22 J$ & 752465 & 7259584 & & \begin{tabular}{|l|l} 
CNSA e \\
Biblioteca \\
MAE
\end{tabular} & 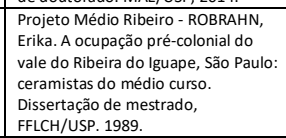 & Rio Bonito \\
\hline $\begin{array}{l}\text { Barra do } \\
\text { Turvo }\end{array}$ & \begin{tabular}{|l|l|} 
Ribeirão do \\
Bugre II
\end{tabular} & não & & & & & $22 \mathrm{~J}$ & 752465 & 7259584 & & \begin{tabular}{|l|} 
CNSA e \\
Biblioteca \\
MAE
\end{tabular} & 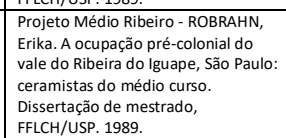 & Rio Turvo \\
\hline $\begin{array}{l}\text { Junqueirópoli } \\
\mathrm{s}\end{array}$ & Aldeia & não & & $22 \mathrm{~K}$ & 459148 & $\begin{array}{l}7631 \\
817\end{array}$ & & & & & \begin{tabular}{|l} 
Arquivo \\
IPHAN- \\
Relarório \\
s \\
\end{tabular} & 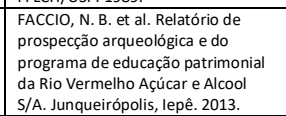 & \\
\hline $\begin{array}{l}\text { Barão de } \\
\text { Antonina }\end{array}$ & \begin{tabular}{|l} 
Salto do \\
Itararéé 4
\end{tabular} & não & & & & & $22 \mathrm{~K}$ & 646729 & 7386065 & 25470 & \begin{tabular}{|l|} 
CNSA e \\
Biblioteca \\
MAE \\
\end{tabular} & 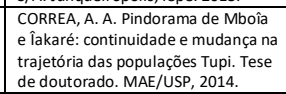 & \\
\hline $\begin{array}{l}\text { Junqueirópoli } \\
s\end{array}$ & Aldeiall & não & & $22 \mathrm{~K}$ & 457053 & \begin{tabular}{|l|l}
7637 \\
847
\end{tabular} & & & & & \begin{tabular}{|l|} 
Arquivo \\
IPHAN -
\end{tabular} & 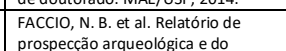 & \\
\hline
\end{tabular}




\begin{tabular}{|c|c|c|c|c|c|c|c|c|c|c|c|c|c|c|c|c|}
\hline & & & & & & & & & & & & & \begin{tabular}{|l|} 
Relarório \\
$\mathrm{s}$
\end{tabular} & $\begin{array}{l}\text { programa de educaçăa patrimonial } \\
\text { da aiv Vermello Acucare Acool } \\
\text { S/A. Junqueiróplis, lepê. 2013. } \\
\end{array}$ & & \\
\hline Castilho & ALEGRINHO & não & & SAD 69 & 22 & 435010 & $\begin{array}{l}7693 \\
3076\end{array}$ & & & & & $\begin{array}{l}\text { Spo09 } \\
27\end{array}$ & \begin{tabular}{|l|} 
CNSAe \\
Biblioteca \\
MAE \\
\end{tabular} & $\begin{array}{l}\text { Projeto de Salvamento Arqueológico } \\
\text { de Porto Primavera, SP. }\end{array}$ & 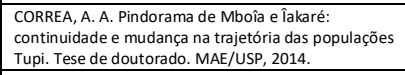 & \\
\hline $\begin{array}{l}\text { Álvares } \\
\text { Machado }\end{array}$ & Aleixo & não & & & $22 \mathrm{~K}$ & 439215 & $\begin{array}{l}7551 \\
040\end{array}$ & & & & & & $\begin{array}{l}\text { CNSA e } \\
\text { Biblioteca } \\
\text { MAE }\end{array}$ & \begin{tabular}{|l} 
KUNZLI. R. Arqueoologia regional. \\
Primeiros resultados das pesauisas \\
realizadas na área de Presidente \\
Prudente, SP. Revista do Museu \\
Paulista. 32: 223-247. São Paulo, \\
1987.
\end{tabular} & & \\
\hline Irapuru & Alianşa & não & & & $22 \mathrm{~K}$ & 450555 & $\begin{array}{l}7617 \\
972 \\
\end{array}$ & & & & & & \begin{tabular}{|l|} 
CNSAe \\
Biblioteca \\
MAE
\end{tabular} & 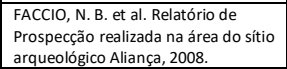 & & \\
\hline $\begin{array}{l}\text { Presidente } \\
\text { Epitácio }\end{array}$ & Alma de gato & não & & & 22 & 395632 & $\begin{array}{l}7620 \\
308\end{array}$ & & & & & $\begin{array}{l}\text { Sp0006 } \\
56\end{array}$ & \begin{tabular}{|l|} 
CNSA e \\
Biblioteca \\
MAE \\
\end{tabular} & 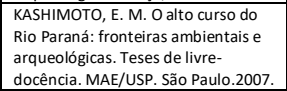 & & \\
\hline Chavantes & $\begin{array}{l}14 \mathrm{CHV} \\
22.246 .448\end{array}$ & Século XVII & & & & & & & $22 \mathrm{~K}$ & 632431 & 7451357 & & \begin{tabular}{|l|} 
Biblioteca \\
MAE
\end{tabular} & 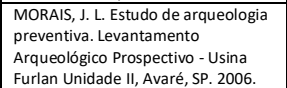 & $\begin{array}{l}\text { CORREA, A. A. Pindorama de Mboîa e T̂akaré: } \\
\text { continuidade e mudancan na arajetória das populaçōes } \\
\text { Tupi. Tese de doutorado. MAE/USP, } 2014\end{array}$ & \\
\hline lepê & Aguinha & $700 \mathrm{AP}$ & & & & & & & $22 \mathrm{~K}$ & 492449 & 7493966 & & $\begin{array}{l}\text { Biblioteca } \\
\text { MAE }\end{array}$ & 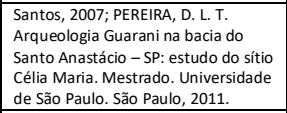 & $\begin{array}{l}\text { CORREA, A. A. Pindorama de Mboîa e T̂akaré: } \\
\text { continuidade e mudancana na arajetória das populaçes } \\
\text { Tuti. Tese de doutorado. MAE/USP, } 2014\end{array}$ & \\
\hline Alto Alegre & Alto Alegre I & não & & SAD 69 & 22 & 587926 & $\begin{array}{l}7602 \\
569\end{array}$ & & & & & $\begin{array}{l}\text { SP011 } \\
14\end{array}$ & CNSA & 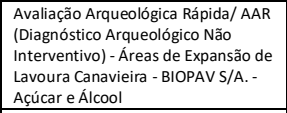 & & \\
\hline Alto Alegre & Alto Alegre II & não & & SAD 69 & 22 & 588755 & $\begin{array}{l}7601 \\
746\end{array}$ & & & & & $\begin{array}{l}\text { SP011 } \\
15\end{array}$ & CNSA & 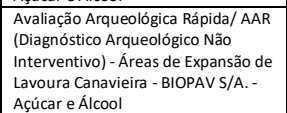 & & \\
\hline Alto Alegre & Alto Alegre III & não & & SAD 69 & 22 & 589695 & $\begin{array}{l}7602 \\
007\end{array}$ & & & & & $\begin{array}{l}\text { SP011 } \\
16\end{array}$ & CNSA & 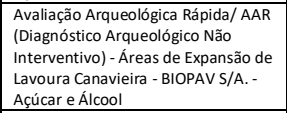 & & \\
\hline Alto Alegre & Alto Alegre IV & não & & SAD 69 & 22 & 591312 & $\begin{array}{l}7602 \\
188\end{array}$ & & & & & $\begin{array}{l}\text { SP011 } \\
17\end{array}$ & CNSA & 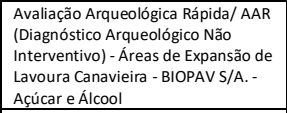 & & \\
\hline Tejupá & Almeida & $\begin{array}{l}1400 \mathrm{AD} ; \\
515 \mathrm{AP} ; \\
560 \pm 60 \mathrm{AP} \\
; 470 \pm 50 \\
\text { AP }\end{array}$ & 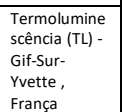 & & & 669200 & $\begin{array}{l}7422 \\
600\end{array}$ & 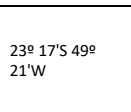 & & & & $\begin{array}{l}\text { SP004 } \\
23\end{array}$ & \begin{tabular}{|l|} 
CNSA, \\
Biblioteca \\
MAEe \\
Inventári \\
\end{tabular} & $\begin{array}{l}\text { POSSE, Z. Populaçäes pré-.históricias } \\
\text { de stios cerânicos no interior do } \\
\text { Brasil. Doutorado. USP. Săo Paulo, } \\
\text { 1984. }\end{array}$ & $\begin{array}{l}\text { SCATAMACCHIA. M. C. M. Tentativa de caracterizaçăo } \\
\text { da a radiçăo Tupiguarani. Dissertaçăo de Mestrado. } \\
\text { USP. Săo Paulo. 1981. }\end{array}$ & 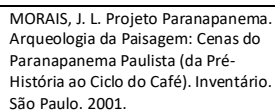 \\
\hline Tatuí & Alpargatas & $758 \pm 50 \mathrm{AP}$ & $\begin{array}{l}\text { Termolumine } \\
\text { scencia (TLL) }\end{array}$ & & 23 & 0295008 & $\begin{array}{l}7455 \\
082\end{array}$ & & & & & $\begin{array}{l}\text { Sp } \\
00419\end{array}$ & $\begin{array}{l}\text { CNSA e } \\
\text { Biblioteca } \\
\text { MAE }\end{array}$ & 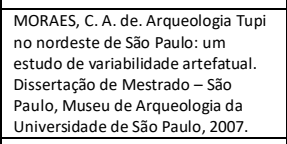 & 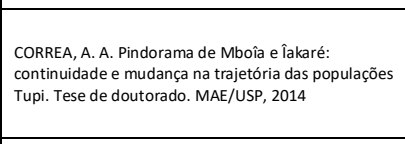 & \\
\hline Piraju & Alves & $\begin{array}{l}1150 \pm 100 \\
\text { AP } \\
; 1020 \mathrm{AP} ; \\
1021 \pm 100 \\
\text { AP } \\
; 955 \pm 100 \\
\text { AP }\end{array}$ & 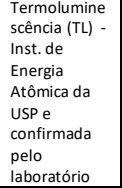 & & & 673000 & $\begin{array}{l}7426 \\
000\end{array}$ & $\begin{array}{l}23015 \text { '57"S } 490 \\
18 \text { '30"W }\end{array}$ & & & & $\begin{array}{l}\text { Spo09 } \\
85 \text { e } \\
\text { Cnsa } \\
25598\end{array}$ & $\begin{array}{l}\text { CNSA e } \\
\text { Biblioteca } \\
\text { MAE }\end{array}$ & $\begin{array}{l}\text { PALLESTRIIII, L. Supra-estrutura e } \\
\text { Infra-estruturas aqueológicas a no } \\
\text { contexto ecológico brasileiro. } \\
\text { Revista do Museu Paulista. Săo } \\
\text { Paulo, XX: 7-32. São Paulo. 1972- } \\
\text { 1973. }\end{array}$ & $\begin{array}{l}\text { POSSE, Z. Populaçōes pré-históricas de sítios } \\
\text { cerâmicos no interior do Brasil. Doutorado. USP. São } \\
\text { Paulo, } 1984 \text {. }\end{array}$ & $\begin{array}{l}\text { PALLESTRINI, } 1988 \text { - relata uma } \\
\text { dataçâo de } 7020 \text { B.P. para esse sítio. }\end{array}$ \\
\hline
\end{tabular}




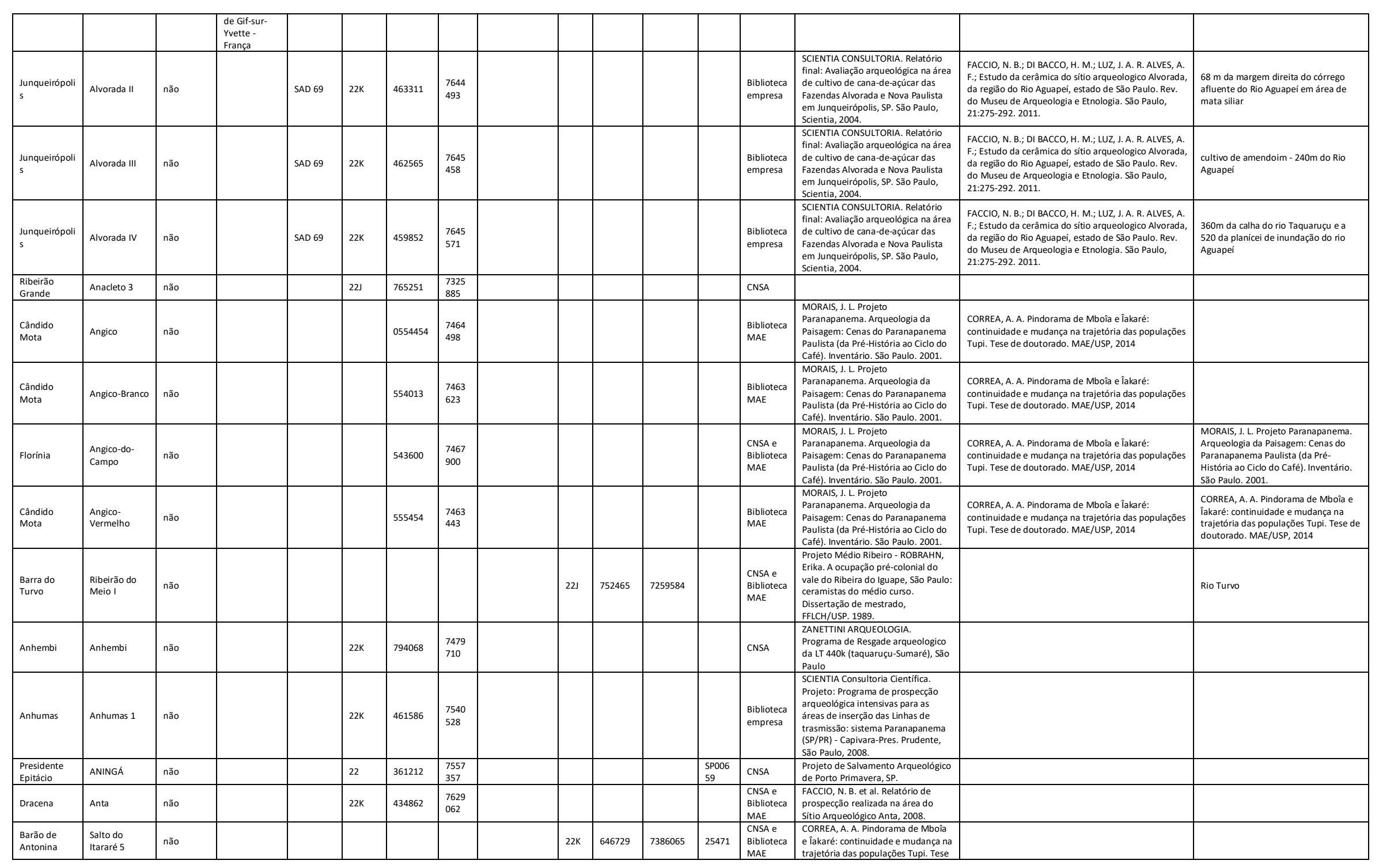




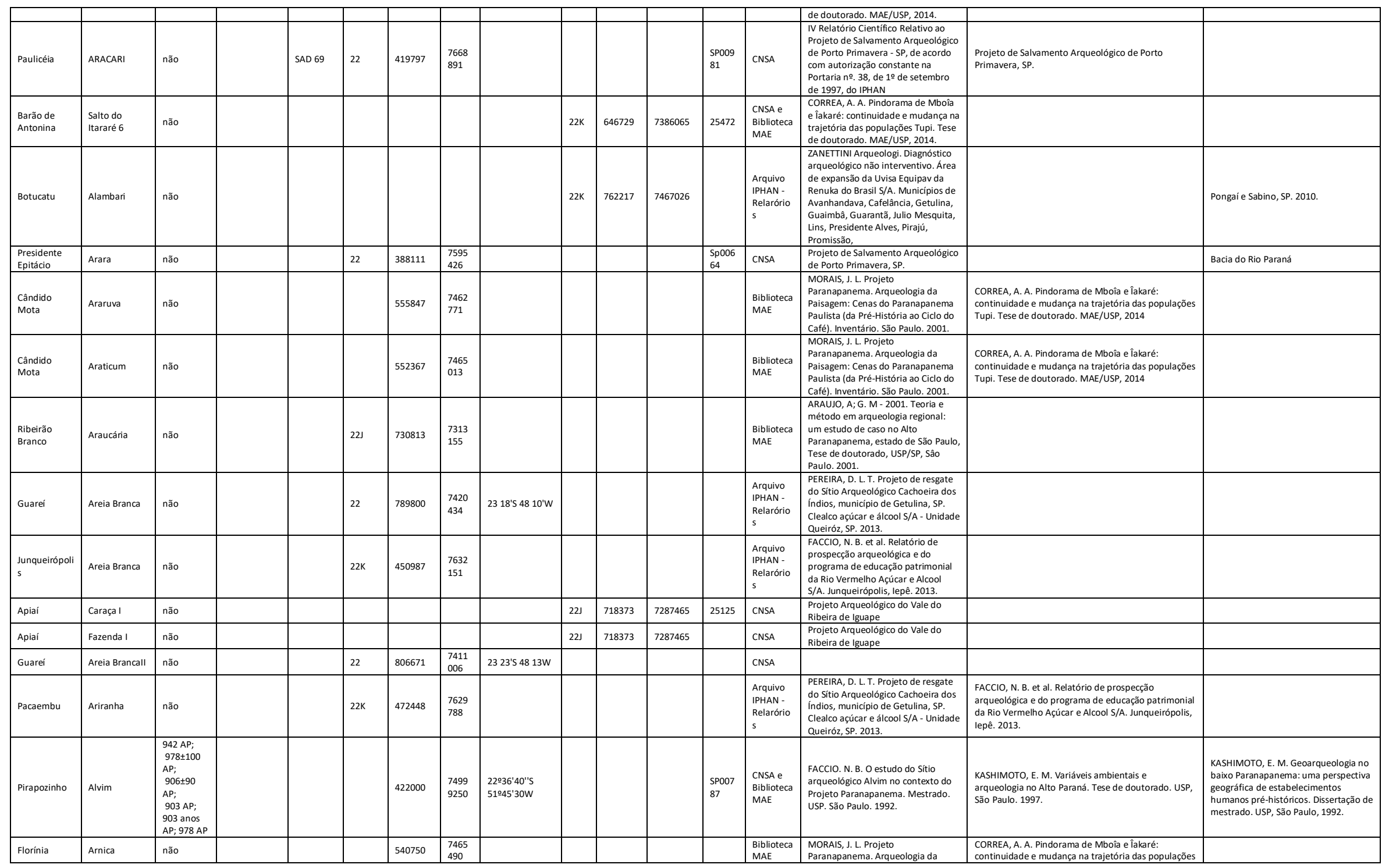




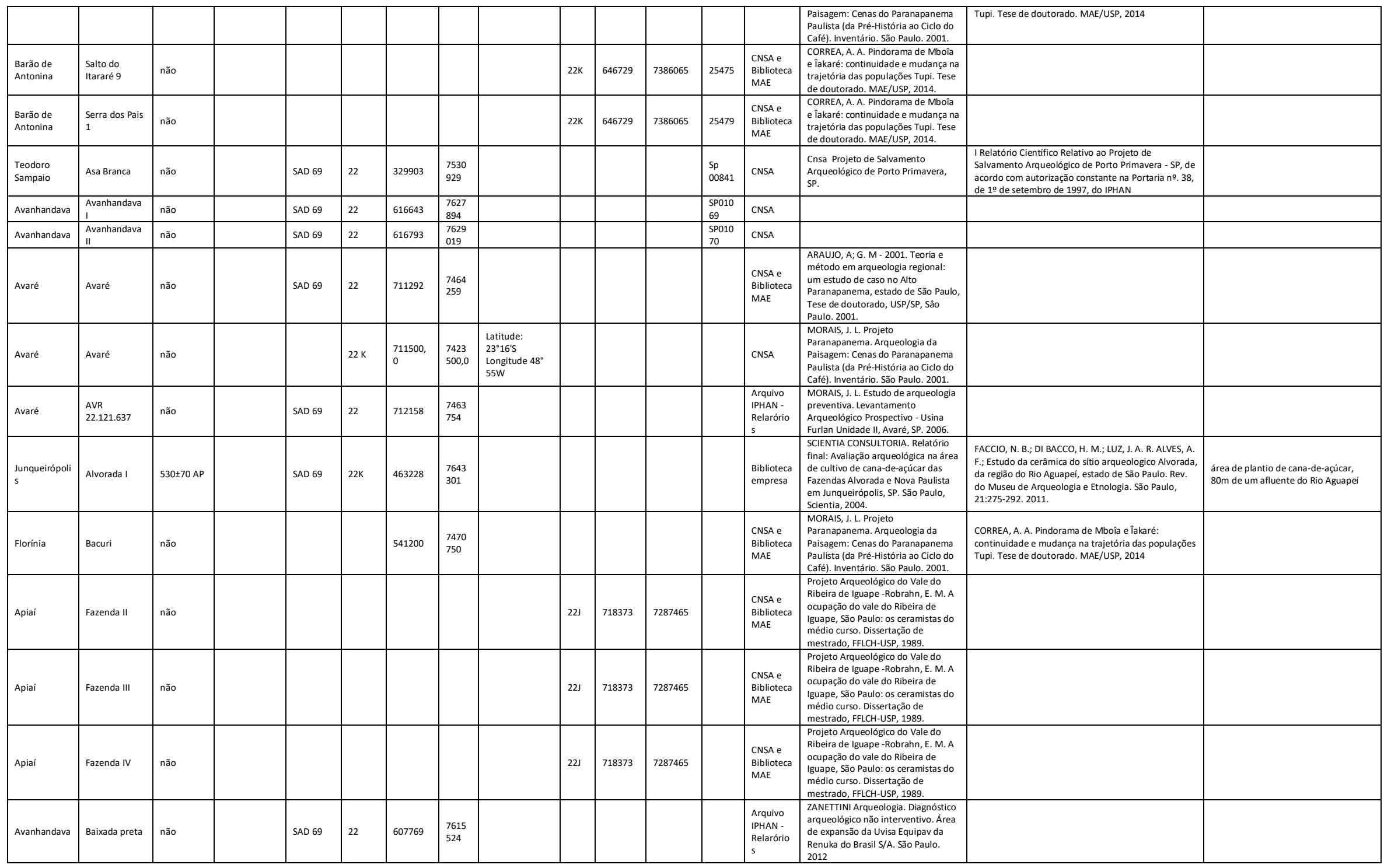




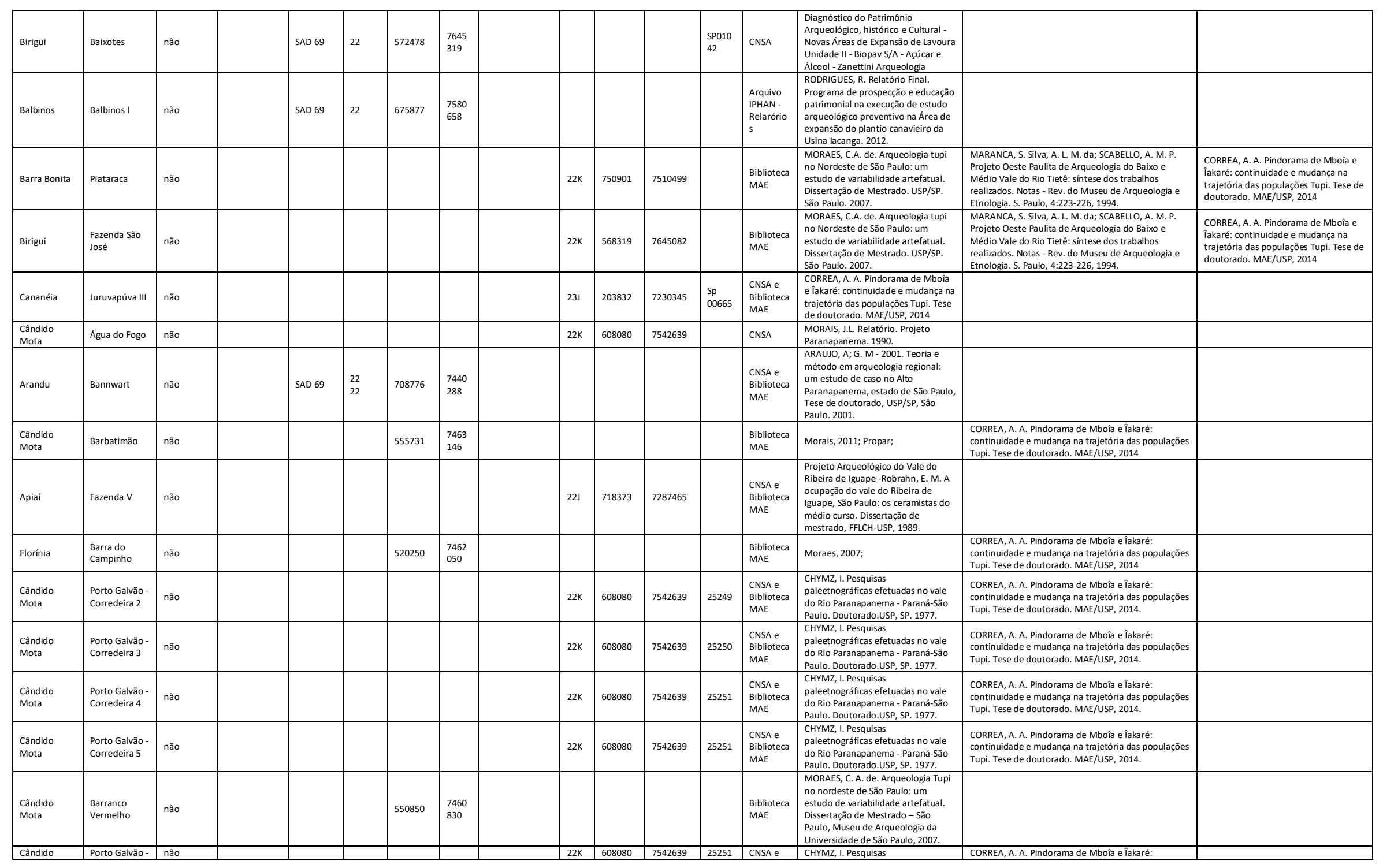




\begin{tabular}{|c|c|c|c|c|c|c|c|c|c|c|c|c|c|c|c|}
\hline Mota & Corredeira 6 & & & & & & & & & & & $\begin{array}{l}\text { Biblioteca } \\
\text { MAE }\end{array}$ & 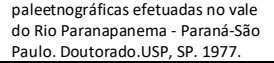 & $\begin{array}{l}\text { continuidade e mudança a a trajetória das populaçöes } \\
\text { Tupi. Tese de doutorado. MAE/USP, } 2014 .\end{array}$ & \\
\hline $\begin{array}{l}\text { Cândido } \\
\text { Mota }\end{array}$ & $\begin{array}{l}\text { Porto Galvão } \\
10\end{array}$ & não & & & & & & $22 \mathrm{~K}$ & 608080 & 7542639 & 25248 & $\begin{array}{l}\text { CNSA } \\
\text { Biblioteca } \\
\text { MAE }\end{array}$ & 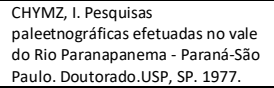 & 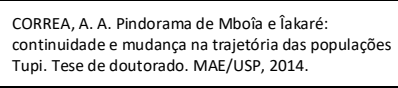 & \\
\hline Florinia & Barreirinho & não & & & 540380 & $\begin{array}{l}7460 \\
790\end{array}$ & & & & & & MAE & 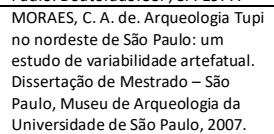 & $\begin{array}{l}\text { CORREA, A. A. Pindorama de Mboîa e liakaré: } \\
\text { continuidade e mudança na trajetória das populaços } \\
\text { Tupi. Tese de doutorado. MAE/USP, } 2014\end{array}$ & \\
\hline Itai & Barreirinho & não & SAS 69 & 22 & 704280 & $\begin{array}{l}7422 \\
046\end{array}$ & & & & & & $\begin{array}{l}\text { Inventári } \\
\text { o }\end{array}$ & 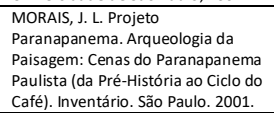 & & \\
\hline $\begin{array}{l}\text { Ribeirão } \\
\text { Grande }\end{array}$ & Barreiro 2 & não & SAD 69 & $22 J$ & 769639 & $\begin{array}{l}7327 \\
785\end{array}$ & & & & & $\begin{array}{l}\text { SP010 } \\
04\end{array}$ & $\begin{array}{l}\text { CNSA } \\
\text { Biblioteca } \\
\text { MAE }\end{array}$ & 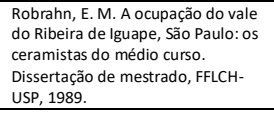 & 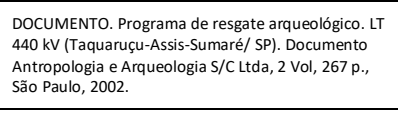 & $\begin{array}{l}\text { Avaliacăo Arqueoológica Rápida Usina } \\
\text { CESTT- Central Energética São Pedro } \\
\text { do Turvo Açucar e Allcool }\end{array}$ \\
\hline Apiai & Gurutuba 10 & não & & & & & & $22 J$ & 718373 & 7287465 & & $\begin{array}{l}\text { CNSA } \\
\text { Biblioteca } \\
\text { MAE }\end{array}$ & 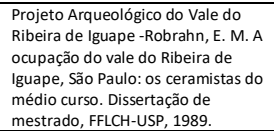 & & \\
\hline $\begin{array}{l}\text { Ribeirão } \\
\text { Grande }\end{array}$ & Barreiro 4 & não & SAD 69 & $22 J$ & 769400 & $\begin{array}{l}7327 \\
516\end{array}$ & & & & & $\begin{array}{l}\text { SP010 } \\
\text { 06 }\end{array}$ & $\begin{array}{l}\text { CNSA } \\
\text { Biblioteca } \\
\text { MAE }\end{array}$ & 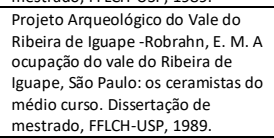 & 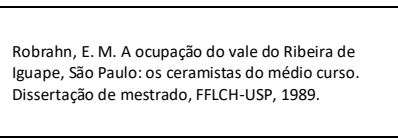 & 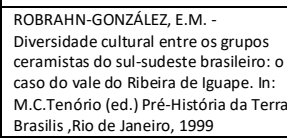 \\
\hline Apiai & Gurutuba 16 & não & & & & & & $22 \sqrt{3}$ & 718373 & 7287465 & & $\begin{array}{l}\text { CNSA } \\
\text { Biblioteca } \\
\text { MAE }\end{array}$ & 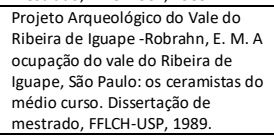 & 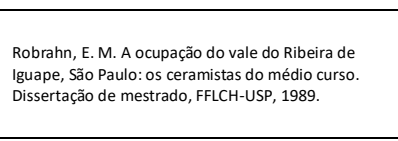 & \\
\hline Angatuba & $\begin{array}{l}\text { Barreiro dos } \\
\text { Italianos }\end{array}$ & não & & 22 & 754632 & $\begin{array}{l}7392 \\
454\end{array}$ & $\begin{array}{l}2^{2} 3^{\circ} 33^{\prime \prime} \mathrm{s} \\
48^{3} 30^{\circ} \mathrm{w}\end{array}$ & & & & & $\begin{array}{l}\text { CNSA } \\
\text { Biblioteca } \\
\text { MAE }\end{array}$ & $\begin{array}{l}\text { Pallestini, } 1975 \text { Interpreteaçōes das } \\
\text { estrtuturas arqueoelogicas em sitios } \\
\text { do Estado de São Paulo. }\end{array}$ & & \\
\hline Apiai & Gurutuba 17 & não & & & & & & $22 J$ & 718373 & 7287465 & & $\begin{array}{l}\text { CNSA } \\
\text { Biblioteca } \\
\text { MAE }\end{array}$ & 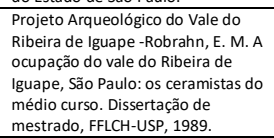 & 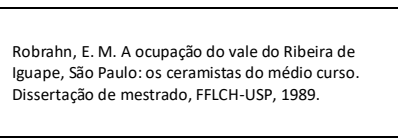 & \\
\hline Apiai & Gurutuba 5 & não & & & & & & 221 & 718373 & 7287465 & & $\begin{array}{l}\text { CNSA } \\
\text { Biblioteca } \\
\text { MAE }\end{array}$ & 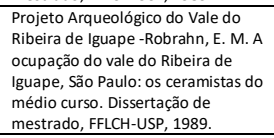 & 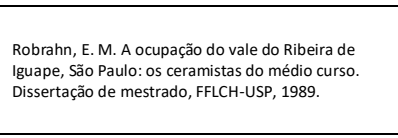 & \\
\hline Apiai & Gurutuba 9 & não & & & & & & $22 J$ & 718373 & 7287465 & & $\begin{array}{l}\text { CNSA } \\
\text { Biblioteca } \\
\text { MAE }\end{array}$ & 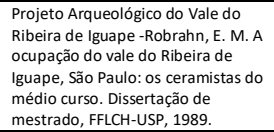 & & \\
\hline Apiai & Gurutuba I & não & & & & & & 221 & 718373 & 7287465 & & $\begin{array}{l}\text { CNSA } \\
\text { Biblioteca } \\
\text { MAE }\end{array}$ & 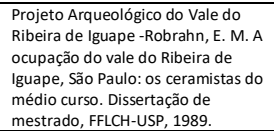 & & \\
\hline
\end{tabular}




\begin{tabular}{|c|c|c|c|c|c|c|c|c|c|c|c|c|c|c|c|}
\hline Botucatu & Araguál & năo & & & & & & $22 \mathrm{~K}$ & 801210 & 7388155 & & $\begin{array}{l}\text { Arquivo } \\
\text { IPAN- } \\
\text { Relarório } \\
\text { s }\end{array}$ & 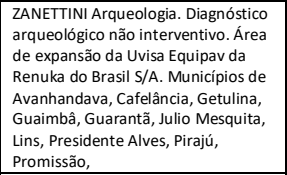 & & Pongaíe Sabino, SP. 2010. \\
\hline Florinia & Baruti & não & & & & 535900 & \begin{tabular}{|l|}
7468 \\
650
\end{tabular} & & & & & $\begin{array}{l}\text { Biblioteca } \\
\text { MAE }\end{array}$ & 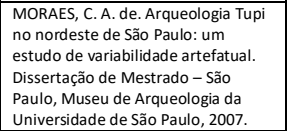 & 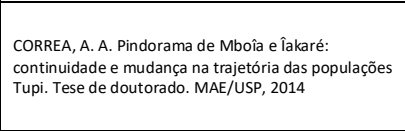 & \\
\hline Reginópolis & Batalha II & não & & SAD 96 & 22 & 681444 & $\begin{array}{l}7568 \\
458\end{array}$ & & & & & CNSA & 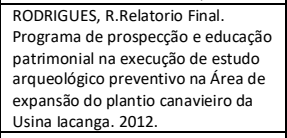 & & \\
\hline Rosana & BEIA FLOR & não & & SAD 69 & 22 & 320958 & \begin{tabular}{|l|}
7526 \\
561
\end{tabular} & & & & $\begin{array}{l}\text { SP009 } \\
26\end{array}$ & CNSA & 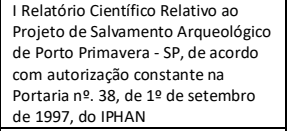 & $\begin{array}{l}\text { Projeto de Salvamento Arqueológico de Porto } \\
\text { Primavera, SP. }\end{array}$ & \\
\hline $\begin{array}{l}\text { Cândido } \\
\text { Mota }\end{array}$ & $\begin{array}{l}\text { Porto Galvão } \\
3\end{array}$ & não & & & & & & $22 \mathrm{~K}$ & 608080 & 7542639 & 25244 & \begin{tabular}{|l|l|} 
CNSA e \\
Biblioteca \\
MAE \\
\end{tabular} & \begin{tabular}{|l|} 
CHYMZZ, I. Pesquisas \\
paleetnográficase efetuadas no vale \\
do Rio Paranapanema - - Parana-são \\
Paulo. Doutorado. USP, SP. 1977.
\end{tabular} & $\begin{array}{l}\text { CORREA, A. A. Pindorama de Mboîa e êakaré: } \\
\text { continuidade emudanca na traietória das populāoses } \\
\text { Tupi. Tese de doutorada. MAE/USP, 2014. }\end{array}$ & \\
\hline Rosana & BEM-TE-VI & não & & SAD 69 & & 291029 & $\begin{array}{l}7505 \\
662\end{array}$ & & & & $\begin{array}{l}\text { SP008 } \\
43\end{array}$ & CNSA & $\begin{array}{l}\text { Projeto de Salvamento Arqueológico } \\
\text { de Porto Primavera, SP. }\end{array}$ & 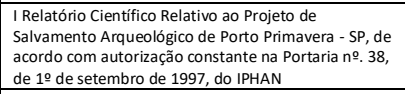 & \\
\hline Apiaí & Gurutuba I & não & & & & & & $22 \sqrt{2}$ & 718373 & 7287465 & 26438 & \begin{tabular}{|l|} 
CNSA e \\
Biblioteca \\
MAE
\end{tabular} & 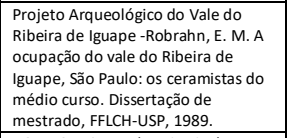 & & \\
\hline \multirow[t]{2}{*}{ Reginópolis } & Bentoca & não & & SAD 96 & 22 & 687943 & $\begin{array}{l}7577 \\
553\end{array}$ & & & & & CNSA & 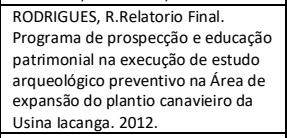 & & \\
\hline & Areia Branca 5 & $\begin{array}{l}1194 \mathrm{AD} \\
1197 \mathrm{AD} \\
1210 \mathrm{AD} \\
11100 \mathrm{AD} \\
1240 \mathrm{AD}\end{array}$ & $\begin{array}{l}\text { № das } \\
\text { amostras: } \\
\text { Beta 24251; } \\
\text { LVD } 297 \text { (TL) }\end{array}$ & & & & & & & & & $\begin{array}{l}\text { Revista } \\
\text { Online }\end{array}$ & 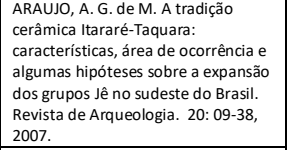 & & \\
\hline \multirow[t]{2}{*}{$\begin{array}{l}\text { Ribeirão } \\
\text { Branco }\end{array}$} & Bertini & não & & & 22J & 0719097 & $\begin{array}{l}7313 \\
321\end{array}$ & & & & & $\begin{array}{l}\begin{array}{l}\text { Biblioteca } \\
\text { MAE }\end{array} \\
\end{array}$ & 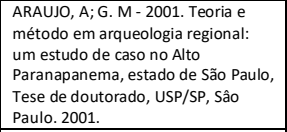 & & \\
\hline & Areia Branca 6 & $\begin{array}{l}648 \text { ad; } \\
545 \text { e } 560 \\
\text { AD }\end{array}$ & $\begin{array}{l}\text { No das } \\
\text { amastras:Bet } \\
\text { a 24452; Beta } \\
358224\end{array}$ & & & & & & & & & $\begin{array}{l}\text { Revista } \\
\text { Online }\end{array}$ & 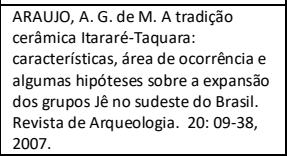 & & \\
\hline $\begin{array}{l}\text { Cândido } \\
\text { Mota }\end{array}$ & 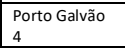 & não & & & & & & $22 \mathrm{~K}$ & 608080 & 7542639 & 25245 & $\begin{array}{ll}\text { CNSA e } \\
\text { Biblioteca } \\
\end{array}$ & \begin{tabular}{|l|}
$\begin{array}{l}\text { CHYMZ, I. Pesquisas } \\
\text { paleetnográficas efetuadas no vale }\end{array}$ \\
\end{tabular} & $\begin{array}{l}\text { CORREA, A.A. P. Pindorama de Mboîa e îakaré: } \\
\text { continuidade e mudança na trajetoria das populaçes }\end{array}$ & \\
\hline
\end{tabular}




\begin{tabular}{|c|c|c|c|c|c|c|c|c|c|c|c|c|c|c|}
\hline & & & & & & & & & & & MAE & \begin{tabular}{|l|} 
do Rio Paranapanema - Parana-são \\
Paulo. Douttorado.USP, SP. 1977.
\end{tabular} & \begin{tabular}{|l|} 
Tupi. Tese de doutorado. MAE/USP, 2014. \\
.
\end{tabular} & \\
\hline $\begin{array}{l}\text { Presidente } \\
\text { Epitácio }\end{array}$ & BIGUÁ & não & & 22 & 360848 & \begin{tabular}{|l}
7559 \\
602
\end{tabular} & & & & $\begin{array}{l}\text { SP008 } \\
44\end{array}$ & CNSA & \begin{tabular}{|l} 
lrojeto de Salvaments Arqueoologico \\
de Porto Primavera, SP.
\end{tabular} & 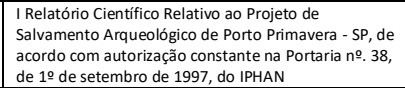 & \\
\hline $\begin{array}{l}\text { Cândido } \\
\text { Mota }\end{array}$ & $\begin{array}{l}\text { Porto Galvão } \\
5\end{array}$ & não & & & & & $22 \mathrm{~K}$ & 608080 & 7542639 & 25246; & \begin{tabular}{|l} 
CNSA \\
Biblioteca \\
MAE
\end{tabular} & 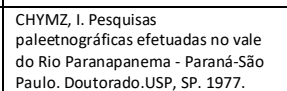 & 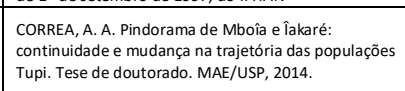 & \\
\hline $\begin{array}{l}\text { Nova } \\
\text { Campina }\end{array}$ & Boa Vista & não & & $22 J$ & 0706680 & $\begin{array}{l}7322 \\
760\end{array}$ & & & & & $\begin{array}{l}\text { Biblioteca } \\
\text { MAE }\end{array}$ & 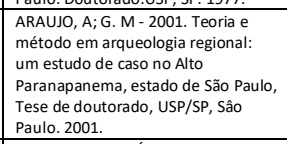 & & \\
\hline $\begin{array}{l}\text { Ribeirão } \\
\text { Grande }\end{array}$ & Boituva 4 & não & SAD 69 & $22 J$ & 772508 & $\begin{array}{l}7323 \\
077\end{array}$ & & & & $\begin{array}{l}\text { Spo10 } \\
11\end{array}$ & \begin{tabular}{|l} 
CNSA e \\
Biblioteca \\
MAE
\end{tabular} & 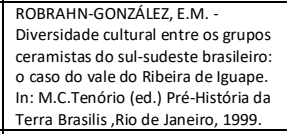 & $\begin{array}{l}\text { Diagnóstico Arqueológico do Projeto de Ampliaçăo da } \\
\text { Mina Limeira }\end{array}$ & \\
\hline Boracéia & Boracéia I & não & & $22 \mathrm{~K}$ & 722732 & \begin{tabular}{|l}
7547 \\
085
\end{tabular} & & & & & $\begin{array}{l}\text { Biblioteca } \\
\text { empresa }\end{array}$ & 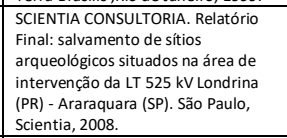 & & $\begin{array}{l}\text { Margem do Córrego ́́gua das Pedras - } \\
\text { Bacia do Rio Tietêe }\end{array}$ \\
\hline Boracéia & Boracéia ll & não & & $22 \mathrm{~K}$ & 727736 & \begin{tabular}{|l}
7550 \\
507
\end{tabular} & & & & & \begin{tabular}{|l|} 
Biblioteca \\
empresa
\end{tabular} & 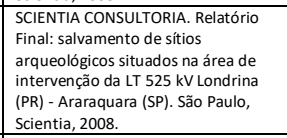 & & $\begin{array}{l}\text { Margem do Córrego Monte Alegre - } \\
\text { Bacia do Rio Tietêe }\end{array}$ \\
\hline Piraju & Brasil & não & & 22 & 670609 & \begin{tabular}{|l}
7437 \\
054
\end{tabular} & & & & 25596 & \begin{tabular}{|l} 
CNSA e \\
Biblioteca \\
MAE
\end{tabular} & 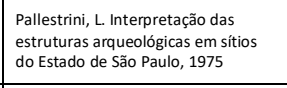 & 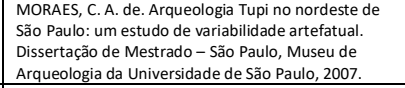 & \\
\hline $\begin{array}{l}\text { Cândido } \\
\text { Mota }\end{array}$ & $\begin{array}{l}\text { Porto Galvão } \\
6\end{array}$ & não & & & & & $22 \mathrm{~K}$ & 608080 & 7542639 & 25247 & \begin{tabular}{|l} 
CNSA \\
Biblioteca \\
MAE
\end{tabular} & 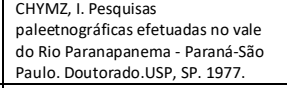 & $\begin{array}{l}\text { CORREA, A. A. Pindorama de Mboîa e Takará: } \\
\text { continuidade e mudancana na trajetoria das populaçōes } \\
\text { Tupi. Tese de doutorado. MAE/USP, 2014. }\end{array}$ & \\
\hline Florinia & Brejaúva & não & & & 558868 & $\begin{array}{l}7462 \\
968\end{array}$ & & & & & $\begin{array}{l}\text { Biblioteca } \\
\text { MAE }\end{array}$ & 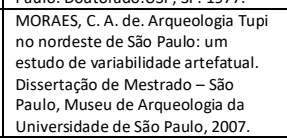 & \begin{tabular}{|l} 
CORREA, A. A. Pindorama de Mboîa e Takará: \\
continuidade e mudanca na trajetória das populaçōes \\
Tupi. Tese de doutorado. MAE/USPP, 2014
\end{tabular} & 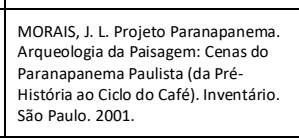 \\
\hline Brejo Alegre & Brejo Alegre I & não & SAD 69 & 22 & 578880 & \begin{tabular}{|l}
7654 \\
074
\end{tabular} & & & & $\begin{array}{l}\text { SP010 } \\
75\end{array}$ & CNSA & 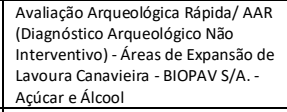 & & \\
\hline Brejo Alegre & Brejo Alegre II & não & SAD 69 & 22 & 578909 & \begin{tabular}{|c}
7654 \\
331
\end{tabular} & & & & $\begin{array}{l}\text { SP010 } \\
76\end{array}$ & CNSA & 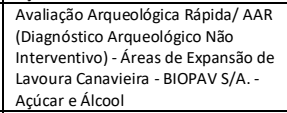 & & \\
\hline Castiliho & $\begin{array}{l}\text { Porto } \\
\text { Independênci } \\
\text { a }\end{array}$ & não & & & & & $22 \mathrm{~K}$ & 449255 & 7691992 & & $\begin{array}{l}\text { Biblioteca } \\
\text { MAE }\end{array}$ & 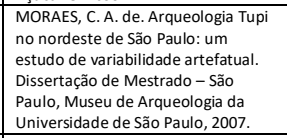 & 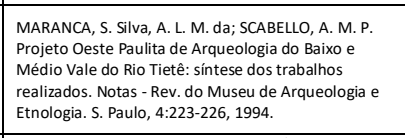 & 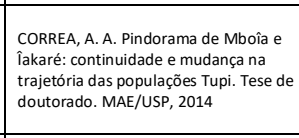 \\
\hline Chavantes & $\begin{array}{l}09 \mathrm{CHV} \\
22.217 .478\end{array}$ & não & & & & & $22 \mathrm{~K}$ & 632431 & 7451357 & & $\begin{array}{l}\text { Biblioteca } \\
\text { MAE }\end{array}$ & Moraes, 2006; & 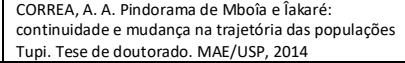 & \\
\hline Botucatu & BTC & não & & & & & $22 \mathrm{~K}$ & 801210 & 7388155 & & Arquivo & \begin{tabular}{|l|l|l|l|l|l|} 
ZANETTII Arqueogia. Diagnóstico \\
\end{tabular} & & \begin{tabular}{|l|} 
Pongai e Sabino, SP. 2010. \\
\end{tabular} \\
\hline
\end{tabular}




\begin{tabular}{|c|c|c|c|c|c|c|c|c|c|c|c|c|c|}
\hline & 222.567 .576 & & & & & & & & & $\begin{array}{l}\text { IPHAN- } \\
\text { Relarório } \\
\mathrm{s}\end{array}$ & 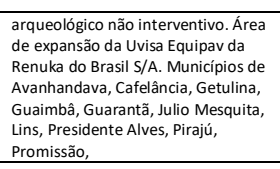 & & \\
\hline Eldorado & Anhanguera & não & & & & & $22 J$ & 792929 & 7284774 & CNSA & 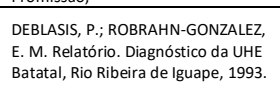 & 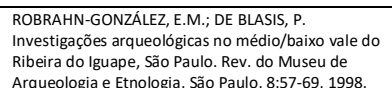 & \\
\hline Apiai & Gurutuba IV & não & & & & & $22 \mathrm{~J}$ & 718373 & 7287465 & $\begin{array}{l}\text { CNSA } \\
\text { Biblioteca } \\
\text { MAE }\end{array}$ & 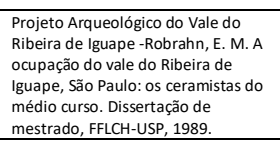 & $\begin{array}{l}\text { BARRETO, C. N. G de B., A ocupação pré-colonial do } \\
\text { vale do Ribeira de Iguape, SP: os sitios conchiferos do } \\
\text { médio curso. Dissertaçâo de mestrado. USP, São } \\
\text { Paulo, 1988. }\end{array}$ & \\
\hline Eldorado & $\begin{array}{l}\text { Córredo das } \\
\text { Ostras }\end{array}$ & não & & & & & $22 J$ & 792929 & 7284774 & CNSA & 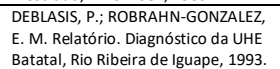 & & \\
\hline Guapiara & Arlindo Cruu & 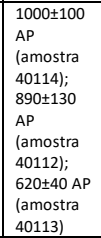 & $\begin{array}{l}\text { entormo de } \\
950 \text { DA e e a } \\
\text { data mais } \\
\text { rescente em } \\
\text { torno de } \\
130 \text { A AD. } \\
\text { LACLCID do } \\
\text { Instituto de } \\
\text { Fisica da USP }\end{array}$ & 22J & 0745221 & $\begin{array}{l}7332 \\
990\end{array}$ & & & & $\begin{array}{l}\text { Biblioteca } \\
\text { MAE }\end{array}$ & $\begin{array}{l}\text { ARAUJo, A; G. M - 2001. Teoria e } \\
\text { método em arqueologia regional: } \\
\text { um estudo de caso no Alto } \\
\text { Paranapanema,a, stadod de São Paulo, } \\
\text { Tese de doutorado, USP/SP, Sâo } \\
\text { Paulo. 2001. }\end{array}$ & & \\
\hline Apiai & Inveja & não & & & & & $22 J$ & 718373 & 7287465 & $\begin{array}{l}\text { Biblioteca } \\
\text { MAE }\end{array}$ & 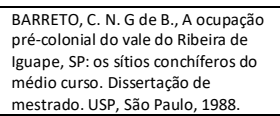 & & \\
\hline Apiai & Lageado 10 & não & & & & & $22 J$ & 718373 & 7287465 & $\begin{array}{l}\text { CNSA } \\
\text { Biblioteca } \\
\text { MAE }\end{array}$ & 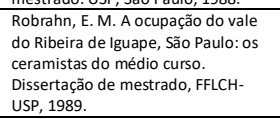 & & \\
\hline Apiai & Lageado 7 & não & & & & & $22 \mathrm{~J}$ & 718373 & 7287465 & $\begin{array}{l}\text { Biblioteca } \\
\text { MAE }\end{array}$ & 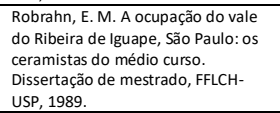 & & \\
\hline Apiai & Lageado IV & não & & & & & $22 J$ & 718373 & 7287465 & $\begin{array}{l}\text { CNSA } \\
\text { Biblioteca } \\
\text { MAE }\end{array}$ & 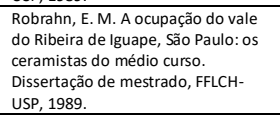 & $\begin{array}{l}\text { BARRETO, C. N. G G de B., A ocupacăo pré-colonial do } \\
\text { vale do Ribeira de Iguape, SP: os sitios conchiferos do } \\
\text { médio curso. Dissertaçâo de mestrado. USP, São } \\
\text { Paulo, 1988. }\end{array}$ & \\
\hline Apiai & Pavão 5 & não & & & & & $22 J$ & 718373 & 7287465 & $\begin{array}{l}\text { CNSA e } \\
\text { Biblioteca } \\
\text { MAE }\end{array}$ & $\begin{array}{l}\text { Projetto Arqueoológico Vade do } \\
\text { Riberia do Iguape }\end{array}$ & 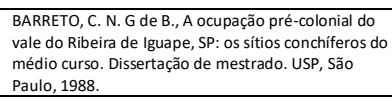 & \\
\hline Apiai & Pavão I & não & & & & & $22 J$ & 718373 & 7287465 & CNSA & $\begin{array}{l}\text { Projeto Arqueológico Vade do } \\
\text { Ribeira do lguape }\end{array}$ & & \\
\hline Apiai & Pavão II & não & & & & & $22 J$ & 718373 & 7287465 & $\begin{array}{l}\text { CNSA } \\
\text { Biblioteca } \\
\text { MAE }\end{array}$ & $\begin{array}{l}\text { Projeto Arqueológico Vade do } \\
\text { Riberir do Iuvape }\end{array}$ & 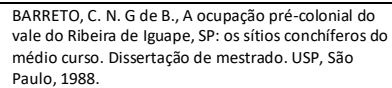 & \\
\hline Apiai & Pavão III & não & & & & & $22 J$ & 718373 & 7287465 & $\begin{array}{l}\text { CNSA } \\
\text { Biblioteca } \\
\text { MAE }\end{array}$ & $\begin{array}{l}\text { Projeto Arqueológico Vade do } \\
\text { Riberia do Iguape }\end{array}$ & 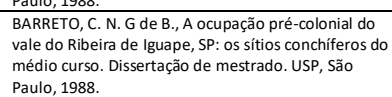 & \\
\hline Apiai & Pavão IV & não & & & & & $22 J$ & 718373 & 7287465 & $\begin{array}{l}\text { CNSA e } \\
\text { Biblioteca } \\
\text { MAE }\end{array}$ & 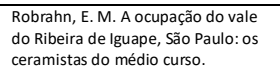 & & \\
\hline
\end{tabular}




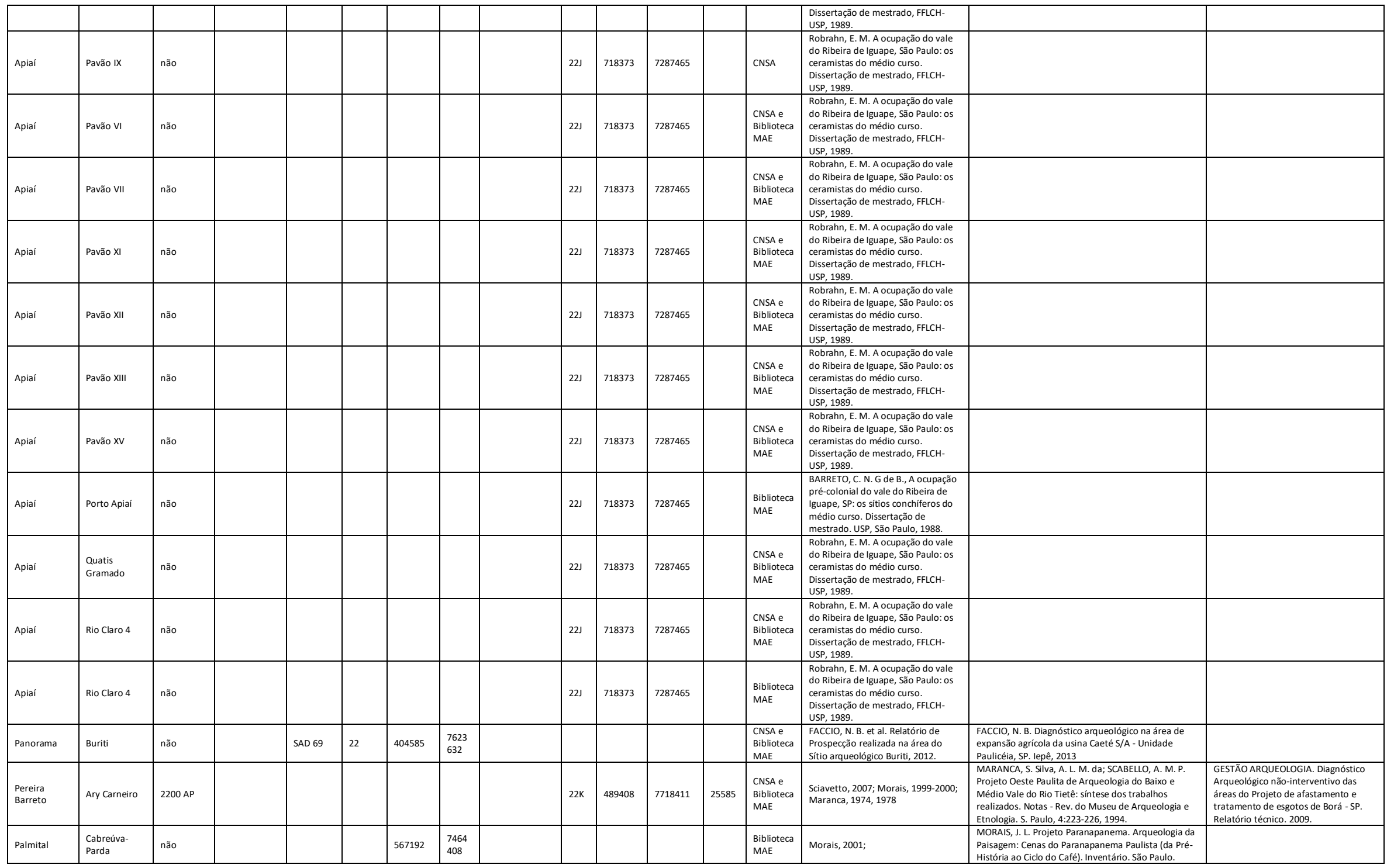




\begin{tabular}{|c|c|c|c|c|c|c|c|c|c|c|c|c|c|c|c|c|}
\hline $\begin{array}{l}\text { Presidente } \\
\text { Epitácio }\end{array}$ & CABURÉ & não & & SAD 69 & 22 & 378772 & $\begin{array}{l}7586 \\
563\end{array}$ & & & & & $\begin{array}{l}\text { Spoos } \\
46\end{array}$ & CNSA & \begin{tabular}{|l} 
Projeto de Salvamento Arqueológico \\
de Porto Primavera, SP.
\end{tabular} & 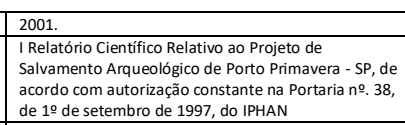 & \\
\hline & $\begin{array}{l}\text { Bairro da } \\
\text { Serra }\end{array}$ & $\begin{array}{l}270+-60 \\
\text { AP }\end{array}$ & & & & & & & & & & & $\begin{array}{l}\text { Biblioteca } \\
\text { MAE }\end{array}$ & 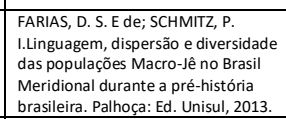 & & 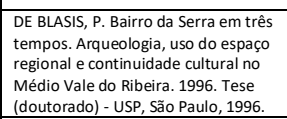 \\
\hline Itai & Caçador 2 & não & & & & 693910 & $\begin{array}{l}7380 \\
903\end{array}$ & & & & & & $\begin{array}{l}\text { Biblioteca } \\
\text { MAE }\end{array}$ & Moraes, 2207; & 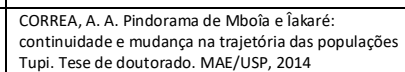 & \\
\hline Queiroz & $\begin{array}{l}\text { Cachoeira dos } \\
\text { Îndios }\end{array}$ & não & & & $22 \mathrm{~K}$ & 587088 & $\begin{array}{l}7582 \\
786\end{array}$ & & & & & & \begin{tabular}{|l} 
Arquivo \\
IPHAN- \\
Relarório \\
s
\end{tabular} & 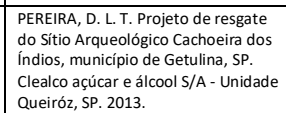 & & \\
\hline Fartura & Manoel Pedro & não & & & & & & & $22 \mathrm{~K}$ & 652113 & 7412483 & & CNSA & \begin{tabular}{|l|} 
CHMYZ, l.; Relatório. Programa de \\
Salvamento Arqueológico no rio \\
titararé
\end{tabular} & & Rio Itararé \\
\hline Tatuí & Cachoeirinha & não & & \begin{tabular}{|l} 
Córrego \\
Alegre
\end{tabular} & 23 & 217709 & $\begin{array}{l}7418 \\
070\end{array}$ & & & & & & $\begin{array}{l}\text { Biblioteca } \\
\text { empresa }\end{array}$ & 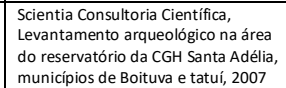 & & \\
\hline chavantes & $\begin{array}{l}\text { CHV } \\
22.328 .438\end{array}$ & não & & & & & & & $22 \mathrm{~K}$ & 632431 & 7451357 & & $\begin{array}{l}\text { Biblioteca } \\
\text { MAE }\end{array}$ & Moraes, 2006; & 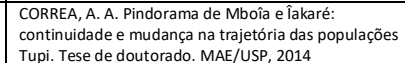 & \\
\hline Arco-riris & $\begin{array}{l}\text { Caingangue } \\
01\end{array}$ & não & & \begin{tabular}{|l} 
Corrego \\
Alegre
\end{tabular} & & 571841 & \begin{tabular}{|l}
7597 \\
263
\end{tabular} & & & & & & \begin{tabular}{|l|} 
CNSA e \\
Biblioteca \\
MAE
\end{tabular} & 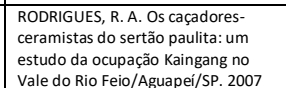 & & \\
\hline $\begin{array}{l}\text { Cândido } \\
\text { Mota }\end{array}$ & Cajarana & não & & & & 559175 & $\begin{array}{l}7463 \\
467\end{array}$ & & & & & & $\begin{array}{l}\text { Biblioteca } \\
\text { MAE }\end{array}$ & Morais, 2011; propar; & $\begin{array}{l}\text { CORREA, A. A. Pindorama de Mboia e êakaré: } \\
\text { continuidade e mudança na trajettoria das populaçôs } \\
\text { Tupi. Tese de doutorado. MAE/USP, } 2014\end{array}$ & 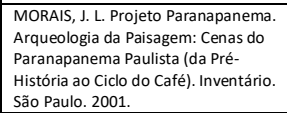 \\
\hline Botucatu & $\begin{array}{l}\text { Benetido } \\
\text { Machado }\end{array}$ & \begin{tabular}{|l|l} 
Idade \\
convencio \\
nal $1:$ \\
$840 \pm 30$ \\
Idade \\
calibrada \\
1 1: $760 \pm 40$ \\
Idade \\
convencio \\
nal \\
$2: 730 \pm 30$ \\
IIdade \\
calibrada \\
2: $6990 \pm 20$
\end{tabular} & 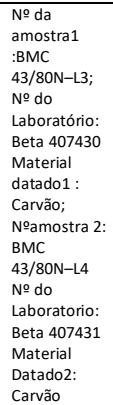 & & & & & $\begin{array}{l}22^{\circ} 54^{\prime} 020 \mathrm{~s} \\
48^{\circ} 25^{\prime \prime} 30^{\prime \prime} \mathrm{W}\end{array}$ & $22 \mathrm{~K}$ & 764145 & 7465177 & & \begin{tabular}{|l} 
Revista \\
Online
\end{tabular} & 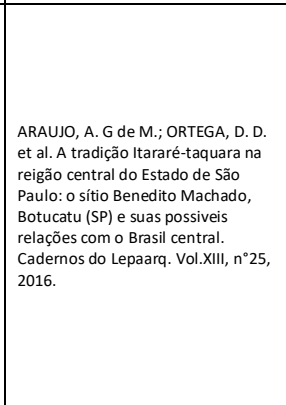 & & \\
\hline $\begin{array}{l}\text { Dois } \\
\text { Córregos }\end{array}$ & Rio Turvo & não & & & & & & & $22 \mathrm{~K}$ & 769331 & 7523373 & & $\begin{array}{l}\text { Biblioteca } \\
\text { MAE }\end{array}$ & Schiavetto, 2007; Moraes, 2007; & 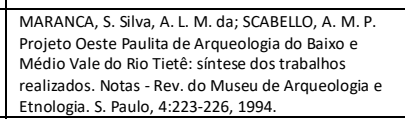 & 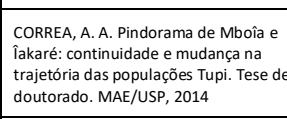 \\
\hline Piraju & Camargo 3 & não & & SAS 69 & 22 & 663005 & $\begin{array}{l}7438 \\
435\end{array}$ & & & & & & $\begin{array}{l}\text { Inventári } \\
\text { o }\end{array}$ & 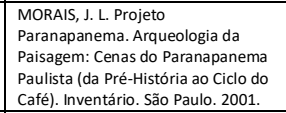 & & \\
\hline Emilianópolis & Breschi 1 & não & & & & & & & $22 \mathrm{~K}$ & 450101 & 7585619 & 25605 & \begin{tabular}{|l|l|} 
CNSA e \\
Biblioteca \\
\end{tabular} & $\begin{array}{l}\text { CORREA, A. A. Pindorama de Mboîa } \\
\text { e lakaré: continuidade e mudanģa na }\end{array}$ & $\begin{array}{l}\text { KUNZLI. R. Arqueologia regional. Primeiros resultados } \\
\text { das pesquisas realizadas na área de Presidente }\end{array}$ & \\
\hline
\end{tabular}




\begin{tabular}{|c|c|c|c|c|c|c|c|c|c|c|c|c|c|c|c|c|}
\hline & & & & & & & & & & & & & MAE & \begin{tabular}{|l|} 
trajetória das populaçāes Tupi. Tese \\
de doutorado. MAE/USP, 2014.
\end{tabular} & $\begin{array}{l}\text { Prudente, SP. Revista do Museu Paulista. 32: 223-247. } \\
\text { Săo Paulo, 1987. }\end{array}$ & \\
\hline Palmital & Cambuí & não & & & & 579474 & $\begin{array}{l}7463 \\
408\end{array}$ & & & & & & \begin{tabular}{|l|l} 
Biblioteca \\
MAE
\end{tabular} & Morais, 2001 & 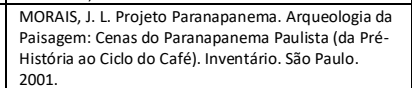 & \\
\hline Tejupá & Bersi & $520 \pm 60 \mathrm{AP}$ & \begin{tabular}{|l|l} 
Termolumine \\
scência (TL)
\end{tabular} & & & 664500 & $\begin{array}{l}7422 \\
400\end{array}$ & $\begin{array}{l}2311^{\prime} 755^{\prime \prime S} 40 \\
23^{\prime} 10^{\prime} \mathrm{W}\end{array}$ & & & & & \begin{tabular}{|l|} 
CNSA, \\
Biblioteca \\
MAEe \\
Inventári \\
o \\
\end{tabular} & Moraes, 2007; Morais, 2000; & $\begin{array}{l}\text { CORREA, A. A. Pindorama de Mboîa e îakaré: } \\
\text { continuidade e mudança na trajetoria das populaçoes } \\
\text { Tupi. Tese de doutorado. MAE/USP, } 2014\end{array}$ & 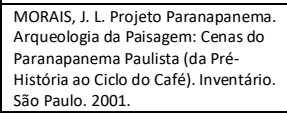 \\
\hline Florinia & Campinho & não & & & & 518170 & $\begin{array}{l}7461 \\
185\end{array}$ & & & & & & \begin{tabular}{|l|} 
Biblioteca \\
MAE
\end{tabular} & 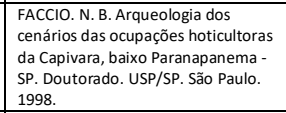 & & destruido \\
\hline Avaré & Campininha & não & & SAS 69 & $22 \mathrm{~F}$ & 711543 & \begin{tabular}{|l}
7423 \\
502
\end{tabular} & & & & & & $\begin{array}{l}\text { Inventári } \\
\text { o }\end{array}$ & 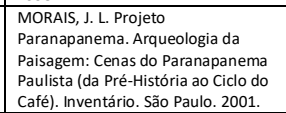 & & \\
\hline Panorama & Campo Belo & não & & SAD 69 & 22 & 407844 & $\begin{array}{l}7618 \\
295\end{array}$ & & & & & & \begin{tabular}{|l|} 
CNSA e \\
Biblioteca \\
MAE
\end{tabular} & 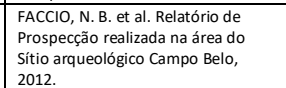 & $\begin{array}{l}\text { Diagnóstico arqueológico na área de expansão } \\
\text { agricola da usina Caeté S/A - Unidade Paulicéia, SP. }\end{array}$ & \\
\hline Emilianópolis & Breschi 2 & não & & & & & & & $22 \mathrm{~K}$ & 450101 & 7585619 & 25606 & \begin{tabular}{|l} 
CNSA \\
Biblioteca \\
MAE
\end{tabular} & 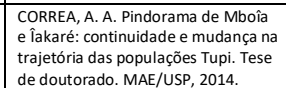 & 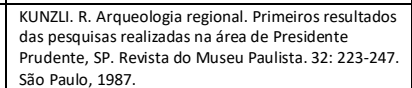 & \\
\hline São Miguel & Campo Verde & não & & SAD 69 & 22 & 773398 & $\begin{array}{l}7488 \\
527\end{array}$ & & & & & & CNSA & 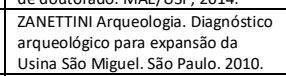 & & \\
\hline Palmital & Canafistula & não & & & & 566953 & $\begin{array}{l}7464 \\
284\end{array}$ & & & & & & $\begin{array}{l}\text { Biblioteca } \\
\text { MAE }\end{array}$ & Morais, 2001 & 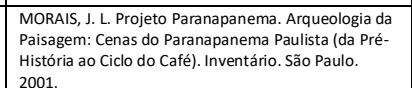 & \\
\hline $\begin{array}{l}\text { Teodoro } \\
\text { Sampaio }\end{array}$ & CANÁRIO & não & & SAD 69 & 22 & 355638 & $\begin{array}{l}7550 \\
219\end{array}$ & & & & & $\begin{array}{l}\text { Spoos } \\
51\end{array}$ & CNSA & $\begin{array}{l}\text { Projeto de Salvamento Arqueológico } \\
\text { de Porto Primavera, SP. }\end{array}$ & 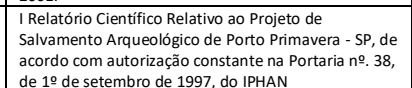 & \\
\hline Fartura & Balsa do pio 1 & não & & & & & & & $22 \mathrm{~K}$ & 652118 & 7412491 & & \begin{tabular}{|l|} 
CNSAe \\
Biblioteca \\
MAE
\end{tabular} & Chmyz; & 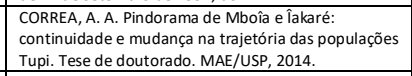 & Rio Itararé \\
\hline Piraju & Canelinha & não & & SAS 69 & 22 & 665532 & \begin{tabular}{|l}
7438 \\
479
\end{tabular} & & & & & & $\begin{array}{l}\text { Inventári } \\
0\end{array}$ & 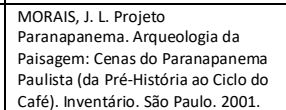 & & \\
\hline Rosana & CANUTO 1 & não & & SAD 69 & 22 & 293980 & \begin{tabular}{|l}
7506 \\
669
\end{tabular} & & & & & $\begin{array}{l}\text { Sp008 } \\
52\end{array}$ & CNSA & $\begin{array}{l}\text { Projeto de Salvamento Arqueológico } \\
\text { de Porto Primavera, SP. }\end{array}$ & 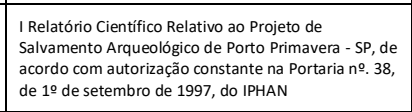 & 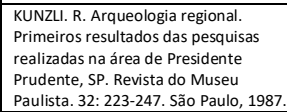 \\
\hline Rosana & CANUTO 2 & não & & SAD 69 & 22 & 287735 & $\begin{array}{l}7501 \\
487\end{array}$ & \begin{tabular}{|l}
$22235^{1} 19^{9} \mathrm{~s}$ \\
$53^{\circ} 04^{1} 10^{\circ} \mathrm{W}$
\end{tabular} & & & & $\begin{array}{l}\text { SP008 } \\
53\end{array}$ & $\begin{array}{l}\text { CNSA } \\
\text { Biblioteca } \\
\text { MAE }\end{array}$ & 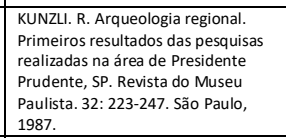 & $\begin{array}{l}\text { KASHIMOTO, E. M. Variáveis ambientais e } \\
\text { arqueologia no Alto Paraná. Tese de doutorado. USP, } \\
\text { Săo Paulo. 1997. }\end{array}$ & 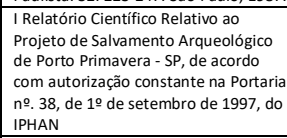 \\
\hline Fartura & Balsa do Pio 2 & não & & & & & & & $22 \mathrm{~K}$ & 652118 & 7412491 & & \begin{tabular}{|l|} 
CNSAe \\
Biblioteca \\
MAE
\end{tabular} & 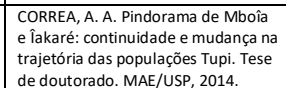 & & Rio Itararé; \\
\hline Itapeva & Bianco & $\begin{array}{l}295 \pm 30 \mathrm{AP} ; \\
770 \pm 30 \mathrm{AP}\end{array}$ & Beta 390821 & & 223 & 0708918 & \begin{tabular}{|l}
7340 \\
525
\end{tabular} & & & & & & $\begin{array}{l}\text { Biblioteca } \\
\text { MAE }\end{array}$ & \begin{tabular}{|l|} 
ARAUJO, A;G. G- 2001. Teoria e \\
método em arqueologia regional: \\
um estudo de caso no Alto \\
Paranapanema, estadod de São Paulo, \\
Tese de doutorado, USP/SP, Sâo \\
\end{tabular} & $\begin{array}{l}\text { PERROTA, R. M. Caracterizacăão da industria cerâmica } \\
\text { do Sitio Bianco (Itapeva - SP): possivivei correlaçóes } \\
\text { culturais. Mestrado. MAE/USP. Săo Paulo, 2015. }\end{array}$ & \\
\hline
\end{tabular}




\begin{tabular}{|c|c|c|c|c|c|c|c|c|c|c|c|c|c|c|c|}
\hline & & & & & & & & & & & & & \begin{tabular}{|l|l|} 
Paulo. 2001. \\
.
\end{tabular} & & \\
\hline Assis & Capivara & não & South 69 & 22 & \begin{tabular}{|l|l|}
5322247 \\
\end{tabular} & \begin{tabular}{|l|l|}
7498 \\
612
\end{tabular} & & & & & & CNSA & & & \\
\hline Fartura & $\begin{array}{l}\text { Barra do Rio } \\
\text { verde } 1\end{array}$ & não & & & & & & $22 \mathrm{~K}$ & 652118 & 7412491 & & $\begin{array}{l}\text { CNSA } \\
\text { Biblioteca } \\
\text { MAE }\end{array}$ & \begin{tabular}{|l|}
$\begin{array}{l}\text { CHMYZ, li, Relatótrio. Programa de } \\
\text { salvamento Arqueologico no rio } \\
\text { ltararé }\end{array}$ \\
\end{tabular} & 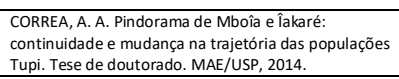 & Rio Itararé \\
\hline Apiai & Rio Claro I & não & & & & & & $22 J$ & 718373 & 7287465 & & \begin{tabular}{|l} 
CNSA \\
Biblioteca \\
MAE
\end{tabular} & 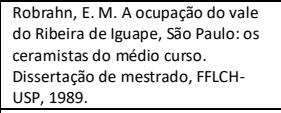 & & \\
\hline Paulicéia & CARÁ-CARÁ & não & SAD 69 & 22 & 418320 & $\begin{array}{l}7665 \\
988\end{array}$ & & & & & $\begin{array}{l}\text { Spoog } \\
79\end{array}$ & CNSA & 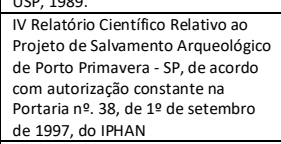 & $\begin{array}{l}\text { Projeto de Salvamento Arqueológico de Porto } \\
\text { Primavera, SP. }\end{array}$ & \\
\hline $\begin{array}{l}\text { Cândido } \\
\text { Mota }\end{array}$ & Caraguatá & não & & & 552000 & $\begin{array}{l}7463 \\
750\end{array}$ & & & & & & $\begin{array}{l}\text { Biblioteca } \\
\text { MAE }\end{array}$ & 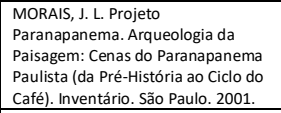 & $\begin{array}{l}\text { CORREA, A. A. Pindorama de Mboîa e Tlakaré: } \\
\text { continuidade e mudanca na arajetórid as sopulaços } \\
\text { Tupi. Tese de doutorado. MAE/USP, 2014 }\end{array}$ & \\
\hline Rosana & CARCARÁ & não & SAD 69 & 22 & 329757 & \begin{tabular}{|l}
7531 \\
627
\end{tabular} & & & & & $\begin{array}{l}\text { SP008 } \\
47\end{array}$ & CNSA & $\begin{array}{l}\text { Projeto de Salvamento Arqueológico } \\
\text { de Porto Primavera, SP. }\end{array}$ & 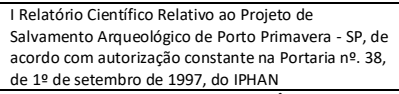 & \\
\hline Fartura & $\begin{array}{l}\text { Barra do Rio } \\
\text { Verde 2 }\end{array}$ & não & & & & & & $22 \mathrm{~K}$ & 652118 & 7412491 & & $\begin{array}{l}\text { CNSAe } \\
\text { Biblioteca } \\
\text { MAE }\end{array}$ & 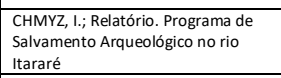 & $\begin{array}{l}\text { CORREA A. A. P. Pindoramade Mboîa e Î́karé: } \\
\text { continuidade e mudanca na trajetoria das populaçöes } \\
\text { Tupi. Tese de doutorado. MAE/USP, } 2014 .\end{array}$ & Rio ltararé \\
\hline Fartura & $\begin{array}{l}\text { Cerâmica de } \\
\text { Amendoim }\end{array}$ & não & & & & & & $22 \mathrm{~K}$ & 652118 & 7412491 & & $\begin{array}{l}\text { CNSA } \\
\text { Biblioteca } \\
\text { MAE }\end{array}$ & \begin{tabular}{|l}
$\begin{array}{l}\text { CHMYZZ, li, Relatórioi. Programa de } \\
\text { Salvamento Arqueoologico no rio } \\
\text { Itararé }\end{array}$ \\
\end{tabular} & $\begin{array}{l}\text { CORREA, A.A. Pindorama de Mboîa e îakaré: } \\
\text { continuidade enudanca natrateitória das populaçes } \\
\text { Tupi. Tese de doutorado. MAE/USP, 2014. }\end{array}$ & Rio Itararé \\
\hline Ibirarema & Caroba & não & & & 592375 & $\begin{array}{l}7464 \\
880\end{array}$ & & & & & & $\begin{array}{l}\text { Biblioteca } \\
\text { MAE }\end{array}$ & 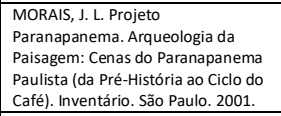 & $\begin{array}{l}\text { CORREA, A. A. Pindorama de Mboîa e Takará: } \\
\text { continuidade e mudancan na trajetória das populaçōes } \\
\text { Tupi. Tese de doutorado. MAE/USP, } 2014\end{array}$ & \\
\hline $\begin{array}{l}\text { Bom Sucesso } \\
\text { de ltararé }\end{array}$ & $\begin{array}{l}\text { Casa } \\
\text { Subterrânea }\end{array}$ & não & & 22 & \begin{tabular}{|l|l|l|l}
6917 \\
\end{tabular} & $\begin{array}{l}7316 \\
360\end{array}$ & 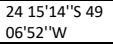 & & & & $\begin{array}{l}\text { SP009 } \\
43\end{array}$ & CNSA & & & \\
\hline $\begin{array}{l}\text { Bom Sucesso } \\
\text { de ltararé }\end{array}$ & $\begin{array}{l}\text { Casa } \\
\text { Subterrânea } 2 \\
\end{array}$ & não & & 22 & |691687 & $\begin{array}{l}7316 \\
788\end{array}$ & $\begin{array}{l}2415^{\prime} 00^{\prime \prime} 499 \\
06^{\prime} 43^{\prime \prime} w\end{array}$ & & & & $\begin{array}{l}\text { SP009 } \\
44\end{array}$ & CNSA & & & \\
\hline $\begin{array}{l}\text { Bom Sucesso } \\
\text { de tararé }\end{array}$ & $\begin{array}{l}\text { Casa } \\
\text { Subterrânea } 3\end{array}$ & não & & 22 & 690864 & $\begin{array}{l}7316 \\
460\end{array}$ & $\begin{array}{l}2415^{\prime} 11 \text { "Is } 49 \\
07^{\prime} 12^{2} \mathrm{~W}\end{array}$ & & & & $\begin{array}{l}\text { SP009 } \\
45\end{array}$ & CNSA & & & \\
\hline Piraju & Cascavel & não & SAS 69 & 22 & 671397 & \begin{tabular}{|l}
7436 \\
790
\end{tabular} & & & & & & CNSA & 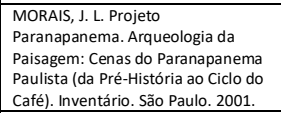 & & \\
\hline Fartura & $\begin{array}{l}\text { Corredeira } \\
\text { Grande }\end{array}$ & não & & & & & & $22 \mathrm{~K}$ & 652118 & 7412491 & & $\begin{array}{l}\text { CNSA } \\
\text { Biblioteca } \\
\text { MAE }\end{array}$ & $\begin{array}{l}\text { CHMYZ, I.; Relatório. Programa de } \\
\text { Salvamento Arqueoologico no rio } \\
\text { Itararé }\end{array}$ & 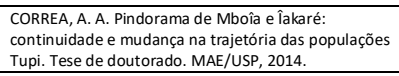 & Rio Itararé \\
\hline $\begin{array}{l}\text { Muritinga do } \\
\text { sul }\end{array}$ & Castilho & não & & & \begin{tabular}{|l|l|} 
& 426170
\end{tabular} & $\begin{array}{l}7680 \\
200\end{array}$ & & & & & & \begin{tabular}{|l|l|} 
CNSA \\
Biblioteca \\
MAE
\end{tabular} & 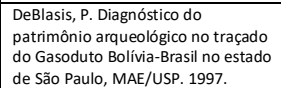 & 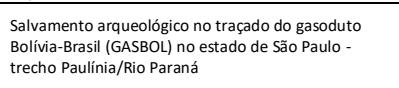 & \\
\hline Fartura & $\begin{array}{l}\text { Primeira volta } \\
5\end{array}$ & não & & & & & & $22 \mathrm{~K}$ & 652113 & 7412483 & & CNSA & $\begin{array}{l}\text { CHMYZ, 1.; Relatáório. Programa de } \\
\text { Salvamento Arqueológico no rio } \\
\text { Itararé }\end{array}$ & & Rio Itararé \\
\hline Paulicéia & CATATAU & não & SAD 69 & 22 & 409207 & $\begin{array}{l}6620 \\
21\end{array}$ & & & & & $\begin{array}{l}\text { Spoog } \\
80\end{array}$ & CNSA & 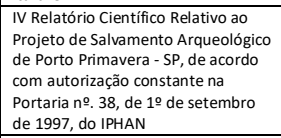 & $\begin{array}{l}\text { Projeto de Salvamento Arqueológico de Porto } \\
\text { Primavera, SP. }\end{array}$ & \\
\hline Apiai & Rio Claro III & não & & & & & & $22 J$ & 718373 & 7287465 & & $\begin{array}{l}\text { CNSA } \\
\text { Biblioteca } \\
\text { MAE }\end{array}$ & 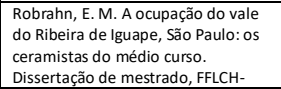 & & \\
\hline
\end{tabular}




\begin{tabular}{|c|c|c|c|c|c|c|c|c|c|c|c|c|c|c|}
\hline Itapeva & Cedro & não & & $22 \sqrt{2}$ & 0708994 & \begin{tabular}{|l}
7336 \\
094
\end{tabular} & & & & & \begin{tabular}{|l} 
Biblioteca \\
MAE
\end{tabular} & \begin{tabular}{|l|} 
USP, 1989. \\
ARAUOD, A; G. M - 2001. Teeria e \\
método em arqueologia regional: \\
um estuddo de caso on Atto \\
Paranapanema, stadodo de São Paulo, \\
Tese de doutorado, USP/SP, Sâo \\
Paulo. 2001. \\
\end{tabular} & & \\
\hline $\begin{array}{l}\text { Cândido } \\
\text { Mota }\end{array}$ & Cedro & não & & & 590636 & $\begin{array}{l}7463 \\
638 \\
638\end{array}$ & & & & & \begin{tabular}{|l|l|} 
Biblioteca \\
MAE \\
\end{tabular} & Morais, 1999. & & \\
\hline Guareí & Vista Alegre & não & & & & & $22 \mathrm{~K}$ & 788122 & 7412568 & & \begin{tabular}{|l} 
Arquivo \\
IPAAN- \\
Relarório \\
s
\end{tabular} & \begin{tabular}{|l} 
BORNAL, W. G. Relatório final do \\
Salvamento Arquueólogico do Sitio \\
Guarei I. municíipio de Guareí. 2010. \\
\end{tabular} & & \\
\hline Ibirarema & $\begin{array}{l}\text { Cedro- } \\
\text { Vermelho }\end{array}$ & não & & & 592500 & $\begin{array}{l}7465 \\
600\end{array}$ & & & & & $\begin{array}{l}\text { Biblioteca } \\
\text { MAE }\end{array}$ & 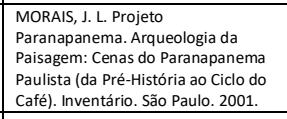 & $\begin{array}{l}\text { CORREA, A. A. Pindorama de Mboîa e T̂akaré: } \\
\text { continuidade e mudancana na trajetoria das populaçes } \\
\text { Tupi. Tese de doutorado. MAE/USP, } 2014\end{array}$ & \\
\hline $\begin{array}{l}\text { Presidente } \\
\text { Epitácio }\end{array}$ & CEGONHA & não & SAD 69 & 22 & 367269 & $\begin{array}{l}7570 \\
221\end{array}$ & & & & \begin{tabular}{|l} 
SP008 \\
48
\end{tabular} & CNSA & $\begin{array}{l}\text { Projeto de Salvamento Arqueológico } \\
\text { de Porto Primavera, SP. }\end{array}$ & 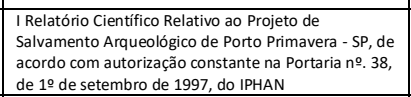 & \\
\hline $\begin{array}{l}\text { Pereira } \\
\text { Barreto }\end{array}$ & Boa Esperanņa & 1040 AP & & & & & $22 \mathrm{~K}$ & 489408 & 7718411 & 25584 & $\begin{array}{l}\text { CNSA } \\
\text { Biblioteca } \\
\text { MAE }\end{array}$ & $\begin{array}{l}\text { Schiavetto, 2007; Maranca, 1978; } \\
\text { Scatamacchia, 1981 }\end{array}$ & 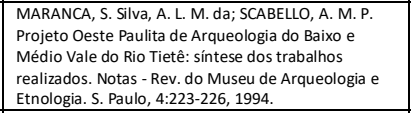 & Museu Paulista - catalogo n. RNA 35 \\
\hline Fartura & do Caminhão & não & & & & & $22 \mathrm{~K}$ & 652118 & 7412491 & 25282 & \begin{tabular}{|l} 
CNSA e \\
Biblioteca \\
MAE
\end{tabular} & 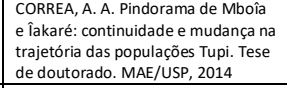 & & \\
\hline Fartura & \begin{tabular}{|l}
$\begin{array}{l}\text { Fazenda Rizzo } \\
3\end{array}$ \\
\end{tabular} & não & & & & & $22 \mathrm{~K}$ & 652118 & 7412491 & & $\begin{array}{l}C \text { CNSA } \\
\text { Biblioteca } \\
\text { MAE }\end{array}$ & \begin{tabular}{|l|} 
CHMYZ, I; Relatório. Programa de \\
Salavamento Arqueológico no rio \\
Itararé
\end{tabular} & 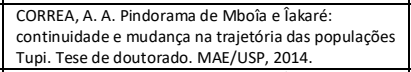 & Rio ltararé \\
\hline Fartura & José Rizzo & não & & & & & $22 \mathrm{~K}$ & 652118 & 7412491 & & $\begin{array}{l}\text { CNSA e } \\
\text { Biblioteca } \\
\text { MAE }\end{array}$ & \begin{tabular}{|l|} 
CHMYZ, l.; Relatório. Programa de \\
Salvamento Arqueológico no rio \\
Itararé
\end{tabular} & $\begin{array}{l}\text { CORREA, A. A. Pindorama de Mboîa e êakaré: } \\
\text { continuidade e mudanca na traietória das populacōes } \\
\text { Tupi. Tese de doutorado. MAE/USP, 2014. }\end{array}$ & Rio Itararé \\
\hline Fartura & Laranjal 1 & não & & & & & $22 \mathrm{~K}$ & 652118 & 7412491 & & $\begin{array}{l}\text { CNSA } \\
\text { Biblioteca } \\
\text { MAE }\end{array}$ & \begin{tabular}{|l|} 
CHMYZ, I. R Relatório. Programa de \\
Salvamento Arqueoológico no rio \\
Itararé
\end{tabular} & 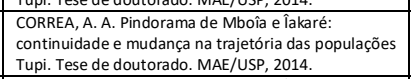 & Rio Itararé \\
\hline Fartura & Laranjal 2 & não & & & & & $22 \mathrm{~K}$ & 652118 & 7412491 & & \begin{tabular}{|l|} 
CNSA \\
Biblioteca \\
MAE \\
\end{tabular} & \begin{tabular}{|l|} 
CHMYZ, I; R Relatório. Programa de \\
Salvamento Arqueoológico no rio \\
Itararé
\end{tabular} & 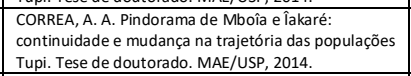 & Rio Itararé \\
\hline lacanga & Céu & não & SAD 69 & 22 & 704259 & \begin{tabular}{|l|l}
7572 \\
169
\end{tabular} & & & & & CNSA & 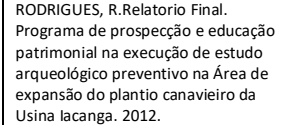 & & \\
\hline Fartura & Laranjal 4 & não & & & & & $22 \mathrm{~K}$ & 652118 & 7412491 & & $\begin{array}{l}\text { CNSA } \\
\text { Biblioteca } \\
\text { MAE }\end{array}$ & $\begin{array}{l}\text { CHMYZZ, I; Relatátíi. Programa de } \\
\text { Salvamento Arqueológico no rio } \\
\text { Itararé }\end{array}$ & $\begin{array}{l}\text { CORREA, A.A. Pindorama de Mboîa e îakaré: } \\
\text { continuidade e mudancana na trajetóría das populaçōes } \\
\text { Tupi. Tese de doutorado. MAE/USP, 2014. }\end{array}$ & Rio Itararé \\
\hline Ibirarema & Chimbuva & não & & & 591820 & \begin{tabular}{|l}
7464 \\
290
\end{tabular} & & & & & \begin{tabular}{|l} 
Biblioteca \\
MAE
\end{tabular} & \begin{tabular}{|l|} 
MORAIS, J.L. Projeto \\
Paranapanema. Arqueologia da \\
Paisagem: Cenas do Paranapanama \\
Paulista (da Pré-Historía ao ciclo do \\
Café). Inventário. Săo Paulo. 2001. \\
\end{tabular} & $\begin{array}{l}\text { CORREA, A. A. Pindorama de Mboîa e Î́akaré: } \\
\text { continuidade e mudanca na trajetória das populaçes } \\
\text { Tupi. Tese de doutorado. MAE/USP, } 2014\end{array}$ & \\
\hline Castiliho & CHOPIM & não & SAD 69 & 22 & 433678 & $\begin{array}{l}7683 \\
028\end{array}$ & & & & $\begin{array}{l}\text { Spoog } \\
08\end{array}$ & \begin{tabular}{|l} 
CNSAe \\
Biblioteca \\
MAE
\end{tabular} & $\begin{array}{l}\text { Projeto de Salvamento Arqueológico } \\
\text { de Porto Primavera, SP. }\end{array}$ & 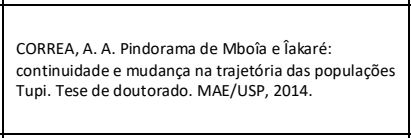 & 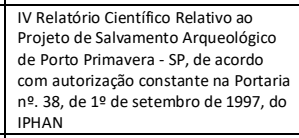 \\
\hline Castilho & CHORÃO & não & SAD 69 & 22 & 435823 & \begin{tabular}{|l}
7685 \\
326
\end{tabular} & & & & $\begin{array}{l}\text { Spoog } \\
20\end{array}$ & CNSA & $\begin{array}{l}\text { Projeto de Salvamento Arqueologico } \\
\text { de Porto Primavera, SP. }\end{array}$ & $\begin{array}{l}\text { CORREA, A. A. Pindorama de Mboîa e êakaré: } \\
\text { continuidade e mudanga na trajetória das populaçōes } \\
\text { Tupi. Tese de doutorado. MAE/USP, 2014. }\end{array}$ & 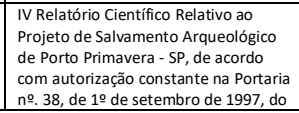 \\
\hline
\end{tabular}









\begin{tabular}{|c|c|c|c|c|c|c|c|c|c|c|c|c|c|c|}
\hline & & & & & & 285 & & & & & \begin{tabular}{|l|} 
IPHAN- \\
Relarório \\
$\mathrm{s}$
\end{tabular} & 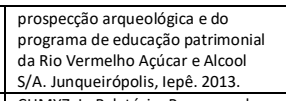 & & \\
\hline Fartura & \begin{tabular}{|l|}
$\begin{array}{l}\text { Primeira volta } \\
4\end{array}$ \\
\end{tabular} & não & & & & & $22 \mathrm{~K}$ & 652118 & 7412491 & & \begin{tabular}{|l|} 
CNSA \\
Biblioteca \\
MAE \\
\end{tabular} & $\begin{array}{l}\text { CHMYZ, I, Relatório. Programa de } \\
\text { Salvamento Arqueoológico no rio } \\
\text { Itararé }\end{array}$ & 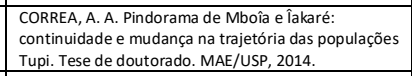 & Rio Itararé \\
\hline Iguape & $\begin{array}{l}\text { Sardon } \\
\text { Icapariniti }\end{array}$ & não & & & & & 23J & 241183 & 7265116 & & \begin{tabular}{|l|} 
CNSA e \\
Biblioteca \\
MAE
\end{tabular} & 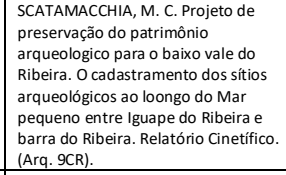 & & \\
\hline Glicerrio & $\begin{array}{l}\text { Córrego Água } \\
\text { Limpa } 1\end{array}$ & não & SAD 69 & 22 & 579135 & \begin{tabular}{|l}
7631 \\
605
\end{tabular} & & & & \begin{tabular}{|l} 
SPO11 \\
01
\end{tabular} & \begin{tabular}{|l|l} 
CNAS \\
Biblioteca \\
MAE
\end{tabular} & 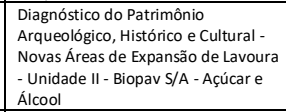 & 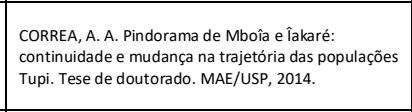 & \\
\hline Glicerrio & $\begin{array}{l}\text { Córrego Água } \\
\text { Limpa 2 }\end{array}$ & não & SAD 69 & 22 & 579082 & $\begin{array}{l}7631 \\
373\end{array}$ & & & & $\begin{array}{l}\text { SPo11 } \\
02\end{array}$ & CNSA & 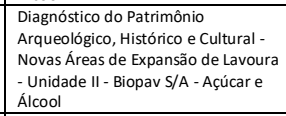 & 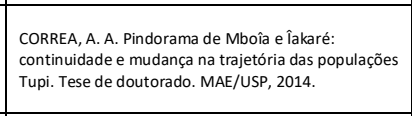 & \\
\hline Itapetininga & Alambari & não & & & & & $22 \mathrm{~K}$ & 801210 & 7388155 & & CNSA & & & $\begin{array}{l}\text { Projeto Saint-Hilaire - } 1984 \text { - registro } \\
\text { de Marisa Coutinho Afonso }\end{array}$ \\
\hline $\begin{array}{l}\text { Ribeirăo do } \\
\text { Sul }\end{array}$ & $\begin{array}{l}\text { Córrego } \\
\text { Capim }\end{array}$ & não & $\begin{array}{l}\text { Córrego } \\
\text { Alegre }\end{array}$ & $22 K$ & 608523 & $\begin{array}{l}7483 \\
580\end{array}$ & & & & $\begin{array}{l}\text { Sp010 } \\
68\end{array}$ & CNSA & 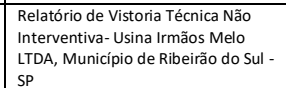 & 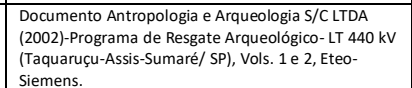 & \\
\hline Riversul & \begin{tabular}{|l} 
Córrego da \\
Divisa
\end{tabular} & não & & $22 \mathrm{~K}$ & 0661952 & $\begin{array}{l}7355 \\
848\end{array}$ & & & & & $\begin{array}{l}\text { Biblioteca } \\
\text { MAE }\end{array}$ & 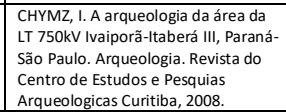 & & \\
\hline Pacaembu & $\begin{array}{l}\text { Córrego da } \\
\text { Paz }\end{array}$ & não & & $22 \mathrm{~K}$ & $\mid 474282$ & \begin{tabular}{|l|l}
7634 \\
683
\end{tabular} & & & & & $\begin{array}{l}\text { Arquivo } \\
\text { IPHAN- } \\
\text { Relarório } \\
\text { s }\end{array}$ & 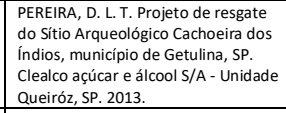 & $\begin{array}{l}\text { FACCIO, N. B. et al. Relatório de prospeccẵo } \\
\text { arqueológica e do programa de educaça patrimonial } \\
\text { da Rio Vermelho Açúcar e Alcool S/A. Junqueirópolis, } \\
\text { lepê. } 2013 \text {. }\end{array}$ & \\
\hline Arandu & $\begin{array}{l}\text { Córrego do } \\
\text { saltinho }\end{array}$ & não & SAD 69 & $\begin{array}{l}22 \\
22\end{array}$ & 703994 & $\begin{array}{l}7443 \\
980\end{array}$ & & & & & CNSA & 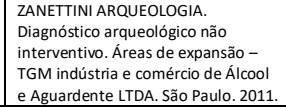 & & \\
\hline Guarantã & $\begin{array}{l}\text { Córego } \\
\text { Taquaral }\end{array}$ & não & $\begin{array}{l}\text { Córego } \\
\text { Alegre }\end{array}$ & $22 \mathrm{~K}$ & 636782 & \begin{tabular}{|l}
7575 \\
670
\end{tabular} & & & & & CNSA & 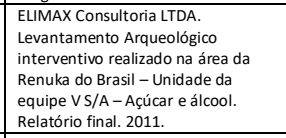 & & \\
\hline Paulicéia & CORRUPIÃo & não & SAD 69 & 22 & 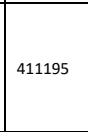 & $\begin{array}{l}7639 \\
214\end{array}$ & & & & $\begin{array}{l}\text { Spoog } \\
78\end{array}$ & CNSA & 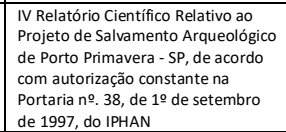 & \begin{tabular}{|l} 
Projejo de Salvamento Arqueológico de Porto \\
Primavera, SP.
\end{tabular} & \\
\hline Rosana & CORUJA & não & SAD 69 & 22 & 289657 & \begin{tabular}{|l}
7504 \\
889
\end{tabular} & & & & $\begin{array}{l}\text { SP008 } \\
54\end{array}$ & CNSA & \begin{tabular}{|l} 
Projeto de Salvamento Arqueológico \\
de Porto Primavera, SP.
\end{tabular} & 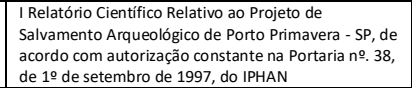 & \\
\hline Fartura & $\begin{array}{l}\text { Salto das } \\
\text { Corredeiras }\end{array}$ & não & & & & & $22 \mathrm{~K}$ & 652118 & 7412491 & & \begin{tabular}{|l} 
CNSA \\
Biblioteca \\
MAE
\end{tabular} & $\begin{array}{l}\text { CHMYZ, l.; Relatário. Programa de } \\
\text { Salvamento Arqueologico no rio } \\
\text { ltararé }\end{array}$ & $\begin{array}{l}\text { CORREA,A.A.A. Pindorama a de Mboía e lîkaré: } \\
\text { continuidade e mudanca na trajetoria das populaçoes } \\
\text { Tupi. Tese de doutorado. MAE/USP, } 2014 .\end{array}$ & Rio Itararé \\
\hline Fartura & $\begin{array}{l}\text { Sítio do } \\
\text { Caminhão }\end{array}$ & não & & & & & $22 \mathrm{~K}$ & 652118 & 7412491 & & CNSA & \begin{tabular}{|l|} 
CHMYZ, I.; Relatório. Programa de \\
Salvamento Arqueológico no rio \\
tiararé
\end{tabular} & & Rio Itararé \\
\hline
\end{tabular}




\begin{tabular}{|c|c|c|c|c|c|c|c|c|c|c|c|c|c|c|c|}
\hline $\begin{array}{l}\text { Ribeirão } \\
\text { Grande }\end{array}$ & Cristal 2 & não & SAD 69 & $22 J$ & 0765909 & \begin{tabular}{|l}
7326 \\
951
\end{tabular} & & & & & & CNSA & & & 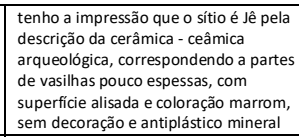 \\
\hline $\begin{array}{l}\text { Ribeirão } \\
\text { Grande }\end{array}$ & Cristal 3 & não & & 22J & 765931 & \begin{tabular}{|l}
7326 \\
680
\end{tabular} & & & & & & CNSA & & & 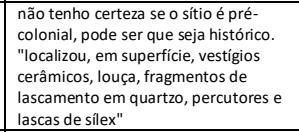 \\
\hline $\begin{array}{l}\text { Ribeirão } \\
\text { Grande }\end{array}$ & Cristal 5 & não & & $22 J$ & 765940 & $\begin{array}{l}7326 \\
541\end{array}$ & & & & & & CNSA & & & 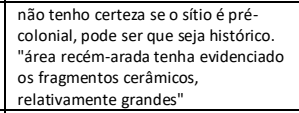 \\
\hline $\begin{array}{l}\text { Teodoro } \\
\text { Sampaio }\end{array}$ & CURIANGO & กão & SAD 69 & 22 & 329077 & \begin{tabular}{|l}
7541 \\
782
\end{tabular} & & & & & $\begin{array}{l}\text { Sp008 } \\
55\end{array}$ & CNSA & $\begin{array}{l}\text { Projeto de Salvamento Arqueológico } \\
\text { de Porto Primavera, SP. }\end{array}$ & 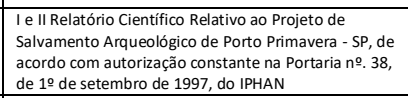 & \\
\hline $\begin{array}{l}\text { Teodoro } \\
\text { Sampaio }\end{array}$ & CURRUÍrA & não & SAD 69 & 22 & 342162 & \begin{tabular}{|l}
7538 \\
892
\end{tabular} & & & & & \begin{tabular}{|l|} 
SP008 \\
56
\end{tabular} & CNSA & $\begin{array}{l}\text { Projeto de Salvamento Arqueológico } \\
\text { de Porto Primavera, SP. }\end{array}$ & 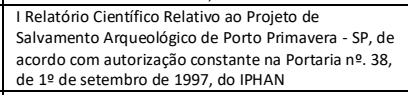 & \\
\hline $\begin{array}{l}\text { Cândido } \\
\text { Mota }\end{array}$ & Curupiá & não & & & 558400 & \begin{tabular}{|l}
7468 \\
650
\end{tabular} & & & & & & $\begin{array}{l}\text { Biblioteca } \\
\text { MAE }\end{array}$ & 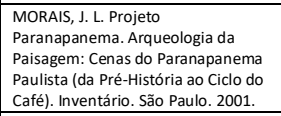 & 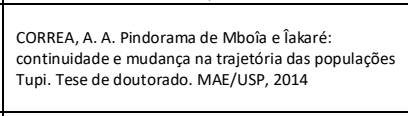 & \\
\hline Piraju & Cury & não & SAS 69 & 22 & 660906 & \begin{tabular}{|l}
7431 \\
504
\end{tabular} & & & & & & $\begin{array}{l}\text { Inventári } \\
\text { • }\end{array}$ & 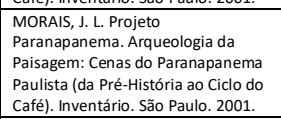 & & \\
\hline Apiaí & Toca da onça & não & & & & & & $22 J$ & 718373 & 7287465 & & $\begin{array}{l}\text { CNSA } \\
\text { Biblioteca } \\
\text { MAE }\end{array}$ & 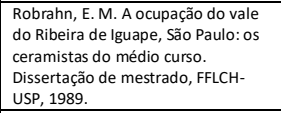 & & \\
\hline Fartura & 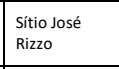 & não & & & & & & $22 \mathrm{~K}$ & 652118 & 7412491 & & CNSA & \begin{tabular}{|l|} 
CHMYZ, li; Relatório. Programa de \\
Salvamento Arqueoologico no rio \\
Itararé
\end{tabular} & & Rio ttararé \\
\hline Piraju & Camargo & $\begin{array}{l}450 \pm 40 \mathrm{AP} ; \\
1030 \mathrm{AP} ; \\
2060 \mathrm{AP} ; \\
4650 \mathrm{AP} ; \\
1030 \pm 100 \\
\mathrm{AP}\end{array}$ & & 22 & \begin{tabular}{|l|l|}
662077 \\
\end{tabular} & \begin{tabular}{|l}
7437 \\
149
\end{tabular} & & & & & $\begin{array}{l}\text { SP0o9 } \\
86\end{array}$ & \begin{tabular}{|l} 
CNSAe \\
Biblioteca \\
MAE
\end{tabular} & $\begin{array}{l}\text { KASHIMOTO, E. M. Variáveis } \\
\text { ambientais earqueologia no Alto } \\
\text { Paraná. Tese de doutorado. USP, São } \\
\text { Paulo. 1997. }\end{array}$ & $\begin{array}{l}\text { POSSE, Z. Populaçāes pré-históricicas de sitios } \\
\text { ceramicos no interior do Brasil. Doutorado. USP. São } \\
\text { Paulo, 19844. }\end{array}$ & 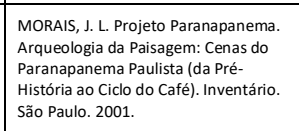 \\
\hline Dracena & Dracena & não & & $22 K$ & \begin{tabular}{|l|l|}
447805 \\
\end{tabular} & \begin{tabular}{|l}
7629 \\
657
\end{tabular} & & & & & & $\begin{array}{l}\text { Arquivo } \\
\text { IPAAN- } \\
\text { Relarório } \\
s\end{array}$ & 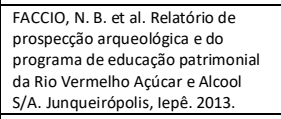 & & \\
\hline $\begin{array}{l}\text { Campina do } \\
\text { Monte Alegre }\end{array}$ & Campina & $540 \pm 50 \mathrm{AP}$ & SAS 69 & 22 & 757500 & \begin{tabular}{|l}
7389 \\
000 \\
000
\end{tabular} & & & & & & $\begin{array}{l}\text { Biblioteca } \\
\text { MAE }\end{array}$ & 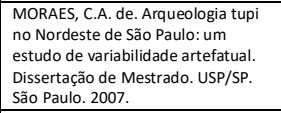 & 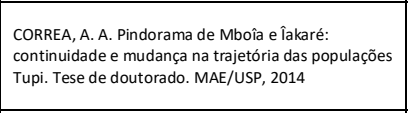 & \\
\hline $\begin{array}{l}\text { Cândido } \\
\text { Mota }\end{array}$ & Embaúba & não & & & 559720 & \begin{tabular}{|l}
7466 \\
200
\end{tabular} & & & & & & $\begin{array}{l}\text { Biblioteca } \\
\text { MAE }\end{array}$ & 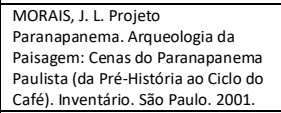 & 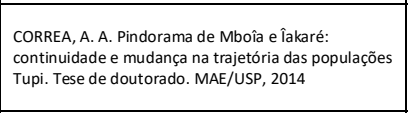 & \\
\hline $\begin{array}{l}\text { Presidente } \\
\text { Epitácio }\end{array}$ & Epitácio & não & SAD 69 & 22 & 382070 & \begin{tabular}{|l|l}
7593 \\
087
\end{tabular} & 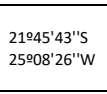 & & & & 5589 & \begin{tabular}{|l} 
CNSAe \\
Biblioteca \\
MAE
\end{tabular} & $\begin{array}{l}\text { KASHIMOTO, E. M. Variáaeis } \\
\text { ambientais araueoologia no Alto } \\
\text { Paraná. Tese de doutorado. USP, São } \\
\text { Paulo. 1997. }\end{array}$ & 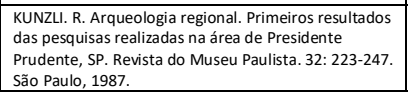 & \\
\hline
\end{tabular}




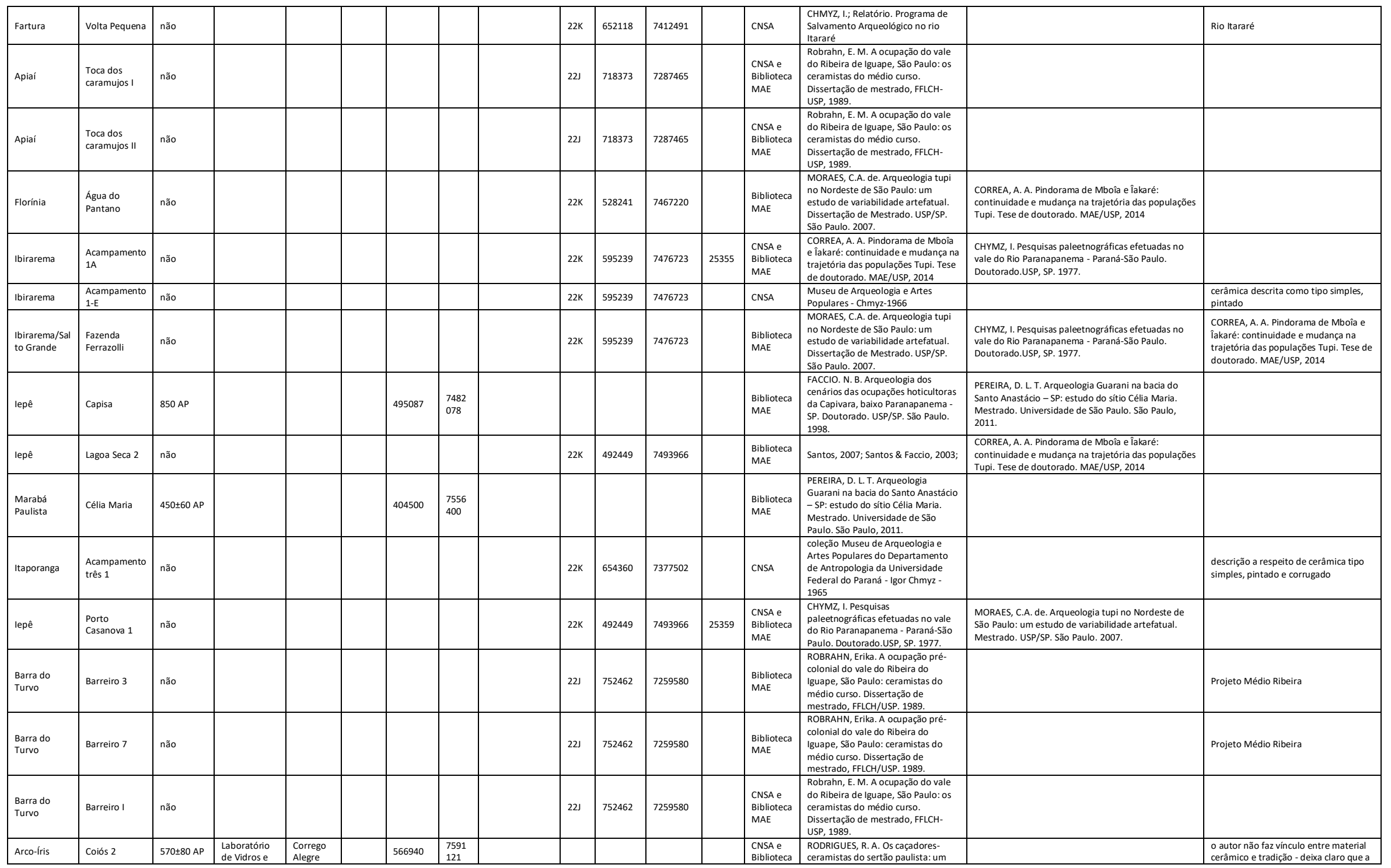




\begin{tabular}{|c|c|c|c|c|c|c|c|c|c|c|c|c|c|c|c|}
\hline & & & \begin{tabular}{|l} 
Datacăão da \\
FATEC
\end{tabular} & & & & & & & & & MAE & 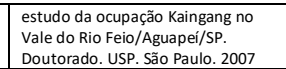 & & $\begin{array}{l}\text { cerâmica analisada é Kaingang e não } \\
\text { Itararé/Taquara/Casa de Pedra }\end{array}$ \\
\hline lepê & \begin{tabular}{|l|} 
Porto \\
Casanova 3
\end{tabular} & não & & & & & & $22 \mathrm{~K}$ & 492449 & 7493966 & 25361 & \begin{tabular}{|l} 
CNSA e \\
Biblioteca \\
MAE
\end{tabular} & 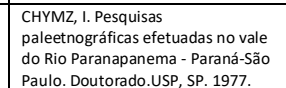 & $\begin{array}{l}\text { MORAES, C.A. de. Arqueoologia tupi no Nordeste de } \\
\text { São Paulo: um estuddo de variabilidade artefatual. } \\
\text { Mestrado. USP/SP. São Paulo. } 2007 \text {. }\end{array}$ & \\
\hline $\begin{array}{l}\text { Barra do } \\
\text { Turvo }\end{array}$ & Barreiro II & não & & & & & & $22 \mathrm{~s}$ & 752462 & 7259580 & & $\begin{array}{l}\text { CNSA } \\
\text { Biblioteca } \\
\text { MAE }\end{array}$ & 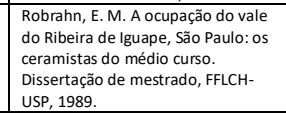 & & \\
\hline lepê & $\begin{array}{l}\text { Porto } \\
\text { Casanova } 4\end{array}$ & não & & & & & & $22 \mathrm{~K}$ & 492449 & 7493966 & 25362 & \begin{tabular}{|l} 
CNSA \\
Biblioteca \\
MAE
\end{tabular} & 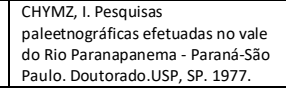 & $\begin{array}{l}\text { MORAES, C.A. de. Arqueoologia tupi no Nordeste de } \\
\text { São Paulo: um estudo de variabilidade artefatual. } \\
\text { Mestrado. USP/SP. Săo Paulo. 2007. }\end{array}$ & \\
\hline Avaré & \begin{tabular}{|l} 
Fazenda \\
Panorâmica
\end{tabular} & não & & SAD 69 & 22 & 710086 & $\begin{array}{l}7434 \\
679\end{array}$ & & & & & \begin{tabular}{|l} 
CNSA e \\
Biblioteca \\
MAE
\end{tabular} & \begin{tabular}{|l|} 
ARAUJO, A; G. M- 2001. Teoria e \\
método em arqueoologia regional: \\
um estudo ode casono Atto \\
Paranapanema, estado do São Paulo, \\
TTese de doutoradodo, USP/SPP, Sâo \\
Paulo. 2001.
\end{tabular} & 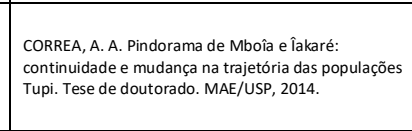 & \\
\hline lepê & $\begin{array}{l}\text { Porto } \\
\text { Casanova } 5\end{array}$ & não & & & & & & $22 \mathrm{k}$ & 492449 & 7493966 & 25363 & \begin{tabular}{|l} 
CNSA e \\
Biblioteca \\
MAE
\end{tabular} & 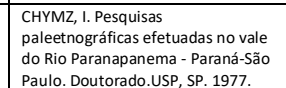 & $\begin{array}{l}\text { MORAES, C.A. de. Arqueologia tupi no Nordeste de } \\
\text { São Paulo: um estudo de variabilidade artefatual. } \\
\text { MMestrado. USP/SP. Săo Paulo. 2007. }\end{array}$ & \\
\hline $\begin{array}{l}\text { Barra do } \\
\text { Turvo }\end{array}$ & Barreiro IV & não & & & & & & $22 \mathrm{~s}$ & 752462 & 7259580 & & \begin{tabular}{|l} 
CNSA \\
Biblioteca \\
MAE
\end{tabular} & 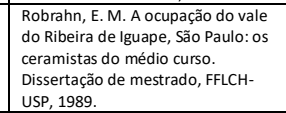 & & Proximidade ao rio Turvo \\
\hline lepê & \begin{tabular}{|l|} 
Porto \\
Casanova 6
\end{tabular} & não & & & & & & $22 \mathrm{~K}$ & 492449 & 7493966 & 25364 & \begin{tabular}{|l|} 
CNSA \\
Biblioteca \\
MAE
\end{tabular} & 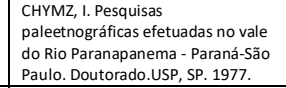 & & \\
\hline Arandu & $\begin{array}{l}\begin{array}{l}\text { Fazenda Santa } \\
\text { Catarina }\end{array} \\
\text { col }\end{array}$ & não & & SAD 69 & 22 & 702385 & $\begin{array}{l}7455 \\
220\end{array}$ & & & & & $\begin{array}{l}\text { CNSA } \\
\text { Biblioteca } \\
\text { MAE }\end{array}$ & 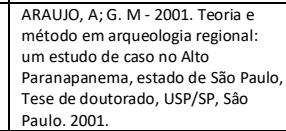 & & \\
\hline Piraju & Colina & $870 \pm 90 \mathrm{AP}$ & & & 22 & 671300 & $\begin{array}{l}7429 \\
400\end{array}$ & & & & & $\begin{array}{l}\text { CNSA } \\
\text { Biblioteca } \\
\text { MAE }\end{array}$ & 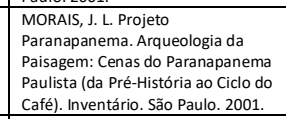 & $\begin{array}{l}\text { MORAES, C.A. de. Arqueoologia tupi no Nordeste de } \\
\text { São Paulo: um estudud de variabilidadade artefatual. } \\
\text { Dissertaçăo de Mestrado. USP/SP. São Paulo. } 2007 .\end{array}$ & \\
\hline Iguape & \begin{tabular}{|l|l} 
Estação \\
Experimental
\end{tabular} & não & & & & & & $23 \mathrm{~s}$ & 241180 & 7265109 & & $\begin{array}{l}\text { Biblioteca } \\
\text { MAE }\end{array}$ & 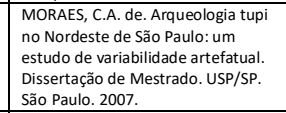 & $\begin{array}{l}\text { CORREA, A. A. Pindorama de Mboîa e îakaré: } \\
\text { continuidade e mudança na trajetoria das populaçes } \\
\text { Tupi. Tese de doutorado. MAE/USP, } 2014\end{array}$ & \\
\hline Arandu & $\begin{array}{l}\text { Fazenda São } \\
\text { Marcos }\end{array}$ & não & & SAD 69 & 22 & 702616 & $\begin{array}{l}7453 \\
498\end{array}$ & & & & & \begin{tabular}{|l} 
CNSA e \\
Biblioteca \\
MAE
\end{tabular} & 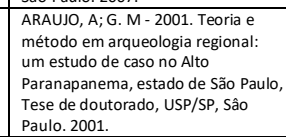 & & \\
\hline $\begin{array}{l}\text { Barra do } \\
\text { Turvo }\end{array}$ & Barreiro V & não & & & & & & $22 \mathrm{~s}$ & 752462 & 7259580 & & $\begin{array}{l}\text { CNSA } \\
\text { Biblioteca } \\
\text { MAE }\end{array}$ & 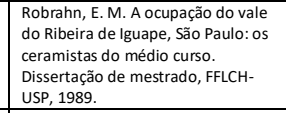 & & Proximidade ao rio Feio \\
\hline Piraju & Fecapi & não & & SAS 69 & 22 & 664567 & $\begin{array}{l}7435 \\
420\end{array}$ & & & & & $\begin{array}{l}\text { Inventári } \\
\text { o }\end{array}$ & 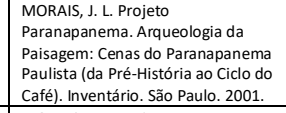 & & \\
\hline Sandovalina & Domingos 2 & $480 \pm 60 \mathrm{AP}$ & & & $22 \mathrm{~K}$ & 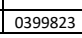 & 7509 & & & & & \begin{tabular}{|l|l|} 
Biblioteca \\
\end{tabular} & MORAIS, I. L. Projeto to & CORREA, A. A. Pindorama de Mboîa e êakaré: & \\
\hline
\end{tabular}




\begin{tabular}{|c|c|c|c|c|c|c|c|c|c|c|c|c|c|c|c|c|}
\hline & & & & & & & 934 & & & & & & MAE & 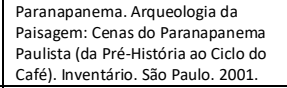 & $\begin{array}{l}\text { continuidade e mudança n a trajetória das populaçöes } \\
\text { Tupi. Tese de doutorado. MAE/USP, } 2014 .\end{array}$ & \\
\hline Itararé & Fase Cambará & $\begin{array}{l}20 \pm 150 \\
\text { AP; } \\
1190 \pm 50 \\
\text { AP }\end{array}$ & C14 & & & & & & $22 \mathrm{~J}$ & 668811 & 7332392 & & \begin{tabular}{|l} 
Biblioteca \\
MAE
\end{tabular} & \begin{tabular}{|l} 
SCATAMACCHIA, M. C. M. Tentativa \\
de caracterizizắa da tradicẫo \\
Tupiguarani. Dissertaço de \\
mestrado. USP. Saro Paulo. 1981. \\
\end{tabular} & 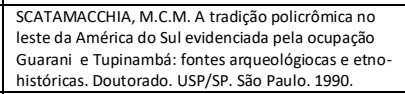 & \\
\hline Palmital & $\begin{array}{l}\begin{array}{l}\text { Figueira- } \\
\text { Branca }\end{array} \\
\end{array}$ & não & & & & 580011 & $\begin{array}{l}7462 \\
475\end{array}$ & & & & & & \begin{tabular}{|l} 
Biblioteca \\
MAE
\end{tabular} & 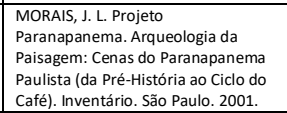 & 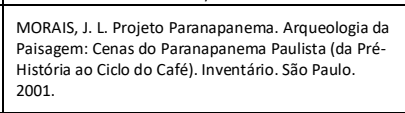 & \\
\hline Rancharia & Figueiredo & não & & & & \begin{tabular}{|l}
5142870 \\
98
\end{tabular} & $\begin{array}{l}7507 \\
3349 \\
43\end{array}$ & & & & & & $\begin{array}{l}\text { Biblioteca } \\
\text { MAE }\end{array}$ & 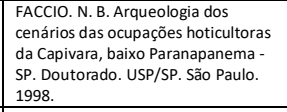 & & \\
\hline Florinia & Florinial & não & & \begin{tabular}{|l} 
Corrego \\
alegre
\end{tabular} & $22 \mathrm{~K}$ & 539499 & $\begin{array}{l}7466 \\
325\end{array}$ & & & & & & \begin{tabular}{|l} 
Biblioteca \\
empresa
\end{tabular} & 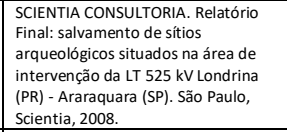 & & margem direita do Rio Paranapanema \\
\hline Arco-Iris & Fogo 01 & não & & \begin{tabular}{|l} 
Corrego \\
Alegre
\end{tabular} & & 565344 & $\begin{array}{l}7597 \\
262\end{array}$ & & & & & & \begin{tabular}{|l} 
CNSA e \\
Biblioteca \\
MAE
\end{tabular} & 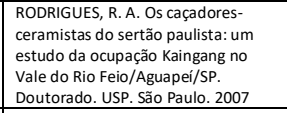 & & 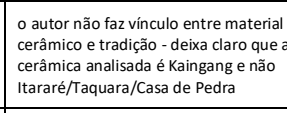 \\
\hline Arco-liris & Fogo 02 & não & & \begin{tabular}{|l} 
Corrego \\
Alegre
\end{tabular} & & 565113 & $\begin{array}{l}7597 \\
373\end{array}$ & & & & & & \begin{tabular}{|l} 
CNSA \\
Biblioteca \\
MAE
\end{tabular} & 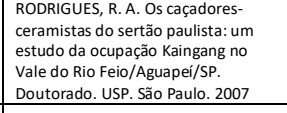 & & 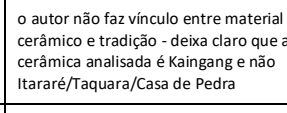 \\
\hline $\begin{array}{l}\text { Presidente } \\
\text { Epitácio }\end{array}$ & $\begin{array}{l}\text { FOGO } \\
\text { APAGOU }\end{array}$ & não & & SAD 69 & 22 & 398390 & \begin{tabular}{|l}
7619 \\
081
\end{tabular} & & & & & $\begin{array}{l}\text { SP008 } \\
57\end{array}$ & CNSA & $\begin{array}{l}\text { Projeto de Salvamento Arqueológico } \\
\text { de Porto Primavera, SP. }\end{array}$ & 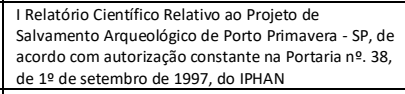 & \\
\hline $\begin{array}{l}\text { Cândido } \\
\text { Mota }\end{array}$ & Figueira & $\begin{array}{l}820 \pm 80 \mathrm{AP} ; \\
428250 \mathrm{AP} \\
; 624 \mathrm{AP}\end{array}$ & & & & 550500 & $\begin{array}{l}7462 \\
550\end{array}$ & & & & & & \begin{tabular}{|l} 
Biblioteca \\
MAE
\end{tabular} & 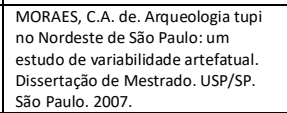 & $\begin{array}{l}\text { CORREA, A. A. Pindorama de Mboîa e îakaré: } \\
\text { continuidade e mudança na trajetória das populaçoes } \\
\text { Tupi. Tese de doutorado. MAE/USP, } 2014\end{array}$ & 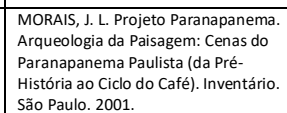 \\
\hline Iguape & Jiporuva & não & & & & & & & 23J & 241180 & 7265109 & & \begin{tabular}{|l} 
Biblioteca \\
MAE
\end{tabular} & 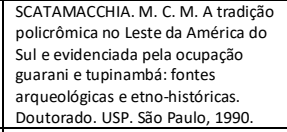 & 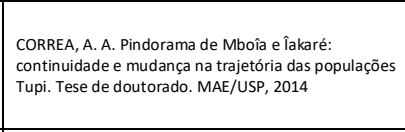 & \\
\hline $\begin{array}{l}\text { Cândido } \\
\text { Mota }\end{array}$ & For do cinzas & não & & & & 549250 & $\begin{array}{l}7463 \\
500\end{array}$ & $\begin{array}{l}2256^{\prime} 0^{\prime \prime 5} 50 \\
011^{\circ} \mathrm{W} W\end{array}$ & & & & & CNSA & \begin{tabular}{|l|} 
MORAIS, J.L. Relatório. Projeto \\
Paranapanema. 1990.
\end{tabular} & & \\
\hline $\begin{array}{l}\text { Alvares } \\
\text { Machado }\end{array}$ & Frauzino & não & & & $22 \mathrm{~K}$ & 439215 & $\begin{array}{l}7551 \\
040\end{array}$ & & & & & & \begin{tabular}{|l} 
CNSA \\
Biblioteca \\
MAE
\end{tabular} & 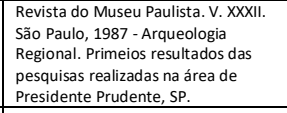 & & \\
\hline Castiliho & FRUXU & não & & SAD 69 & 22 & 434923 & \begin{tabular}{|l}
7698 \\
867
\end{tabular} & & & & & $\begin{array}{l}\text { Spoog } \\
23\end{array}$ & CNSA & $\begin{array}{l}\text { Projeto de Salvamento Arqueológico } \\
\text { de Porto Primavera, SP. }\end{array}$ & 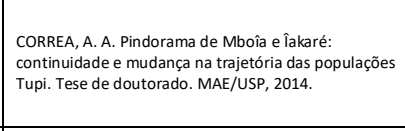 & 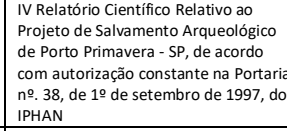 \\
\hline Piraju & Funil & não & & & & 671102 & $\begin{array}{l}7434 \\
660 \\
660\end{array}$ & $\begin{array}{l}23111^{2} 1 " 1 \mathrm{~S} 45 \\
19377^{7} \mathrm{~W}\end{array}$ & & & & & CNSA & \begin{tabular}{|l|} 
MORAIS, J.L. Relatótíio. Projeto \\
Paranapanema. 1990.
\end{tabular} & & \\
\hline $\begin{array}{l}\text { Teodoro } \\
\text { Sampaio }\end{array}$ & GAIVOTA & não & & SAD 69 & 22 & 337596 & $\begin{array}{l}7536 \\
954\end{array}$ & & & & & $\begin{array}{l}\text { SP008 } \\
58\end{array}$ & CNSA & $\begin{array}{l}\text { Projeto de Salvamento Arqueológico } \\
\text { de Porto Primavera, SP. }\end{array}$ & 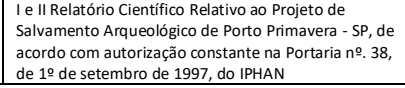 & \\
\hline
\end{tabular}




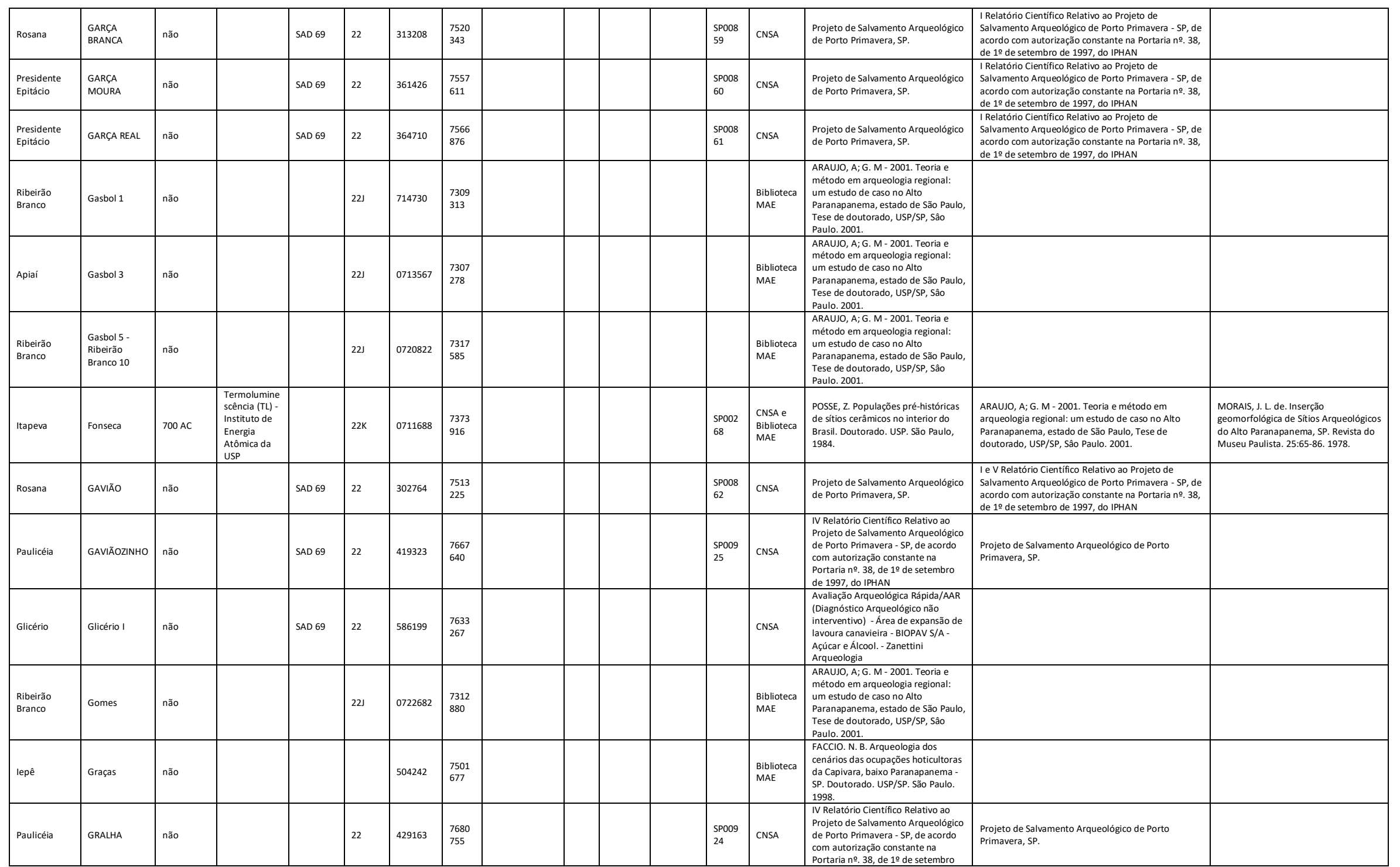




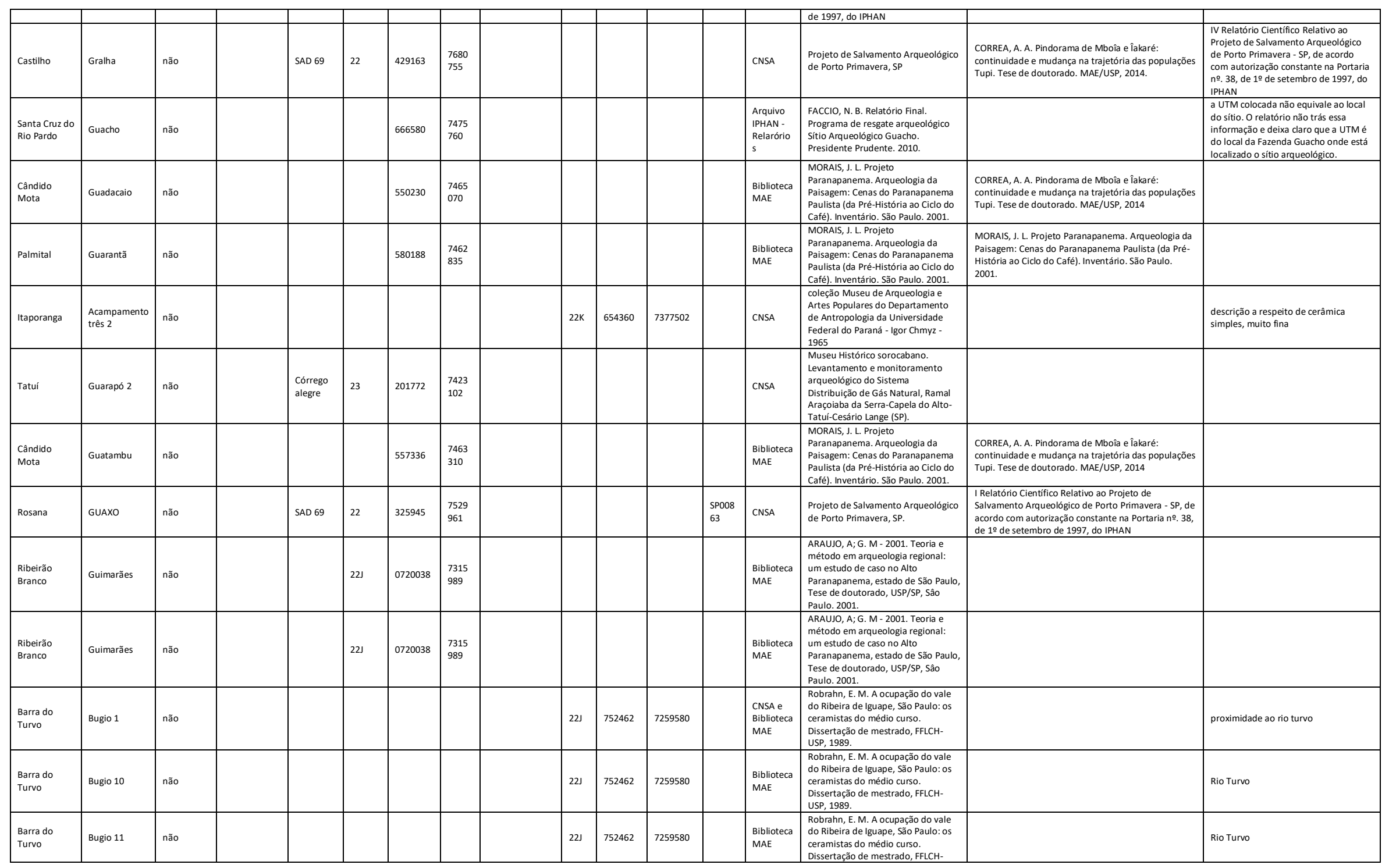




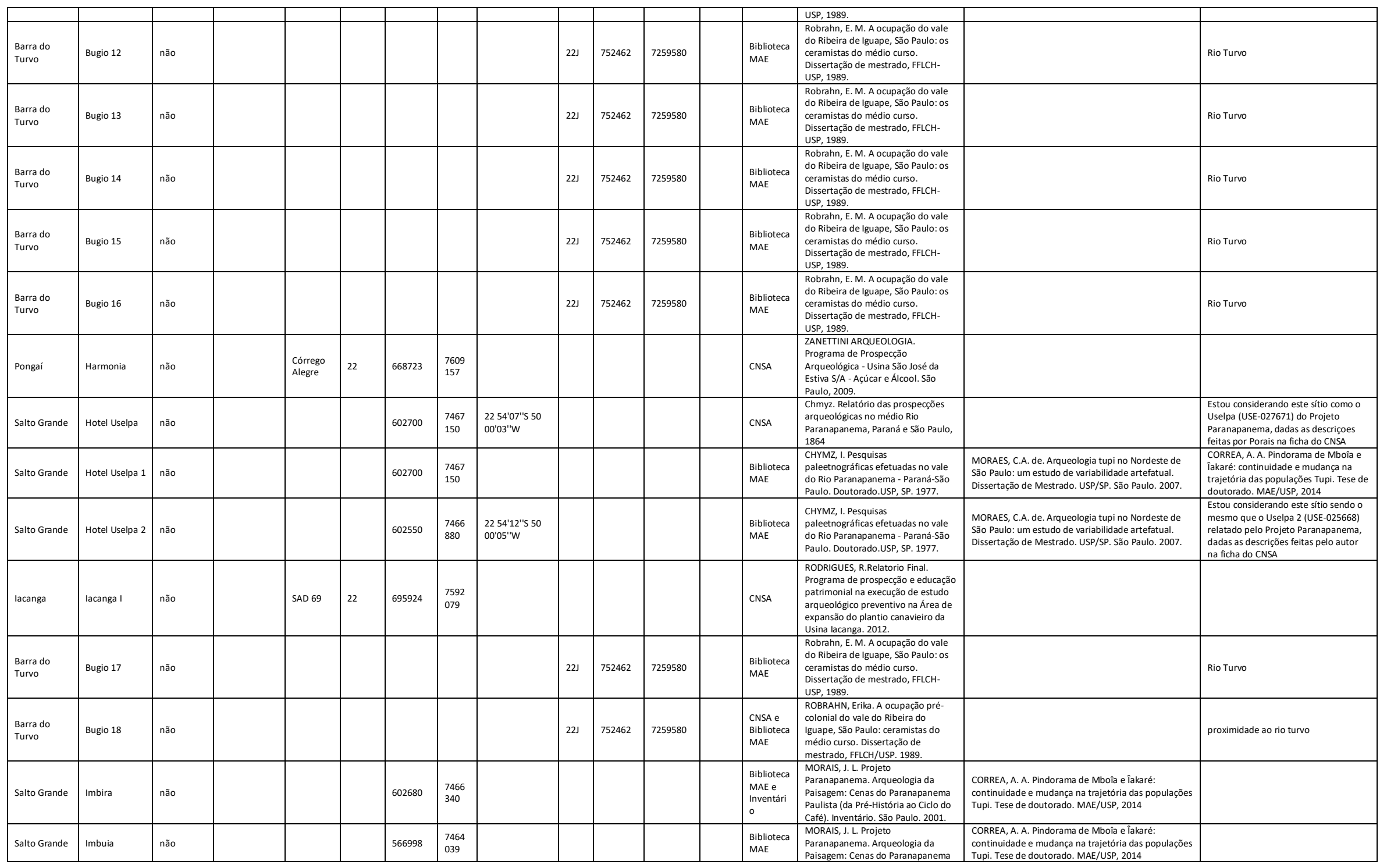




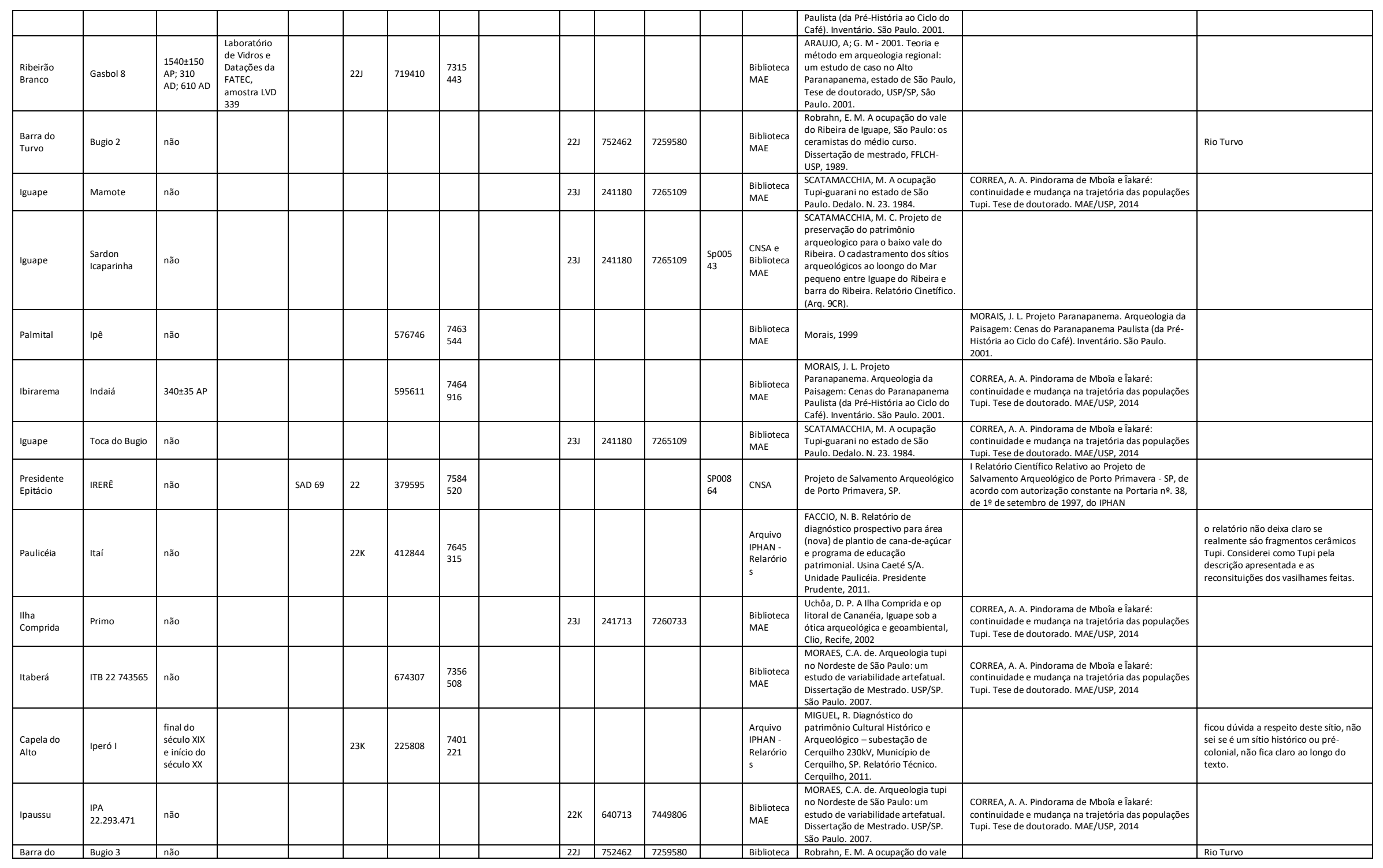




\begin{tabular}{|c|c|c|c|c|c|c|c|c|c|c|c|c|c|c|c|}
\hline Turvo & & & & & & & & & & & & MAE & 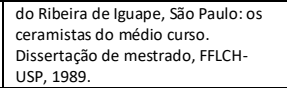 & & \\
\hline Rosana & JABURU & não & SAD 69 & 22 & 322349 & $\begin{array}{l}7526 \\
847\end{array}$ & & & & & $\begin{array}{l}\text { Spo08 } \\
65\end{array}$ & CNSA & $\begin{array}{l}\text { Projeto de Salvamento Arqueológico } \\
\text { de Porto Primavera, SP. }\end{array}$ & 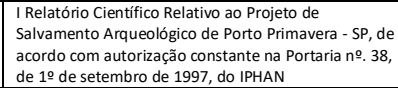 & \\
\hline Salto Grande & Jacaratía & não & & & 602700 & $\begin{array}{l}7467 \\
150\end{array}$ & & & & & & \begin{tabular}{|l} 
Biblioteca \\
MAE e \\
Inventári \\
o \\
\end{tabular} & 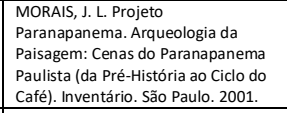 & $\begin{array}{l}\text { CORREA, A.A. Aindorama de Mboîa e êakaré: } \\
\text { continuidade e mudança na trajetoria das populaçoses } \\
\text { Tupi. Tese de doutorado. MAE/USP, } 2014 .\end{array}$ & \\
\hline Itaberá & $\begin{array}{l}\text { Cemitério do } \\
\text { espanhol }\end{array}$ & não & & & & & & $22 \mathrm{~K}$ & 689494 & 7359456 & & $\begin{array}{l}\text { Biblioteca } \\
\text { MAE }\end{array}$ & 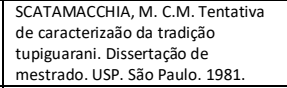 & & \\
\hline Pirapozinho & Itororó & Século XVII & & & \begin{tabular}{|l|l|}
424630 \\
\end{tabular} & $\begin{array}{l}7498 \\
250\end{array}$ & 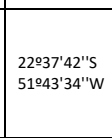 & & & & 25602 & \begin{tabular}{|l} 
CNSA \\
Biblioteca \\
MAE
\end{tabular} & 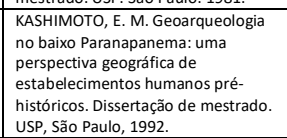 & $\begin{array}{l}\text { KUNZLI. R. Arqueoologia regional. Primeiros resultados } \\
\text { das pesquisas realizadas na área de Presidente } \\
\text { Prudente, SP. Revista do Museu Paulista. 32: 223-247. } \\
\text { Săo Paulo, 1987. }\end{array}$ & 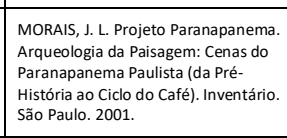 \\
\hline Tupi Paulista & Jaobi & não & & $22 \mathrm{~K}$ & \begin{tabular}{|l|l}
446016 \\
\end{tabular} & $\begin{array}{l}7638 \\
285\end{array}$ & & & & & & \begin{tabular}{|l} 
Arquivo \\
IPHAN- \\
Relarório \\
s \\
\end{tabular} & 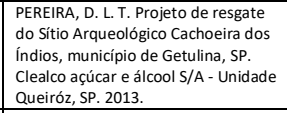 & & \\
\hline |birarema & Japecanga & não & & & 592920 & $\begin{array}{l}7465 \\
330\end{array}$ & & & & & & $\begin{array}{l}\text { Biblioteca } \\
\text { MAE }\end{array}$ & 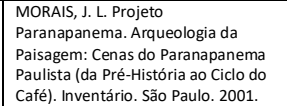 & $\begin{array}{l}\text { CORREA, A. A. Pindorama de Mboîa e îakaré: } \\
\text { continuidade e mudança na trajetória das populaçōes } \\
\text { Tupi. Tese de doutorado. MAE/USP, } 2014\end{array}$ & \\
\hline Salto Grande & Jataí & não & & & 602550 & $\begin{array}{l}7466 \\
880\end{array}$ & & & & & & \begin{tabular}{|l} 
Biblioteca \\
MAE e \\
Inventári \\
o \\
\end{tabular} & 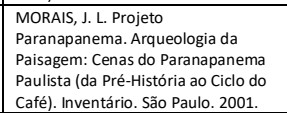 & $\begin{array}{l}\text { CORREA, A. A. Pindorama de Mboîa e îakaré: } \\
\text { continuidade e mudança na trajetória das populaçoses } \\
\text { Tupi. Tese de doutorado. MAE/USP, } 2014 .\end{array}$ & \\
\hline Salto Grande & Jauvá & não & & & 602700 & $\begin{array}{l}7466 \\
590\end{array}$ & & & & & & \begin{tabular}{|l|} 
Biblioteca \\
MAEe éfi \\
Inventári \\
o \\
\end{tabular} & 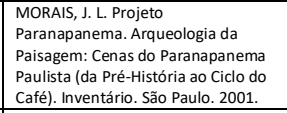 & $\begin{array}{l}\text { CORREA, A. A. Pindorama de Mboia e êakaré: } \\
\text { continuidade e mudanca na trajetória das populaçose } \\
\text { Tupi. Tese de doutorado. MAE/USP, 2014. }\end{array}$ & \\
\hline Salto Grande & Jequitibá & não & & & |603097 & $\begin{array}{l}7465 \\
620\end{array}$ & & & & & & \begin{tabular}{|l} 
Biblioteca \\
MAE é \\
Inventári \\
o \\
\end{tabular} & 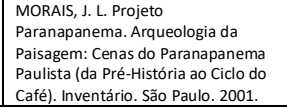 & $\begin{array}{l}\text { CORREA, A. A. Pindorama de Mboîa e îakaré: } \\
\text { continuidade e mudança na trajettória das populações } \\
\text { Tupi. Tese de doutorado. MAE/USP, } 2014 \text {. }\end{array}$ & \\
\hline Florínia & Jerivá & não & & & 542700 & $\begin{array}{l}7466 \\
350\end{array}$ & & & & & & $\begin{array}{l}\text { Biblioteca } \\
\text { MAE }\end{array}$ & 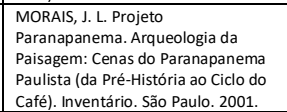 & $\begin{array}{l}\text { CORREA, A. A. Pindorama de Mboîa e Îakaré: } \\
\text { continuidade e mudança na trajetória das populaçoses } \\
\text { Tupi. Tese de doutorado. MAE/USP, 2014 }\end{array}$ & \\
\hline Itaberá & $\begin{array}{l}\text { José } \\
\text { Fernandes }\end{array}$ & não & & & & & & $22 \mathrm{~K}$ & 689494 & 7359456 & 25504 & \begin{tabular}{|l} 
CNSA \\
Biblioteca \\
MAE
\end{tabular} & \begin{tabular}{|l} 
MARANCA, Silvia, Nota prévia sobre \\
o sitio José ernandes.s II: Revista do \\
Museu Paulista. V. 18, 1968. p. 105- \\
118
\end{tabular} & & $\begin{array}{l}\text { cerâmica: vasos carenados, simples e } \\
\text { pintados }\end{array}$ \\
\hline Canitar & João Costa & não & & & 624862 & $\begin{array}{l}7458 \\
801\end{array}$ & & & & & & \begin{tabular}{|l} 
Arquivo \\
IPHAN. \\
Relarório \\
s
\end{tabular} & 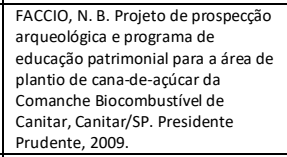 & & \\
\hline Castilho & $\begin{array}{l}\text { JOÃ̃ DE } \\
\text { BARRO }\end{array}$ & não & SAD 69 & 22 & 426310 & $\begin{array}{l}7680 \\
782\end{array}$ & & & & & $\begin{array}{l}\text { Spoog } \\
17\end{array}$ & \begin{tabular}{|l} 
CNSA e \\
Biblioteca \\
MAE
\end{tabular} & $\begin{array}{l}\text { Projeto de Salvamento Arqueológico } \\
\text { de Porto Primavera, SP. }\end{array}$ & $\begin{array}{l}\text { CORREA, A. A. Pindorama de Mboîa e Îakaré: } \\
\text { continuidade emudancana trajetéria das populases } \\
\text { Tupi. Tesese de doutorado. MAE/USP, 2014. }\end{array}$ & 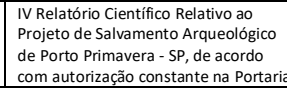 \\
\hline
\end{tabular}




\begin{tabular}{|c|c|c|c|c|c|c|c|c|c|c|c|c|c|c|c|c|}
\hline & & & & & & & & & & & & & & & & $\begin{array}{l}\begin{array}{l}\text { no. } 38 \text {, de } 1 \text { ' de setembro de } 1997 \text {, do } \\
\text { IPHAN }\end{array} \\
\end{array}$ \\
\hline Itaberá & Prassevichus & não & & & & & & $240 \mathrm{~S} 48^{\circ} \mathrm{W}$ & $22 \mathrm{~K}$ & 689494 & 7359456 & & $\begin{array}{l}\text { Biblioteca } \\
\text { MAE }\end{array}$ & 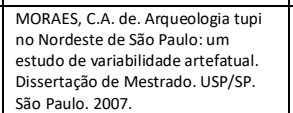 & $\begin{array}{l}\text { PALLESTRINI, L; MORAIS, J.L. de Prasś́vichus - Aldeia } \\
\text { pré-histórica no municíio de Itaberá, SP. Revista do } \\
\text { Museu Paulista. 29:151-168, 1983-1984. }\end{array}$ & 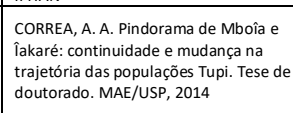 \\
\hline Itaberá & SP PI-8 & não & & & & & & & $22 \mathrm{~K}$ & 689494 & 7359456 & & $\begin{array}{l}\text { Biblioteca } \\
\text { MAE }\end{array}$ & $\begin{array}{l}\text { SCATAMACCHIA, M. C.M. Tentativa } \\
\text { de caracterizäo da tracicăo } \\
\text { tupiguarani. Dissertaçao de } \\
\text { mestrado. USP. São Paulo. } 1981 . \\
\end{array}$ & & \\
\hline Itaberá & SP-IP-8 & não & & & & & & & $22 \mathrm{~K}$ & 689494 & 7359456 & & $\begin{array}{l}\text { Biblioteca } \\
\text { MAE }\end{array}$ & 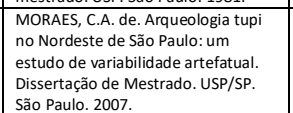 & $\begin{array}{l}\text { CORREA, A. A. Pindorama de Mboîa e ếakaré: } \\
\text { continuidade e mudança na trajetóría das populaçôes } \\
\text { Tupi. Tese de doutorado. MAE/USP, } 2014\end{array}$ & \\
\hline Rosana & JURITI & não & & SAD 69 & 22 & 314769 & \begin{tabular}{|l}
7520 \\
913
\end{tabular} & $\begin{array}{l}2224^{2} 28,2 " \mathrm{~s} 5 \\
47^{\prime} 58,2 \text { "W }\end{array}$ & & & & $\begin{array}{l}\text { SP008 } \\
66\end{array}$ & CNSA & $\begin{array}{l}\text { Projeto de Salvamento Arqueológico } \\
\text { de Porto Primavera, SP. }\end{array}$ & 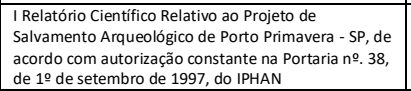 & \\
\hline Itapetininga & Itapetininga 1 & não & & & & & & & $22 \mathrm{~K}$ & 801206 & 7388156 & $\begin{array}{l}\text { Sp } \\
01031\end{array}$ & \begin{tabular}{l|l} 
CNSA e \\
Biblioteca \\
MAE
\end{tabular} & 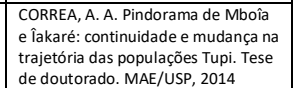 & & \\
\hline Pacaembu & Kandiri & não & & & $22 \mathrm{~K}$ & 475341 & $\begin{array}{l}7618 \\
735\end{array}$ & & & & & & \begin{tabular}{|l} 
Arquivo \\
IPHAN- \\
Relarório \\
s \\
\end{tabular} & 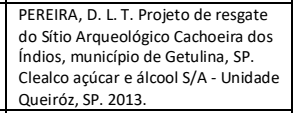 & $\begin{array}{l}\text { FACCIO, N. B. et al. Relatório de prospecção } \\
\text { arqueoológica e do programa de educacăo patrionial } \\
\text { da Rio Vermelho Açúcar e Alcool S/A. Junqueirónolis, } \\
\text { lepê. 2013. }\end{array}$ & \\
\hline Itapeva & $\begin{array}{l}\text { Fazenda } \\
\text { Caputera }\end{array}$ & não & & & & & & & $22 \mathrm{~K}$ & 715742 & 7346051 & & $\begin{array}{l}\text { Biblioteca } \\
\text { MAE }\end{array}$ & \begin{tabular}{|l|} 
SCATAMACCHIA, M. A occupação \\
tupi-iuaranio do ostatod de São \\
Paulo Dedalo. n. .23. 1984. \\
\end{tabular} & 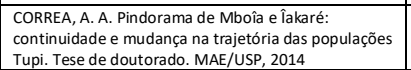 & \\
\hline $\begin{array}{l}\text { Alvares } \\
\text { Machado }\end{array}$ & Kuribayashi & não & & & $22 \mathrm{~K}$ & 444194 & $\begin{array}{l}7554 \\
530\end{array}$ & & & & & & $\begin{array}{l}\text { CNSA e } \\
\text { Biblioteca } \\
\text { MAE }\end{array}$ & 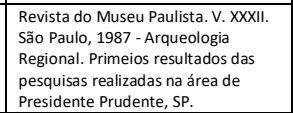 & & \\
\hline $\begin{array}{l}\text { Barra do } \\
\text { Turvo }\end{array}$ & Bugio 4 & não & & & & & & & $22 J$ & 752462 & 7259580 & & $\begin{array}{l}\text { Biblioteca } \\
\text { MAE }\end{array}$ & 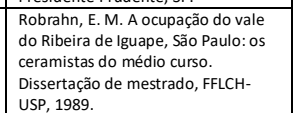 & & Rio Turvo \\
\hline $\begin{array}{l}\text { Barra do } \\
\text { Turvo }\end{array}$ & Bugio 5 & não & & & & & & & $22 J$ & 752462 & 7259580 & & $\begin{array}{l}\text { Biblioteca } \\
\text { MAE }\end{array}$ & 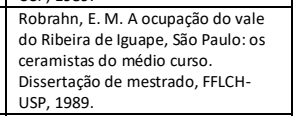 & & Rio Turvo \\
\hline $\begin{array}{l}\text { Barra do } \\
\text { Turvo }\end{array}$ & Bugio 6 & não & & & & & & & $22 J$ & 752462 & 7259580 & & $\begin{array}{l}\text { Biblioteca } \\
\text { MAE }\end{array}$ & 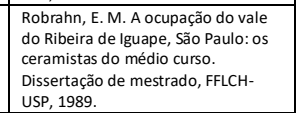 & - & Rio Turvo \\
\hline Iguape & Jaire & $\begin{array}{l}1589 \mathrm{AD} ; \\
40 \mathrm{AC} ; \\
1360 \mathrm{AD} ; \\
1506 \mathrm{AP}\end{array}$ & $\begin{array}{l}\text { Termolumine } \\
\text { scencia (TLL) }\end{array}$ & & & & & & 23J & 241180 & 7265109 & & $\begin{array}{l}\text { Biblioteca } \\
\text { MAE }\end{array}$ & 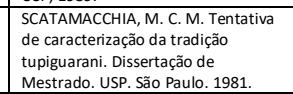 & 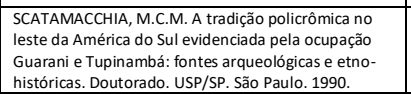 & \\
\hline $\begin{array}{l}\text { Presidente } \\
\text { Epitácio }\end{array}$ & $\begin{array}{l}\text { Lagoa São } \\
\text { Paulo 2 }\end{array}$ & não & & SAD 69 & 22 & 391640 & \begin{tabular}{|l}
7597 \\
939
\end{tabular} & $\begin{array}{l}219243^{\prime} 18 \text { "s } \\
52^{2}-02^{2} 45^{\prime \prime} \mathrm{W}\end{array}$ & & & & & $\begin{array}{l}\text { CNSA e } \\
\text { Biblioteca } \\
\text { MAE }\end{array}$ & 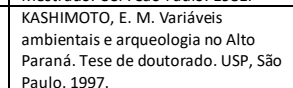 & & \\
\hline Buri & Jango Luis & $\begin{array}{l}980 \pm 100 \\
\text { AP } \\
; ; 1260 \text { AP } \\
; 1540 \pm 150 \\
\text { AP; } 765 \\
\text { AD; } 1076 \\
\text { AP }\end{array}$ & $\begin{array}{l}\text { (Scatamacchi } \\
\text { a- mestrado) }\end{array}$ & & 22 & 754632 & \begin{tabular}{|l}
7392 \\
454
\end{tabular} & $\begin{array}{l}23^{\circ} 33^{\prime \prime S} \\
48^{3} 30^{\prime} \mathrm{W}\end{array}$ & & & & & \begin{tabular}{l|} 
CNSA e \\
Biblioteca \\
MAE
\end{tabular} & 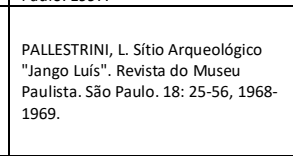 & $\begin{array}{l}\text { POSSE, Z. Populações pré--históricicas de stitios } \\
\text { cerâmicos no interior do Brasili. Doutorado. USP. São } \\
\text { Paulo, } 1984 \text {. }\end{array}$ & 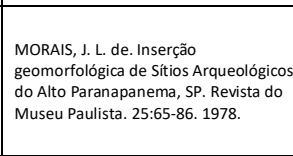 \\
\hline Pereira & Kondo & $1320 \mathrm{AP}$ & & & & & & & $22 \mathrm{~K}$ & 489408 & 7718411 & 25586 & CNSAe & Maranca, 1974; Maranca, silva E & SCATAMACCHIA, M.C.M. Tentativa de caracterização & Museu Paulista - catalogo n. RNA 26 \\
\hline
\end{tabular}




\begin{tabular}{|c|c|c|c|c|c|c|c|c|c|c|c|c|c|c|c|}
\hline Barreto & & ;668 AP & & & & & & & & & & \begin{tabular}{|l|l} 
Biblioteca \\
MAE
\end{tabular} & \begin{tabular}{|l|} 
Scabello, 1994; \\
Scatamacchia, 1981
\end{tabular} & $\begin{array}{l}\text { da tradiçăo tupiguarani. Dissertaçăo de mestrado. } \\
\text { USP. Să Paulo. } 1981 .\end{array}$ & \\
\hline Itaí & Lajeadinho & não & SAS 69 & 22 & 694740 & \begin{tabular}{|l}
7407 \\
699
\end{tabular} & & & & & & $\begin{array}{l}\text { Inventári } \\
{ }^{\circ}\end{array}$ & 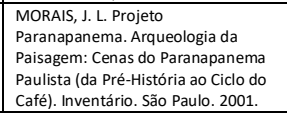 & & \\
\hline Piraju & Lambari & não & SAS 69 & 22 & $\mid 665825$ & $\begin{array}{l}7438 \\
574\end{array}$ & & & & & & $\begin{array}{l}\text { Biblioteca } \\
\text { MAE e } \\
\text { Inventári } \\
\text { o }\end{array}$ & 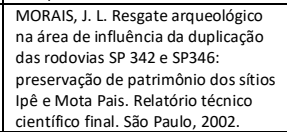 & $\begin{array}{l}\text { CORREA, A. A. Pindorama de Mboîa e Takará: } \\
\text { continuidade e mudança na trajetória das populaçōes } \\
\text { Tupi. Tese de doutorado. MAE/USP, } 2014\end{array}$ & 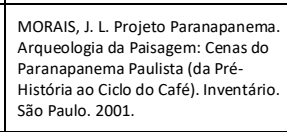 \\
\hline Reginópolis & Lambari & não & SAD 96 & 22 & 692964 & \begin{tabular}{|l}
7582 \\
529
\end{tabular} & & & & & & CNSA & 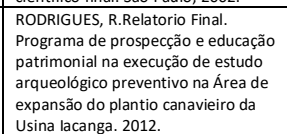 & & \\
\hline $\begin{array}{l}\text { Presidente } \\
\text { Epitácio }\end{array}$ & $\begin{array}{l}\text { Lagoa São } \\
\text { Paulo }\end{array}$ & $\begin{array}{l}760 \pm 100 \\
\text { AP; } 1050\end{array}$ & & 22 & 400004 & $\begin{array}{l}7605 \\
232\end{array}$ & $\begin{array}{l}21039 \text { '12"s } \\
\text { 512557'59"W }\end{array}$ & & & & $\begin{array}{l}\text { SP003 } \\
45\end{array}$ & $\begin{array}{l}\text { CNSA } \\
\text { Biblioteca } \\
\text { MAE }\end{array}$ & 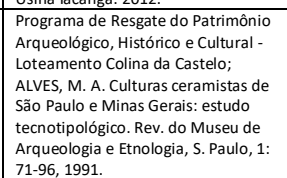 & $\begin{array}{l}\text { PALLESTRINI, L. Sítio arqueológico da Lagoa São } \\
\text { Paulo: Presidente Epitácio- SP. Revista de Pré- } \\
\text { Historia. Sãa Paulo: Instituto de Pré-História da USP, } \\
\text { v. 6. p. 380-410. } 1984\end{array}$ & $\begin{array}{l}\text { KASHIMOTO, E. M. Varíueis } \\
\text { ambientais earqueoologia no Alto } \\
\text { Paraná. Tese de doutorado. USP, São } \\
\text { Paulo. 1997. }\end{array}$ \\
\hline Itapira & Virgolino & กล̃o & & & & & & $23 \mathrm{~K}$ & 312509 & 7517744 & $\begin{array}{l}\text { SP011 } \\
94\end{array}$ & \begin{tabular}{|l} 
CNSA \\
Biblioteca \\
MAE
\end{tabular} & 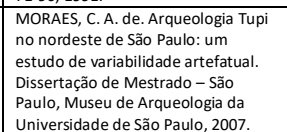 & $\begin{array}{l}\text { CORREA, A. A. Pindorama de Mboîa e Tiakaré: } \\
\text { continuidade e mudanca na trajetória das populaçōes } \\
\text { Tupi. Tese de doutorado. MAE/USP, } 2014\end{array}$ & \\
\hline $\begin{array}{l}\text { Barra do } \\
\text { Turvo }\end{array}$ & Bugio 7 & não & & & & & & $22 J$ & 752462 & 7259580 & & $\begin{array}{l}\text { Biblioteca } \\
\text { MAE }\end{array}$ & 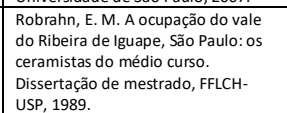 & & Rio Turvo \\
\hline lepê & Lagoa Seca & 770 AP & & & 487099 & $\begin{array}{l}7481 \\
574\end{array}$ & & & & & & \begin{tabular}{|l} 
Biblioteca \\
MAE
\end{tabular} & $\begin{array}{l}\text { FACCIO. N. B. Arqueologia dos } \\
\text { cenários das occupaçoes hoticultoras } \\
\text { da Capivara, buaiox Paranaapanema- } \\
\text { SP. Doutorado. USP/SP. São Paulo. } \\
\text { 1998. }\end{array}$ & 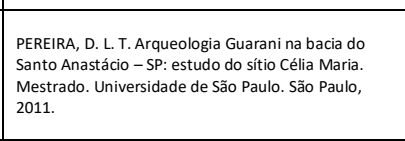 & 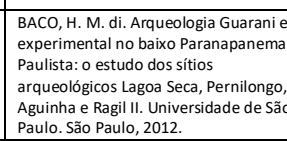 \\
\hline Itararé & Aqueduto & não & & & & & & $22 J$ & 668811 & 7332392 & 25499 & $\begin{array}{l}\text { CNSA e } \\
\text { Biblioteca } \\
\text { MAE }\end{array}$ & 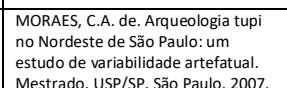 & $\begin{array}{l}\text { CMYZZ, I.; Relatótíio. Programa de Salvamento } \\
\text { Arqueológico no rio Itararé implantado nas áreas dos } \\
\text { rios Itararé }\end{array}$ & \\
\hline Itararé & $\begin{array}{l}\text { Barragem } \\
\text { Maringá }\end{array}$ & não & & & & & & $22 J$ & 668811 & 7332392 & 25481 & \begin{tabular}{|l} 
CNSA \\
Biblioteca \\
MAE
\end{tabular} & 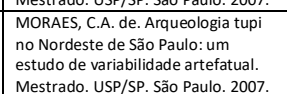 & $\begin{array}{l}\text { CMYZ, I. : Relatóório. Programa de Salvamento } \\
\text { Arqueológico no rio ltararé implantado nas áreas dos } \\
\text { rios Itararé }\end{array}$ & \\
\hline Pirapozinho & Laranjeiras & não & & & 425140 & $\begin{array}{l}7497 \\
350\end{array}$ & $\begin{array}{l}2237^{7} 42^{\prime \prime S} 51 \\
43^{4} 44^{\prime \prime} \mathrm{w}\end{array}$ & & & & & $\begin{array}{l}\text { CNSA e } \\
\text { Inventári } \\
\text { o }\end{array}$ & 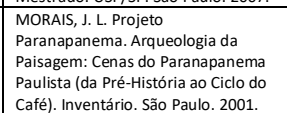 & & \\
\hline $\begin{array}{l}\text { Ribeirão } \\
\text { Grande }\end{array}$ & Leiteria 7 & não & & 22J & \begin{tabular}{|l|l|}
764702 \\
\end{tabular} & $\begin{array}{l}7326 \\
440\end{array}$ & & & & & & CNSA & & & \\
\hline $\begin{array}{l}\text { Ribeirão } \\
\text { Branco }\end{array}$ & Leonir & não & & 22J & 0707226 & \begin{tabular}{|l}
7308 \\
806
\end{tabular} & & & & & & $\begin{array}{l}\text { Biblioteca } \\
\text { MAE }\end{array}$ & $\begin{array}{l}\text { ARAUJO, A; G. M - 2001. Teoria e } \\
\text { método em arqueoologia regional: } \\
\text { um estudd de caso no Alto } \\
\text { Paranapanema, estado de São Paulo, } \\
\text { Tese de douttorado, USP/SP, sâo } \\
\text { Paulo. 2001. }\end{array}$ & & \\
\hline lepê & Lima & não & & & 503538 & \begin{tabular}{|l}
7501 \\
580
\end{tabular} & & & & & & \begin{tabular}{|l} 
Biblioteca \\
MAE
\end{tabular} & $\begin{array}{l}\text { MOREASS.C. A. de. Arqueoologia Tupi } \\
\text { no nordeste de Săo Paulo: um }\end{array}$ & $\begin{array}{l}\text { CORREA, A. A. Pindorama de Mboîa e Îakaré: } \\
\text { continuidade e mudanca na trajetoria das populaçóes }\end{array}$ & \\
\hline
\end{tabular}




\begin{tabular}{|c|c|c|c|c|c|c|c|c|c|c|c|c|c|c|}
\hline & & & & & & & & & & & & 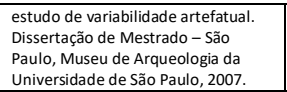 & Tupi. Tese de doutorado. MAE/USP, 2014 & \\
\hline Itararé & $\begin{array}{l}\text { Campo de } \\
\text { futebol da } \\
\text { Usina }\end{array}$ & não & & & & & $22 \mathrm{~J}$ & 668811 & 7332392 & 25482 & $\begin{array}{l}\text { CNSA e } \\
\text { Biblioteca } \\
\text { MAE }\end{array}$ & $\begin{array}{l}\text { MORAES, C.A. de. Arqueologia tupi } \\
\text { no Nordeste de säo Paulo: um } \\
\text { estudo de variabilidade artefatual. } \\
\text { Mestrado. USP/SP. São Paulo. } 2007 .\end{array}$ & $\begin{array}{l}\text { CMYZZ 1.; Relatório. Programa de Salvamento } \\
\text { Arqueológico no rio tararé implantado nas áreas dos } \\
\text { rios ttararé }\end{array}$ & \\
\hline Apiai & Louzarde & não & & $22 J$ & 0707720 & $\begin{array}{l}7306 \\
360\end{array}$ & & & & & $\begin{array}{l}\text { Biblioteca } \\
\text { MAE }\end{array}$ & $\begin{array}{l}\text { ARAUJO, A; G. M- 2001. Teoria e } \\
\text { método em arqueuologia regional: } \\
\text { um estudo de caso no Alto } \\
\text { Paranapanema, estado de Sao Paulo, } \\
\text { Tese de doutorado, USP/SP, Sâo } \\
\text { Paulo. 2001. }\end{array}$ & & \\
\hline $\begin{array}{l}\text { Ribeirão do } \\
\text { Sul }\end{array}$ & Luminé & não & SAD 69 & 22 & 619002 & $\begin{array}{l}7474 \\
386\end{array}$ & & & & $\begin{array}{l}\text { SP011 } \\
11\end{array}$ & CNSA & 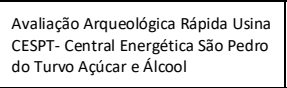 & 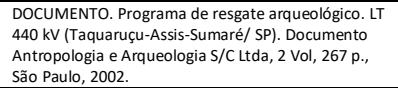 & \\
\hline Flora Rica & Масасо & não & & $22 \mathrm{~K}$ & 450290 & $\begin{array}{l}6010 \\
49\end{array}$ & & & & & $\begin{array}{l}\text { CNSA e } \\
\text { Biblioteca } \\
\text { MAE }\end{array}$ & 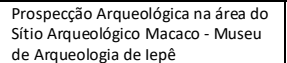 & $\begin{array}{l}\text { FACCio, N. B. et al. Relatótio de Prospecção realizada } \\
\text { na área do Sitio Arquológico Macaco, } 2008 .\end{array}$ & \\
\hline $\begin{array}{l}\text { Presidente } \\
\text { Epitácio }\end{array}$ & $\begin{array}{l}\text { MACAARICO DE } \\
\text { COLEIRA }\end{array}$ & não & SAD 69 & 22 & 388094 & \begin{tabular}{|l}
7618 \\
263
\end{tabular} & & & & $\begin{array}{l}\text { Spoos } \\
67\end{array}$ & CNSA & $\begin{array}{l}\text { Projeto de Salvamento Arqueológico } \\
\text { de Porto Primavera, SP. }\end{array}$ & 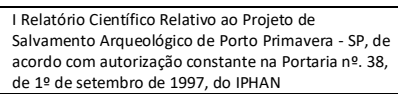 & \\
\hline $\begin{array}{l}\text { Presidente } \\
\text { Epitácio }\end{array}$ & $\begin{array}{l}\text { MACARICO } \\
\text { PRETO }\end{array}$ & não & SAD 69 & 22 & 400081 & $\begin{array}{l}7621 \\
312\end{array}$ & & & & $\begin{array}{l}\text { Spoos } \\
68\end{array}$ & CNSA & $\begin{array}{l}\text { Projeto de Salvamento Arqueológico } \\
\text { de Porto Primavera, SP. }\end{array}$ & 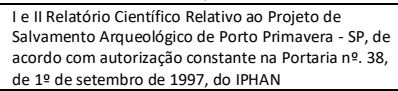 & \\
\hline $\begin{array}{l}\text { Presidente } \\
\text { Epitácio }\end{array}$ & $\begin{array}{l}\text { MAÇARIQUIN } \\
\text { HO }\end{array}$ & não & SAD 69 & 22 & 358232 & $\begin{array}{l}7553 \\
130\end{array}$ & & & & $\begin{array}{l}\text { Spoos } \\
69\end{array}$ & CNSA & $\begin{array}{l}\text { Projeto de Salvamento Arqueológico } \\
\text { de Porto Primavera, SP. }\end{array}$ & 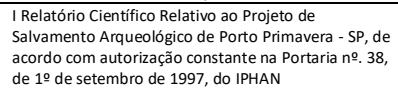 & \\
\hline Paulicéia & MACUCO & não & SAD 69 & 22 & 411390 & \begin{tabular}{|l}
7640 \\
492
\end{tabular} & & & & $\begin{array}{l}\text { SP008 } \\
70\end{array}$ & CNSA & $\begin{array}{l}\text { Projeto de Salvamento Arqueológico } \\
\text { de Porto Primavera, } S \text { P. }\end{array}$ & 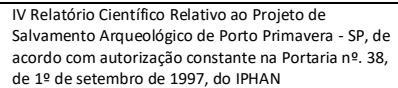 & \\
\hline Castilho & MAGUARI & não & SAD 69 & 22 & 421109 & $\begin{array}{l}7674 \\
015\end{array}$ & & & & $\begin{array}{l}\text { SP0o9 } \\
16\end{array}$ & $\begin{array}{l}\text { CNSA e } \\
\text { Biblioteca } \\
\text { MAE }\end{array}$ & $\begin{array}{l}\text { Projeto de Salvamento Arqueológico } \\
\text { de Porto Primavera, SP. }\end{array}$ & $\begin{array}{l}\text { CORREA, A. A. Pindorama de Mboîa e lîkaré: } \\
\text { continuidade e mudança na trajetoria das populaçoes } \\
\text { Tupi. Tese de doutorado. MAE/USP, } 2014 .\end{array}$ & 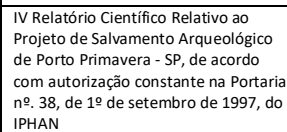 \\
\hline $\begin{array}{l}\text { Nova } \\
\text { Campina }\end{array}$ & Mamangaba & não & & $22 J$ & 0707066 & $\begin{array}{l}3256 \\
29\end{array}$ & & & & & $\begin{array}{l}\text { Biblioteca } \\
\text { MAE }\end{array}$ & $\begin{array}{l}\text { ARAUJO, A; G. M- 2001. Teoria e } \\
\text { método em arqueeologia regional: } \\
\text { um estudo de caso no Alto } \\
\text { Paranapanema, estado de São Paulo, } \\
\text { Tese de douttorado, USP/SP, Sâo } \\
\text { Paulo. 2001. }\end{array}$ & & \\
\hline Itararé & Сара̃о & não & & & & & $22 J$ & 668811 & 7332392 & 25429 & $\begin{array}{l}\text { CNSAe } \\
\text { Biblioteca } \\
\text { MAE }\end{array}$ & 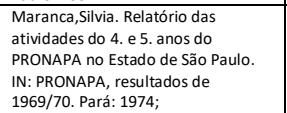 & & \\
\hline $\begin{array}{l}\text { Presidente } \\
\text { Prudente }\end{array}$ & Mandaguari & não & SAD 69 & 22 & 469845 & $\begin{array}{l}7568 \\
265\end{array}$ & & & & & CNSA & 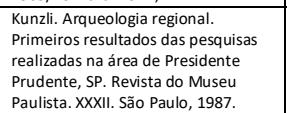 & & \\
\hline Itaporanga & $\begin{array}{l}\text { Acampamento } \\
\text { três } 3\end{array}$ & não & & & & & $22 \mathrm{~K}$ & 654360 & 7377502 & & CNSA & $\begin{array}{l}\text { coleção Museu de Arqueoologia e } \\
\text { Artes Popplares do Departamento } \\
\text { de Antropologia da Universidade } \\
\text { Federal do Paranáa - - gor Chmyz - } \\
\text { 19665 }\end{array}$ & & $\begin{array}{l}\text { descrição a respeito de cerâmica tipo } \\
\text { simples, pintado e corrugado }\end{array}$ \\
\hline Rancharia & Marambaia & não & & & 504464 & $\begin{array}{l}7513 \\
946\end{array}$ & & & & & $\begin{array}{l}\text { Biblioteca } \\
\text { MAE }\end{array}$ & 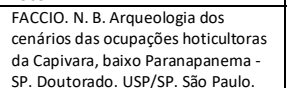 & 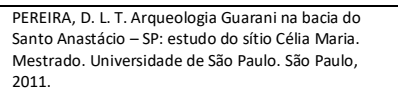 & \\
\hline
\end{tabular}




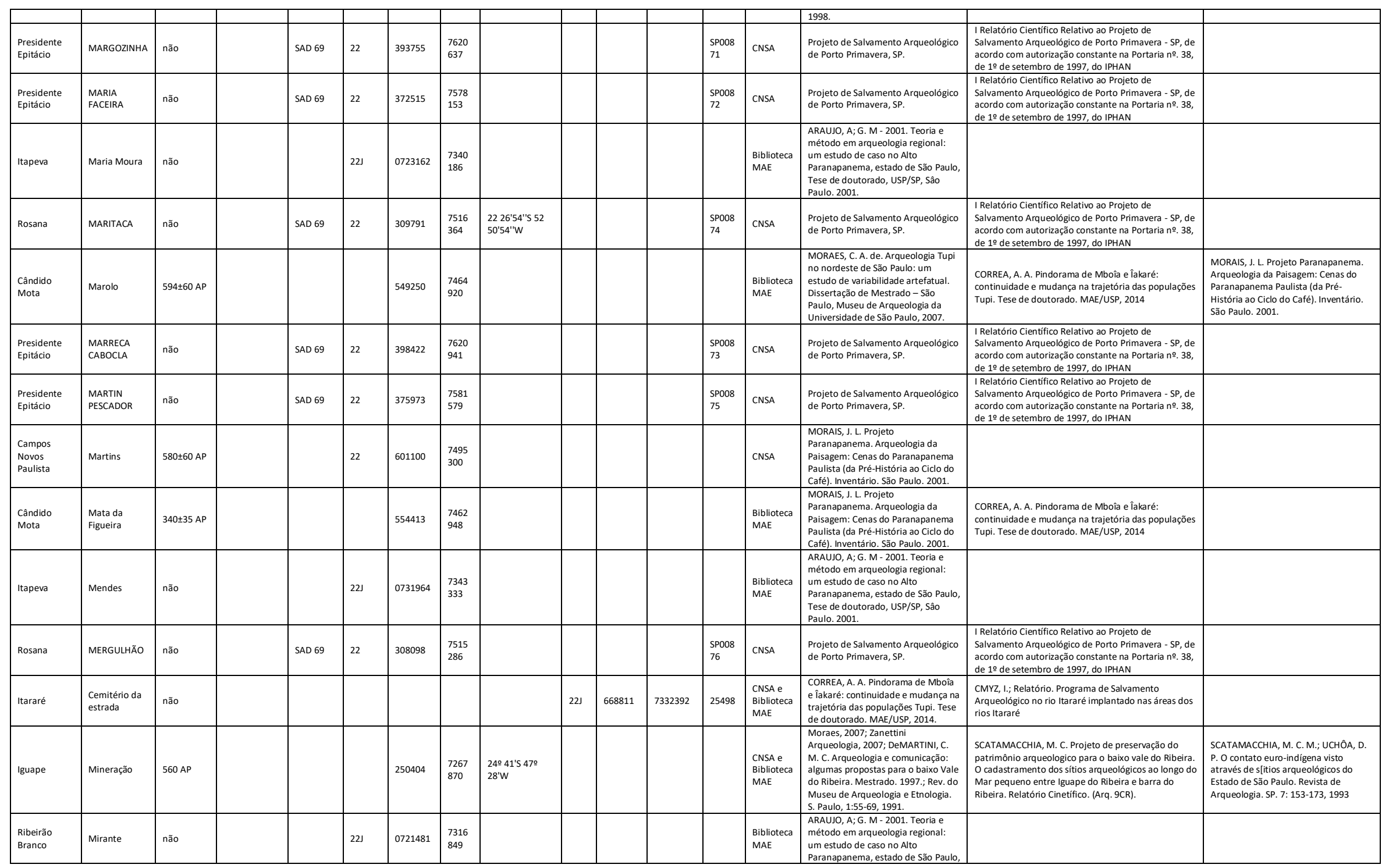




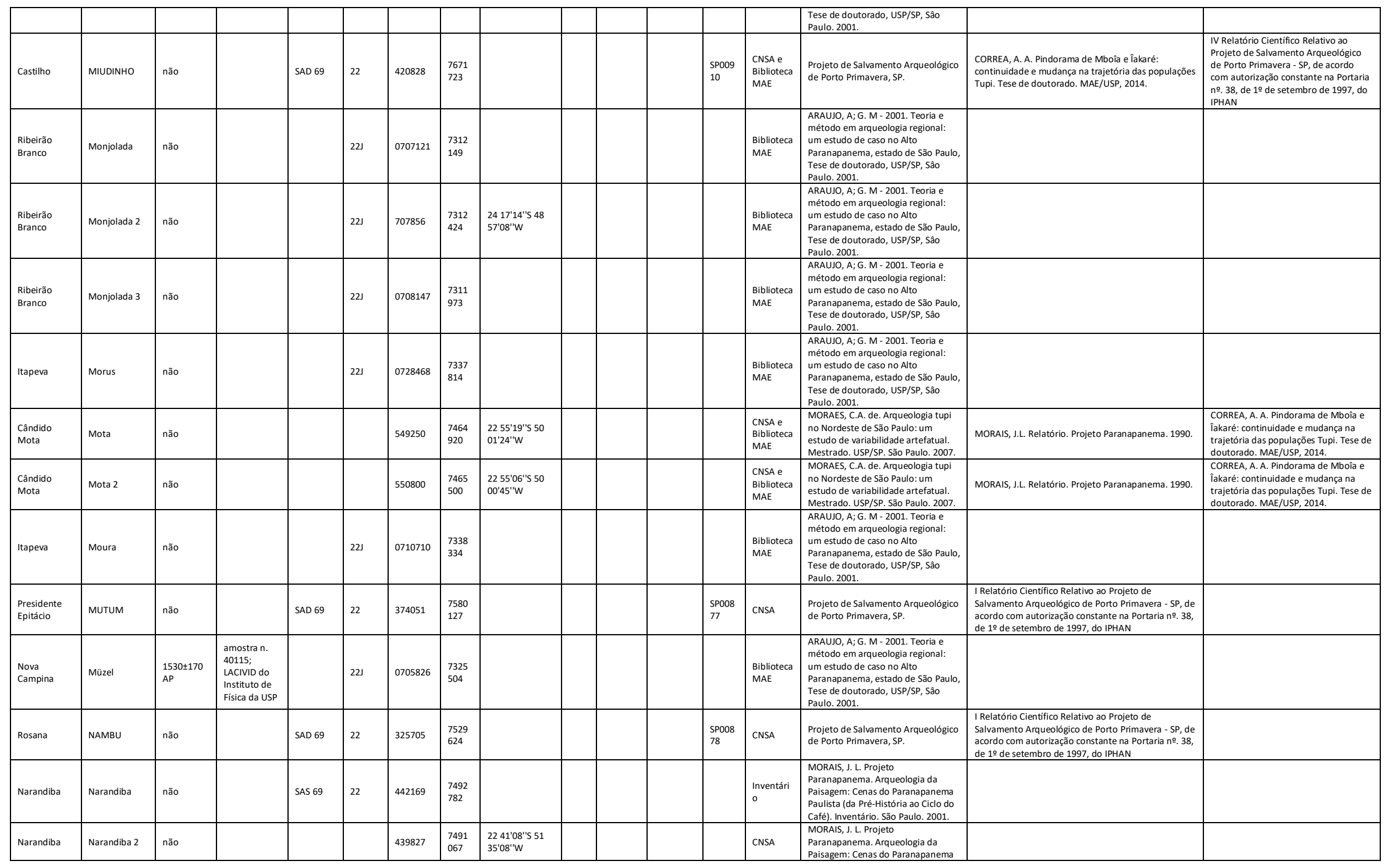




\begin{tabular}{|c|c|c|c|c|c|c|c|c|c|c|c|c|c|c|c|}
\hline & & & & & & & & & & & & & $\begin{array}{l}\text { Paulista (da Pré-História ao Ciclo do } \\
\text { Café). Inventário. Săo Paulo. } 2001 .\end{array}$ & & \\
\hline Narandiba & Narandiba 3 & não & & SAS 69 & 22 & 440662 & \begin{tabular}{|l}
7491 \\
095
\end{tabular} & & & & & $\begin{array}{l}\text { Inventári } \\
\text { • }\end{array}$ & 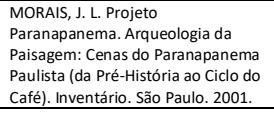 & & \\
\hline Itaporanga & Paredão & não & & & & & & & $22 \mathrm{~K}$ & 654360 & 7377502 & CNSA & $\begin{array}{l}\text { coleçăo Museu de Arqueologia e } \\
\text { Artes Populares do Departamento } \\
\text { de Antropologia da Universidade } \\
\text { Federal do Paranáa - I gor Chmyz - } \\
\text { 19665 }\end{array}$ & & $\begin{array}{l}\text { descrição a respeito de cerâmica tipo } \\
\text { simples, pintado e corrugado }\end{array}$ \\
\hline Itaporanga & $\begin{array}{l}\text { Riacho sem } \\
\text { nome } 1\end{array}$ & não & & & & & & & $22 \mathrm{~K}$ & 654360 & 7377502 & CNSA & 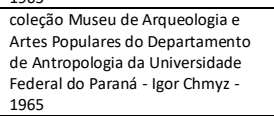 & & \\
\hline $\begin{array}{l}\text { Ribeirão } \\
\text { Branco }\end{array}$ & Neri & não & & & $22 J$ & |0719884 & $\begin{array}{l}7315 \\
435\end{array}$ & & & & & $\begin{array}{l}\text { Biblioteca } \\
M A E\end{array}$ & $\begin{array}{l}\text { ARAUUO, A; G. M - 2001. Teoria e } \\
\text { método em arqueologia regional: } \\
\text { um estudo de casono Alto } \\
\text { Paranapanema, estado do Săo Paulo, } \\
\text { Tese de douttorado, USP/SPP, Sâa } \\
\text { Paulo. 2001. }\end{array}$ & & \\
\hline lepê & Neves & $\begin{array}{l}755 \pm 80 \text { AP; } \\
1800 \mathrm{AP}\end{array}$ & & & & 509761 & \begin{tabular}{|l}
7508 \\
365
\end{tabular} & & & & & $\begin{array}{l}\text { Biblioteca } \\
\text { MAE }\end{array}$ & 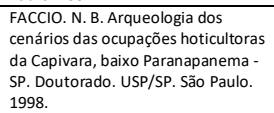 & 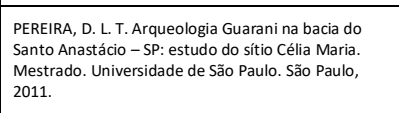 & $\begin{array}{l}\text { A coordenada UTM oferecida na } \\
\text { bibliografifia aponta para o município de } \\
\text { Rancharia }\end{array}$ \\
\hline $\begin{array}{l}\text { Junqueirópoli } \\
s\end{array}$ & Nova Palmeira & não & & & $22 \mathrm{~K}$ & 448492 & \begin{tabular}{|l}
7647 \\
140
\end{tabular} & & & & & $\begin{array}{l}\text { Arquivo } \\
\text { IPHAN- } \\
\text { Relarório } \\
s\end{array}$ & 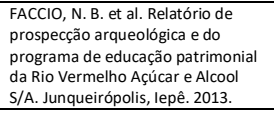 & & \\
\hline Piraju & Nunes & $\begin{array}{l}880 \pm 90 \text { AP } \\
; 879 \pm 80 \\
\text { AP }\end{array}$ & \begin{tabular}{|l} 
Termolumine \\
scência (TL)- \\
Laboratorio \\
de \\
Dosimetria \\
Termolumine \\
scente do \\
Departament \\
o de Fisica \\
Nuclear DA \\
UsP-são \\
Paulo- \\
Equipe erof. \\
Shiigueo \\
Watanabe \\
\end{tabular} & & & 672200 & \begin{tabular}{|l}
7426 \\
000
\end{tabular} & $\begin{array}{l}2315 ' 57 " 549 \\
1858 \text { "W }\end{array}$ & & & & $\begin{array}{l}\text { CNSA } \\
\text { Biblioteca } \\
\text { MAE }\end{array}$ & $\begin{array}{l}\text { MORAIS, J.L. de. } \\
\text { Aerofotoarqueoologia: um estudo de } \\
\text { caso no Projeto Paranaapanema. } \\
\text { Revista do Museu Paulista. } 30 \text { : } 99- \\
\text { 114. 1985. }\end{array}$ & $\begin{array}{l}\text { KASHIMOTO, E. M. Variáveis ambientais e } \\
\text { arqueoologia no Alto Paraná. Tese de doutorado. USP, } \\
\text { Săo Paulo. 1997. }\end{array}$ & \\
\hline $\begin{array}{l}\text { Ribeirão } \\
\text { Branco }\end{array}$ & Olian & não & & & 22J & 0720616 & $\begin{array}{l}7315 \\
892\end{array}$ & & & & & $\begin{array}{l}\text { Biblioteca } \\
\text { MAE }\end{array}$ & $\begin{array}{l}\text { ARAUJO, A; G. M - 2001. Teoria e } \\
\text { método em arqueologia regional: } \\
\text { um estudo de caso no Altog } \\
\text { Paranapanemana, estado de São Paulo, } \\
\text { Tese de doutorado, USP/SPP, Sâa } \\
\text { Paulo. 2001. }\end{array}$ & & \\
\hline $\begin{array}{l}\text { Barra do } \\
\text { Turvo }\end{array}$ & Bugio 8 & não & & & & & & & $22 J$ & 752462 & 7259580 & $\begin{array}{l}\text { Biblioteca } \\
\text { MAE }\end{array}$ & 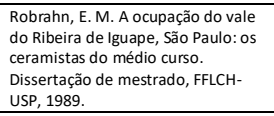 & & Rio Turvo \\
\hline $\begin{array}{l}\text { Campos } \\
\text { Novos } \\
\text { Paulista }\end{array}$ & Onça Otilia & não & & SAD 69 & 22 & 592555 & \begin{tabular}{|l}
7507 \\
627
\end{tabular} & & & & & CNSA & $\begin{array}{l}\text { Diagnóstico Arqueológico não } \\
\text { interventivive em áreas de cana e } \\
\text { futura instalacáá de Agroindústria } \\
\text { de Usina de Açucar e Destiladia de } \\
\text { Álcool Fazenda atsa. Filomena - } \\
\text { Zanettini Arqueologia }\end{array}$ & & \\
\hline $\begin{array}{l}\text { Barra do } \\
\text { Turvo }\end{array}$ & Bugio 9 & não & & & & & & & 22J & 752462 & 7259580 & $\begin{array}{l}\text { Biblioteca } \\
\text { MAE }\end{array}$ & $\begin{array}{l}\text { Robrahn, E.M. A ocupacăo do vale } \\
\text { do Ribeira de ge guape, Săa Paulo: os } \\
\text { ceramistas do médio curso. }\end{array}$ & & Rio Turvo \\
\hline
\end{tabular}




\begin{tabular}{|c|c|c|c|c|c|c|c|c|c|c|c|c|c|c|c|c|}
\hline & & & & & & & & & & & & & & $\begin{array}{l}\text { Dissertacẵo de mestrado, FFLCH- } \\
\text { USP, 1989. }\end{array}$ & & \\
\hline Florinia & Рaca & não & & & & 540130 & \begin{tabular}{|l}
7470 \\
007
\end{tabular} & & & & & & $\begin{array}{l}\text { Biblioteca } \\
M A E\end{array}$ & 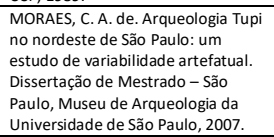 & 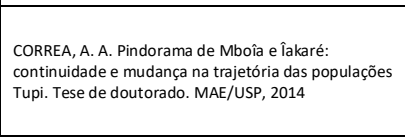 & \\
\hline Piraju & Paineira & não & & SAS 69 & 22 & 665435 & $\begin{array}{l}7438 \\
310\end{array}$ & & & & & & \begin{tabular}{|l} 
Biblioteca \\
MAE e \\
Inventári \\
o \\
\end{tabular} & 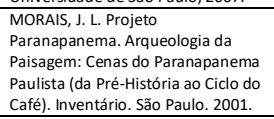 & 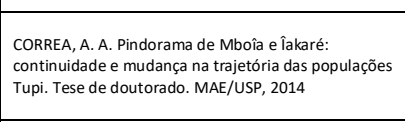 & \\
\hline $\begin{array}{l}\text { Cândido } \\
\text { Mota }\end{array}$ & Pajeú & $\begin{array}{l}875 \pm 90 \text { AP } \\
; 340 \pm 35 \\
\text { AP } \\
; 607 \text { AP }\end{array}$ & & & & 0550000 & $\begin{array}{l}7464 \\
780\end{array}$ & & & & & & MAE & 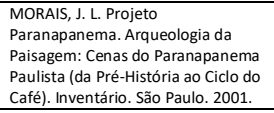 & 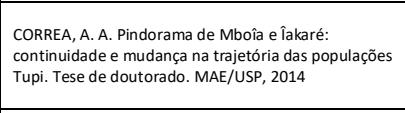 & \\
\hline $\begin{array}{l}\text { Campina do } \\
\text { Monte Alegre }\end{array}$ & Panema & $\begin{array}{l}2030 \pm 200 \\
\text { AP } \\
; 290 \pm 40 \\
\text { AP }\end{array}$ & 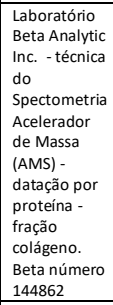 & & $22 \mathrm{~K}$ & 755715 & $\begin{array}{l}7387 \\
730\end{array}$ & & & & & & \begin{tabular}{|l} 
Biblioteca \\
MAE
\end{tabular} & $\begin{array}{l}\text { MORAES, C. A. de. Arqueoologia Tupi } \\
\text { no nordeste de eão Paullo um } \\
\text { estudo de variabilidade artefatual. } \\
\text { Dissertaço de Mestrado - São } \\
\text { Paulo, Museu de Arqueoologia da } \\
\text { Universidade de Săo Paulo, 2007. }\end{array}$ & 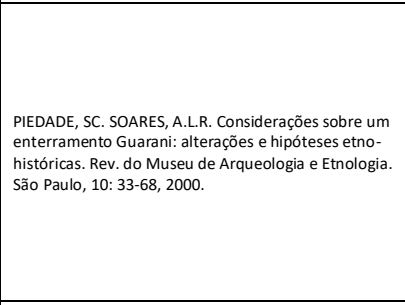 & 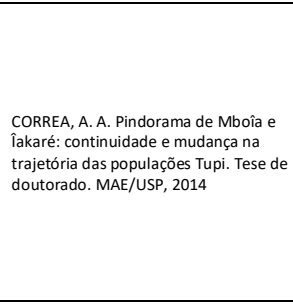 \\
\hline lepê & Pernilongo & $750 \mathrm{AP}$ & & & & & & & $22 \mathrm{~K}$ & 492449 & 7493966 & & $\begin{array}{l}\text { Biblioteca } \\
\text { MAE }\end{array}$ & 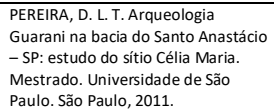 & 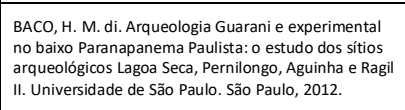 & \\
\hline $\begin{array}{l}\text { Presidente } \\
\text { Epitácio }\end{array}$ & PAPAGAIO & não & & SAD 69 & 22 & 393406 & \begin{tabular}{|l|l|}
7620 \\
605
\end{tabular} & & & & & $\begin{array}{l}\text { SP008 } \\
79\end{array}$ & CNSA & $\begin{array}{l}\text { Projeto de Salvamento Arqueológico } \\
\text { de Porto Primavera, SP. }\end{array}$ & 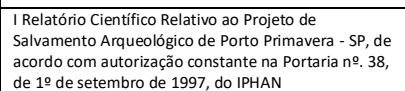 & \\
\hline $\begin{array}{l}\text { Barra do } \\
\text { Turvo }\end{array}$ & Bugre 1 & não & & & & & & & 225 & 752462 & 7259580 & & $\begin{array}{l}\text { CNSA } \\
\text { Biblioteca } \\
\text { MAE }\end{array}$ & 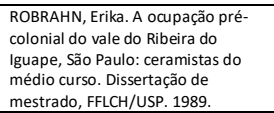 & & proximidade ao rio Bugre \\
\hline Rosana & PARDAL & não & & SAD 69 & 22 & 285839 & \begin{tabular}{|l}
7499 \\
293
\end{tabular} & $\begin{array}{l}2235^{\prime} 59 \text { "s } 53 \\
05^{\circ} 00^{\prime \prime} \mathrm{W}\end{array}$ & & & & $\begin{array}{l}\text { Spoo8 } \\
80\end{array}$ & CNSA & $\begin{array}{l}\text { Projeto de Salvamento Arqueológico } \\
\text { de Porto Primavera, SP. }\end{array}$ & 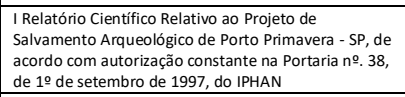 & \\
\hline Itaporanga & $\begin{array}{l}\text { Riacho sem } \\
\text { nome 22 }\end{array}$ & não & & & & & & & $22 \mathrm{~K}$ & 654360 & 7377502 & & CNSA & 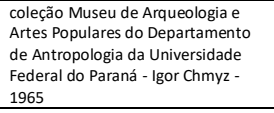 & & \\
\hline Itapeva & Paredão & não & & & 22J & 0724996 & \begin{tabular}{|l}
7339 \\
783
\end{tabular} & & & & & & $\begin{array}{l}\text { Biblioteca } \\
\text { MAE }\end{array}$ & $\begin{array}{l}\text { ARAUUO, A; G. M - 2001. Teoria e } \\
\text { método em arqueologia regional: } \\
\text { um estudo de casono Alto } \\
\text { Paranapanema, estado do São Paulo, } \\
\text { Tese de douttorado, USP/SP, Sâa } \\
\text { Paulo. 2001. }\end{array}$ & & \\
\hline Rosana & $\begin{array}{l}\text { PÁSSARO } \\
\text { PRETO }\end{array}$ & não & & SAD 69 & 22 & 312263 & \begin{tabular}{|l}
7519 \\
369
\end{tabular} & & & & & $\begin{array}{l}\text { Spoo8 } \\
81\end{array}$ & CNSA & $\begin{array}{l}\text { Projeto de Salvamento Arqueológico } \\
\text { de Porto Primavera, SP. }\end{array}$ & 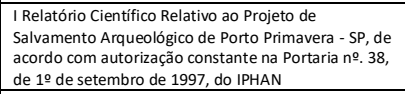 & \\
\hline Paulicéia & PATATIVA & não & & SAD 69 & 22 & 420837 & $\begin{array}{l}7670 \\
846\end{array}$ & & & & & $\begin{array}{l}\text { Spoog } \\
11\end{array}$ & CNSA & $\begin{array}{l}\text { Projeto de Salvamento Arqueológico } \\
\text { de Porto Primavera, SP. }\end{array}$ & 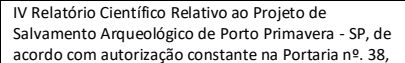 & \\
\hline
\end{tabular}




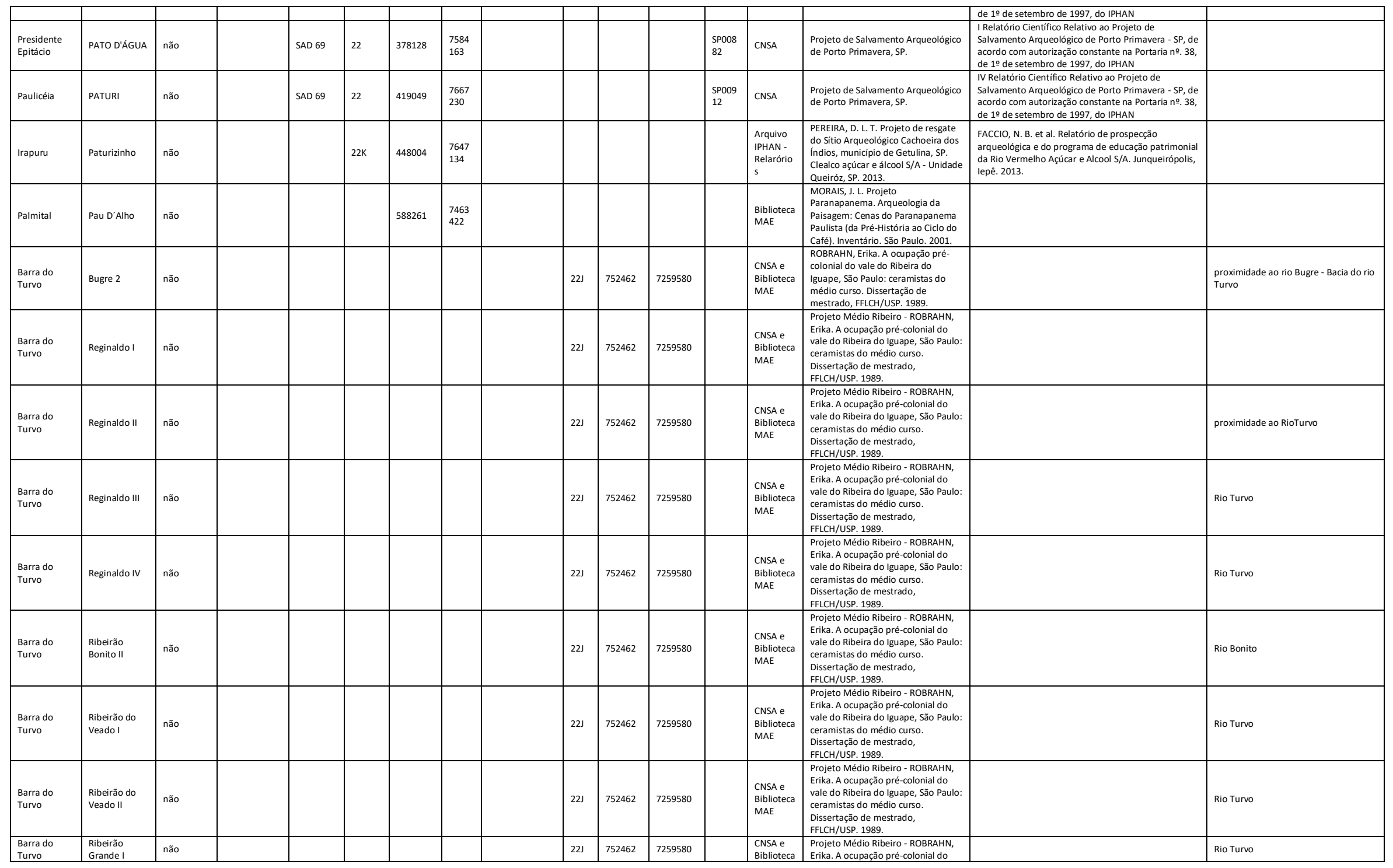




\begin{tabular}{|c|c|c|c|c|c|c|c|c|c|c|c|c|c|c|c|}
\hline & & & & & & & & & & & & MAE & \begin{tabular}{|l} 
vale do Ribeira do Iguape, Săo Paulo: \\
ceramistas do mélio ourso. \\
Dissertaçá de mestrado, \\
FFLCH/USP. 1989. \\
\end{tabular} & & \\
\hline $\begin{array}{l}\text { Barra do } \\
\text { Turvo }\end{array}$ & \begin{tabular}{|l} 
Ribeirão \\
Grande II
\end{tabular} & não & & & & & & $22 \mathrm{~s}$ & 752462 & 7259580 & & $\begin{array}{l}\text { CNSA e } \\
\text { Biblioteca } \\
\text { MAE }\end{array}$ & 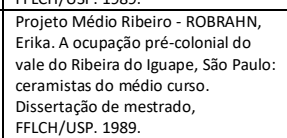 & & Rio Turvo \\
\hline $\begin{array}{l}\text { Barra do } \\
\text { Turvo }\end{array}$ & $\begin{array}{l}\text { Salto Grande } \\
10\end{array}$ & não & & & & & & $22 \mathrm{~s}$ & 752462 & 7259580 & & $\begin{array}{l}\text { Biblioteca } \\
\text { MAE }\end{array}$ & 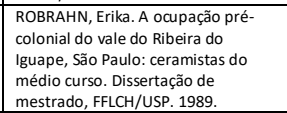 & & Projeto Médio Ribeira \\
\hline $\begin{array}{l}\text { Barra do } \\
\text { Turvo }\end{array}$ & $\begin{array}{l}\text { Salto Grande } \\
11\end{array}$ & não & & & & & & $22 \mathrm{~J}$ & 752462 & 7259580 & & $\begin{array}{l}\text { Biblioteca } \\
\text { MAE }\end{array}$ & 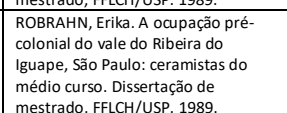 & & Projeto Médio Ribeira \\
\hline Itapeva & Pedra Grande & não & & 22 & 707010 & \begin{tabular}{|l}
7334 \\
390
\end{tabular} & $\begin{array}{l}2405^{2} 21 " 548 \\
57^{\prime} 49^{\circ} \mathrm{W}\end{array}$ & & & & $\begin{array}{l}\text { Spoog } \\
37\end{array}$ & \begin{tabular}{|l} 
CNSA e \\
Biblioteca \\
MAE
\end{tabular} & 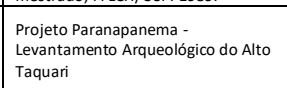 & 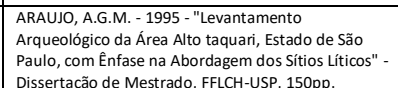 & \\
\hline Itapeva & Pedra Grande & não & & $22 J$ & 0707907 & $\begin{array}{l}7334 \\
314\end{array}$ & & & & & & $\begin{array}{l}\text { Biblioteca } \\
\text { MAE }\end{array}$ & 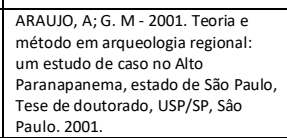 & & \\
\hline Itapeva & Pedra Grande & não & & $22 J$ & 0707760 & $\begin{array}{l}3354 \\
57\end{array}$ & & & & & & $\begin{array}{l}\text { Biblioteca } \\
\text { MAE }\end{array}$ & 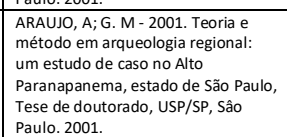 & & \\
\hline Itapeva & $\begin{array}{l}\text { Pedra Grande } \\
2\end{array}$ & não & & 22 & 707760 & \begin{tabular}{|l}
7335 \\
450
\end{tabular} & $\begin{array}{l}240446^{4 \prime} 548 \\
57^{\prime 2} 23^{\prime \prime} \mathrm{W}\end{array}$ & & & & $\begin{array}{l}\text { Spoog } \\
37\end{array}$ & $\begin{array}{l}\text { CNSA e } \\
\text { Biblioteca } \\
\text { MAE }\end{array}$ & \begin{tabular}{|l|}
$\begin{array}{l}\text { Projeto Paranapanema- } \\
\text { Levantamento Arqueológico do Alto } \\
\text { Taquari }\end{array}$ \\
\end{tabular} & 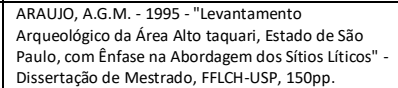 & \\
\hline Piraju & Peixe Canivete & não & SAS 69 & 22 & 666304 & $\begin{array}{l}7437 \\
357\end{array}$ & & & & & & \begin{tabular}{|l} 
Biblioteca \\
MAE e \\
Inventári \\
o
\end{tabular} & 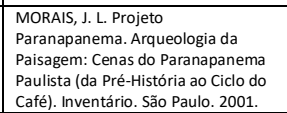 & $\begin{array}{l}\text { CORREA, A. A. Pindorama de Mboîa ễakaré: } \\
\text { continuidade e mudança na trajetória das populaçôs } \\
\text { Tupi. Tese de doutorado. MAE/USP, } 2014\end{array}$ & \\
\hline Penápolis & Penápolis I & não & SAD 69 & 22 & 602253 & \begin{tabular}{|l|l}
7624 \\
348
\end{tabular} & & & & & $\begin{array}{l}\text { Spo10 } \\
52\end{array}$ & $\begin{array}{l}\text { CNSA e } \\
\text { Biblioteca } \\
\text { MAE }\end{array}$ & 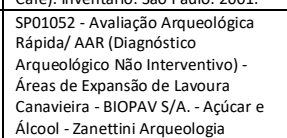 & & \\
\hline Rosana & PERDIZ & não & SAD 69 & 22 & 323618 & $\begin{array}{l}7525 \\
788\end{array}$ & & & & & $\begin{array}{l}\text { Sp008 } \\
83\end{array}$ & CNSA & $\begin{array}{l}\text { Projeto de Salvamento Arqueológico } \\
\text { de Porto Primavera, SP. }\end{array}$ & 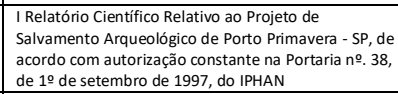 & \\
\hline Tejupá & Pereira & não & & $22 \mathrm{~K}$ & 674610 & $\begin{array}{l}7424 \\
135\end{array}$ & $\begin{array}{l}230^{\circ} 17 \mathrm{~W} \text { 439 } \\
200^{\prime} \mathrm{S}\end{array}$ & & & & 25595 & \begin{tabular}{|l} 
CNSAe \\
Biblioteca \\
MAE
\end{tabular} & \begin{tabular}{|l} 
PALLESTRIIII, L. Traballhos de campo \\
em arqueologia do drasil. Revista do \\
Museu Paulista. Nova Série. V.22. p. \\
113-134. Säo Paulo .1975. \\
\end{tabular} & Projeto Paranapanema & $\begin{array}{l}\text { MORAES, C.A. de. Arqueologia tupi ino } \\
\text { Nordestede Sãa Paulo: um estudode de } \\
\text { variabilidade artetatual Mestrado. } \\
\text { USP/SP. São Paulo. 2007. }\end{array}$ \\
\hline Paulicéia & PERIQUITO & não & & 22 & 420354 & $\begin{array}{l}7672 \\
260\end{array}$ & & & & & $\begin{array}{l}\text { Spoog } \\
15\end{array}$ & CNSA & $\begin{array}{l}\text { Projeto de Salvamento Arqueológico } \\
\text { de Porto Primavera, SP. }\end{array}$ & 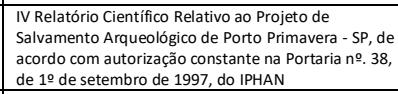 & \\
\hline $\begin{array}{l}\text { Presidente } \\
\text { Epitácio }\end{array}$ & PERNALONGA & não & SAD 69 & 22 & 392575 & $\begin{array}{l}7620 \\
859\end{array}$ & & & & & $\begin{array}{l}\text { Spoo8 } \\
84\end{array}$ & CNSA & $\begin{array}{l}\text { Projeto de Salvamento Arqueológico } \\
\text { de Porto Primavera, SP. }\end{array}$ & 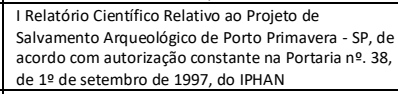 & \\
\hline Itararé & Fazenda & não & & & & & & 221 & 668811 & 7332392 & 25500 & CNSAe & \begin{tabular}{|l} 
MORAES, C.A. de. Arqueologia tupi \\
\end{tabular} & CMYZ, I.; Relatório. Programa de Salvamento & \\
\hline
\end{tabular}




\begin{tabular}{|c|c|c|c|c|c|c|c|c|c|c|c|c|c|c|c|c|}
\hline & Classe 1 & & & & & & & & & & & & \begin{tabular}{|l|}
$\begin{array}{l}\text { Biblioteca } \\
\text { MAE }\end{array}$ \\
\end{tabular} & \begin{tabular}{|l|} 
no Nordeste de Sãa Paulo: um \\
estudo de variabilidade artefatual. \\
Mestrado. USP/SP. Săo Paulo. 2007. \\
\end{tabular} & $\begin{array}{l}\text { Arqueológico no rio Itararé ímplantado nas áreas dos } \\
\text { rios Itararé }\end{array}$ & \\
\hline $\begin{array}{l}\text { Cândido } \\
\text { Mota }\end{array}$ & Peroba & $\begin{array}{l}917 \pm 100 \\
A P\end{array}$ & & & & 597508 & \begin{tabular}{|l}
7467 \\
560
\end{tabular} & & & & & & $\begin{array}{l}\text { Biblioteca } \\
\text { MAE }\end{array}$ & 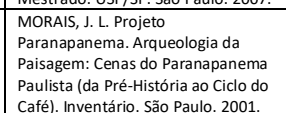 & $\begin{array}{l}\text { CORREA, A. A. Pindorama de Mboîa e lîkaré: } \\
\text { continuidade e mudança na trajetoria das populaçoes } \\
\text { Tupi. Tese de doutorado. MAE/USP, } 2014\end{array}$ & \\
\hline Salto Grande & \begin{tabular}{|l|} 
Peroba Rosa \\
\end{tabular} & não & & & & 597508 & $\begin{array}{l}7467 \\
560\end{array}$ & & & & & & \begin{tabular}{|l|} 
Biblioteca \\
MAE e \\
Inventári \\
o \\
\end{tabular} & 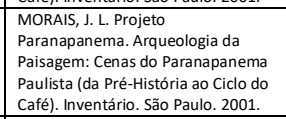 & 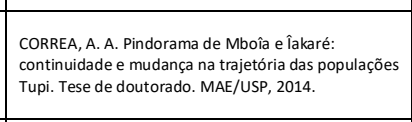 & \\
\hline Piraju & Piapara & 710士70 AP & & SAS 69 & 22 & 666215 & $\begin{array}{l}7438 \\
568\end{array}$ & & & & & & \begin{tabular}{|l|} 
Biblioteca \\
MAE e \\
Inventári \\
o
\end{tabular} & 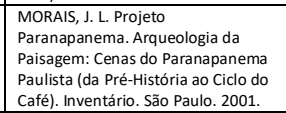 & $\begin{array}{l}\text { CORREA, A. A. Pindorama de Mboîa e îakaré: } \\
\text { continuidade e mudança na trajetơria das populaçoses } \\
\text { Tupi. Tese de doutorado. MAE/USP, } 2014\end{array}$ & \\
\hline Itararé & $\begin{array}{l}\text { Fazenda } \\
\text { Classe 2 }\end{array}$ & não & & & & & & & $22 J$ & 668811 & 7332392 & $\begin{array}{l}\text { Cnsa } \\
25501\end{array}$ & \begin{tabular}{|l|} 
CNSA e \\
Biblioteca \\
MAE
\end{tabular} & 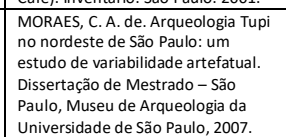 & $\begin{array}{l}\text { CORREA, A. A. Pindorama de Mboîa e îakaré: } \\
\text { continuidade e mudança na trajetoria das populaçōes } \\
\text { Tupi. Tese de doutorado. MAE/USP, } 2014\end{array}$ & \\
\hline Itararé & $\begin{array}{l}\text { Fazenda } \\
\text { Classe } 8\end{array}$ & não & & & & & & & $22 J$ & 668811 & 7332392 & 25501 & \begin{tabular}{|l|} 
CNSA e \\
Biblioteca \\
MAE
\end{tabular} & 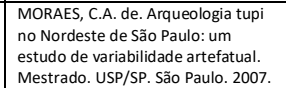 & $\begin{array}{l}\text { CMYZ, li; Relatório. Programa de Salvamento } \\
\text { Arqueológico no rio tararé implantado nas áreas dos } \\
\text { rios tararé }\end{array}$ & \\
\hline Rosana & PICA-PAU & não & & SAD 69 & & 288818 & \begin{tabular}{|l}
7504 \\
024
\end{tabular} & $\begin{array}{l}2233^{\prime 2} 26 " \mathrm{~S} 53 \\
03^{\prime} 13^{\prime \prime} \mathrm{W}\end{array}$ & & & & $\begin{array}{l}\text { SP008 } \\
85\end{array}$ & CNSA & $\begin{array}{l}\text { Projeto de Salvamento Arqueológico } \\
\text { de Porto Primavera, SP. }\end{array}$ & 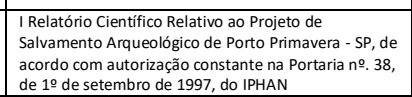 & \\
\hline $\begin{array}{l}\text { Barra do } \\
\text { Turvo }\end{array}$ & $\begin{array}{l}\text { Salto Grande } \\
12\end{array}$ & não & & & & & & & $22 J$ & 752462 & 7259580 & & \begin{tabular}{l|} 
Biblioteca \\
MAE
\end{tabular} & 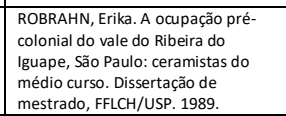 & & Projeto Médio Ribeira \\
\hline lacanga & Pindorama & não & & SAD 69 & 22 & 704215 & \begin{tabular}{|l}
7571 \\
395
\end{tabular} & & & & & & CNSA & 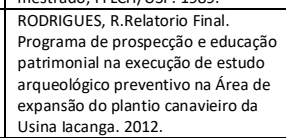 & & \\
\hline Itapeva & Pinha & não & & & $22 J$ & 0723701 & $\begin{array}{l}7339 \\
881\end{array}$ & & & & & & \begin{tabular}{|l|} 
Biblioteca \\
MAE
\end{tabular} & 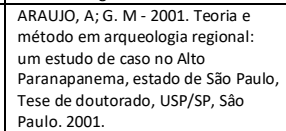 & & \\
\hline Panorama & PINHÉ & não & & SAD 69 & 22 & 403059 & $\begin{array}{l}7623 \\
812\end{array}$ & & & & & $\begin{array}{l}\text { Sp008 } \\
86\end{array}$ & CNSA & \begin{tabular}{|l} 
Projeto de Salvamento Arqueológico \\
de Porto Primavera, SP
\end{tabular} & 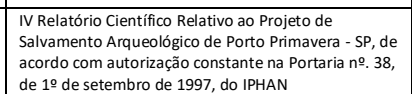 & \\
\hline $\begin{array}{l}\text { Barra do } \\
\text { Turvo }\end{array}$ & $\begin{array}{l}\text { Salto Grande } \\
13\end{array}$ & não & & & & & & & $22 J$ & 752462 & 7259580 & & $\begin{array}{l}\text { Biblioteca } \\
\text { MAE }\end{array}$ & 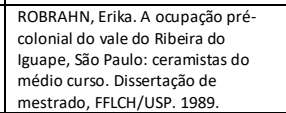 & & Projeto Médio Ribeira \\
\hline Piraju & Pintado & não & & SAS 69 & 22 & 665688 & $\begin{array}{l}7438 \\
768\end{array}$ & & & & & & \begin{tabular}{|l|} 
Biblioteca \\
MAE e \\
inventári \\
o \\
\end{tabular} & 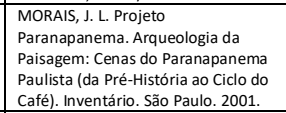 & 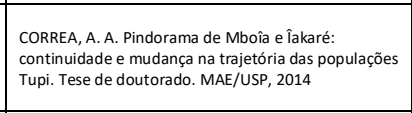 & \\
\hline Paulicéia & PINTASSILGO & não & & SAD 69 & 22 & 409871 & \begin{tabular}{|l}
7661 \\
528
\end{tabular} & & & & & $\begin{array}{l}\text { SP008 } \\
87\end{array}$ & CNSA & $\begin{array}{l}\text { Projetto de Salvamento Arqueológico } \\
\text { de Porto Primavera, SP. }\end{array}$ & 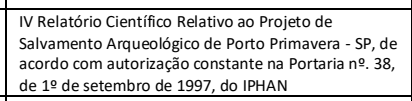 & \\
\hline
\end{tabular}




\begin{tabular}{|c|c|c|c|c|c|c|c|c|c|c|c|c|c|c|c|}
\hline & & $1355 \mathrm{AD}$ & 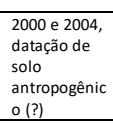 & & & 600 & & & & & & MAE & 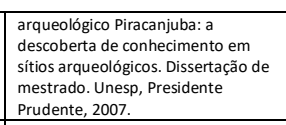 & $\begin{array}{l}\text { Arqueofauna do Sitio Piracanjuba, Piraju - SP. Rev. Do } \\
\text { Museu de Arqueologia e Etnologia, Săo Paulo, 17: } \\
\text { 231-249, 2007. }\end{array}$ & \begin{tabular}{|l|l|} 
da UHE Piraju \\
\end{tabular} \\
\hline Sorocaba & Pirajibu & $\begin{array}{l}415 \pm 105 \\
\text { AP }\end{array}$ & & $23 \mathrm{k}$ & 0256415 & $\begin{array}{l}7404 \\
462\end{array}$ & & & & & & $\begin{array}{l}\text { CNSA e } \\
\text { Biblioteca } \\
\text { MAE }\end{array}$ & $\begin{array}{l}\text { BERNARDO, W. E. Evicências } \\
\text { arqueológicas preliminares en la } \\
\text { region de Sorocaba ; são Paulo- } \\
\text { Brasil. Revista Textos } \\
\text { Antropologicicos. n.8, La Paz.1998. p. } \\
\text { 117-134. }\end{array}$ & $\begin{array}{l}\text { CORREA, A. A. Pindorama de Mboîa e lîkaré: } \\
\text { continuidade e mudança na trajetoria das populaçoes } \\
\text { Tupi. Tese de doutorado. MAE/USP, } 2014\end{array}$ & \\
\hline Itararé & $\begin{array}{l}\text { Ponte estreita } \\
1\end{array}$ & não & & & & & & $22 \mathrm{~J}$ & 668811 & 7332392 & 25502 & \begin{tabular}{|l|} 
CNSA e \\
Biblioteca \\
MAE
\end{tabular} & 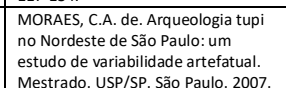 & \begin{tabular}{|l} 
CMYZ, I; Relatório. Programa de Salvamento \\
Arqueológico no rio Itararáe implantado nas áreas dos \\
rios Itararé
\end{tabular} & \\
\hline Itararé & $\begin{array}{l}\text { Ponte estreita } \\
2\end{array}$ & não & & & & & & $22 \mathrm{~J}$ & 668811 & 7332392 & 25503 & \begin{tabular}{|l} 
CNSA \\
Biblioteca \\
MAE
\end{tabular} & 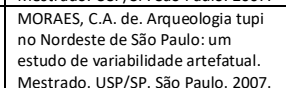 & \begin{tabular}{|l} 
CMYZ, I; Relató́rio. Programa de Salvamento \\
Arqueológico no rio tararáé implantado nas áreas dos \\
rios tararáe
\end{tabular} & \\
\hline $\begin{array}{l}\text { Estrela do } \\
\text { Norte }\end{array}$ & Pirapozinho & não & & 22 & 405639 & $\begin{array}{l}7513 \\
421\end{array}$ & & & & & $\begin{array}{l}\text { SP006 } \\
51\end{array}$ & CNSA & $\begin{array}{l}\text { Programa de Resgate Arqueoológico } \\
\text { da LT 440 kV (Taquarucusu-Sumaré), } \\
\text { são Paulo } \\
\end{array}$ & $\begin{array}{l}\text { CORREA, A.A. Pindorama de Mboîa e êakaré: } \\
\text { continuidade e mudança na trajetoria das populaçōes } \\
\text { Tupi. Tese de doutorado. MAE/USP, } 2014 .\end{array}$ & \\
\hline Itararé & Santa Bárbara & não & & & & & & $22 \mathrm{~J}$ & 668811 & 7332392 & 25429 & $\begin{array}{l}\text { CNSA e } \\
\text { Biblioteca } \\
\text { MAE }\end{array}$ & 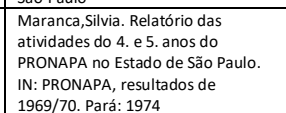 & & \\
\hline Sandovalina & Pirapozinho & não & & $22 \mathrm{~K}$ & 405639 & $\begin{array}{l}7513 \\
421\end{array}$ & & & & & & $\begin{array}{l}\text { Biblioteca } \\
\text { MAE }\end{array}$ & 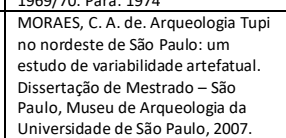 & & \\
\hline Itararé & SP-BA-68 & não & & & & & & $22 \mathrm{~J}$ & 668811 & 7332392 & & $\begin{array}{l}\text { Biblioteca } \\
\text { MAE }\end{array}$ & 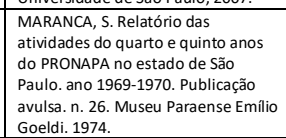 & & \\
\hline Canitar & Poção & não & & 22 & 625371 & \begin{tabular}{|l}
7458 \\
707
\end{tabular} & & & & & & \begin{tabular}{|l} 
Arquivo \\
IPANAN- \\
Relarório \\
s
\end{tabular} & 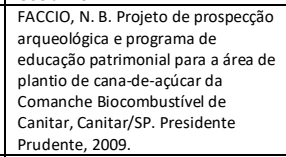 & & \\
\hline Salto Grande & Polidores & não & & & 602700 & $\begin{array}{l}7466 \\
590\end{array}$ & $\begin{array}{l}2245^{\prime} 222^{\prime \prime} 549 \\
59^{\prime} 49^{\prime \prime} \mathrm{W}\end{array}$ & & & & & $\begin{array}{l}\text { Biblioteca } \\
\text { MAE }\end{array}$ & 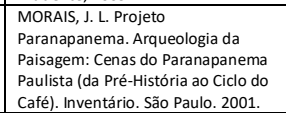 & $\begin{array}{l}\text { CORREA, A. A. Pindorama de Mboîa ễakaré: } \\
\text { continuidade e mudança na trajetoria das populaçōes } \\
\text { Tupi. Tese de doutorado. MAE/USP, } 2014 .\end{array}$ & \\
\hline Paulicéia & РОМВА & não & & 22 & 434637 & \begin{tabular}{|l}
7697 \\
061
\end{tabular} & & & & & $\begin{array}{l}\text { Spoog } \\
77\end{array}$ & CNSA & 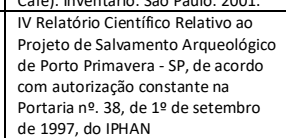 & $\begin{array}{l}\text { Projeto de Salvamento Arqueológico de Porto } \\
\text { Primavera, SP. }\end{array}$ & \\
\hline Castilho & Pomba & não & & 22 & 434637 & $\begin{array}{l}7697 \\
061\end{array}$ & & & & & & CNSA & $\begin{array}{l}\text { Projeto de Salvamento Arqueológico } \\
\text { de Porto Primavera, SP }\end{array}$ & $\begin{array}{l}\text { CORREA, A. A. Pindorama de Mboîa e lâkaré: } \\
\text { continuidadade mudança na trajetória das populaçếes } \\
\text { Tupi. Tese de doutorado. MAE/USP, } 2014 .\end{array}$ & 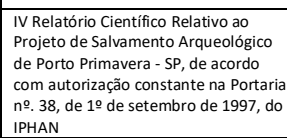 \\
\hline $\begin{array}{l}\text { Laranjal } \\
\text { Paulista }\end{array}$ & $\begin{array}{l}\text { Aldeia do } \\
\text { Porto }\end{array}$ & não & & & & & & $23 \mathrm{~K}$ & 209303 & 7448106 & & $\begin{array}{l}\text { Biblioteca } \\
\text { MAE }\end{array}$ & \begin{tabular}{|l} 
PARI, M. L. et al. Levantamento do \\
Patrimônio arqueológico da regiäo \\
de Monte-Mor-SP. Clio. \\
Arqueológica. n17. 2004. \\
\end{tabular} & & \\
\hline Laranjal & Santo Antônio & \begin{tabular}{|l|l} 
não \\
\end{tabular} & & & & & & $23 \mathrm{~K}$ & 209303 & 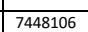 & & Biblioteca & \begin{tabular}{|l} 
Aqued, M. L. et. al al. Levantamento do \\
PAR
\end{tabular} & & \\
\hline
\end{tabular}




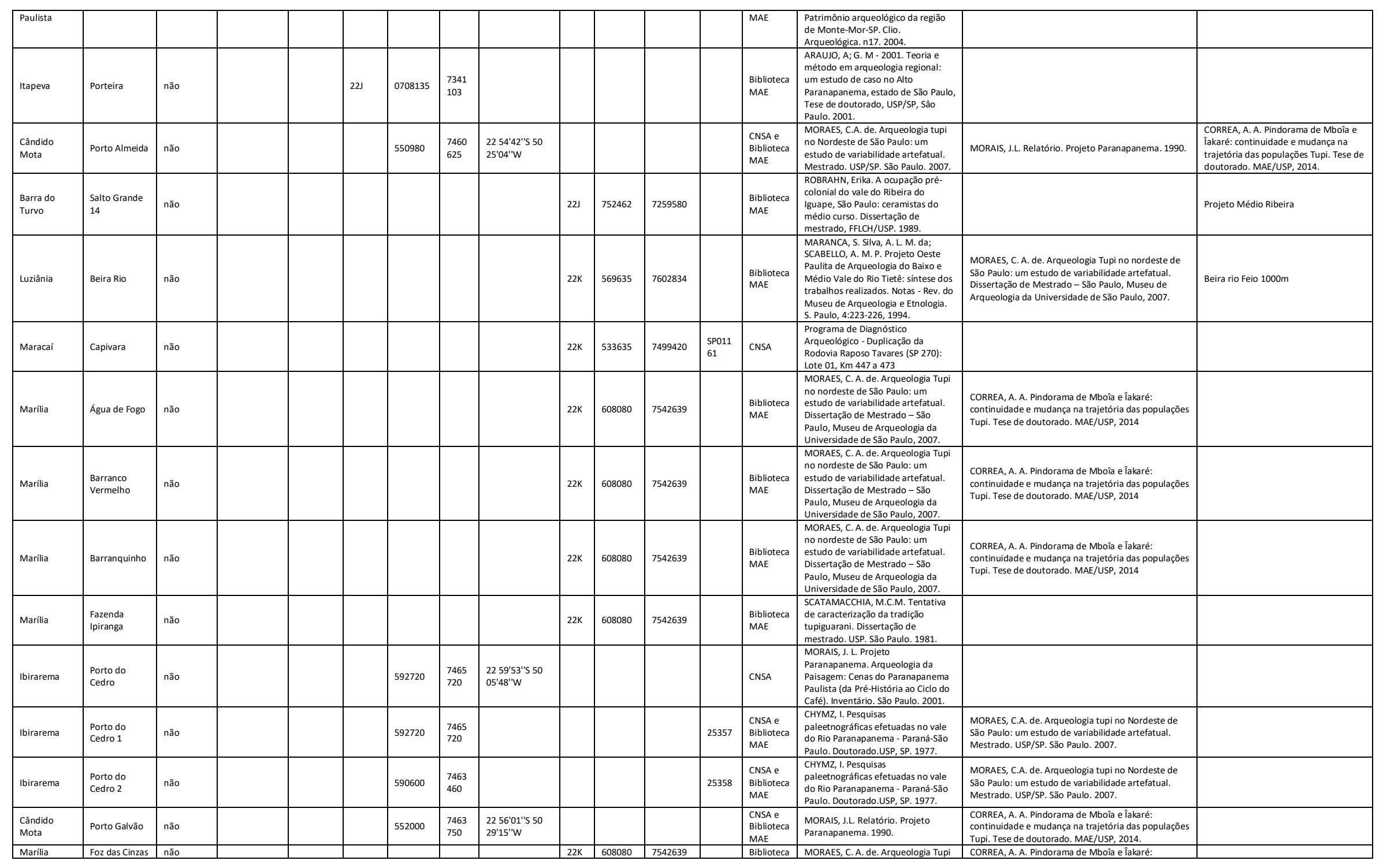




\begin{tabular}{|c|c|c|c|c|c|c|c|c|c|c|c|c|c|c|c|}
\hline & & & & & & & & & & & & MAE & 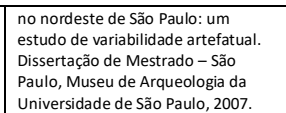 & $\begin{array}{l}\text { continuidade e mudança na trajettória das populaçōes } \\
\text { Tupi. Tese de doutorado. MAE/USP, } 2014\end{array}$ & \\
\hline Martinópolis & Biazi & não & & & & & & $22 \mathrm{~K}$ & 482026 & 7550487 & 25573 & \begin{tabular}{|l|l} 
CNSA e \\
Biblioteca \\
MAE
\end{tabular} & 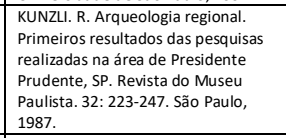 & & Proximidade ao Córrego Figueira \\
\hline Martinópolis & Fachiano & não & & & & & & $22 \mathrm{~K}$ & 482026 & 7550487 & 25574 & \begin{tabular}{|l|} 
CNSA e \\
Biblioteca \\
MAE
\end{tabular} & \begin{tabular}{|l|} 
KUNZLI. R. Arqueologia regional. \\
Primeiros resultados das pesquisas \\
realizadas na área de Presidente \\
Prudente, SP. Revista do Museu \\
Paulista. 32: 223-247. São Paulo, \\
1987. \\
\end{tabular} & & \\
\hline $\begin{array}{l}\text { Mirante do } \\
\text { Paranapane } \\
\text { ma }\end{array}$ & Pirapozinho & não & & & & & & $22 \mathrm{~K}$ & 406488 & 7534268 & \begin{tabular}{|l} 
SP \\
So651
\end{tabular} & \begin{tabular}{|l|} 
CNSA, \\
Biblioteca \\
MAE, \\
Biblioteca \\
empresa \\
\end{tabular} & 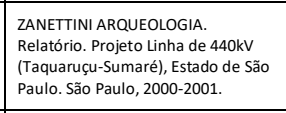 & $\begin{array}{l}\text { MORAES, C.A. de. Arqueoologia tupi no Nordeste de } \\
\text { São Paulo: um estudo de variabilidade artefatual. } \\
\text { Dissertaçấo de Mestrado. USP/SP. São Paullo. } 2007 .\end{array}$ & 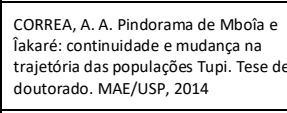 \\
\hline $\begin{array}{l}\text { Monte } \\
\text { Castelo }\end{array}$ & Santo Antônio & não & & & & & & $22 \mathrm{~K}$ & 441015 & 7644462 & & $\begin{array}{l}\text { Biblioteca } \\
\text { MAE }\end{array}$ & 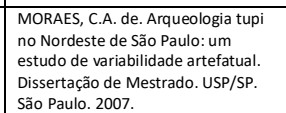 & 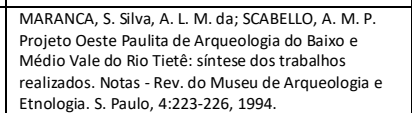 & 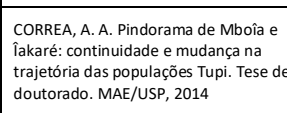 \\
\hline $\begin{array}{l}\text { Cândido } \\
\text { Mota }\end{array}$ & $\begin{array}{l}\text { Porto Galvão } \\
1\end{array}$ & não & & & 552000 & $\begin{array}{l}7463 \\
750\end{array}$ & & & & & 25236 & \begin{tabular}{|l} 
CNSA e \\
Biblioteca \\
MAE
\end{tabular} & 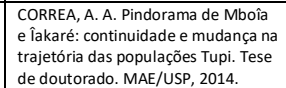 & $\begin{array}{l}\text { MORAESS, C.A. de. Arqueoologia tupi no Nordeste de } \\
\text { Säo Paulo: Um estudo de variabilidade arteftartual. } \\
\text { Mestrado. USP/SP. Săo Paulo. 2007. }\end{array}$ & 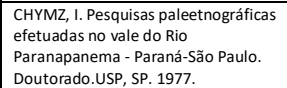 \\
\hline Ourinhos & \begin{tabular}{|l}
$\begin{array}{l}\text { Fazenda Santa } \\
\text { Terezinha }\end{array}$ \\
\end{tabular} & não & & & & & & $22 \mathrm{~K}$ & 615767 & 7458298 & 25583 & \begin{tabular}{|l|} 
CNSA e \\
Biblioteca \\
MAE
\end{tabular} & 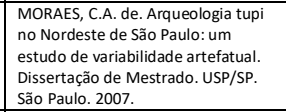 & & \\
\hline $\begin{array}{l}\text { Cândido } \\
\text { Mota }\end{array}$ & $\begin{array}{l}\text { Porto Galvăo } \\
2\end{array}$ & não & & & 550500 & $\begin{array}{l}7462 \\
750\end{array}$ & $\begin{array}{l}2256^{\prime} 32 \text { "s } 50 \\
00^{\prime} 10^{\prime \prime} \mathrm{W}\end{array}$ & & & & 25246 & \begin{tabular}{|l|} 
CNSA e \\
Biblioteca \\
MAE
\end{tabular} & 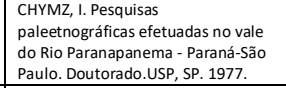 & 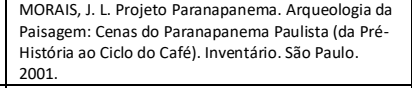 & 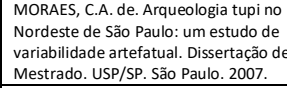 \\
\hline $\begin{array}{l}\text { Palmares } \\
\text { Paulista }\end{array}$ & $\begin{array}{l}\text { Palmares } \\
\text { Paulista } 1\end{array}$ & não & & & & & & $22 \mathrm{~K}$ & 728411 & 7667028 & $\begin{array}{l}\text { SP010 } \\
50\end{array}$ & \begin{tabular}{|l|} 
CNSA e \\
Biblioteca \\
MAE
\end{tabular} & 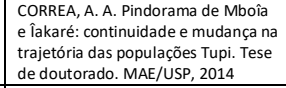 & & \\
\hline $\begin{array}{l}\text { Paraguaçu } \\
\text { Paulista }\end{array}$ & $\begin{array}{l}\text { Água do } \\
\text { Matusalém }\end{array}$ & não & & & & & & $22 \mathrm{~K}$ & 543516 & 7519670 & & $\begin{array}{l}\text { Biblioteca } \\
\text { MAE }\end{array}$ & 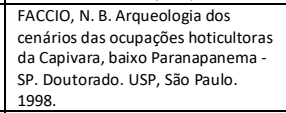 & $\begin{array}{l}\text { CORREA, A. A. Pindorama de Mboîa e lakakaŕ: } \\
\text { continuidade e mudança na trajetória das populaços } \\
\text { Tupi. Tese de doutorado. MAE/USP, } 2014\end{array}$ & \\
\hline $\begin{array}{l}\text { Paraguaçu } \\
\text { Paulista }\end{array}$ & $\begin{array}{l}\text { Água do } \\
\text { Pinhalzinho }\end{array}$ & não & & & & & & $22 \mathrm{~K}$ & 543516 & 7519670 & & $\begin{array}{l}\text { Biblioteca } \\
\text { MAE }\end{array}$ & 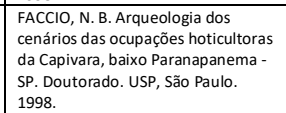 & \begin{tabular}{|l} 
CORREA, A. A. Pindorama de Mboîa e êakaré: \\
continuidade e mudança na trajetoria das populaçoes \\
Tupi. Tese de doutorado. MAE/USP, 2014
\end{tabular} & \\
\hline Parauã & & não & & & & & & $22 \mathrm{~K}$ & 543516 & 7519670 & & $\begin{array}{l}\text { Biblioteca } \\
\text { MAE }\end{array}$ & 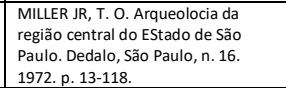 & $\begin{array}{l}\text { CORREA, A. A. Pindorama de Mboîa e êakaré: } \\
\text { continuidade e mudança na trajetoria das populaçoes } \\
\text { Tupi. Tese de doutorado. MAE/USP, } 2014\end{array}$ & \\
\hline Paulicéia & Barranqueiro & não & & & & & & $22 \mathrm{~K}$ & 413702 & 7642841 & $\begin{array}{l}\text { Sp008 } \\
42\end{array}$ & \begin{tabular}{|l} 
CNSA \\
Biblioteca \\
MAE
\end{tabular} & 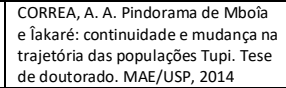 & & \\
\hline Rosana & Porto Maria & não & SAD 69 & 22 & 313890 & $\begin{array}{l}7520 \\
702\end{array}$ & $\begin{array}{l}22 \cdot 24 \text { '35"s } \\
52248 \cdot 29 " \mathrm{~W}\end{array}$ & & & & 25629 & \begin{tabular}{|l} 
Biblioteca \\
MAE
\end{tabular} & 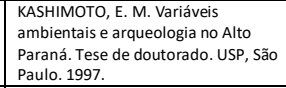 & & \\
\hline Paulicéia & \begin{tabular}{|l|l|}
$\begin{array}{l}\text { Brasilândia } 7- \\
\text { BR7 }\end{array}$ \\
\end{tabular} & não & & & & & & $22 \mathrm{~K}$ & 413702 & 7642841 & & \begin{tabular}{|l|l|} 
Biblioteca \\
MAE
\end{tabular} & $\begin{array}{l}\text { CORREA, A. A. Pindorama de Mbôia } \\
\text { e lakaré: continuidade e mudança na }\end{array}$ & \begin{tabular}{|l} 
KASHIMOTO, E. M. Oalto curso do Rio Paraná: \\
fronteiras ambientais earqueológicas. Teses de livre-
\end{tabular} & \\
\hline
\end{tabular}




\begin{tabular}{|c|c|c|c|c|c|c|c|c|c|c|c|c|c|c|c|c|}
\hline & & & & & & & & & & & & & & \begin{tabular}{|l} 
trajetétria das populaçōes Tupi. Tese \\
de doutorado. MAE/USP, 2014
\end{tabular} & docência. MAE/USP. São Paulo.2007. & \\
\hline Sorocaba & Porto & $\begin{array}{l}415 \pm 105 \\
A P\end{array}$ & & & & & & & $23 \mathrm{~K}$ & 249171 & 7398870 & & $\begin{array}{l}\text { Biblioteca } \\
\text { MAE }\end{array}$ & $\begin{array}{l}\text { BERNARDO, W. E. Evicências } \\
\text { arqueológicas preliminares en la } \\
\text { region de Sorocaba ; } 5 \text { ăo Paulo - } \\
\text { Brasil. Revista Textos } \\
\text { Antropológicos. n.8, La Paz.1998. p. } \\
\text { 117-134. }\end{array}$ & \begin{tabular}{|l} 
CORREA, A. A. Pindorama de Mboîa e lakará: \\
continuidade e mudança na atrajetoria das populaçoses \\
Tupi. Tese de doutorado. MAE/USP, 2014
\end{tabular} & \\
\hline lepê & \begin{tabular}{|l|} 
Porto \\
Casanova 2
\end{tabular} & \begin{tabular}{|l|}
$980 \pm 100$ \\
AP \\
$; 11300150$ \\
AP
\end{tabular} & & & & & & & $22 \mathrm{~K}$ & 492449 & 7493966 & 25360 & \begin{tabular}{|l} 
CNSA \\
Biblioteca \\
MAE
\end{tabular} & $\begin{array}{l}\text { Radicarbon, Vol. 15, n. 2, } 1973 \\
\text { (APUD CORREA, 2014); Noelli, 1999- } \\
\text { 2000; }\end{array}$ & $\begin{array}{l}\text { CHYMZ, I. Pesquiisas paleetnográfícas efetuadas no } \\
\text { vale do Rio Paranapanema - Paraná-São Paulo. } \\
\text { Doutorado. USP, SP. 1977. }\end{array}$ & \\
\hline Rosana & $\begin{array}{l}\text { Porto } \\
\text { Primavera }\end{array}$ & não & & SAD 69 & 22 & 299586 & \begin{tabular}{|l}
7512 \\
001
\end{tabular} & $\begin{array}{l}\text { 22029'12's } \\
52256^{\prime} 53 \text { "W }\end{array}$ & & & & & $\begin{array}{l}\text { Biblioteca } \\
\text { MAE }\end{array}$ & 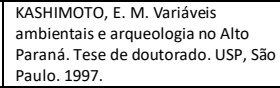 & & sítio destruido segundo a pesquisadora \\
\hline Florinia & $\begin{array}{l}\text { Porto Quebra } \\
\text { Canoa }\end{array}$ & não & & & & 542400 & $\begin{array}{l}7467 \\
000\end{array}$ & $\begin{array}{l}2254^{\prime 155} 500 \\
35^{\prime} 10^{\prime \prime} \mathrm{W}\end{array}$ & & & & & \begin{tabular}{|l} 
CNSA \\
Biblioteca \\
MAE
\end{tabular} & 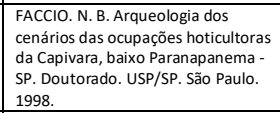 & & \\
\hline Florinia & $\begin{array}{l}\text { Porto Quebra- } \\
\text { Canoa 2 }\end{array}$ & não & & & & 540050 & $\begin{array}{l}4605 \\
50\end{array}$ & & & & & & $\begin{array}{l}\text { Biblioteca } \\
\text { MAE }\end{array}$ & 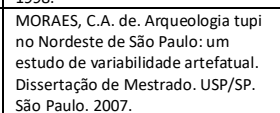 & $\begin{array}{l}\text { CORREA, A. A. Pindorama de Mboîa e lâkaré: } \\
\text { continuidade e mudanca na trajetória das populaçōes } \\
\text { Tupi. Tese de doutorado. MAE/USP, } 2014\end{array}$ & \\
\hline Florínia & $\begin{array}{l}\text { Porto Quebra- } \\
\text { Canoa } 3\end{array}$ & não & & & & 530660 & $\begin{array}{l}7460 \\
750\end{array}$ & & & & & & \begin{tabular}{|l} 
Biblioteca \\
MAE
\end{tabular} & 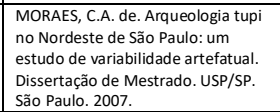 & $\begin{array}{l}\text { CORREA,A.A. Pindorama de Mbốe e lâkaré } \\
\text { continuidade e mudanca na trajetória das populaçōes } \\
\text { Tupi. Tese de doutorado. MAE/USP, } 2014\end{array}$ & \\
\hline $\begin{array}{l}\text { Pereira } \\
\text { Barreto }\end{array}$ & Cinco llthas & não & & & & & & & $22 \mathrm{~K}$ & 489408 & 7718411 & & $\begin{array}{l}\text { Biblioteca } \\
\text { MAE }\end{array}$ & 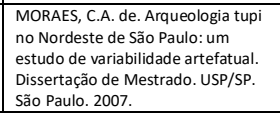 & 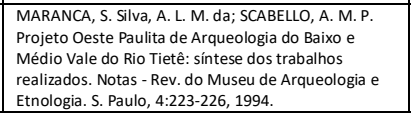 & 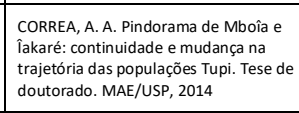 \\
\hline $\begin{array}{l}\text { Bom Sucesso } \\
\text { de Itararé }\end{array}$ & Posse 2 & não & & & 22 & 690477 & \begin{tabular}{|l|l}
7312 \\
278
\end{tabular} & $\begin{array}{l}2417^{\prime} 10549 \\
07^{\prime 2} 25^{\prime \prime} \mathrm{W}\end{array}$ & & & & \begin{tabular}{|l|l|} 
SP0099 \\
56
\end{tabular} & CNSA & & & \\
\hline Itapeva & Pouso Alto & não & & & $22 J$ & 698040 & $\begin{array}{l}7335 \\
560\end{array}$ & 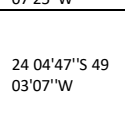 & & & & $\begin{array}{l}\text { SP009 } \\
48\end{array}$ & \begin{tabular}{|l} 
CNSA \\
Biblioteca \\
MAE
\end{tabular} & 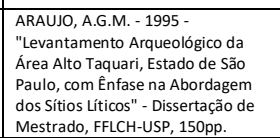 & 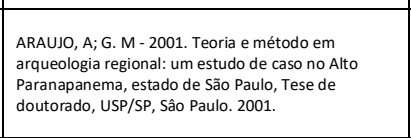 & \begin{tabular}{|l} 
Projeto Paranapanema - Levantamento \\
Arqueológicico do Alto Taquari
\end{tabular} \\
\hline Apiai & Quatis & $\begin{array}{l}1160 \pm 110 \\
\text { AP; } 740 \\
\text { AD; } 940 \text { AD }\end{array}$ & \begin{tabular}{|l|} 
Laboratórió \\
de Vidrose \\
Dataçes da \\
FATES das \\
amostra LvD \\
340 \\
340
\end{tabular} & & $22 J$ & 0713009 & $\begin{array}{l}7304 \\
883\end{array}$ & & & & & & $\begin{array}{l}\begin{array}{l}\text { Biblioteca } \\
\text { MAE }\end{array} \\
\end{array}$ & $\begin{array}{l}\text { ARAUJO, A; G. M - 2001. Teeria e } \\
\text { método em arqueologia regional: } \\
\text { um estuddo de casono Alto } \\
\text { Paranapanema, estado do São Paulo, } \\
\text { Tese de deutoradodo, USP/SP, Sâo } \\
\text { Paulo. 2001. }\end{array}$ & & \\
\hline Itai & \begin{tabular}{|l} 
Prassévichus \\
\end{tabular} & não & & & & 692800 & \begin{tabular}{|l}
7383 \\
000
\end{tabular} & $\begin{array}{l}2339^{\prime} 0^{\circ 0 " 5} 49 \\
066^{\circ} 0^{\circ} \mathrm{W}\end{array}$ & & & & & CNSA & 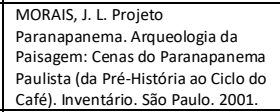 & & \\
\hline $\begin{array}{l}\text { Cândido } \\
\text { Mota }\end{array}$ & Primavera & não & & & & 566241 & $\begin{array}{l}7465 \\
415\end{array}$ & & & & & & \begin{tabular}{|l} 
Arquivo \\
IPANAN- \\
Relarorio \\
$\mathrm{s}$
\end{tabular} & 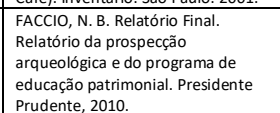 & & \\
\hline lepê & Ragil & $\begin{array}{l}1660 \pm 170 \\
\mathrm{AP} ; \\
1668 \mathrm{AP} ; \\
1668 \mathrm{AP}\end{array}$ & & & & 496309 & \begin{tabular}{|l}
7483 \\
967
\end{tabular} & & & & & & $\begin{array}{l}\text { Biblioteca } \\
\text { MAE }\end{array}$ & \begin{tabular}{|l|} 
FACCIO. N. B. Arqueologia dos \\
cenários das ocupacóes hoticultoras \\
da Capivara, baixo Paranapanema- \\
SP. Doutorado. USP/SP. Săo Paulo. \\
1998.
\end{tabular} & 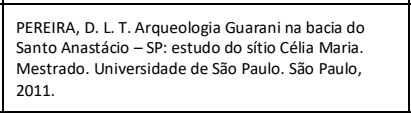 & \\
\hline $\begin{array}{l}\text { Pereira } \\
\text { Barreto }\end{array}$ & SP PD-2 & não & & & & & & & $22 \mathrm{~K}$ & 489408 & 7718411 & & $\begin{array}{l}\text { Biblioteca } \\
\text { MAE }\end{array}$ & $\begin{array}{l}\text { SCATAMACCHIA, M.C.M. Tentativa } \\
\text { de caracterizacăo da tradição }\end{array}$ & & \\
\hline
\end{tabular}




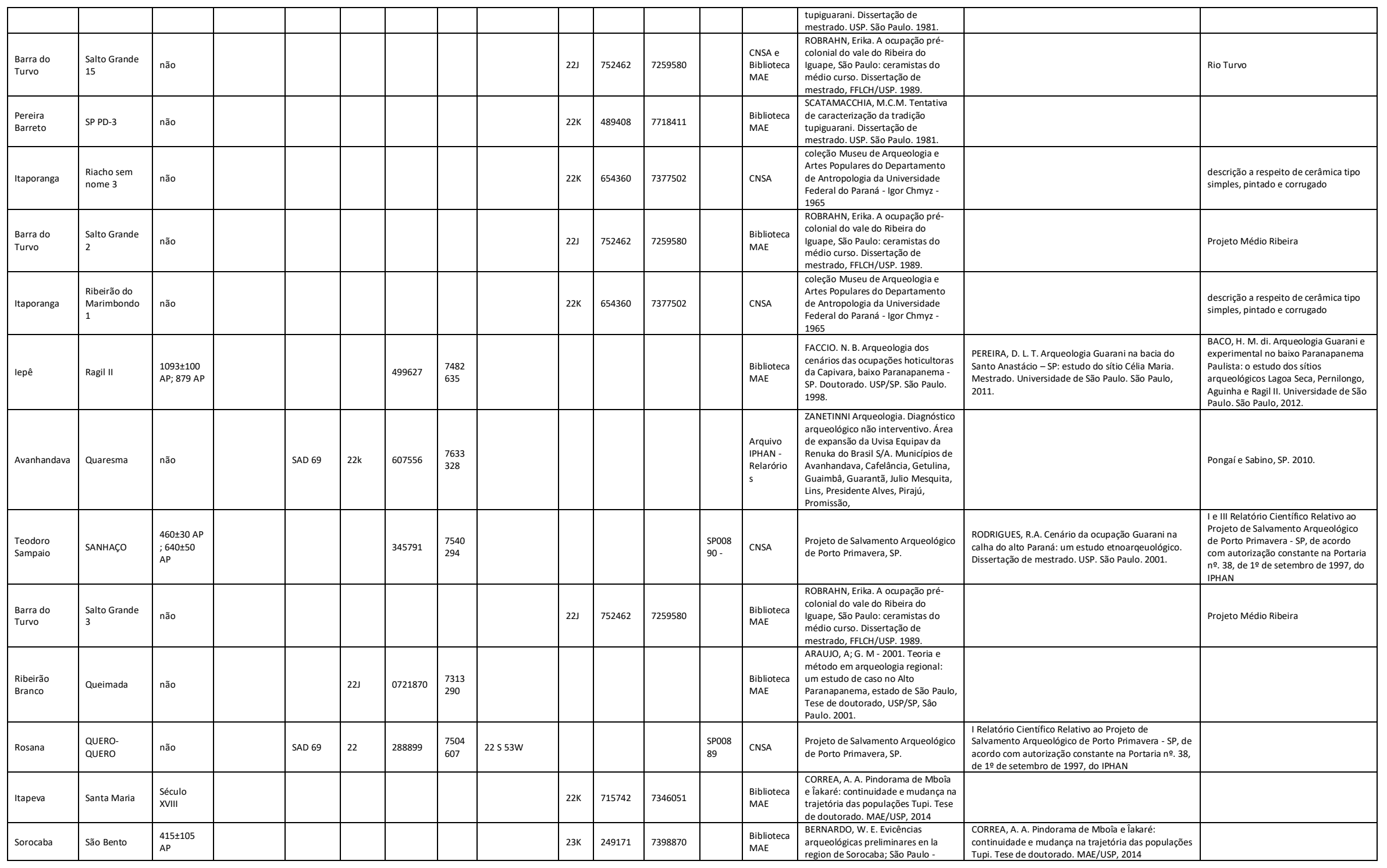




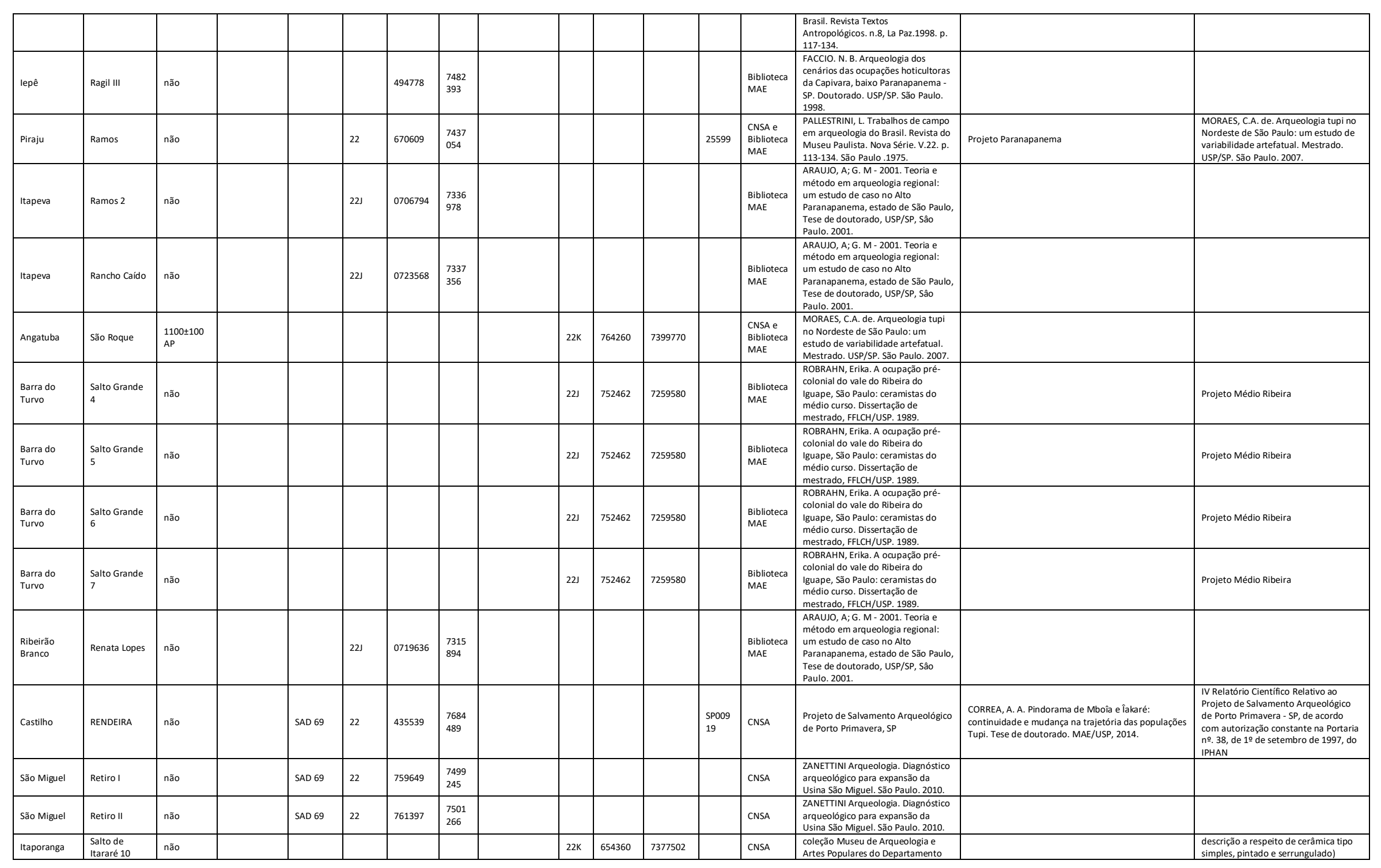




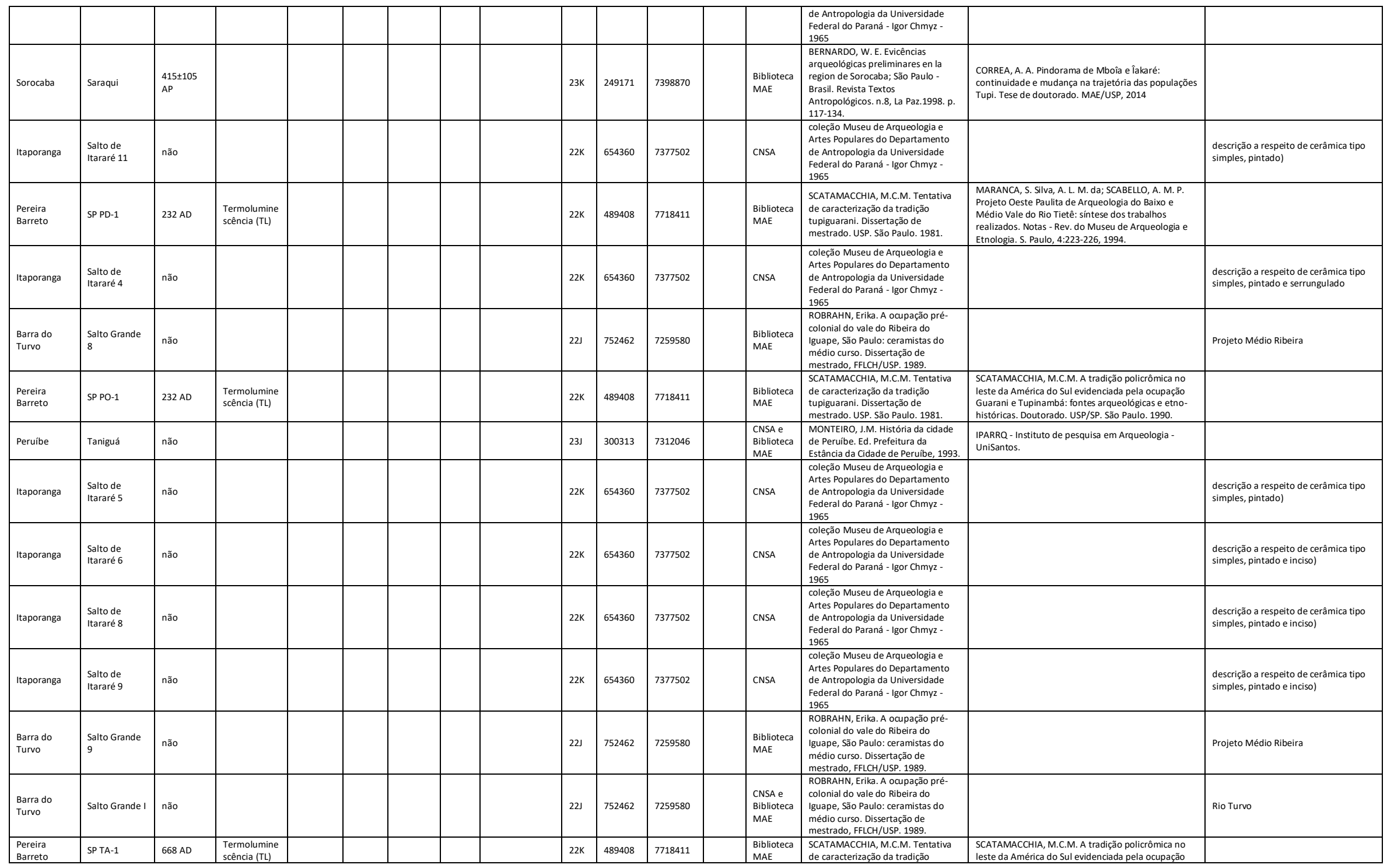




\begin{tabular}{|c|c|c|c|c|c|c|c|c|c|c|c|c|c|c|}
\hline & & & & & & & & & & & & \begin{tabular}{|l|} 
tupiguarani. Dissertaçăo de \\
mestrado. USP. Săo Paulo. 1981.
\end{tabular} & 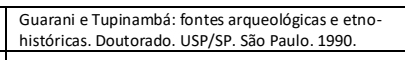 & \\
\hline Fartura & \begin{tabular}{|l} 
Estrada Velha \\
de Fartura
\end{tabular} & não & & & & & $22 \mathrm{~K}$ & 652119 & 7412484 & & CNSA & $\begin{array}{l}\text { CHMYZ, I.; Relatório. Programa de } \\
\text { Salvamento Arqueológico no rio } \\
\text { Itraráé }\end{array}$ & & Rio Itararé \\
\hline Peruibe & Taninguá & não & & & & & 23J & 300313 & 7312046 & & \begin{tabular}{|l|l} 
Biblioteca \\
MAE
\end{tabular} & 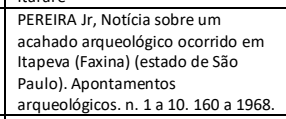 & $\begin{array}{l}\text { CORREA, A. A. Pindorama de Mboia e êakaré: } \\
\text { continuidade e mudança na trajettoria das populaçôs } \\
\text { Tupi. Tese de doutorado. MAE/USP, } 2014\end{array}$ & \\
\hline lacanga & $\begin{array}{l}\text { Riberiāozinho } \\
1\end{array}$ & não & SAD 69 & 22 & 703874 & $\begin{array}{l}7585 \\
615\end{array}$ & & & & & CNSA & 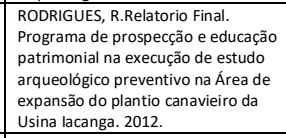 & & \\
\hline lacanga & $\begin{array}{l}\text { Riberiăozinho } \\
\text { II }\end{array}$ & não & SAD 69 & 22 & 702481 & \begin{tabular}{|l}
7584 \\
653
\end{tabular} & & & & & CNSA & 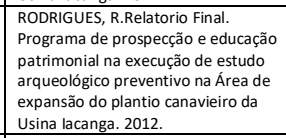 & & \\
\hline $\begin{array}{l}\text { Ribeirão } \\
\text { Branco }\end{array}$ & Ribeiro & não & & $22 J$ & 0719311 & \begin{tabular}{|l}
7313 \\
536
\end{tabular} & & & & & $\begin{array}{l}\text { Biblioteca } \\
\text { MAE }\end{array}$ & $\begin{array}{l}\text { ARAUJO, A; G. M - 2001. Teoria e } \\
\text { método em arqueologia regional: } \\
\text { um estudodo de caso no Alto } \\
\text { Paranapanema, estado de Săo Paulo, } \\
\text { Tese de doutorado, USP/SP, Sâo } \\
\text { Paulo. 2001. }\end{array}$ & & \\
\hline $\begin{array}{l}\text { Ribeirão } \\
\text { Branco }\end{array}$ & Ribeiro 2 & não & & $22 J$ & $\mid 0718319$ & \begin{tabular}{|l}
7313 \\
695
\end{tabular} & & & & & $\begin{array}{l}\text { Biblioteca } \\
\text { MAE }\end{array}$ & $\begin{array}{l}\text { ARAUJO, A; G. M - 2001. Teeria e } \\
\text { método em arqueologia regional: } \\
\text { um estuddo ole casono Alto } \\
\text { Paranapanema, estado de São Paulo, } \\
\text { Tese de doutorado, USP/SP, Sầ } \\
\text { Paulo. 2001. }\end{array}$ & & \\
\hline Fartura & $\begin{array}{l}\text { Estrada Velha } \\
\text { de Fartura } 2\end{array}$ & não & & & & & $22 \mathrm{~K}$ & 652119 & 7412484 & & CNSA & \begin{tabular}{|l|} 
CHMYZZ, l, R Relatório. Programa de \\
Salvamento Arqueológico no rio \\
Itararé
\end{tabular} & & Rio Itararé \\
\hline Fartura & $\begin{array}{l}\text { Fazenda Rizzo } \\
2\end{array}$ & não & & & & & $22 \mathrm{~K}$ & 652119 & 7412484 & & CNSA & $\begin{array}{l}\text { CHMYZ, I.; Relatório. Programa de } \\
\text { Sallavanento Arqueoologico no rio } \\
\text { Itararé }\end{array}$ & & Rio Itararé \\
\hline Fartura & Laranjal 3 & não & & & & & $22 \mathrm{~K}$ & 652119 & 7412484 & & \begin{tabular}{|l|l|} 
CNSA e \\
Biblioteca \\
MAE \\
\end{tabular} & $\begin{array}{l}\text { CHMYZ, I; Relatório. Programa de } \\
\text { Salvamento Arqueoológico no rio } \\
\text { Itararé }\end{array}$ & 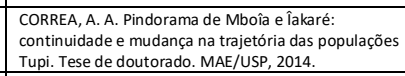 & Rio Itararé \\
\hline Fartura & $\begin{array}{l}\text { Primeira volta } \\
3\end{array}$ & não & & & & & $22 \mathrm{~K}$ & 652119 & 7412484 & & CNSA & \begin{tabular}{|l} 
CHMYZ, I., Relatário. Programa de \\
Salvamento Arqueologicic no rio \\
Itararé
\end{tabular} & & Rio Itararé \\
\hline $\begin{array}{l}\text { Campos } \\
\text { Novos } \\
\text { Paulista }\end{array}$ & $\begin{array}{l}\text { Rio novo dos } \\
\text { Martins }\end{array}$ & não & SAD 69 & 22 & 600905 & $\begin{array}{l}7496 \\
324\end{array}$ & & & & & CNSA & \begin{tabular}{|l|} 
Diagnóstico Arqueológico não \\
interventivo em áreas de cana e \\
futurua instalaçấo de Agroindústria \\
de Usina de Açúcar e Destiladia de \\
Álcool Fazenda Sta. Filomena - \\
Zanettini Arqueologia \\
\end{tabular} & & \\
\hline $\begin{array}{l}\text { Ribeirão do } \\
\text { Sul }\end{array}$ & $\begin{array}{l}\text { Rio Novo dos } \\
\text { Martins }\end{array}$ & não & SAD 69 & $22 \mathrm{~K}$ & 600905 & $\begin{array}{l}7496 \\
324\end{array}$ & & & & & $\begin{array}{l}\text { Arquivo } \\
\text { IPHAN- } \\
\text { Relarório } \\
\text { s }\end{array}$ & 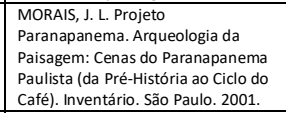 & & \\
\hline Piraju & \begin{tabular}{|l} 
Arraia (PRJ \\
22.726.352)
\end{tabular} & não & & & & & $22 \mathrm{~K}$ & 666018 & 7433795 & & $\begin{array}{l}\text { Biblioteca } \\
\text { MAE }\end{array}$ & 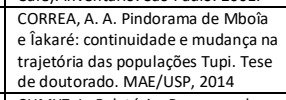 & & \\
\hline Fartura & $\begin{array}{l}\text { Primeira volta } \\
6\end{array}$ & não & & & & & $22 \mathrm{k}$ & 652119 & 7412484 & & CNSA & $\begin{array}{l}\text { CHMYZ, I., Relatáó́io. Programa de } \\
\text { Salvamento Arqueológico no rio } \\
\text { Itararé }\end{array}$ & & Rio Itararé \\
\hline Fartura & Rio Verde 1 & não & sols & & 201700 & 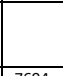 & $22 \mathrm{~K}$ & 652119 & 7412484 & 5000 & CNSA & $\begin{array}{l}\text { CHMYZ, l.; Relatório. Programa de } \\
\text { Salvamento Arqueológico no rio } \\
\text { Itararé }\end{array}$ & 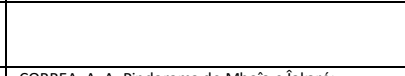 & Rio Itararé \\
\hline
\end{tabular}




\begin{tabular}{|c|c|c|c|c|c|c|c|c|c|c|c|c|c|c|c|}
\hline & & & & & & 789 & & & & & 22 & & \begin{tabular}{|l|} 
de Porto Primavera, SP \\
\end{tabular} & $\begin{array}{l}\text { continuidade mudança na trajettória das populaç̧̄es } \\
\text { Tupi. Tese de doutorado. MAE/USP, } 2014 .\end{array}$ & 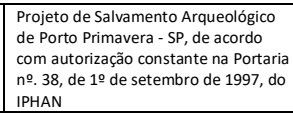 \\
\hline Fartura & Rio Verde 5 & não & & & & & & $22 \mathrm{~K}$ & 652119 & 7412484 & & CNSA & \begin{tabular}{|l}
$\begin{array}{l}\text { CHMYZ, I.; Relatório. Programa de } \\
\text { Salvamento Arqueológico no rio } \\
\text { tararé }\end{array}$ \\
\end{tabular} & & Rio Itararé \\
\hline Castilho & ROLINHA & não & SAD 69 & 22 & 435010 & $\begin{array}{l}7693 \\
076\end{array}$ & & & & & $\begin{array}{l}\text { SP0o9 } \\
21\end{array}$ & CNSA & \begin{tabular}{|l} 
Projeto de Salvamento Arqueológico \\
de Porto Primavera, SP
\end{tabular} & 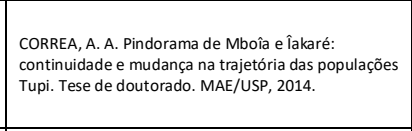 & 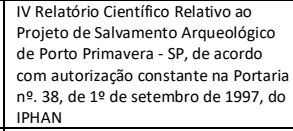 \\
\hline Riversul & $\begin{array}{l}\text { RVS } 22 \\
474548\end{array}$ & não & & & 647450 & \begin{tabular}{|l}
7359 \\
907
\end{tabular} & & & & & & $\begin{array}{l}\text { Biblioteca } \\
\text { MAE }\end{array}$ & 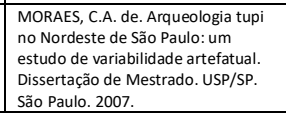 & $\begin{array}{l}\text { CORREA, A. A. Pindorama de Mboîa e liakaré: } \\
\text { continuidade e mudança na trajetoria das populaçoes } \\
\text { Tupi. Tese de doutorado. MAE/USP, } 2014\end{array}$ & \\
\hline Riversul & $\begin{array}{l}\text { RVS } 22 \\
483554\end{array}$ & não & & & 648314 & $\begin{array}{l}7355 \\
480\end{array}$ & & & & & & $\begin{array}{l}\text { Biblioteca } \\
\text { MAE }\end{array}$ & 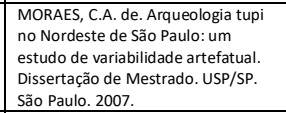 & $\begin{array}{l}\text { CORREA, A. A. Pindorama de Mboîa e êakaré: } \\
\text { continuidade e mudança na trajetoria das populaçoes } \\
\text { Tupi. Tese de doutorado. MAE/USP, } 2014\end{array}$ & \\
\hline Riversul & $\begin{array}{l}\text { RVS } 22 \\
513557\end{array}$ & não & & & 651356 & $\begin{array}{l}7355 \\
740\end{array}$ & & & & & & $\begin{array}{l}\text { Biblioteca } \\
\text { MAE }\end{array}$ & 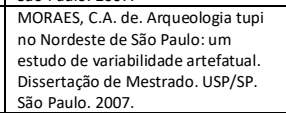 & $\begin{array}{l}\text { CORREA, A. A. Pindorama de Mboîa e êakaré: } \\
\text { continuidade e mudança na trajetoria das populaçōes } \\
\text { Tupi. Tese de doutorado. MAE/USP, } 2014\end{array}$ & \\
\hline Riversul & \begin{tabular}{|l} 
RVS 22 \\
524559
\end{tabular} & não & & & 652403 & $\begin{array}{l}7355 \\
901\end{array}$ & & & & & & $\begin{array}{l}\text { Biblioteca } \\
\text { MAE }\end{array}$ & 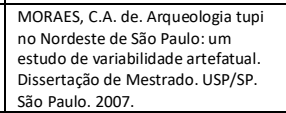 & $\begin{array}{l}\text { CORREA, A. A. Pindorama de Mboîa e liakaré: } \\
\text { continuidade e mudanca a a trajetoria das populaçoes } \\
\text { Tupi. Tese de doutorado. MAE/USP, } 2014\end{array}$ & \\
\hline Rosana & SABIÁ & não & SAD 69 & 22 & 287030 & $\begin{array}{l}7500 \\
423\end{array}$ & $\begin{array}{l}2235^{2} 21 " \text { S53 } \\
044^{\prime \prime} \mathrm{W}\end{array}$ & & & & $\begin{array}{l}\text { SP008 } \\
88\end{array}$ & CNSA & $\begin{array}{l}\text { Projeto de Salvamento Arqueológico } \\
\text { de Porto Primavera, SP. }\end{array}$ & 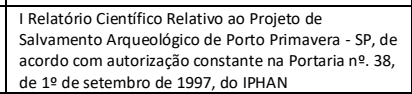 & \\
\hline Florinia & Saguarai & não & & & 520250 & \begin{tabular}{|l}
7462 \\
050
\end{tabular} & & & & & & \begin{tabular}{|l} 
Biblioteca \\
MAE
\end{tabular} & 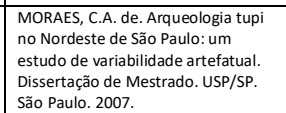 & 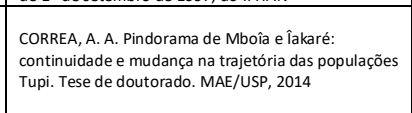 & 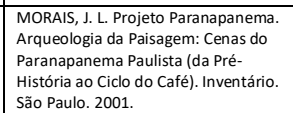 \\
\hline $\begin{array}{c}\text { Marabá } \\
\text { Paulista }\end{array}$ & Saltinho & não & SAD 69 & 22 & 408693 & $\begin{array}{l}7571 \\
346\end{array}$ & & & & & $\begin{array}{l}\text { Spo10 } \\
36\end{array}$ & CNSA & 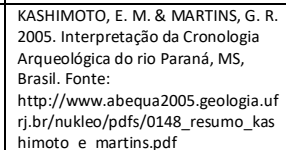 & $\begin{array}{l}\text { AAR-Novas Áreas de Expansão de Lavoura-Decasa } \\
\text { Destilaria de Álcool S/A-Unidade Caiuâ }\end{array}$ & \\
\hline Piraju & Bucuvuçu & não & & & & & & $22 \mathrm{~K}$ & 666018 & 7433795 & & $\begin{array}{l}\text { Biblioteca } \\
\text { MAE }\end{array}$ & 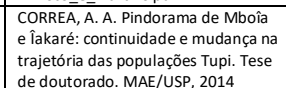 & & \\
\hline Itaporanga & $\begin{array}{l}\text { Serra dos Pais } \\
1\end{array}$ & não & & & & & & $22 \mathrm{~K}$ & 654360 & 7377502 & & CNSA & $\begin{array}{l}\text { coleção Museu de Arqueologia e } \\
\text { Artes Poppulares do o epartamento } \\
\text { de Antropologia da Universidade } \\
\text { Federal do Paraná - I gor Chmyz - } \\
\text { 1965 }\end{array}$ & & $\begin{array}{l}\text { descrição a respeito de cerâmica tipo } \\
\text { simples, pintado) }\end{array}$ \\
\hline $\begin{array}{l}\text { Presidente } \\
\text { Bernardes }\end{array}$ & Breschil & não & & & & & & $22 \mathrm{~K}$ & 442730 & 7566305 & & CNSA & \begin{tabular}{|l|} 
KUNZLI. R. Arqueologia regional. \\
Primeiros resultados das pesquisas \\
realizadas na ârea de Presidente \\
Prudente, SPR. Revista do Museu \\
Paulista. 32: 223-247. São Paulo, \\
1987. \\
\end{tabular} & & proximidade ao Córrego Santo Antônio \\
\hline $\begin{array}{l}\text { Presidente } \\
\text { Bernardes }\end{array}$ & Breschill & não & & & & & & $22 \mathrm{~K}$ & 442730 & 7566305 & & CNSA & \begin{tabular}{|l|} 
KUNZUI. R. Arqueologia regional. \\
Primeiros resultados das pesquisas \\
realizadas sáreas de Presidentes
\end{tabular} & & $\begin{array}{l}\text { proximidade ao Rio Abacaxi - Bacia do } \\
\text { Paranáa }\end{array}$ \\
\hline
\end{tabular}




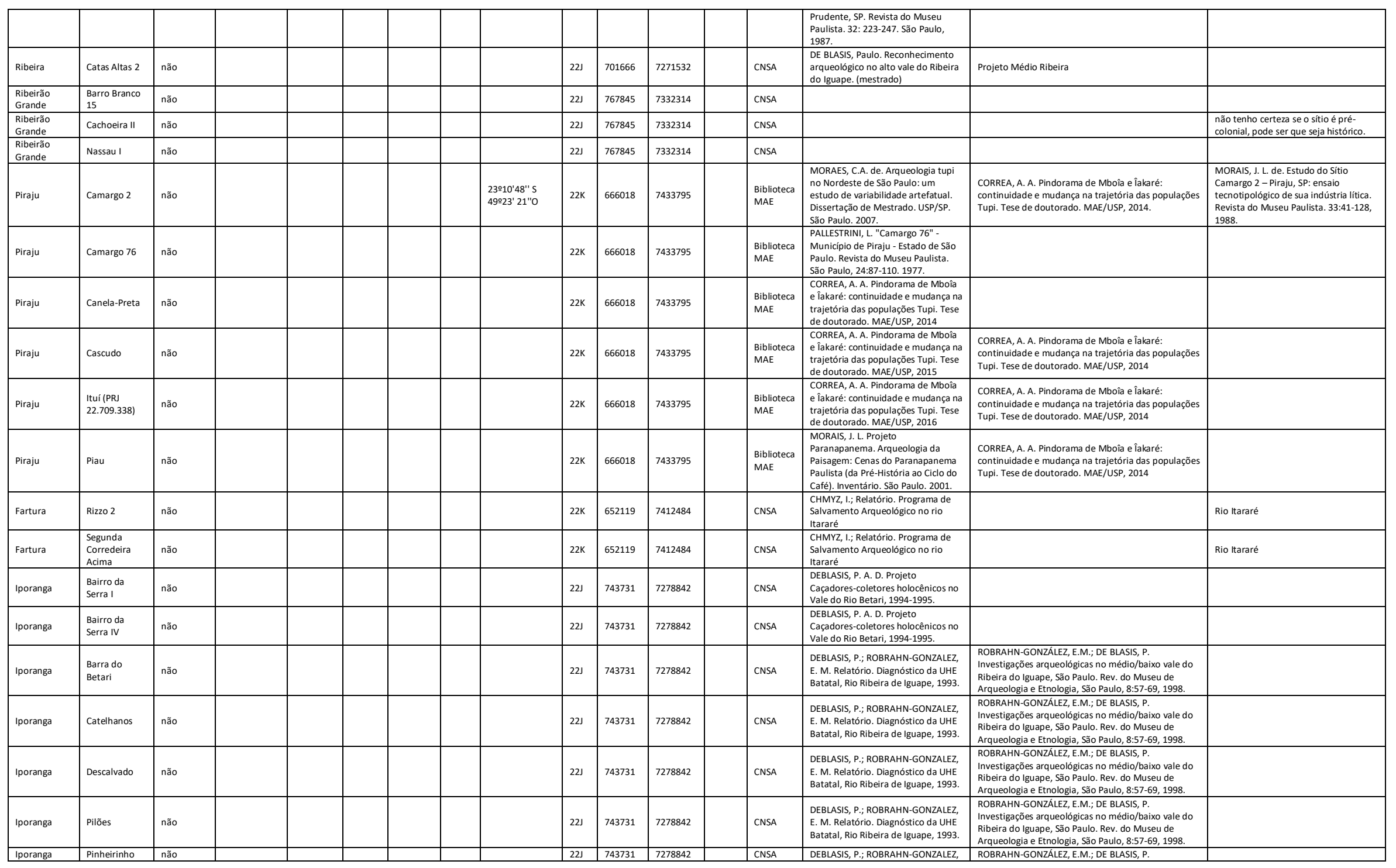




\begin{tabular}{|c|c|c|c|c|c|c|c|c|c|c|c|c|c|c|c|c|}
\hline & & & & & & & & & & & & & & \begin{tabular}{|l} 
E. M. Relatótrio. Diagnóstico da UHE \\
Batatal, Rio Ribeira de Iguape, 1993.
\end{tabular} & 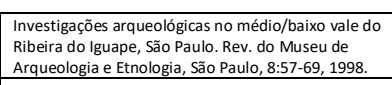 & \\
\hline Iporanga & Tio Grande & não & & & & & & & 223 & 743731 & 7278842 & & $\begin{array}{l}\text { CNSAe } \\
\text { Biblioteca } \\
\text { MAE }\end{array}$ & \begin{tabular}{|l} 
DEBLASIS, P; ROBRAHN-GONZALEZ, \\
E. M. Relatorio. Diangóstico da UHE \\
Batatal, Rio Ribeira de Iguape, 1993.
\end{tabular} & 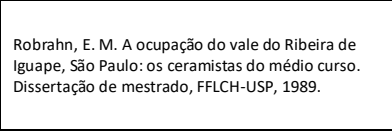 & 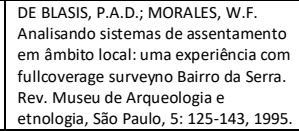 \\
\hline Ribeira & Ilha Rasa & não & & & & & & & $22 J$ & 701667 & 7271534 & $\begin{array}{l}\text { SPPo5 } \\
51\end{array}$ & CNSA & 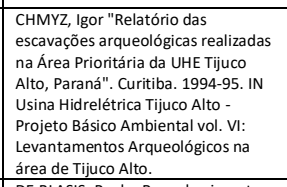 & & \\
\hline Ribeira & Ilha Rasa 1 & não & & & & & & & $22 J$ & 701667 & 7271534 & & CNSA & \begin{tabular}{|l|} 
DE BLASIS, Paulo. Reconhecimento \\
arqueologico no alto vale do Ribeira \\
do Iguape. (mestrado) \\
do on
\end{tabular} & Projeto Médio Ribeira & \\
\hline Ribeira & Oliveiras 1 & não & & & & & & & $22 J$ & 701667 & 7271534 & & CNSA & $\begin{array}{l}\text { De BLASIS, , aualo. Reconhecimento } \\
\text { arqueologicono alto vale do Ribeira } \\
\text { do Iguape. (mestrado) }\end{array}$ & Projeto Médio Ribeira & \\
\hline Ribeira & Tigre 1 & não & & & & & & & $22 J$ & 701667 & 7271534 & & CNSA & $\begin{array}{l}\text { DE BLASIS, , paulo. Reconhecimento } \\
\text { arquelógico no alto vale do Ribeira } \\
\text { do Iguape. (mestrado) }\end{array}$ & Projeto Médio Ribeira & \\
\hline Salto Grande & $\begin{array}{l}\text { Salto Grande } \\
\text { do } \\
\text { Paranapanem } \\
\text { a } \\
\end{array}$ & não & & & & 604097 & \begin{tabular}{|l}
7465 \\
837
\end{tabular} & $\begin{array}{l}2254^{4} 42^{\prime \prime 5} 49 \\
59^{4} 40^{\circ} \mathrm{W}\end{array}$ & & & & & $\begin{array}{l}\text { Biblioteca } \\
\text { MAE }\end{array}$ & 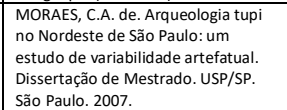 & $\begin{array}{l}\text { MORAIS, J.L. de; PIEDADE, S. C. O homem pré- } \\
\text { históricico de Salto Grande do Paranapanema. Notas - } \\
\text { Rev. do Museu de Arqueologia e Etnologia, S. Paulo, } \\
\text { 4:220-222, 1994. }\end{array}$ & 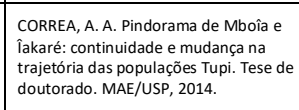 \\
\hline Ribeira & Toca do Tigre & não & & & & & & & $22 J$ & 701667 & 7271534 & & CNSA & $\begin{array}{l}\text { DE ELASIS, paulo. Reconhecimento } \\
\text { arqueologico ono alto vale do Ribeira } \\
\text { do Iguape. (mestrado) }\end{array}$ & Projeto Médio Ribeira & \\
\hline $\begin{array}{l}\text { Pereira } \\
\text { Barreto }\end{array}$ & SP TA-2 & 972 AD & \begin{tabular}{|l} 
Termolumine \\
scência (TL)
\end{tabular} & & & & & & $22 \mathrm{~K}$ & 489408 & 7718411 & & $\begin{array}{l}\text { Biblioteca } \\
\text { MAE }\end{array}$ & 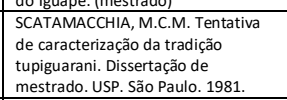 & 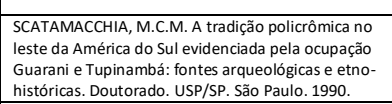 & \\
\hline Piraju & Piraju & não & & & & & & & $22 \mathrm{~K}$ & 666018 & 7433795 & & $\begin{array}{l}\text { Biblioteca } \\
\text { MAE }\end{array}$ & 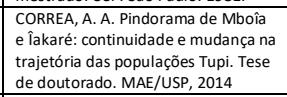 & & \\
\hline $\begin{array}{l}\text { Presidente } \\
\text { Epitácio }\end{array}$ & Santa fé & não & & SAD 69 & 22 & 360542 & \begin{tabular}{|l}
7555 \\
209
\end{tabular} & 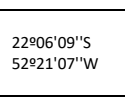 & & & & 25614 & $\begin{array}{l}\text { CNSA } \\
\text { Biblioteca } \\
\text { MAE }\end{array}$ & $\begin{array}{l}\text { KASHIMOTOO, E. M. Variáveis } \\
\text { ambientais a arqueologiano Alto } \\
\text { Paraná. Tese de doutorado. USP, São } \\
\text { Paulo. 1997. }\end{array}$ & & \\
\hline Pongaí & Santa Helena & não & & SAD 69 & $22 \mathrm{~K}$ & 673825 & \begin{tabular}{|l}
7606 \\
209
\end{tabular} & & & & & & $\begin{array}{l}\text { Arquivo } \\
\text { IPAAN } \\
\text { Relarório } \\
\text { s }\end{array}$ & 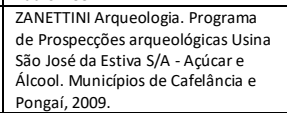 & & \\
\hline Piraju & Pirajuba & não & & & & & & & $22 \mathrm{~K}$ & 666018 & 7433795 & & \begin{tabular}{|l|l} 
Biblioteca \\
MAE
\end{tabular} & 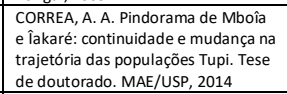 & & \\
\hline Votorantim & Santa Maria 3 & não & & \begin{tabular}{|l} 
Corrego \\
Alegre
\end{tabular} & 23 & 247416 & \begin{tabular}{|l|l|}
7391 \\
111
\end{tabular} & & & & & & CNSA & \begin{tabular}{|l} 
A Lasca arqueologia. Programa de \\
arqueologia Alphaville Votorantim.
\end{tabular} & & \\
\hline $\begin{array}{l}\text { Campos } \\
\text { Novos } \\
\text { Paulista }\end{array}$ & Santa Otilia & não & & SAD 69 & $22 \mathrm{~K}$ & 592555 & \begin{tabular}{|l|}
7507 \\
627
\end{tabular} & & & & & & $\begin{array}{l}\text { Arquivo } \\
\text { IPHAN- } \\
\text { Relarório } \\
\mathrm{s}\end{array}$ & 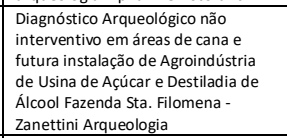 & & $30 \mathrm{~m}$ do Ri. Pari \\
\hline Piraju & Piratininga & não & & & & & & & $22 \mathrm{~K}$ & 666018 & 7433795 & & \begin{tabular}{l|l}
$\begin{array}{l}\text { Biblioteca } \\
\text { MAE }\end{array}$ \\
\end{tabular} & 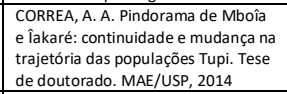 & & \\
\hline Piraju & Timburizeiro & não & & & & & & & $22 \mathrm{~K}$ & 666018 & 7433795 & & \begin{tabular}{l|l} 
Biblioteca \\
\end{tabular} & CoRREA, A. A. Pindorama de Mbốa & & \\
\hline
\end{tabular}




\begin{tabular}{|c|c|c|c|c|c|c|c|c|c|c|c|c|c|c|c|c|}
\hline & & & & & & & & & & & & & MAE & $\begin{array}{l}\text { e îakaré: continuidade e mudança na } \\
\text { trajetória das populaç̧es Tupi. Tese } \\
\text { de doutorado. MAE/USP, } 2014\end{array}$ & & \\
\hline Pirapozinho & $\begin{array}{l}\text { Loreto- } \\
\text { Pirapozinho } \\
\text { (Loreto) }\end{array}$ & não & & & & & & & $22 \mathrm{~K}$ & 448759 & 7536718 & 1714 & CNSA & & & 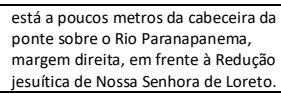 \\
\hline Pompéia & $\begin{array}{l}\text { Regadas } \\
\text { Garcia }\end{array}$ & não & & & & & & & $22 \mathrm{~K}$ & 583880 & 7555769 & 25604 & \begin{tabular}{|l|} 
CNSA e \\
Biblioteca \\
MAE
\end{tabular} & 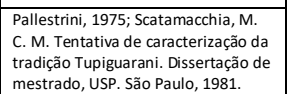 & $\begin{array}{l}\text { POSSE, Z. Populaçäes pré--históricas de sitios } \\
\text { cerâmicos no interior do Brasili. Doutorado. USP. São } \\
\text { Paulo, } 1984 .\end{array}$ & \\
\hline $\begin{array}{l}\text { Teodoro } \\
\text { Sampaio }\end{array}$ & São Francisco & não & & SAD 69 & 22 & 374109 & \begin{tabular}{|l|}
7523 \\
742
\end{tabular} & & & & & & CNSA & \begin{tabular}{|l|l} 
Diagnóstico arqueolóǵgicon oño \\
interventivo - ETH Bio energia S/A
\end{tabular} & & \\
\hline lacanga & São Luiz। & não & & SAD 69 & 22 & 705739 & $\begin{array}{l}7576 \\
816\end{array}$ & & & & & & CNSA & 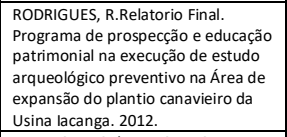 & & \\
\hline Săo Miguel & São Miguel 1 & não & & & & & & $\begin{array}{l}22^{\circ} 45^{\prime} 38 \mathrm{~s} " \mathrm{~s} \\
48^{8} 42^{2} 33^{\prime \prime} \mathrm{W}\end{array}$ & $22 \mathrm{~K}$ & 735224 & 7481166 & & $\begin{array}{l}\text { Revista } \\
\text { online }\end{array}$ & 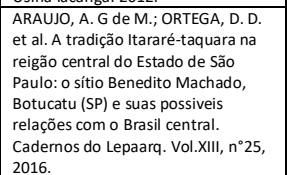 & $\begin{array}{l}\text { ROBRAAN-GONZZALE, Erika M., ZANETTINI, Paulo E. } \\
\text { Relatório do Programa de Resgate da Linha de } \\
\text { Transmissão } \\
440 \text { kV (Taquaruçu - Assis - Sumaré)/SP, realizado } \\
\text { para a SIEMENS S/A, 2002. }\end{array}$ & \\
\hline $\begin{array}{l}\text { Presidente } \\
\text { Epitácio }\end{array}$ & CABECA SECA & não & & & & & & & $22 \mathrm{~K}$ & 385259 & 7592527 & $\begin{array}{l}\text { SP008 } \\
45\end{array}$ & CNSA & $\begin{array}{l}\text { Projeto de Salvamento Arqueológico } \\
\text { de Porto Primavera, SP. }\end{array}$ & 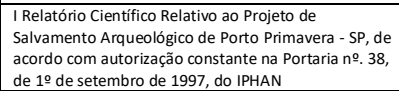 & \\
\hline $\begin{array}{l}\text { Ribeirão } \\
\text { Branco }\end{array}$ & São Sebastiäo & não & & & $22\rfloor$ & 0706945 & \begin{tabular}{|c|}
7308 \\
138
\end{tabular} & & & & & & $\begin{array}{l}\text { Biblioteca } \\
\text { MAE }\end{array}$ & $\begin{array}{l}\text { ARAUUO, A; G. M- 2001. Teoria e } \\
\text { método em arqueoelogia regional: } \\
\text { um estudo de caso no Alto } \\
\text { Paranapanema, estado de Săo Paulo, } \\
\text { Tese de doutorado, USP/SP, Sâo } \\
\text { Paulo. 2001. }\end{array}$ & & \\
\hline Itapira & SP TA-3 & 578 AD & $\begin{array}{l}\text { Termolumine } \\
\text { scência (TL) }\end{array}$ & & & & & & $23 \mathrm{~K}$ & 312509 & 7517744 & & $\begin{array}{l}\text { Biblioteca } \\
\text { MAE }\end{array}$ & 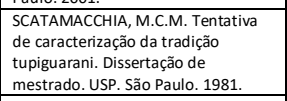 & 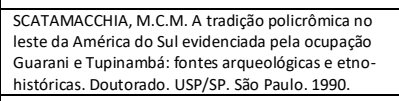 & \\
\hline Palmital & Sarã & não & & & & 579836 & \begin{tabular}{|l|l}
7462 \\
618
\end{tabular} & & & & & & $\begin{array}{l}\text { Biblioteca } \\
\text { MAE }\end{array}$ & 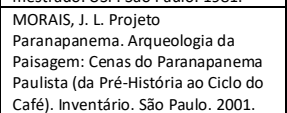 & $\begin{array}{l}\text { MORAIS, I. L. Projeto Paranapanema. Arqueologia da } \\
\text { Paisagem: Cenas do Paranapanema Paulista (da Pré- } \\
\text { História a o Ciclo do Caf́e). Inventário. Săo Paulo. } \\
2001 \text {. }\end{array}$ & \\
\hline $\begin{array}{l}\text { Teodoro } \\
\text { Sampaio }\end{array}$ & SARACURA & não & & & & 331023 & $\begin{array}{l}7532 \\
416\end{array}$ & & & & & $\begin{array}{l}\text { SP008 } \\
91\end{array}$ & CNSA & $\begin{array}{l}\text { Projeto de Salvamento Arqueológico } \\
\text { de Porto Primavera, SP. }\end{array}$ & 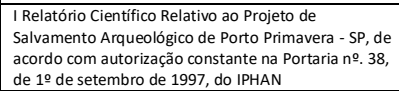 & \\
\hline $\begin{array}{l}\text { Araçoiaba da } \\
\text { Serra }\end{array}$ & Sarapuí & não & & & $23 \mathrm{~K}$ & 217670 & $\begin{array}{l}7392 \\
678\end{array}$ & & & & & & CNSA & $\begin{array}{l}\text { DOCUMENTO Ltda, 2009. Programa } \\
\text { de Gestấo do } \\
\text { PatrimônioArqueoológico, Histórico e } \\
\text { Cultural (Etapa diagnóstico) das } \\
\text { obras de duplicacacao da Rodovia SP. } \\
270 \text { (Raposo Tavares). }\end{array}$ & & \\
\hline Sarapui & Sarapuí 01 & não & & & 23к & 213388 & \begin{tabular}{|l}
7382 \\
156
\end{tabular} & & & & & & $\begin{array}{l}\text { Arquivo } \\
\text { IPHAN- } \\
\text { Relarório } \\
\text { s }\end{array}$ & 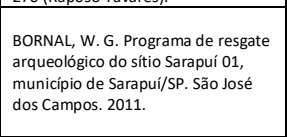 & & $\begin{array}{l}\text { a cerâmica descrita como Tupiguarani } \\
\text { no relatório aparenta ser mais } \\
\text { cerámicic de contatoto presença de } \\
\text { alças, apliques, acabarentos de } \\
\text { superficie uque na săo tipicamente } \\
\text { Tupiguarani. }\end{array}$ \\
\hline $\begin{array}{l}\text { Presidente } \\
\text { Prudente }\end{array}$ & Balotari 1 & não & & & & & & & $22 \mathrm{~K}$ & 385259 & 7592527 & 25607 & $\begin{array}{l}\text { CNSAe } \\
\text { Biblioteca } \\
\text { MAE }\end{array}$ & 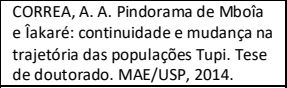 & 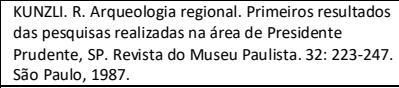 & \\
\hline $\begin{array}{l}\text { Presidente } \\
\text { Prudente }\end{array}$ & Balotari 2 & não & & & & & & & $22 \mathrm{~K}$ & 385259 & 7592527 & 25608 & $\begin{array}{l}\text { CNAA e } \\
\text { Biblioteca }\end{array}$ & $\begin{array}{l}\text { CORREA, A. A. Pindorama de Mboîa } \\
\text { e lakaré: continuidade e mudanca na }\end{array}$ & $\begin{array}{l}\text { KUNZZI. R. Arqueoologia regional. Primeiros resultados } \\
\text { das pesquisas realizads na area de Presidente }\end{array}$ & \\
\hline
\end{tabular}




\begin{tabular}{|c|c|c|c|c|c|c|c|c|c|c|c|c|c|c|c|}
\hline & & & & & & & & & & & & MAE & \begin{tabular}{|l|} 
trajetotoria das populaçöes Tupi. Tese \\
de doutorado. MAE/USP, 2014.
\end{tabular} & \begin{tabular}{|l|}
$\begin{array}{l}\text { Prudente, SP. Revista do Museu Paulista. 32: 223-247. } \\
\text { Săo Paulo, 1987. }\end{array}$ \\
\end{tabular} & \\
\hline 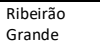 & Nassau XI & não & & & & & & $22 J$ & 767845 & 7332314 & & CNSA & & & \\
\hline $\begin{array}{l}\text { Pereira } \\
\text { Barreto }\end{array}$ & SP TA-5 & $930 \mathrm{AD}$ & $\begin{array}{l}\text { Termolumine } \\
\text { scência (TL) }\end{array}$ & & & & & $22 \mathrm{~K}$ & 489408 & 7718411 & & $\begin{array}{l}\text { Biblioteca } \\
\text { MAE }\end{array}$ & $\begin{array}{l}\text { SCATAMACCHIA. M.C.M. Tentativa } \\
\text { de caracterizaçáa da tradiçâao } \\
\text { tupiguarani. Dissertaçáo de } \\
\text { mestrado. USP. São Paulo. } 1981 . \\
\end{array}$ & 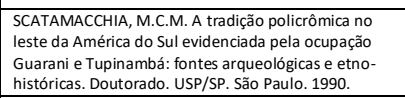 & \\
\hline $\begin{array}{l}\text { Presidente } \\
\text { Epitácio }\end{array}$ & SEM-FIM & não & & SAD 69 & 22 & 395809 & $\begin{array}{l}7618 \\
531\end{array}$ & & & & \begin{tabular}{|l|} 
SP008 \\
92
\end{tabular} & CNSA & $\begin{array}{l}\text { Projeto de Salvamento Arqueológico } \\
\text { de Porto Primavera, SP. }\end{array}$ & 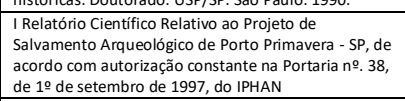 & \\
\hline Salto Grande & $\begin{array}{l}\text { Fazenda } \\
\text { Ferrazolli }\end{array}$ & não & & & & & & $22 \mathrm{~K}$ & 604260 & 7468306 & & CNSA & 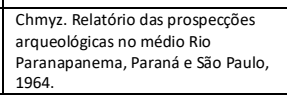 & & \\
\hline $\begin{array}{l}\text { Presidente } \\
\text { Prudente }\end{array}$ & Balotari 3 & não & & & & & & $22 \mathrm{~K}$ & 385259 & 7592527 & 25609 & $\begin{array}{l}\text { CNSA } \\
\text { Biblioteca } \\
\text { MAE }\end{array}$ & 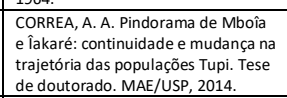 & 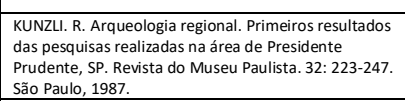 & \\
\hline Pacaembu & Sertãozinho & não & & & $22 \mathrm{~K}$ & 472448 & $\begin{array}{l}7629 \\
788\end{array}$ & & & & & \begin{tabular}{|l} 
Arquivo \\
IPHAN- \\
Relarório \\
s
\end{tabular} & 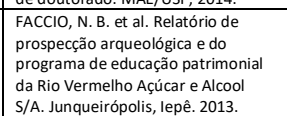 & & \\
\hline Taciba & Silva & não & & & & 468600 & \begin{tabular}{|l}
7524 \\
504
\end{tabular} & & & & & $\begin{array}{l}\text { Biblioteca } \\
\text { MAE }\end{array}$ & 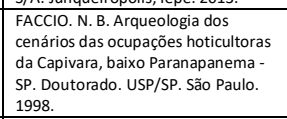 & & destruído \\
\hline Itapeva & Silveira & não & & & $22 \mathrm{~K}$ & 0709016 & $\begin{array}{l}7373 \\
856\end{array}$ & & & & & $\begin{array}{l}\text { Biblioteca } \\
\text { MAE }\end{array}$ & 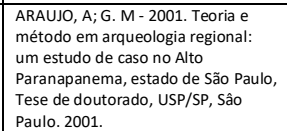 & & \\
\hline Panorama & SIRIEMA & não & & SAD 69 & 22 & 403914 & \begin{tabular}{|l}
7625 \\
767
\end{tabular} & & & & $\begin{array}{l}\text { Spoo8 } \\
93\end{array}$ & CNSA & $\begin{array}{l}\text { Projeto de Salvamento Arqueológico } \\
\text { de Porto Primavera, SP. }\end{array}$ & 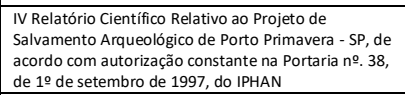 & \\
\hline $\begin{array}{l}\text { Presidente } \\
\text { Epitácio }\end{array}$ & SIRRRI & não & & SAD 69 & 22 & 357260 & \begin{tabular}{|l}
7552 \\
209
\end{tabular} & & & & $\begin{array}{l}\text { Spoo8 } \\
94\end{array}$ & CNSA & $\begin{array}{l}\text { Projeto de Salvamento Arqueológico } \\
\text { de Porto Primavera, SP. }\end{array}$ & 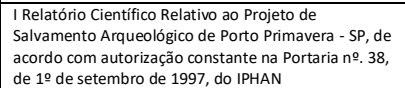 & \\
\hline Porto Feliz & Śtio 10 & não & & SAD 69 & 23 & 228297 & \begin{tabular}{|l}
7441 \\
406
\end{tabular} & & & & $\begin{array}{l}\text { SP010 } \\
87\end{array}$ & CNSA & 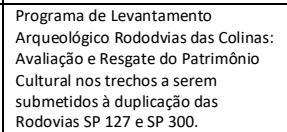 & 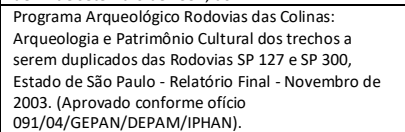 & \\
\hline Salto & $\begin{array}{l}\text { Sitio 14- Săo } \\
\text { Gabriel }\end{array}$ & não & & SAD 69 & 23 & 264202 & $\begin{array}{l}7434 \\
681\end{array}$ & & & & \begin{tabular}{|l|} 
SP010 \\
62
\end{tabular} & CNSA & 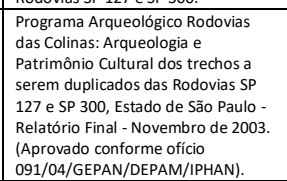 & 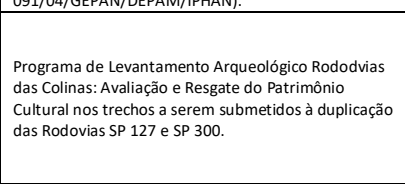 & \\
\hline $\begin{array}{l}\text { Presidente } \\
\text { Prudente }\end{array}$ & Cottini & não & & & & & & $22 \mathrm{~K}$ & 385259 & 7592527 & & CNSA & 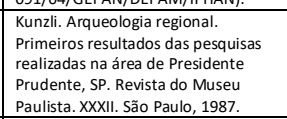 & & \\
\hline $\begin{array}{l}\text { Presidente } \\
\text { Prudente }\end{array}$ & \begin{tabular}{|l} 
Fazenda \\
Peegador
\end{tabular} & não & & & & & & $22 \mathrm{~K}$ & 385259 & 7592527 & 25610 & \begin{tabular}{|l|} 
CNSA e \\
Biblioteca \\
MAE \\
\end{tabular} & \begin{tabular}{|l} 
CORREA, A. A. Pindorama de Mboîa \\
e İakaré: continuidade e mudança na \\
trajeteria das populacóes TTupi. Tese \\
de doutorado. MAE/USP, 2014 \\
\end{tabular} & 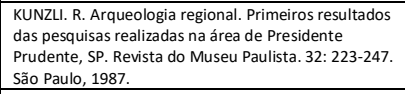 & \\
\hline
\end{tabular}




\begin{tabular}{|c|c|c|c|c|c|c|c|c|c|c|c|c|c|c|}
\hline & & & & & & \begin{tabular}{|l|l|}
744 & \\
\end{tabular} & & & & & & $\begin{array}{l}\text { arqueooĺ́gico para expansão da } \\
\text { Usina Săo Miguel. Săo Paulo. } 2010 .\end{array}$ & 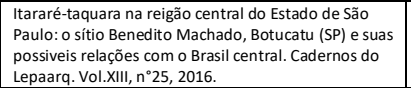 & \\
\hline $\begin{array}{l}\text { Presidente } \\
\text { Epitácio }\end{array}$ & Sосо́ воI & não & SAD 69 & 22 & 364699 & \begin{tabular}{|l}
7567 \\
985
\end{tabular} & & & & $\begin{array}{l}\text { SP008 } \\
95\end{array}$ & CNSA & $\begin{array}{l}\text { Projeto de Salvamento Arqueológico } \\
\text { de Porto Primavera, SP. }\end{array}$ & 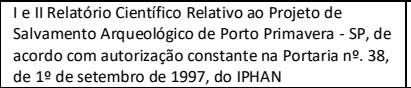 & \\
\hline $\begin{array}{l}\text { Presidente } \\
\text { Epitácio }\end{array}$ & SOcozINHO & não & SAD 69 & 22 & 365217 & $\begin{array}{l}7566 \\
773\end{array}$ & & & & $\begin{array}{l}\text { SP008 } \\
{ }_{96}\end{array}$ & CNSA & $\begin{array}{l}\text { Projeto de Salvamento Arqueológico } \\
\text { de Porto Primavera, SP. }\end{array}$ & 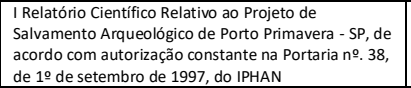 & \\
\hline $\begin{array}{l}\text { Presidente } \\
\text { Prudente }\end{array}$ & Ferreira & não & & & & & $22 \mathrm{~K}$ & 385259 & 7592527 & & CNSA & $\begin{array}{l}\text { Kunzli. Arqueologia regional. } \\
\text { Primeiros resultados das pesquisas } \\
\text { realizadas na área de Presidente } \\
\text { Prudente, SP. Revitsa do Museu } \\
\text { Paulista. XXxll. Säo Paulo, 1987. }\end{array}$ & & \\
\hline Riversul & SP BA C-10 & não & & & & & $22 \mathrm{~K}$ & 659585 & 7363869 & & $\begin{array}{l}\text { Biblioteca } \\
\text { MAE }\end{array}$ & 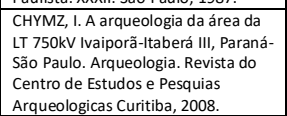 & & sítio destruído \\
\hline Riversul & SP BA C-16 & não & & & & & $22 \mathrm{~K}$ & 659585 & 7363869 & & $\begin{array}{l}\text { Biblioteca } \\
\text { MAE }\end{array}$ & 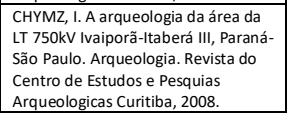 & & sítio destruído \\
\hline Riversul & SP BAC-2 & não & & & & & $22 \mathrm{~K}$ & 659585 & 7363869 & & $\begin{array}{l}\text { Biblioteca } \\
\text { MAE }\end{array}$ & 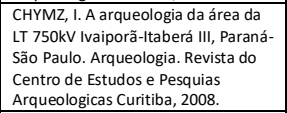 & & sítio destruído \\
\hline Rancharia & $\begin{array}{l}\text { Agua das } \\
\text { Favas }\end{array}$ & não & & & & & $22 \mathrm{~K}$ & 510938 & 7541771 & & $\begin{array}{l}\text { Biblioteca } \\
\text { MAE }\end{array}$ & 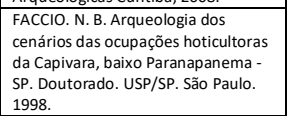 & & \\
\hline Registro & $\begin{array}{l}\text { Colégio São } \\
\text { José }\end{array}$ & não & & & & & 23J & 210568 & 7287777 & & $\begin{array}{l}\text { Biblioteca } \\
\text { MAE }\end{array}$ & \begin{tabular}{|l|} 
SCATAMACCHIA, M. A ocupação \\
tupi-guaranio do estado de Sẫo \\
Paulo Dedalo . . 23. 1984. . \\
\end{tabular} & 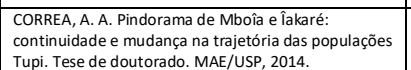 & \\
\hline Riversul & $\begin{array}{l}\text { Cemitério do } \\
\text { espanhol }\end{array}$ & não & & & & & $22 \mathrm{~K}$ & 659563 & 7363880 & & $\begin{array}{l}\text { Biblioteca } \\
\text { MAE }\end{array}$ & 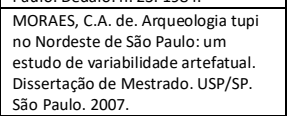 & $\begin{array}{l}\text { CORREA, A. A. Pindorama de Mboia e ểaká: } \\
\text { continuidade e mudancan na trajetória das populaçoses } \\
\text { Tupi. Tese de doutorado. MAE/USP, } 2014\end{array}$ & \\
\hline Riversul & $\begin{array}{l}\text { José } \\
\text { Fernandes }\end{array}$ & não & & & & & $22 \mathrm{~K}$ & 659563 & 7363880 & 25504 & $\begin{array}{l}\text { CNSAe } \\
\text { Biblioteca } \\
\text { MAE }\end{array}$ & $\begin{array}{l}\text { MARANCA, S. Nota prévia sobre o } \\
\text { sitito José Fernandes } \\
\text { (SP_IP_12)Revista do Museu } \\
\text { Pauulista. Novav Sereie. vol. XVIIII. São } \\
\text { Paulo, 1968/1969. }\end{array}$ & $\begin{array}{l}\text { CORREA, A.A. Pindorama de Mboîa e êakaré: } \\
\text { continuidade e mudancan na trajetória das populaçōes } \\
\text { Tupi. Tese de doutorado. MAE/USP, } 2014\end{array}$ & \\
\hline Riversul & SP BA C-5 & não & & & & & $22 \mathrm{~K}$ & 659563 & 7363880 & & $\begin{array}{l}\text { Biblioteca } \\
\text { MAE }\end{array}$ & 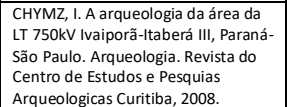 & & sítio destruído \\
\hline Riversul & SP BA C-6 6 & não & & & & & $22 k$ & 659563 & 7363880 & & $\begin{array}{l}\text { Biblioteca } \\
\text { MAE }\end{array}$ & 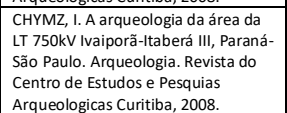 & & sitio destruido \\
\hline Riversul & SP BAC-7 & não & & & & & $22 \mathrm{~K}$ & 659563 & 7363880 & & $\begin{array}{l}\text { Biblioteca } \\
\text { MAE }\end{array}$ & 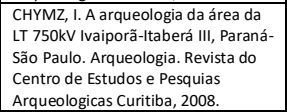 & & acampamento \\
\hline Salto Grande & $\begin{array}{l}\text { Água do } \\
\text { Lajeado }\end{array}$ & não & & & & & $22 \mathrm{~K}$ & 604260 & 7468302 & & $\begin{array}{l}\text { CNSA e } \\
\text { Biblioteca } \\
\text { MAE }\end{array}$ & 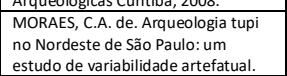 & $\begin{array}{l}\text { CHYMZ, I. Pesquisas paleetnográficicas fétuadas no } \\
\text { vale do Rio Paranapanema - Paraná-São Paulo. } \\
\text { Doutorodo. USP, SP. 19777. }\end{array}$ & 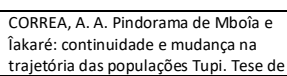 \\
\hline
\end{tabular}




\begin{tabular}{|c|c|c|c|c|c|c|c|c|c|c|c|c|c|c|}
\hline & & & & & & & & & & & & $\begin{array}{l}\text { Dissertação de Mestrado. USP/SP. } \\
\text { Săo Paulo. } 2007 .\end{array}$ & & doutorado. MAE/USP, 2014 \\
\hline Salto Grande & Sorocabana & não & & & & & $22 \mathrm{~K}$ & 604260 & 7468302 & & $\begin{array}{l}\text { Biblioteca } \\
\text { MAE }\end{array}$ & \begin{tabular}{|l|} 
MORAES, C.A. de. Arqueologia tupi \\
no Norddste de Säp Pauloum um \\
estudo de variabilidade artefatual. \\
Dissertacăa de Mestrado. USP/SP. \\
São Paulo. 2007.
\end{tabular} & $\begin{array}{l}\text { CHYMZZ, I. Pesquisas paleetnográfícas efetuadas no } \\
\text { vale do Rio Paranapanema - Paraná-são Paulo. } \\
\text { Doutorado. USP, SP. 1977. }\end{array}$ & 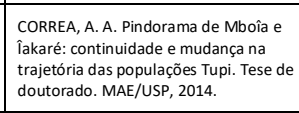 \\
\hline $\begin{array}{l}\text { Santo } \\
\text { Anastácio }\end{array}$ & Carlos Castro & não & & & & & $22 \mathrm{~K}$ & 432685 & 7569737 & & \begin{tabular}{|l} 
Biblioteca \\
MAE
\end{tabular} & 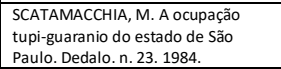 & 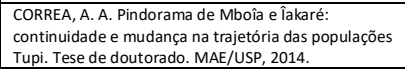 & \\
\hline Sorocaba & Araçoiaba & não & & & & & $23 \mathrm{~K}$ & 249171 & 7398870 & & $\begin{array}{l}\text { Biblioteca } \\
\text { MAE }\end{array}$ & 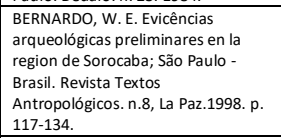 & 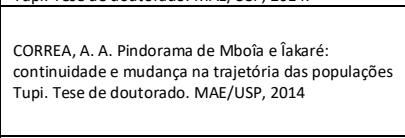 & \\
\hline Sorocaba & Caguassu & não & & & & & $23 \mathrm{~K}$ & 249171 & 7398870 & & $\begin{array}{l}\text { Biblioteca } \\
M A E\end{array}$ & \begin{tabular}{|l|} 
BERNARDO, W. E. Evicências \\
arqueológicas preliminares en la \\
reqiog de Sorocaba; São Paulo- \\
Brasil. Revista Textos \\
Antropológicos. n.8, La Paz.1998. p. \\
117-134. \\
\end{tabular} & 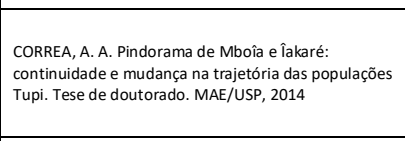 & \\
\hline Sorocaba & Cercado & não & & & & & $23 \mathrm{~K}$ & 249171 & 7398870 & & \begin{tabular}{|l} 
Biblioteca \\
MAE
\end{tabular} & $\begin{array}{l}\text { BERNARDO, W. E. Evicências } \\
\text { arqueológicas preliminares en la } \\
\text { region de Sorocaba ; } 5 \text { ão Paulo - } \\
\text { Brasil. Revista Textos } \\
\text { Antropologicicos. n.8, La Paz.1998. p. } \\
\text { 117-134. }\end{array}$ & $\begin{array}{l}\text { CORREA, A. A. Pindorama de Mboîa e îakaré: } \\
\text { continuidade e mudanca na trajetória das populašes } \\
\text { Tupi. Tese de doutorado. MAE/USP, } 2014\end{array}$ & \\
\hline Sorocaba & Corumbá & não & & & & & $23 \mathrm{~K}$ & 249171 & 7398870 & & \begin{tabular}{|l} 
Biblioteca \\
MAE
\end{tabular} & 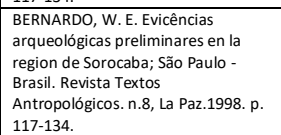 & $\begin{array}{l}\text { CORREA, A.A. Pindorama de Mboîa e Tâkará: } \\
\text { continuidade e mudancan na trajetória das populaçōes } \\
\text { Tupi. Tese de doutorado. MAE/USP, } 2014\end{array}$ & \\
\hline Sorocaba & Éden & não & & & & & $23 \mathrm{~K}$ & 249171 & 7398870 & & $\begin{array}{l}\text { Biblioteca } \\
\text { MAE }\end{array}$ & \begin{tabular}{|l|} 
BERNARDO, W. E. Evicências \\
arqueológicas preliminares en la \\
region de Sorocabaa são Paulo - \\
Brasil. Revista Textos \\
Antropologicicos. n.8, La Paz.1998. p. \\
117-134. \\
\end{tabular} & $\begin{array}{l}\text { CORREA, A. A. Pindorama de Mboîa e Takará: } \\
\text { continuidade e mudanca na trajetória das populaçōes } \\
\text { Tuti. Tese de doutorado. MAE/USP, } 2014\end{array}$ & \\
\hline Sorocaba & Ipanema & não & & & & & $23 \mathrm{~K}$ & 249171 & 7398870 & & $\begin{array}{l}\text { Biblioteca } \\
\text { MAE }\end{array}$ & \begin{tabular}{|l|} 
BERNARDO, W. E. Evicências \\
arqueológicas preliminares en la \\
region de Sorocaba; São Paulo- \\
Brasil. Revista Textos \\
Antropológicos. n.8, La Paz.1998. p. \\
117-134. \\
\end{tabular} & $\begin{array}{l}\text { CORREA, A. A. Pindorama de Mboîa e Îakaré: } \\
\text { continuidade e mudanca na trajetória das populaçōes } \\
\text { Tupi. Tese de doutorado. MAE/USP, } 2014\end{array}$ & \\
\hline Sorocaba & Ipiró & não & & & & & $23 \mathrm{~K}$ & 249171 & 7398870 & & $\begin{array}{l}\text { Biblioteca } \\
\text { MAE }\end{array}$ & \begin{tabular}{|l} 
BERNARDO, W. E. Evicências \\
arqueológicas preliminares en la \\
region de Sorocabaa Săa Paulo - \\
Brasil. Revista Textos \\
Antropológicos. n.8, La Paz.1998. p. \\
117-134. \\
\end{tabular} & $\begin{array}{l}\text { CORREA, A. A. Pindorama de Mboîa e Takará: } \\
\text { continuidade e mudancan na trajetória das populaçōes } \\
\text { Tupi. Tese de doutorado. MAE/USP, } 2014\end{array}$ & \\
\hline Rosana & SUINDARA & não & SAD 69 & 22 & 434280 & \begin{tabular}{|l|l}
7683 \\
015
\end{tabular} & & & & $\begin{array}{l}\text { Spoog } \\
18\end{array}$ & CNSA & $\begin{array}{l}\text { Projeto de Salvamento Arqueológico } \\
\text { de Porto Primavera, SP. }\end{array}$ & 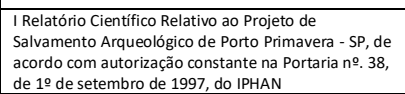 & \\
\hline Paulicéia & TACHA & não & SAD 69 & 22 & 419969 & \begin{tabular}{|l|l|}
7670 \\
203
\end{tabular} & & & & $\begin{array}{l}\text { Spoog } \\
13\end{array}$ & CNSA & $\begin{array}{l}\text { Projeto de Salvamento Arqueológico } \\
\text { de Porto Primavera, SP }\end{array}$ & 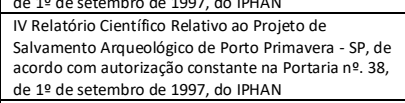 & \\
\hline Taciba & Taciba 1 & não & SAD 69 & 22 & 462345 & \begin{tabular}{|l|}
7500 \\
202
\end{tabular} & & & & & CNSA & $\begin{array}{l}\text { SCIENTIA Consultoria Científica. } \\
\text { Programa de prospecçōes } \\
\text { arqueológicas intensivas para as } \\
\text { áreas de inserção da Linna de } \\
\text { transmissãa Capivara - Presidente } \\
\text { Prudente. São Paulo, } 2008\end{array}$ & & \\
\hline Palmital & Taiúva & não & & & 582793 & \begin{tabular}{|l}
7461 \\
970
\end{tabular} & & & & & 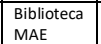 & \begin{tabular}{|l|} 
MORAIS, J. L. Projeto \\
Paranapanema. Arqueologia da
\end{tabular} & & \\
\hline
\end{tabular}




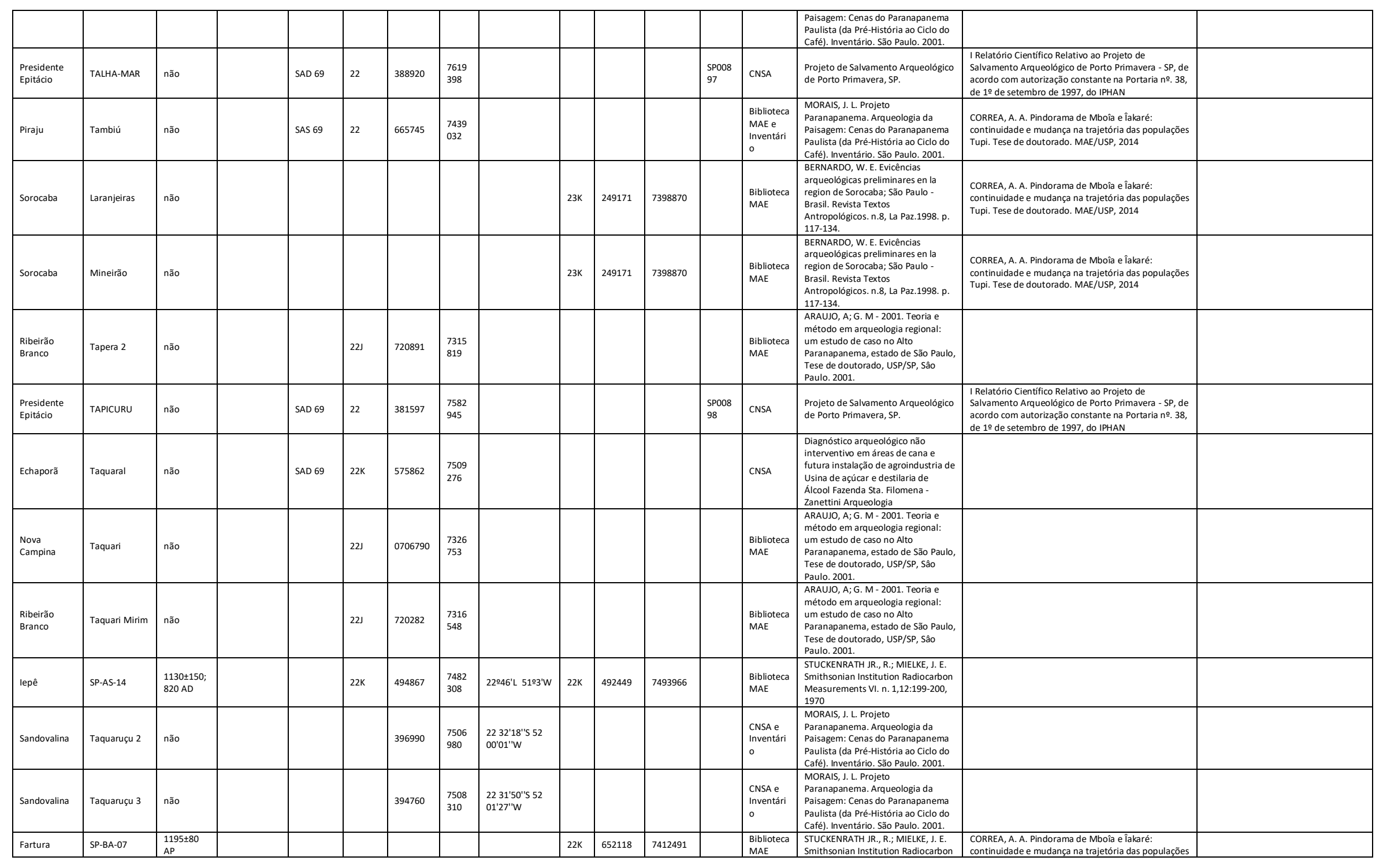




\begin{tabular}{|c|c|c|c|c|c|c|c|c|c|c|c|c|c|c|c|c|}
\hline & & & & & & & & & & & & & & $\begin{array}{l}\begin{array}{l}\text { Measurements VI. n. 1,12:199-200, } \\
1970\end{array} \\
190\end{array}$ & Tupi. Tese de doutorado. MAE/USP, 2014 & \\
\hline Tatuí & Tatuí1 & não & & $\begin{array}{l}\text { Córrego } \\
\text { Alegre }\end{array}$ & 23 & 218178 & $\begin{array}{l}7416 \\
320\end{array}$ & & & & & & \begin{tabular}{|l|} 
CNSA e \\
Biblioteca \\
Empresa
\end{tabular} & $\begin{array}{l}\text { SCIENTIA CONSULTORIA. Relatório } \\
\text { Final: salvamento de sitios } \\
\text { arqueologicos situados na área de } \\
\text { intervenção da LT 525 kV Londrina } \\
\text { (PR) - Araraquara (SP). São Paulo, } \\
\text { Scientia, 2008. }\end{array}$ & & \\
\hline $\begin{array}{l}\text { Barăode } \\
\text { Antonina }\end{array}$ & SP-BA-7 & \begin{tabular}{|l|}
$1870 \pm 100$ \\
AP: \\
$850 \pm 150$ \\
AP \\
\end{tabular} & & & & & & $\begin{array}{l}23035 \text { 's } \\
49936 \text { 'W }\end{array}$ & $22 \mathrm{~K}$ & 646729 & 7386065 & & $\begin{array}{l}\text { Biblioteca } \\
\text { MAE }\end{array}$ & 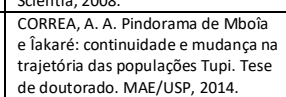 & & \\
\hline Rosana & TESOURINHA & não & & SAD 69 & & 315034 & $\begin{array}{l}7520 \\
787\end{array}$ & $\begin{array}{l}2224^{4} 32^{\prime \prime S} 52 \\
47^{\prime} 48^{\prime \prime} \mathrm{W}\end{array}$ & & & & $\begin{array}{l}\text { Spoo8 } \\
99\end{array}$ & CNSA & \begin{tabular}{|l} 
Projeto de Salvamento Arqueológico \\
de Porto Primavera, SP.
\end{tabular} & 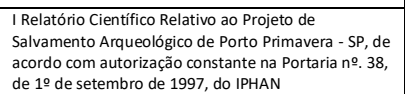 & \\
\hline Paulicéia & TICO-TICO & não & & SAD 69 & 22 & 409625 & $\begin{array}{l}7657 \\
754\end{array}$ & & & & & $\begin{array}{l}\text { Spoog } \\
01\end{array}$ & CNSA & $\begin{array}{l}\text { Projeto de Salvamento Arqueológico } \\
\text { de Porto Primavera, SP }\end{array}$ & 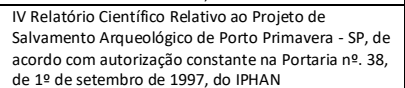 & \\
\hline Sandovalina & Taquaruçu & Século XVII & & & & 3547914 & $\begin{array}{l}7507 \\
303\end{array}$ & $\begin{array}{l}2232^{\prime} 13 \text { "S } 52 \\
01^{\prime} 18^{\prime \prime} \mathrm{W}\end{array}$ & & & & $\begin{array}{l}\text { Spoo8 } \\
19\end{array}$ & \begin{tabular}{|l|} 
CNSA e \\
Biblioteca \\
MAE
\end{tabular} & Projeto Paranapanema; & 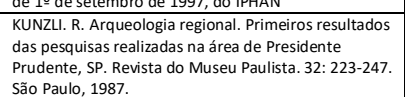 & 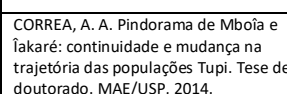 \\
\hline \multirow[t]{2}{*}{ lepê } & \begin{tabular}{|l} 
Terra do Sol \\
Nascente
\end{tabular} & $750 \mathrm{AP}$ & & & & 492375 & $\begin{array}{l}7480 \\
939\end{array}$ & & & & & & $\begin{array}{l}\text { Biblioteca } \\
\text { MAE }\end{array}$ & 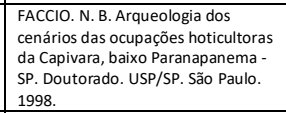 & 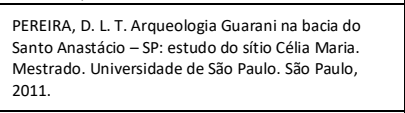 & \\
\hline & Ivaporunduva & não & & & & & & & & & & & $\begin{array}{l}\text { Biblioteca } \\
\text { MAE }\end{array}$ & 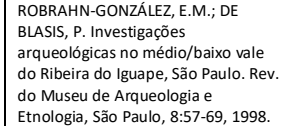 & & \\
\hline \multirow[t]{2}{*}{ Rosana } & TISIU & não & & SAD 69 & 22 & 320645 & $\begin{array}{l}7526 \\
298\end{array}$ & & & & & $\begin{array}{l}\text { Spoog } \\
02\end{array}$ & CNSA & $\begin{array}{l}\text { Projeto de Salvamento Arqueológico } \\
\text { de Porto Primavera, SP. }\end{array}$ & 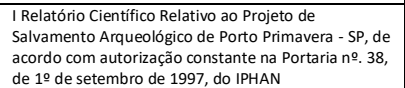 & \\
\hline & Ostras & não & & & & & & & & & & & $\begin{array}{l}\text { Biblioteca } \\
\text { MAE }\end{array}$ & 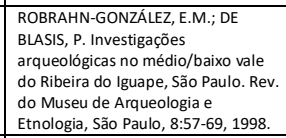 & & \\
\hline \multirow[t]{4}{*}{ Iporanga } & \begin{tabular}{|l} 
Torre de \\
Pedra
\end{tabular} & $1654 \mathrm{AD}$ & GIF-10041 & & & & & & $22 J$ & 743731 & 7278841 & $\begin{array}{l}\text { SP002 } \\
38\end{array}$ & \begin{tabular}{|l} 
CNSA e \\
Biblioteca \\
MAE
\end{tabular} & 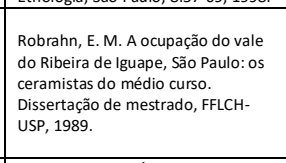 & $\begin{array}{l}\text { CORREA, A. A. Pindorama de Mboîa e lîkaré: } \\
\text { continuidade e mudanca na trajetoria das populaçoes } \\
\text { Tupi. Tese de doutorado. MAE/USP, } 2014 .\end{array}$ & 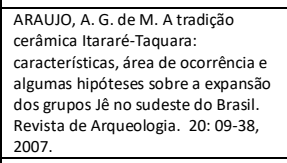 \\
\hline & Parado & não & & & & & & & & & & & $\begin{array}{l}\text { Biblioteca } \\
\text { MAE }\end{array}$ & 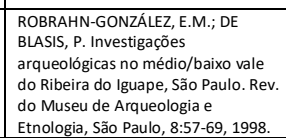 & & \\
\hline & Sapatu & não & & & & & & & & & & & $\begin{array}{l}\text { Biblioteca } \\
\text { MAE }\end{array}$ & 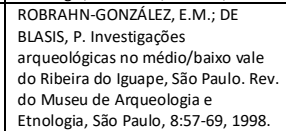 & & \\
\hline & Taquaruira & não & & & & & & & & & & & $\begin{array}{l}\text { Biblioteca } \\
\text { MAE }\end{array}$ & 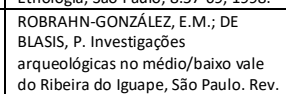 & & \\
\hline
\end{tabular}




\begin{tabular}{|c|c|c|c|c|c|c|c|c|c|c|c|c|c|c|c|c|}
\hline & & & & & & & & & & & & & & $\begin{array}{l}\text { do Museu de Arqueologia e } \\
\text { Etnologia, são Paulo, 8:57-69, } 1998 .\end{array}$ & & \\
\hline Tejupá & Tonom & não & & & & 674100 & $\begin{array}{l}7413 \\
400\end{array}$ & 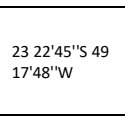 & & & & & $\begin{array}{l}\text { CNSA e } \\
\text { Inventári } \\
\text { o }\end{array}$ & 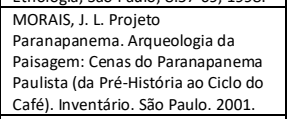 & & \\
\hline $\begin{array}{l}\text { Pereira } \\
\text { Barreto }\end{array}$ & Trentim & $\begin{array}{l}1070 \mathrm{AP} ; \\
{ }_{\mathrm{AP}}=15\end{array}$ & \begin{tabular}{|l} 
Termolumine \\
scencia atT) \\
Institututo de \\
Energia \\
Atônica da \\
USP
\end{tabular} & & & & & & $22 \mathrm{~K}$ & 489408 & 7718411 & 25587 & \begin{tabular}{|l|} 
CNSA e \\
Biblioteca \\
MAE
\end{tabular} & 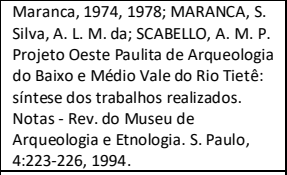 & $\begin{array}{l}\text { SCATAMACCHIA, M.C.M. Tentativa de caracterizacãão } \\
\text { da a radičăo tupiguarani. Dissertação de mestrado. } \\
\text { UsP. Săo Paulo. } 1981 .\end{array}$ & Museu Paulista - catalogo n. RNA 27 \\
\hline Itapura & Três Lagoas & $1400 \mathrm{AP}$ & $\begin{array}{l}\text { Termolumine } \\
\text { scência (TL)- } \\
\text { Instituto de } \\
\text { Energia } \\
\text { Atônica da } \\
\text { usp }\end{array}$ & & & & & & $22 \mathrm{~K}$ & 447134 & 7716869 & & \begin{tabular}{|l|} 
CNSA e \\
Biblioteca \\
MAE
\end{tabular} & $\begin{array}{l}\text { Acervo Museu Paulista/USP número } \\
\text { de catalogo RNA-34 }\end{array}$ & $\begin{array}{l}\text { Maranca, 1974, 1978; Maranca, siva E Scabello, } \\
\text { 1994; Cnsa 25480; Corréa, 2014 }\end{array}$ & $\begin{array}{l}\text { datação por TL pelo Instituto de } \\
\text { energia Atômica da USP }\end{array}$ \\
\hline $\begin{array}{l}\text { Ribeirão } \\
\text { Branco }\end{array}$ & Três Águas & não & & & $22 J$ & 723760 & $\begin{array}{l}7313 \\
868\end{array}$ & & & & & & $\begin{array}{l}\text { Biblioteca } \\
\text { MAE }\end{array}$ & $\begin{array}{l}\text { ARAUJO, A; G. M - 2001. Teoria e } \\
\text { método em arqueoologia regional: } \\
\text { um estudo de caso no Alto } \\
\text { Paranapanema, estado de São Paulo, } \\
\text { Tese de douttorado, USP/SP, sâo } \\
\text { Paulo. 2001. }\end{array}$ & & \\
\hline $\begin{array}{l}\text { Ribeirão } \\
\text { Branco }\end{array}$ & Três Águas 2 & não & & & $22 J$ & 723552 & $\begin{array}{l}7313 \\
706\end{array}$ & & & & & & $\begin{array}{l}\text { Biblioteca } \\
\text { MAE }\end{array}$ & $\begin{array}{l}\text { ARAUJO, A; G. M - 2001. Teoria e } \\
\text { método em arqueoologia regional: } \\
\text { um estudo de caso no Alto } \\
\text { Paranapanema, estado de São Paulo, } \\
\text { Tese de douttorado, USP/SP, Sâo } \\
\text { Paulo. 2001. }\end{array}$ & & \\
\hline Tatuí & $\begin{array}{l}\text { Fazenda } \\
\text { Guarapiranga }\end{array}$ & não & & & & & & & $23 \mathrm{~K}$ & 208478 & 7414771 & & $\begin{array}{l}\text { Biblioteca } \\
\text { MAE }\end{array}$ & 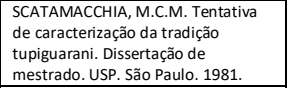 & & \\
\hline Paulicéia & TRÊS POTES & não & & SAD 69 & 22 & 411257 & $\begin{array}{l}7653 \\
128\end{array}$ & & & & & $\begin{array}{l}\text { Spoog } \\
00\end{array}$ & CNSA & $\begin{array}{l}\text { Projeto de Salvamento Arqueológico } \\
\text { de Porto Primavera, SP }\end{array}$ & 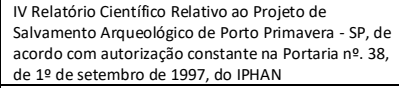 & \\
\hline Piraju & Trigal & não & & SAD 69 & 22 & 667398 & $\begin{array}{l}7440 \\
054\end{array}$ & & & & & 00007 & CNSA & 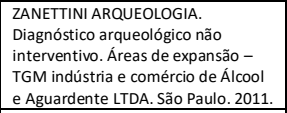 & & \\
\hline $\begin{array}{l}\text { Presidente } \\
\text { Epitácio }\end{array}$ & TRINTA-RÉlS & não & & SAD 69 & 22 & 389871 & $\begin{array}{l}7620 \\
701\end{array}$ & & & & & $\begin{array}{l}\text { Spoog } \\
03\end{array}$ & CNSA & $\begin{array}{l}\text { Projeto de Salvamento Arqueológico } \\
\text { de Porto Primavera, SP. }\end{array}$ & 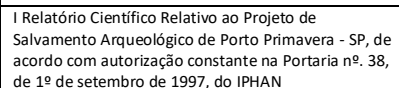 & \\
\hline $\begin{array}{l}\text { Presidente } \\
\text { Epitácio }\end{array}$ & tUCANo & กล̃o & & SAD 69 & 22 & 372854 & \begin{tabular}{|l}
7578 \\
579
\end{tabular} & & & & & $\begin{array}{l}\text { SP009 } \\
06\end{array}$ & CNSA & $\begin{array}{l}\text { Projeto de Salvamento Arqueológico } \\
\text { de Porto Primavera, SP. }\end{array}$ & 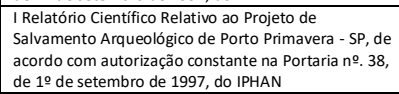 & \\
\hline Paulicéia & TUIM & não & & & & 412258 & \begin{tabular}{|c|c|}
7645 \\
134
\end{tabular} & & & & & \begin{tabular}{|l|l} 
SP0099 \\
04
\end{tabular} & CNSA & $\begin{array}{l}\text { Projeto de Salvamento Arqueológico } \\
\text { de Porto Primavera, SP }\end{array}$ & 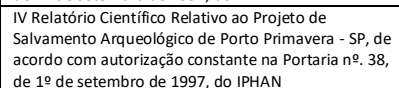 & \\
\hline Rosana & TUIIII & não & & SAD 69 & 22 & 327441 & \begin{tabular}{|l}
7531 \\
618
\end{tabular} & $\begin{array}{l}2218445 " 52 \\
40311 " \mathrm{~W}\end{array}$ & & & & \begin{tabular}{|l|l} 
Spoog \\
05
\end{tabular} & CNSA & $\begin{array}{l}\text { Projeto de Salvamento Arqueológico } \\
\text { de Porto Primavera, SP }\end{array}$ & 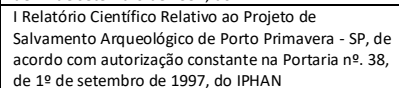 & \\
\hline chavantes & Tupaceretã 1 & não & & & $22 \mathrm{~K}$ & 624771 & $\begin{array}{l}7444 \\
862\end{array}$ & & & & & & $\begin{array}{l}\text { Biblioteca } \\
\text { empresa }\end{array}$ & 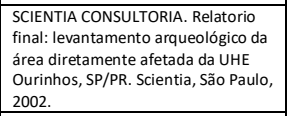 & & $\begin{array}{l}\text { sitio apenas identificado em } \\
\text { prospecçăo }\end{array}$ \\
\hline $\begin{array}{l}\text { Presidente } \\
\text { Pris }\end{array}$ & URUBU & não & & SAD 69 & 22 & 373089 & 7579 & & & & & \begin{tabular}{|l|l|} 
SP009 & \\
\end{tabular} & CNSA & Projeto de Salvamento Arqueológico & $\mid$ I Relatório Científico Relativo ao Projeto de & \\
\hline
\end{tabular}




\begin{tabular}{|c|c|c|c|c|c|c|c|c|c|c|c|c|c|c|}
\hline \begin{tabular}{|l|l|} 
Epitácio \\
\end{tabular} & & & & & & 033 & & & & \begin{tabular}{|l|l}
07 \\
\end{tabular} & & de Porto Primavera, SP. & $\begin{array}{l}\text { Salvamento Arqueológico de Porto Primavera - SP, de } \\
\text { acordo com autorizaçá constante na Portaria no. 38, } \\
\text { de 1ㅇ de setembro de 1997, do IPHAN } \\
\end{array}$ & \\
\hline 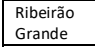 & Velho 1 & não & & $22 J$ & 764666 & \begin{tabular}{|l|}
7324 \\
030
\end{tabular} & & & & & CNSA & & & \\
\hline $\begin{array}{l}\text { Ribeirão } \\
\text { Grande }\end{array}$ & Velho 2 & não & & $22 \sqrt{2}$ & 765254 & $\begin{array}{l}7324 \\
635\end{array}$ & & & & & CNSA & & & 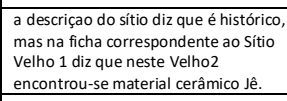 \\
\hline lacanga & Ventania & não & SAD 69 & 22 & 697362 & \begin{tabular}{|l}
7575 \\
466
\end{tabular} & & & & & CNSA & 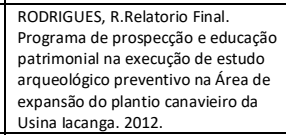 & & \\
\hline Timburi & $\begin{array}{l}\text { Porto Maria } \\
\text { Fernanda } 1\end{array}$ & não & & & & & $22 \mathrm{~K}$ & 642735 & 7432852 & 25715 & \begin{tabular}{|l|l|} 
CNSA e \\
Biblioteca \\
MAE \\
\end{tabular} & 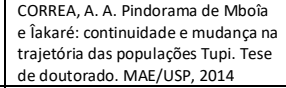 & & Rio Itararé \\
\hline $\begin{array}{l}\text { Tatuí } \\
\end{array}$ & Guarapiranga & não & & & & & $23 \mathrm{~K}$ & 208483 & 7414765 & & CNSA & & & \\
\hline Timburi & $\begin{array}{l}\text { Porto Maria } \\
\text { Fernanda 2 }\end{array}$ & não & & & & & $22 \mathrm{~K}$ & 642735 & 7432852 & 25716; & \begin{tabular}{|l|l|} 
CNSA e \\
Biblioteca \\
MAE
\end{tabular} & 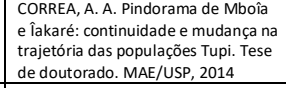 & & \\
\hline Paulicéia & ХORORÓ & não & SAD 69 & 22 & 395632 & $\begin{array}{l}7620 \\
306\end{array}$ & & & & $\begin{array}{l}\text { SP009 } \\
14\end{array}$ & CNSA & $\begin{array}{l}\text { Projeto de Salvamento Arqueológico } \\
\text { de Porto Primavera, SP }\end{array}$ & 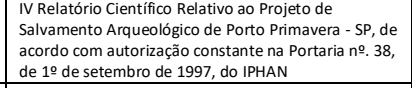 & \\
\hline Timburi & $\begin{array}{l}\text { Ribeirão da } \\
\text { Estufa } 1\end{array}$ & não & & & & & $22 \mathrm{~K}$ & 642735 & 7432852 & 25717 & \begin{tabular}{|l} 
CNSA \\
Biblioteca \\
MAE \\
\end{tabular} & 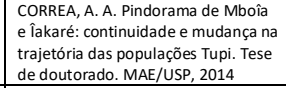 & & \\
\hline Timburi & $\begin{array}{l}\text { Riberião da } \\
\text { Estufa 2 }\end{array}$ & não & & & & & $22 \mathrm{~K}$ & 642735 & 7432852 & 25718 & \begin{tabular}{|l|} 
CNSA \\
Biblioteca \\
MAE
\end{tabular} & 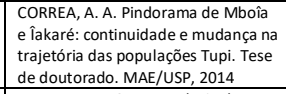 & & \\
\hline Vera Cruz & $\begin{array}{l}\text { Fazenda } \\
\text { Ipiranga }\end{array}$ & não & & & & & $22 \mathrm{~K}$ & 621545 & 7542416 & & $\begin{array}{l}\text { Biblioteca } \\
\text { MAE }\end{array}$ & \begin{tabular}{|l|} 
MILLER JR, T. O. Arrueolocia da \\
regiäo central do EStado de São \\
Paulo. Dedalo, são Paulo, n. 16. \\
1972. p. 13-118. \\
\end{tabular} & 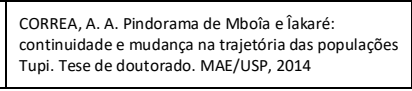 & \\
\hline
\end{tabular}

